\title{
IMPROVNG
}
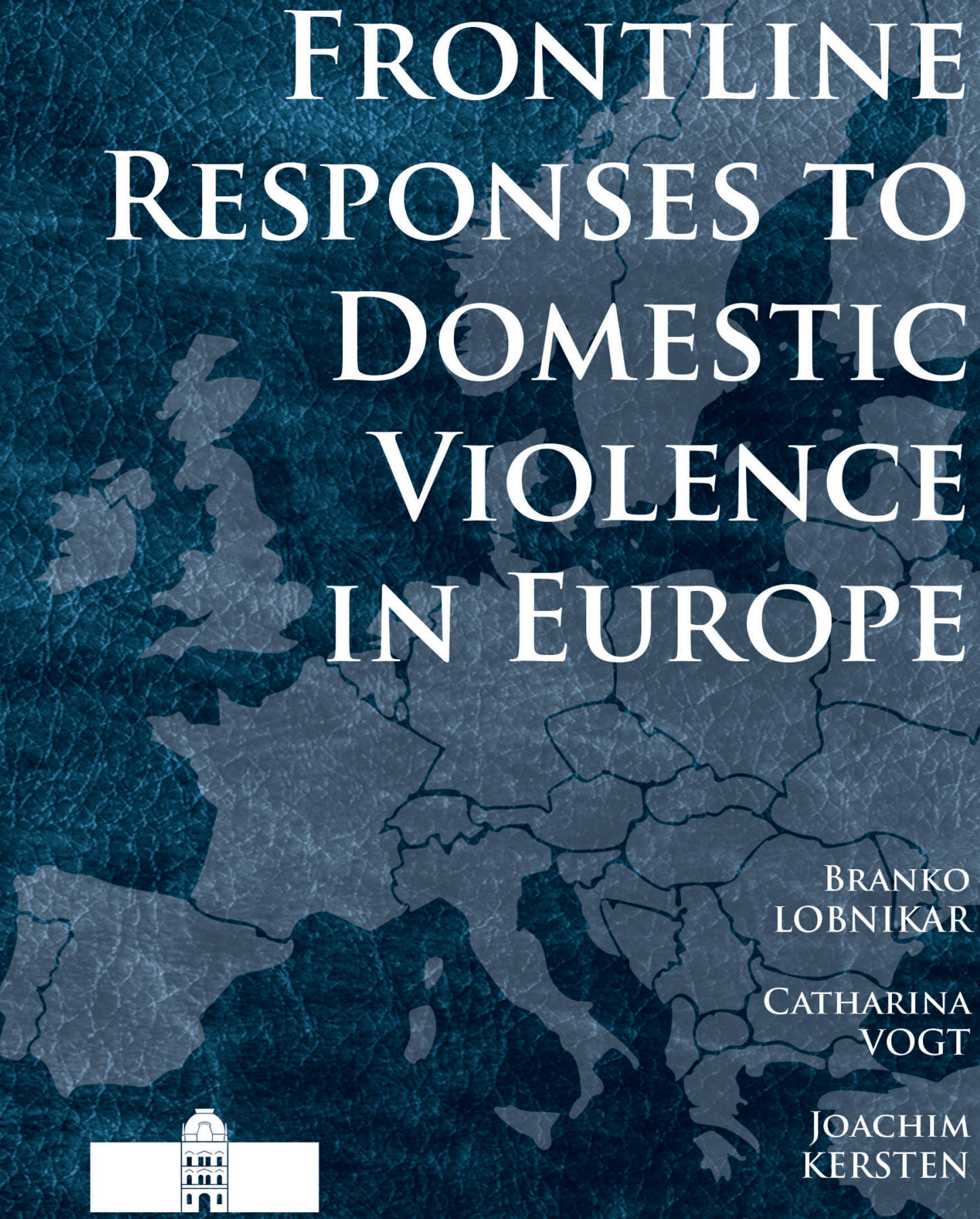

\section{BRANKO LOBNIKAR}


4 ist

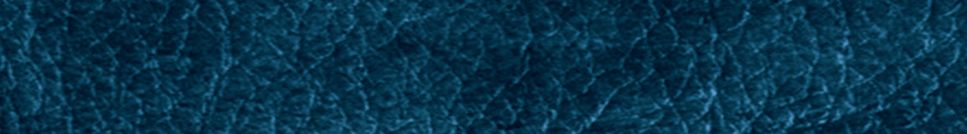

3.1.2.

(1)

W.7.

$$
\text { (1) }
$$

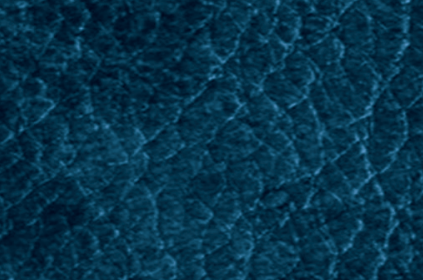

aris

$\cos 2$

1. 3 ?

13:

28.

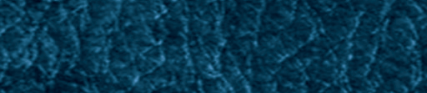

(1)

1)

3

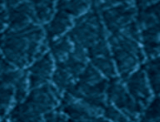

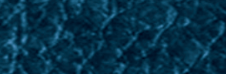

to

(⿻)

xtrat

3.

(1) 


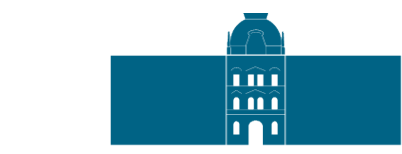

University of Maribor

Faculty of

Criminal Justice and Security

\title{
IMPROVING FRONTLINE RESPONSES TO DOMESTIC VIOLENCE IN EUROPE
}

\author{
Editors \\ Branko Lobnikar \\ Catharina Vogt \\ Joachim Kersten
}

December 2021 
Title Improving Frontline Responses to Domestic Violence in Europe

Editors Branko Lobnikar

(University of Maribor, Faculty of Criminal Justice and Security)

Catharina Vogt

(German Police University)

Joachim Kersten

(German Police University)

Review Danijela Frangež

(University of Maribor, Faculty of Criminal Justice and Security)

Elizabeth A. Stanko

(Royal Holloway, University of London)

Language editing Murray James Bales \& Josh Rocchio

Technical editors Jan Perša

(University of Maribor, University Press)

Dunja Legat

(University of Maribor, University Press)

Cover designer Jan Perša

(University of Maribor, University Press)

Cover graphic Leather texture, author lovepixs from Pixabay.com CC0

Europe, author Clker-Free-Vector-Images from Pixabay.com

$\mathrm{CCO}$

Graphic material Authors \& editors

Published by University of Maribor

University Press

Slomškov trg 15, 2000 Maribor, Slovenia

https://press.um.si, zalozba@um.si

Issued by University of Maribor

Faculty of Criminal Justice and Security

Kotnikova ulica 8, 1000 Ljubljana, Slovenia

https://www.fvv.um.si, fvv@ffvv.uni-mb.si

Edition $1^{\text {st }}$

Publication type E-book

Available at http://press.um.si/index.php/ump/catalog/book/628

Published at Maribor, Slovenia, December 2021 
This book is published under a Creative Commons 4.0 International licence (CC BY-NC-ND 4.0). This license allows reusers to copy and distribute the material in any medium or format in unadapted form only, for noncommercial purposes only, and only so long as attribution is given to the creator.

Any third-party material in this book is published under the book's Creative Commons licence unless indicated otherwise in the credit line to the material. If you would like to reuse any third-party material not covered by the book's Creative Commons licence, you will need to obtain permission directly from the copyright holder.

https://creativecommons.org/licenses/by-nc-nd/4.0/

\section{(-)IMPRODOVA}

IMPRODOVA | Improving Frontline Responses to High Impact Domestic Violence

This project has received funding from the European Union's Horizon 2020 research and innovation programme under grant agreement No 787054.
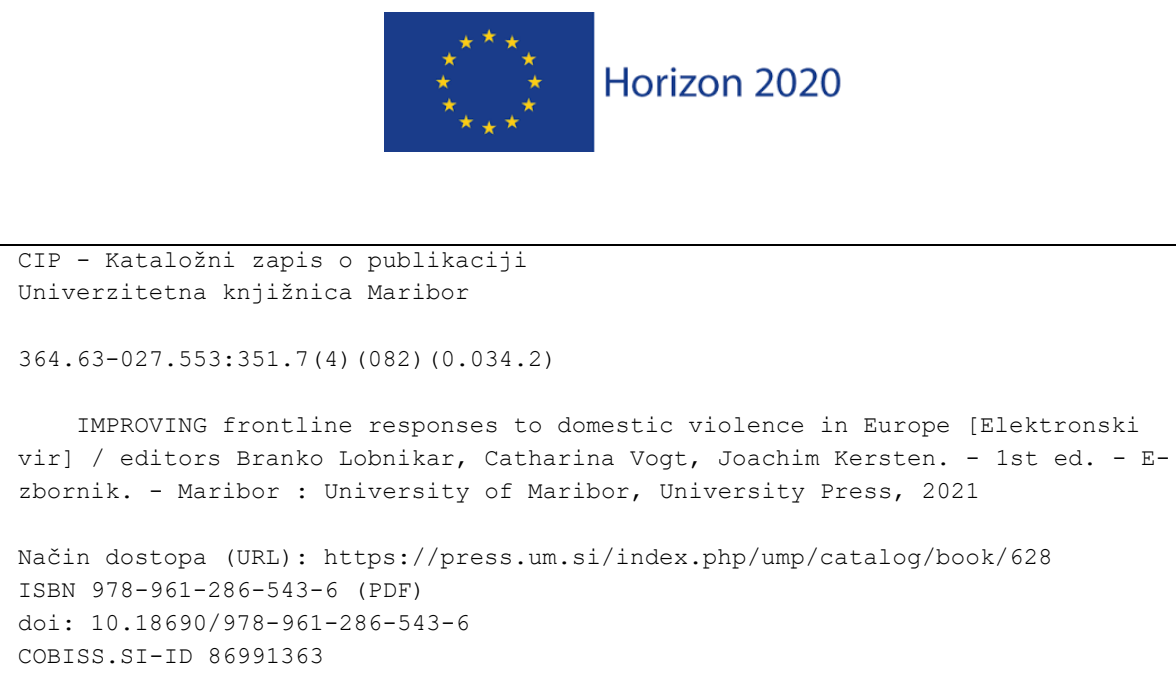


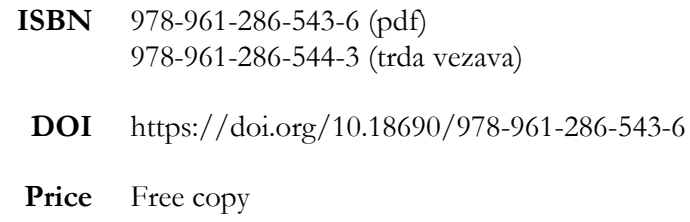

DOI https://doi.org/10.18690/978-961-286-543-6

Price Free copy

For publisher prof. dr. Zdravko Kačič, rektor of University of Maribor

Attribution Lobnikar, B., Vogt, C. \& Kersten, J. (eds.). (2021). Improving Frontline Responses to Domestic Violence in Europe. Maribor: University Press. doi: 10.18690/978-961-286-543-6 


\section{Table of Contents}

INTRODUCTION

Innovative Proposal Concerning the Human Factors Shaping Institutional Responses to Domestic Violence - the IMPRODOVA Project

Joachim Kersten, Catharina Vogt \& Branko Lobnikar

\section{THE MANAGEMENT OF DOMESTIC VIOLENCE IN $21^{\mathrm{ST}}$} CENTURY

International Policy Framework

Norbert Leonhardmair, Paul Herbinger \& Marion Neunkirchner

Policy Development Module

Martta October \& Suvi Nipuli

Domestic Violence Risk Assessment and Case Documentation

Marianne Mela \& Jarmo Houtsonen

Inter-agency Cooperation and Coordination: the Characteristics of a "Good Partnership” Against Domestic Violence

Thierry Delpeuch \& François Bonnet

Risk-assessment and Victim-support Recommendations During the COVID-19-related Lockdowns

Joachim Kersten, Catharina Vogt, Michele Burman, Jarmo Houtsonen,

Norbert Leonhardmair \& Paul Herbinger

FRONTLINE RESPONSE TO DOMESTIC VIOLENCE IN EUROPE 
Frontline Response to High Impact Domestic Violence in Finland

Martta October, Marianne Mela, Suvi Nipuli \& Jarmo Houtsonen

Frontline Response to High Impact Domestic Violence in France

Marion Tillous, Thierry Delpeuch \& François Bonnet

Frontline Response to High Impact Domestic Violence in Germany

Stefanie Giljohann, Catharina Vogt, Lisa Sondern, Paulina Juszczyk,

Joachim Kersten \& Bettina Pfleiderer

Frontline Response to High Impact Domestic Violence in Hungary

Gábor Héra \& Dóra Szegő

Frontline Response to High Impact Domestic Violence in Portugal

Paulo Machado, Lúcia G. Pais, Sérgio Felgueiras \& Carina Quaresma

Frontline Responses to Domestic Abuse in Scotland

Ruth Friskney, Oona Brooks-Hay \& Michele Burman

Frontline Response to Domestic Violence in Slovenia

Karmen Jereb, Aleksander Koporec Oberčkal, Kaja Prislan, Boštjan Slak \&

Branko Lobnikar VIOLENCE INTERVENTION AND PREVENTION

A Digital Communication Platform for Inter-agency Collaboration to Manage High-impact Domestic Abuse: Structure and Essentials

Catharina Vogt

Development of a Training Platform on Domestic Violence

Bettina Pfleiderer \& Paulina Juszczyk

Recommendations for an Innovative Gender-sensitive Training and Education for Various Frontline Responder Groups

Bettina Pfleiderer \& Paulina Juszczyk

Roadmap Towards an Integrated European Response to Domestic Violence Branko Lobnikar, Catharina Vogt \& Joachim Kersten 


\section{INTRODUCTION}

11 
4 ist

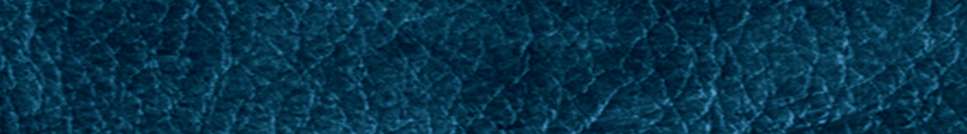

3.1.2.

(1)

W.7.

$$
\text { (1) }
$$

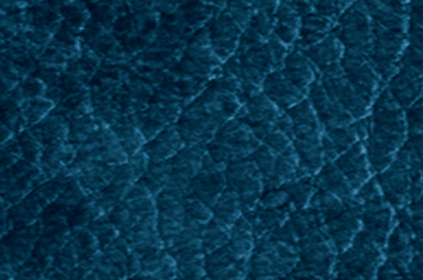

aris

$\cos 2$

1. 3 ?

13:

28.

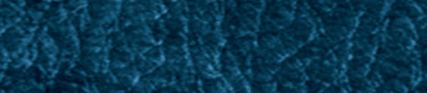

(1)

1)

3

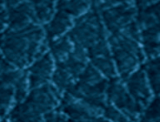

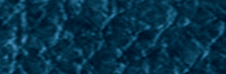

to

(⿻)

xtrat

3.

(1) 


\section{INNOVATIVE Proposal}

CONCERNING THE HUMAN

FACTORS SHAPING INSTITUTIONAL

RESPONSES TO DOMESTIC

\section{VIOLENCE - THE IMPRODOVA PROJECT}

JOACHIM Kersten, ${ }^{1}$ CATHARINA VOGT ${ }^{1} \&$

BRANKO LOBNIKAR ${ }^{2}$

${ }^{1}$ German Police University, Münster, Germany.

E-mail: joachim.kersten@t-online; catharina.vogt@dhpol.de

${ }^{2}$ University of Maribor, Faculty of Criminal Justice and Security, Ljubljana, Slovenia.

E-mail: branko.lobnikar@fvv.uni-mb.si

Abstract The introductory chapter of this book presents the book's structure as a whole and gives a brief overview of its single chapters and their interrelatedness. The aim of IMPRODOVA Improving Frontline Responses to High Impact Domestic Violence was to deliver recommendations, toolkits and collaborative training for European police organisations and medical and social work professionals to improve and integrate the institutional response to high-impact domestic violence. IMPRODOVA had two main components: analysis of current institutional responses to high-impact domestic violence and the development of effective solutions to improve those responses. Efforts were made to avoid a one-size-fits-all approach and contextualise our solutions, tools and guidelines to make them applicable to a wide range of societies.

Keyowrds: IMPRODOVA, domestic violence, Europe, police, social work, health sector, training 
IMPRODOVA $^{1}$ - Improving Frontline Responses to High Impact Domestic Violence - was a research and innovation proposal concerned with the human factors that influence institutional responses to domestic violence, the behaviour of an intimate or ex-partner that causes physical, sexual or psychological harm, including physical aggression, sexual coercion, and psychological abuse and controlling behaviour. As one of many frontline responders, police organisations may be expected to feature among the greatest providers of support for victims of high-impact domestic violence (HIDV). Yet, World Health Organization figures show that less than $10 \%$ of victims of domestic violence actually turn to the police for help. Whether victims instead seek support from other frontline responders still has to be investigated. One reason for this is the perceived or actual inadequacy of the police's response. Here, we encounter the first important human factor. Police officers are accused of being insensitive to victims' concerns. However, the low overall number reported by the WHO conceals the wide variety of response rates in different settings where the response of police and the victim support agencies have managed to provide low-threshold access to victims of HIDV. Across Europe, one can find positive examples of best practices from which IMPRODOVA sought to learn. IMPRODOVA focused on improving and integrating the responses of police, social work, non-governmental organisations, and other actors that make up the ecosystem of frontline responders to increase the reporting of domestic violence. Reporting rates to the police, which are typically the only agency available to citizens on a $24 / 7$ basis, might serve as an indicator of the overall ecosystem's successful performance.

IMPRODOVA's operational definition of high-impact domestic violence includes serious and reported violence within the family, against the children, partners and the elderly. Here, "serious" can refer to the intensity, duration or consequences of the violence.

IMPRODOVA sought to design and provide solutions that would form part of an integrated response to HIDV based on comprehensive empirical research into how police and other frontline responders (e.g. medical and social work professionals) respond to domestic violence in European countries. IMPRODOVA aimed to

\footnotetext{
${ }^{1}$ The IMPRODOVA project received funding from the European Union's Horizon 2020 research and innovation programme under grant agreement No 787054.
} 
deliver recommendations, toolkits, and collaborative training for European police organisations and medical and social work professionals to improve and integrate the institutional response to HIDV. The intention was to use the positive feedback loop to increase HIDV reporting rates to police, the medical profession, community and social work practitioners who act as the first responders and agents of risk assessment. All of the project results are freely available on the Internet ${ }^{2}$.

IMPRODOVA had two main components: 1) analysis of current institutional responses to HIDV; and 2) the development of effective solutions to improve those responses. The first component entailed an in-depth qualitative study of frontline responders' ecosystems in eight European countries.

In these eight countries in Europe (Austria, Finland, France, Germany, Portugal, Scotland/UK, Hungary and Slovenia; and with regard to some themes, a ninth country, Bulgaria), institutional responses to HIDV were studied within the IMPRODOVA project. This involved comprehensive fieldwork, following social workers and police officers during their shifts, interviewing field operatives and staff from relevant professions and organisations, along with collecting the views of management and policymakers. As part of this investigation, we documented the work routines and forms of cooperation engaged by frontline responders to HIDV. We also revealed multiple human factors that might constrain their daily work and cooperation and developed a better understanding of why the frontline responders' local ecosystems have developed in the way they have, identifying gaps and deficiencies and documenting practical solutions that emerge in day-to-day life collaborative work.

We mapped the frontline responders' conflicting interpretations of HIDV, as shaped by cultural and professional frames, different moral boundaries and other human factors. We also analysed organisational factors like resources and management. The focus was on how these human factors influence the response of police and interagency cooperation, how e.g. police cooperate with women's shelters, community organisations, medical experts and others that make up the local response ecosystems.

\footnotetext{
2 recommendations: https://improdova.eu/results/reports/index.php; toolkits and training materials: https://training.improdova.eu/en/; publications: https://improdova.eu/results/publications/index.php
} 
Throughout, IMPRODOVA highlighted the needs of domestic violence victims. For two reasons, special consideration in this research was paid to communities of underprivileged populations and ethnic minority backgrounds: 1) high-impact domestic violence is often more prevalent in these neighbourhoods; 2) victims from ethnic minorities are often less likely to report to the police or seek help from outsiders due to mistrust, prejudice or a fear of being deported. IMPRODOVA intended to research the most concerning aspects of HIDV.

IMPRODOVA's second component considered solutions to improve institutional responses to high-impact domestic violence. While different institutions and agencies have issued a range of recommendations to improve institutional responses to high-impact domestic violence, effective and sustainable implementation is still lacking. ${ }^{3}$ Several reasons can be pointed to for this gap between the lofty ambitions and the actual outcomes: the lack of human resources, insufficient training and resources, low morale, political resistance, bureaucratic overload as factors on the side of institutions and, on the side of clients or victims, mistrust, fear, prejudice, and a lack of knowledge and information.

The research and analysis of frontline responders' ecosystems in IMPRODOVA's first component highlighted the mentioned gap between the ideal and the actual. This gave researchers an in-depth understanding of the human factors that influence the work of frontline responders in practice. Building on this foundation, IMPRODOVA prepared for the second component to develop solutions that will have a sustainable impact by adapting existing recommendations and offering new ideas for better cooperation and an effective, low-threshold, multi-agency response to high-impact domestic violence. This entailed solutions that were validated bottom-up to help victims more effectively. The solutions developed by IMPRODOVA may be expected to improve inter-agency partnerships by integrating stakeholder knowledge from NGOs and frontline responders. The indepth research fed into innovative policy recommendations, giving local, national and European policymakers guidance on strengthening low-threshold responses and designing preventative measures in this field. The output of IMPRODOVA's second component was a set of policy recommendations addressing local, national

\footnotetext{
${ }^{3}$ Council of Europe: Istanbul Convention - Action against violence against women and domestic violence, Council of Europe Treaty Series - No. 210, URL: http://www.coe.int/en/web/conventions/full-list//conventions/rms/090000168008482e (2017-08-24).
} 
and European policymakers; risk-assessment tools with a high level of interoperability among different professions; practical toolkits for all frontline responders involved and training materials focused on improving interagency cooperation and interacting with different types of victims.

The evidence-based output from IMPRODOVA's first component was evaluated and validated by stakeholders and IMPRODOVA's partner organisations: Law Enforcement Agencies (LEAs) and other representatives of the ecosystem of frontline responders in the IMPRODOVA consortium. They performed limited local field tests of the newly proposed approaches and solutions.

Drafting workable solutions requires Europe to be viewed as comprising societies with different living standards, levels of institutional efficacy, and national cultures and identities. Efforts were made in the IMPRODOVA project to avoid a one-sizefits-all approach and contextualise our solutions, tools and guidelines to make them applicable to a wide range of societies. This avoided the problems of high-level policy guidelines being drafted too generally while ignoring the obstacles and constraints of the many human factors that appear along the way from policy to practice.

This book presents a comprehensive view on the research and findings of IMPRODOVA and locates this in relation to state-of-the-art research. The most pressing topics regarding how to manage domestic violence in the twenty-first century are addressed, stressing international policies, the assessment of the maturity of HIDV-related policies, recommendations for a good partnership in inter-agency cooperation, and HIDV risk assessment and victim support during COVID-19related lockdowns. These topics are accompanied by a presentation of the status quo and best practices of HIDV frontline responses in various European countries. Based on these findings, developing domestic violence response protocols via a European platform is proposed and highlighted. 


\section{THE MANAGEMENT OF DOMESTIC VIOLENCE IN $21^{\text {ST }}$ CENTURY}


4 ist

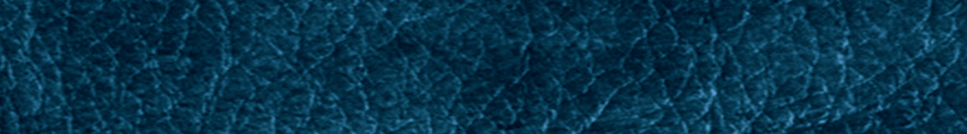

3.1.2.

(1)

W.7.

$$
\text { (1) }
$$

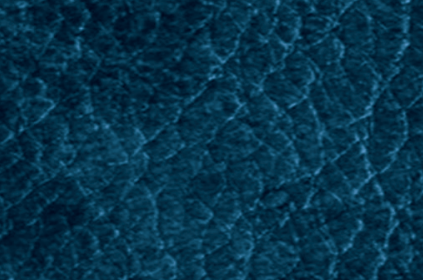

aris

$\cos 2$

1. 3 ?

13:

28.

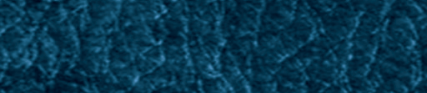

(1)

1)

3

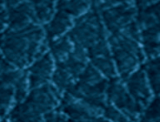

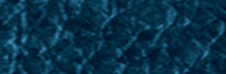

to

(⿻)

xtrat

3.

(1) 


\title{
INTERNATIONAL POLICY
}

\section{FRAMEWORK}

\author{
Norbert LeONHARDMAir, PAUl Herbinger \& \\ MARION NEUNKIRCHNER \\ Vienna Centre for Societal Security, Vienna, Austria. \\ E-mail: norbert.leonhardmair@vicesse.eu,paul.herbinger@vicesse.eu, \\ marion.neunkirchner@vicesse.eu
}

\begin{abstract}
This chapter describes the international policy framework and efforts made on the international and European level to further the fight against violence against women and domestic violence. The respective national legal frameworks and organisational context of front-line responder services are discussed in-depth in the following chapters. The IMPRODOVA project followed a bottom-up approach in its investigation of ground-level practices of cooperation of frontline responder services, which are, however, only meaningfully understood when interpreted in the governing national legal and policy framework. While numerous international policy documents relate to domestic violence, the ratification of the Convention on Preventing and Combating Violence against Women and Domestic Violence in 2011 represents perhaps the most significant attempt to institute a comprehensive policy framework in this field. The "Istanbul Convention" includes the first legally binding, international, and wide-reaching set of norms to combat violence against women in general and domestic violence specifically.

\author{
Keywords: \\ domestic \\ violence, \\ international \\ policy \\ framework, \\ Istanbul \\ convention, \\ first \\ responders,
} police
\end{abstract}




\section{Introduction}

This chapter describing the international policy framework and efforts made by on international and European level to further the fight against violence against women and domestic violence, sets the stage for the in-depth country reports (Chapter 3), which outlines the respective national legal frameworks and organizational context of frontline responder services. ${ }^{1}$

The IMPRODOVA project followed a bottom-up approach in its investigation of ground-level practices of cooperation of frontline responder services, which are, however, only meaningfully understood when interpreted in the governing national legal and policy framework. Nevertheless, innovative and good local and organizational practices often are found not just enabled by, but in spite of the governing legal and procedural framework. The interplay of international (minimum) standards and local practices, mediated via the national legal framework, cannot be understood as a one-way trickling top-down prescription of requirements, which are nationally transposed and locally implemented. Policy making on an international level even took note of progressive and ground-breaking practices inspired by advocacy groups formed by frontline responder organisations. On the other hand, we find examples of countries that have not formally ratified international conventions but exceed in their national and local commitment to combat Domestic Violence.

\section{Overview of international conventions, declarations, and treaties combatting Violence against Women and Domestic Violence by different $\mathrm{UN}$ bodies and the $\mathrm{COE}^{2}$}

- 1979: Convention on the Elimination of all Forms of Discrimination against Women (CEDAW)

\footnotetext{
${ }^{1}$ A more detailed discussion of the translation of international policies at the national level can be found in Herbinger et. al. (2020)

${ }^{2}$ Related policies addressing Violence Against Women in general, protection of women migrant workers, human trafficking of women and girls, cultural practices affecting women's health, gender equality, sexual violence against women (incl. in conflict, as in 1993 with the establishment of the International Criminal Tribunal for the former Yugoslavia) and links to reproductive health are not listed without reference to domestic violence. A comprehensive overview of UN conventions, GA resolutions, SG reports and studies, and HRC resolutions can be found at the homepage of UN Women (2021) Violence Against Women [Online] URL:

https://www.un.org/womenwatch/daw/vaw/v-hrc.htm (accessed 2021-07-23).
} 
- 1985: General Assembly Resolution on Domestic Violence

- 1989: Convention on the Rights of the Child

- 1993: Vienna Declaration and Programme of Action

- 1993: Declaration on the Elimination of Violence against Women

- 1994: Appointment of the Special Rapporteur on violence against women, its causes and consequences

- 1995: Beijing Platform for Action

- 1996: United Nations Trust Fund in Support of Actions to Eliminate Violence against Women

- 1999: International Day for the Elimination of Violence Against Women/ 16 days of Activism

- 2006: Secretary-General's In-Depth Study on All Forms of Violence against Women

- 2008: UN launch of UNiTE campaign to End Violence against Women

- 2010: HRC Resolution on accelerating efforts to eliminate all forms of violence against women

- 2011: COE Convention on preventing and combating violence against women and domestic violence

The 1990s saw what was arguably the first major surge of international policy frameworks and documents addressing Violence Against Women in general, and Domestic Violence in particular. Against the background of earlier initiatives and institutions such as the United Nations Convention on the Elimination of Discrimination against Women (CEDAW) adopted in 1979 (United Nations); the 1985 UN General Assembly Resolution on Domestic Violence; and the 1989 UN Convention on the Rights of the Child (CRC); the United Nations, Council of Europe, and European Union began drafting documents intended to provide guidance and legal grounds for the national responses to Domestic Violence. While the CEDAW did not yet include references to violence against women, focusing instead on the legally binding imperative to ensure equal rights between the sexes, its acknowledgement of the structural inequality experienced by women formed the entry point for ground-breaking resolutions relating specifically to the topic of violence. The United Nations General Assembly adopted the first of these, the Declaration on the Elimination of Violence against Women (A/RES/48/104Resolution 48/104), saw its ratification in 1993. It has been 
furthered in 2004 under the same title by Resolution A/RES/58/147 by the UN General Assembly. In 1993, the appointment of a Special Rapporteur on violence against women was requested in the Vienna Declaration and Programme of Action (United Nations human rights,1993), which was established in the World Conference on Human Rights, recognizing violence against women as a human rights violation. Others followed, such as the 1995 Beijing Declaration and Platform for Action (United Nations, 1995), which included the objective to end all forms of violence towards women as well as practical measures to be taken by states, international organizations and NGOs. Since 2003 three resolutions prepared by the Secretary-General on an in-depth study on all forms of violence against women have been launched ${ }^{3}$.

The 2010 resolution of the UN Human Rights Council (HRC) committed to accelerating efforts to eliminate all forms of violence against women. In 2015, countering Violence against Women was included in the Sustainable Development Goals. The UN Human Rights Council (HRC) has also passed several resolutions on eliminating discrimination and violence against women (UN Women, n.d). Frequently relating to these UN resolutions, the Council of Europe, as well as the European Union adopted several instruments to combat this form of violence, pertinent examples being: the Council of Europe Recommendation on the Protection of Women Against Violence (REC(2002)5), (Committee of Ministers, 2002), the 2005 Convention addressing human trafficking (Council of Europe, 2005) and the Istanbul Convention on Preventing and Combatting Violence against Women and Domestic Violence (Istanbul 11/05/2011). Similarly, Directive 2004/81/EC and Directive 2011/36/EU (European Parliament \& of the Council, 2011) specifically targeted Violence against Women in the context of human trafficking, while the Victims of Crime Directive of 2012 (Directive (2012/29/EU)) (European Parliament \& Council of the European Union, 2012) provided minimum standards on the rights, support and protection of victims in general.

Since 2012, the UN General Assembly has adopted resolutions on the intensification of efforts to eliminate all forms of violence against women every two years, in addition to reports of the Special Rapporteur on violence against women. ${ }^{4}$

\footnotetext{
${ }^{3}$ UN (2021) Work of the General Assembly on violence against women; https://www.un.org/womenwatch/daw/vaw/v-work-ga.htm.

${ }^{4}$ UN Women (2021) Global norms and standards: Ending violence against women; https://www.unwomen.org/en/what-we-do/ending-violence-against-women/global-norms-and-standards.
} 
Notable achievements were establishing the UN International Day for the Elimination of Violence against Women (25 November) in 1999, which coincided with the UN acknowledging and taking part in the "16 Days of Activism" established by the international women's movement already in 1991.

\section{Victims of Crime Directive 2012/29/EU}

Victims of Crime Directive (2012/29/EU) (European Parliament \& Council of the European Union, 2012) outlines frameworks specific to the implementation of national strategies to combat Violence against Women and Domestic Violence. IMPRODOVA's focus on the protection of Victims of Domestic Violence lies inter alia: on the implementation of Victim's support services (Art. 8 and 9), on training of practitioners (Art. 25), and cooperation and coordination of services (Art. 26). As large section of the Victims of Crime Directive Articles relates strongly to the Istanbul Convention. However, the discussions in the following sections will relate only to compliance to the latter in an effort to reduce complexity.

\section{The Convention on Preventing and Combating Violence against Women and Domestic Violence (Istanbul Convention)}

While numerous international policy documents (only a selection of which have been outlined above) relate to the topic of Domestic Violence, the ratification of the Convention on Preventing and Combating Violence against Women and Domestic Violence in 2011 represents perhaps the most important attempt to institute a comprehensive policy framework in this field. The "Istanbul Convention" includes the first legally binding, international and wide-reaching set of norms to combat Violence against Women in general, and Domestic Violence specifically. Across twelve chapters and eighty-one articles, the Convention entails several detailed measures in the areas of policy, prevention, provision, protection and prosecution, as well as comprehensive definitions for each of these forms of violence.

Violence against Women "is understood as a violation of human rights and a form of discrimination against women and shall mean all acts of gender-based violence that result in, or are likely to result in, physical, sexual, psychological or economic harm or suffering to women, including threats of such acts, coercion or arbitrary deprivation of liberty, whether occurring in public or in private life". (Art 3 Sec a) This definition makes it possible to address both physical and psychological 
violence, as well as forced marriages, genital mutilation, forced sterilizations, rape, and sexual harassment. Article 2 further encourages the application of the Convention to victims of Domestic Violence (Art 2 Sec 2), which is defined as "all acts of physical, sexual, psychological or economic violence that occur within the family or domestic unit or between former or current spouses or partners, whether or not the perpetrator shares or has shared the same residence with the victim". (Art $3 \mathrm{Sec}$ B) While the application of the Convention to all forms of Violence against Women (Art 2 Sec 1) both in times of peace and in situations of armed conflict (Art 2 Sec 3) are legally binding, the inclusion of Domestic Violence within its scope remains a recommendation. The peculiarity of this differentiation shall be addressed in a later section.

Among numerous detailed measures to combat Violence against Women, the Istanbul Convention includes norms on risk assessment and risk management, outlining the imperative to "take necessary legislative or other measures" (Art $51 \mathrm{Sec}$ 1) to ensure that relevant authorities evaluate the risk of lethality, seriousness of the situation as well as the risk of repeated violence. Chapter IV includes articles outlining the imperative to provide specialized support for victims such as the proper provision of information (Art 19), assistance in individual/collective complaints (Art 21), specialist support services (Art 22), shelters (Art 23), as well as support and encouragement for reporting (Art 27). Further chapters extend the purview of the convention, for example, to areas of migration and asylum (Chapter VII), international cooperation (Chapter VIII), prevention (Chapter III) and substantive law (Chapter V).

In that, the Istanbul Convention outlines policy guidelines and recommendations across the whole cycle of intervention from prevention, intervention to prosecution.

\section{From international policies to national implementation and organisational practices}

IMPRODOVA approached the exploration of the existing national policy framework via the National Action Plans (NAP) as an entry point. The review of the countries showed that those vary between countries and over time with respect to the specificity of their focus as NAP against violence, against violence against women, against domestic violence. The NAPs requested them to organize and 
demonstrate their policy response to Domestic Violence; however, the reference to international guidelines and policies within them is very heterogeneous, as to which international treaties, conventions, and declarations are mentioned or whether there are any references to them at all. The NAPs served as a chain link between international policies, the national legal framework and the local and organisational implementation of guidelines in investigating the gap between formal provisions and organisational practices.

The definition of DV in the Istanbul Convention is often used as the leading definition of DV within the country's National Action Plans (NAPs). Within this framework, the definition is based on a gender-related violence concept, mainly understood as violence against women and children. Differences between frontline responder's definitions were not collected in all partner countries, since in most cases, all three FLR sectors use the same definition of DV according to the respective national policies (NAP). However, there is little awareness among ground-level practitioners on international policies or national policy definitions in practice.

Generally, the cross-national comparison is a complex undertaking, particularly in the context of DV, as different countries use distinctive concepts and varied definitions of DV. Furthermore, these distinctive concepts caused the phenomenon itself to appear in a different light in each context. Intimate partner violence (IPV), domestic violence (DV) and family violence (FV) are the main terms that are used across all countries to describe this phenomenon.

A further gap can be demonstrated by the definition of "high impact" DV cases, which predominantly are not covered by a specific sub-definition of DV within national policies. While in most countries many different legal provisions apply to DV cases, Portugal and the UK as the only two countries among the selected European Member States (MS), which have defined DV as a separate criminal offence.

The country-specific differences between legal structures, policies, and national strategies against DV cause FLRs to cooperate in different ways, enable specific definitions of DV, and use different risk assessments. In most partner countries, however, the Istanbul Convention (IC) is central in implementing national policies. 
As of 2021, the convention has been ratified in all partner countries except Hungary and the UK (Council of Europe, 2018).

\section{References}

Committee of Ministers. (2002). Recommendation $\operatorname{Rec}(2002) 5$ of the Committee of Ministers to member states on the protection of women against violence. https://search.coe.int/cm/Pages/result_details.aspx?ObjectID=09000016805e2612

Council of Europe. (2014). Council of Europe Convention on preventing and combating violence against women and domestic violence. https:// rm.coe.int/168008482eCouncil\%20of\%20Europe

Council of Europe. (2005). Action against Trafficking in Human Beings. https://www.coe.int/en/web/antihuman-trafficking/about-the-convention

Council of Europe. (2018). Complete list of the Council of Europe's treaties. https://www.coe.int/en/web/conventions/full-list/-/conventions/treaty/210/signatures

European Parliament \& of the Council. (2011). Directive 2011/36/EU of the European Parliament and of the Council of 5 April 2011 on preventing and combating trafficking in human beings and protecting its victims, and replacing Council Framework Decision 2002/629/JHA, Official Journal of the European Union, (101), 1-11. https://eur-lex.europa.eu/legalcontent/EN/TXT/?qid=1566304719526\&uri=CELEX:32011L0036

European Parliament \& Council of the European Union. (2012). Directive 2012/29/EU of the European Parliament and of the Council of 25 October 2012 establishing minimum standards on the rights, support and protection of victims of crime, and replacing Council Framework Decision 2001/220/JHA. Official Journal of the European Union, (315), 57-73. https://eur-lex.europa.eu/eli/dir/2012/29/oj

Herbinger, P., Neunkirchner, M., \& Leonhardmair, N. (2020). European Legislation to Fight Domestic Violence. European Law Enforcement Research Bulletin, (20), 141-154. https://bulletin.cepol.europa.eu/index.php/bulletin/article/view/415

UN Entity for Gender Equality and the Empowerment of Women. (n.d.). Violence against women. https://www.un.org/womenwatch/daw/vaw/v-sg-study.htm

UN General Assembly. (1985). Domestic violence: resolution / adopted by the General Assembly. https://www.refworld.org/docid/3b00f00b64.html

UN General Assembly. (1989). Convention on the Rights of the Child. Treaty Series, 1577, p. 3. https://www.refworld.org/docid/3ae6b38fo.html

UN General Assembly. (1993). Vienna Declaration and Programme of Action. https://www.refworld.org/docid/3ae6b39ec.html

UN General Assembly. (2003). Elimination of domestic violence against women. https://undocs.org/pdf?symbol=en/A/RES/58/147

United Nations. (1995). Beijing Declaration and Platform of Action, adopted at the Fourth World Conference on Women. https://www.refworld.org/docid/3dde04324.html

United Nations human rights. (1979). Convention on the Elimination of All Forms of Discrimination against Women, Treaty Series, 1249, 13. https://ohchr.org/en/professionalinterest/pages/cedaw.aspx

United Nations human rights. (1993). Declaration on the Elimination of Violence against Women. https://www.ohchr.org/EN/ProfessionalInterest/Pages/ViolenceAgainstWomen.aspx 


\section{Policy Development Module}

\section{MARTTA OCTOBER \& SUVI NIPULI}

Finnish Institute for Health and Welfare Finland, Helsinki, Finland.

E-mail: martta.october@thl.fi,suvi.nipuli@thl.fi

Abstract The Policy Development Module aims to make the Domestic Violence combatting policy planning process more structured and inclusive. The Checklist and Manual developed during IMPRODOVA research and innovation project form together a tool designed for Policy drafters, decision-makers and other key professionals responsible for planning the Policy's Feedback Cycle on national and local levels. This Policy Development tool enables a critical examination of relevant information and helps to consider all viable policy perspectives and tools, leading to increased understanding between different professions. It makes the Policy planning more inclusive and aids in engaging all salient stakeholders, including the representatives of the practitioners who work at the front-line and implement the policy. Consequently, the participants will develop a common purpose and a shared view on tackling the multidimensional societal challenges posed by Domestic Violence. The Checklist consists of eight sections, each of which should be noted when drafting a new policy document and planning the indicators for its follow-up. The Manual gives more details and practical examples of each section and therefore supports the use of the Checklist.

Keywords:
domestic
violence,
checklist,
manual,
policy
development,
first
responders,
police 


\section{Introduction}

National action plans and other policy documents are important processes to aid states in their implementation of human rights policies and other norms related to the prevention of domestic violence and the protection of its victims. This policy development module aims to make the policy planning process more structured and inclusive. The checklist and manual developed during the IMPRODOVA research and innovation project form together a tool designed for policy drafters, decision makers and other key professionals responsible for planning the policy's feedback cycle on both national and local levels.

At first sight, the tool may appear quite general and even simplistic. This impression is due to its cross-border and intra-national adaptability. The tool is, however, scalable and can be modified and adapted to different national or local needs, be it the drafting of a national action plan or local directions for a single profession.

The planning of policies and actions, whether national or local, should be inclusive and engage all salient stakeholders, including the representatives of the practitioners who work at the front line and implement the policy. The proposed tool enables a critical examination of relevant information and considers all viable policy perspectives and tools, leading to increased understanding between different professions. Consequently, the participants will develop a common purpose and a shared view on how to tackle the multidimensional societal challenges posed by domestic violence. Such solutions tend to avoid administrative silos and combine the theories of counter-violence work with practical knowledge on the field. ${ }^{1}$

An underlying approach for creating a new policy using this tool is to accompany each item of action with a systematic follow-up and evaluation process. With the help of the tool, the information from frontline practitioners and other information on different levels is gathered using an organized systematic method and fed into policy planning. The tool also supports the improvement of data collection and documentation of domestic violence for all users.

\footnotetext{
1 See for example: Munro, Eileen (2011): The Munro Review of Child Protection: Final Report; https://assets.publishing.service.gov.uk/government/uploads/system/uploads/attachment_data/file/175391/M unro-Review.pdf
} 
The checklist consists of eight different sections, each of which should be noted when drafting a new policy document and planning the indicators for its follow-up. The manual gives more details and practical examples of each section and therefore supports the use of the checklist.

\section{Background and formation of the framework}

All tools developed within IMPRODOVA follow the overarching aim of improving the well-being of victims of domestic abuse by reducing the frequency, impact and intensity of violence with the ultimate goal of overcoming violence entirely. ${ }^{2}$ The tools developed must also be sensitive to the complexity of the phenomenon of domestic abuse in its societal, economic, psychological, as well as health and wellbeing dimensions. In line with the Council of Europe Convention on preventing and combating violence against women and domestic violence, any tool must also be sensitive to the structural nature of violence against women. This demand is based on the fact that gender-based violence and the frequent exposure of women and girls to serious forms of violence such as domestic violence, sexual harassment and rape is common. ${ }^{3}$

On the policy-making level, the problem often lies at the abstract and general formulation of the planned actions. It is hard to transform the abstract ambitions of the policy into practically implementable solutions and effects. The key high-level officials responsible for drafting the policies tend to tackle the problem of domestic abuse from the point of view of their own background or the Ministry, which may not support communicating with other relevant fields horizontally and all relevant actors vertically. This policy development module aims to overcome these common shortcomings of policymaking and assessment by addressing the planning with a structured checklist and a manual on its use.

\footnotetext{
2 According to the Council of Europe Convention on Preventing and Combating Violence against Women and Domestic Violence and its Explanatory Report, any tool must also be sensitive to the structural nature of violence against women. The Explanatory Report can be found at: https://rm.coe.int/16800d383a .

${ }^{3}$ For more statistical information on Gender Based Violence, see Gender Statistics Database of the European Institute for Gender Equality, available at: https://eige.europa.eu/gender-statistics/dgs/browse/genvio .
} 


\section{Policy Maturity Model Checklist}

\begin{tabular}{l|l|l}
\hline $\begin{array}{l}\text { 1. Feedback methods } \\
\text { 1.1. Check relevant country reports of human rights } \\
\text { convention monitoring mechanisms }\end{array}$ & Yes & \\
\hline $\begin{array}{l}\text { 1.2. Include systematic feedback from the grass-root level to } \\
\text { the top }\end{array}$ & & \\
\hline $\begin{array}{l}\text { 1.3. Confirm confidential whistleblowing mechanisms, both } \\
\text { internal and external }\end{array}$ & & \\
\hline $\begin{array}{l}\text { 1.4. Ensure systematic feedback from NGOs } \\
\text { 1.5. Include the victim's perspective }\end{array}$ & Yes & In process \\
\hline $\begin{array}{l}\text { 2. Indicators } \\
\text { 2.1. Are there indicator(s) measuring prevalence }\end{array}$ & \\
\hline $\begin{array}{l}\text { 2.2. Are there indicator(s) measuring the number and } \\
\text { availability of services }\end{array}$ & & \\
\hline 2.3. Are there indicator(s) measuring concrete resources & & \\
\hline $\begin{array}{l}\text { 2.4. Are there indicator(s) measuring the human rights-based } \\
\text { approach }\end{array}$ & & In process \\
\hline 3. Dealing with overlaps & Yes &
\end{tabular}

3.1. Is the approach systemic and coordinated with a combined effect with other policies

\begin{tabular}{|c|c|c|}
\hline 3.2. Are the reporting cycles sufficiently open to the parties & & \\
\hline 3.3. Are the reporting cycles frequently enough & & \\
\hline 3.4. Is there a common database of previous reports & & \\
\hline 4. How are boundaries crossed? & Yes & In process \\
\hline 4.1. Is there a multi-agency approach on the strategical level & & \\
\hline 4.2. Is there a multi-agency approach on the practical level & & \\
\hline 5. Theory and Practice & Yes & In process \\
\hline 5.1. Are the policies made into practical guidelines/tools & & \\
\hline 5.2. Is there regular training on the guidelines/tools & & \\
\hline $\begin{array}{l}\text { 5.3. Are the superiors committed to the use of the } \\
\text { guideline/tools }\end{array}$ & & \\
\hline 5.4. Are the existing guidelines/tools being used on the field & & \\
\hline 6. Specified Resources & Yes & In process \\
\hline 6.1. Are specific resources allocated to the implementation & & \\
\hline 7. Maturity presentation & Yes & In process \\
\hline $\begin{array}{l}\text { 7.1. Is a sufficiently nuanced maturity level presentation being } \\
\text { used }\end{array}$ & & \\
\hline 7.2. Is reporting back to the grass-root level included & & \\
\hline 8. Defining 'fully implemented' & Yes & In process \\
\hline 8.1. Is 'fully implemented' defined & & \\
\hline
\end{tabular}




\section{Manual - How to use the Policy Maturity Model Checklist}

\section{Introduction}

In this manual, the dimensions of the checklist are explained in cursive and written as concrete instructions for those responsible for drafting of the policy maturity model. In some of them, also an ideal implementation of the policy is written. Both national and local examples of each dimension are given.

\section{Categories of the Checklist}

\section{Feedback methods}

1.1 Check relevant country reports of human rights convention monitoring mechanisms (such as GREVIO)

When implementing a policy, gather all information from the related human rights conventions and their monitoring bodies' reports. Ideally, the documents can be found in a national, regularly updated database.

National: See the relevant conventions obligating your country, such as the UN Convention on the Rights of the Child, the UN Convention on the Elimination on all forms of Discrimination against Women (CEDAW), the UN Convention against Torture and Other Cruel, Inhuman or Degrading Treatment or Punishment (OHCHR) and especially, if applicable, The Council of Europe Convention on preventing and Combating Violence against Women (The Istanbul Convention). Check especially the Country reporting mechanisms of each Convention.

Local: See above. Also check for national bodies' recommendations or directions given directly to the entity/entities you are addressing, such as for example the National police board's directions to the police forces.

\subsection{Include systematic feedback from grass-root level to the top}

Organize regular information gathering from the grass-root level to the top. 
National: Organize regular anonymous collection of feedback from the local level. For example, the National police board may send out a questionnaire to the local police forces. The questionnaire may include the experiences of the personnel of using a specific tool, such as a risk assessment form, to find out factors that may enhance or hinder the effective prevention of domestic violence.

Local: See above. In addition, experiences can be gathered also by interviewing the local professionals.

\subsection{Confirm confidential whistleblowing mechanisms, both internal and external}

Establish a feedback method within the entity/entities that the policy addresses. Internally, a whistleblower can bring concerns to the attention of the managing level within the organization. Externally, a whistleblower can bring concerns to light by contacting a third party outside of the concerned organization such as the ombudsman.

Ideally, the whistleblowing mechanisms are well established and their information is being utilized systematically. Furthermore, every police department and social welfare district should have at least one 'DV liaison officer' to act as a contact person for organizational personnel, NGOs and ministries. The liaison officer could share information and facilitate training in domestic violence but also report to the ombudsman e.g. on negligence in domestic violence cases, lack of resources or nonfulfilment of required training.

National: Most countries have a mechanism for individual concern reporting, such as the ombudsman-system or the national preventive mechanism, an international initiative under the governance of the UN Optional Protocol of the Convention Against Torture. However, some countries have specific independent rapporteurs for themes such as violence against women. These mechanisms should be utilized for external whistleblowing. Regularly check the reports of the external monitoring mechanisms in order to gather silent messages of possible concerns related to the services of a specific entity, such as the police. Internally, the whistle-blowing mechanisms should include the possibility of anonymous reporting.

After analyses, examination and actions, the information gathered by whistleblowing mechanism(s) should be shared with the relevant audience and published openly, if publishing is possible without ethical dilemmas. The gathered information should be utilized in training, in raising awareness, improving organizational performance and in encouraging employees to speak up when needed. 
Local: See above. In addition, the services are monitored locally depending on the country. For example, the municipalities responsible for organizing/producing/procuring a support service should monitor the level of the service and have both internal and external reporting mechanisms for individual complaints.

\subsection{Ensure systematic feedback. from NGOs and relevant Trade Unions}

Establish regular meetings/ roundtables/ hearings with relevant NGOs.

National: Whenever planning a national action plan/policy document, NGOs should be included in the process of planning. When following up the implementation, ministries can organize roundtables with the relevant NGOs. Working closely with NGOs that work with vulnerable groups and marginalized people (immigrants, refugees, homeless women, sex workers, the elderly, victims of honour-related violence, and disabled people) is recommended.

Local: NGOs be included in strategic and practical multi-agency approaches, such as local working groups responsible for preventing violence. Whenever the victim of violence is in a vulnerable situation due to her/his immigration status, disability, age or extreme fear, special attention should be paid on inviting a competent NGO specialist to the multi-agency meeting with the consent of the victim in order to meet her/his special needs.

\subsection{Include the victim's perspective}

Establish a method for hearing from experts by experience, either including them in the implementation process or gathering regular feedback. from targets of the policy.

Ideally, every year relevant NGOs and Victim Support Services are invited to give a performance feedback of how effectively public authorities have managed to intervene and prevent domestic violence and to assist victims. NGOs and Victim Support Services are also invited to give suggestions how public authorities can improve these areas. 
National: Some countries have well-organized groups of experts by experience, which they regularly include in policy planning and monitoring. This may be done by organizing seminars or asking for written statements at several stages of implementation.

Local: On the local level, the services should gather regular feedback from the customers/patients of the service. This should include the possibility of giving feedback and identifying yourself for later follow-up, as well as anonymous input. The gathered information should feed directly to the service development as well as the monitoring of the implementation of the policy.

\section{Indicators}

\subsection{Indicator(s) measuring prevalence}

Check for Repeated / Frequent survey information $\rightarrow$ for example the number of incidents, prevalence, attitudes, type / severity of injury etc.

Ideally, information systems should be user-proof and enable an individual to enter only correct data in the system. For data accuracy, mandatory classifications should be versatile enough in order to enable the user to enter exact data. Statistical discrepancies should be analysed. Discrepancies and disparities that indicate negligence or malpractice will then be examined.

National: Collect and follow information from crime offence reports, criminal justice measures such as restraining orders, regular victim surveys and health statistics / surveys. See also surveys measuring changes in attitudes related to violence or gender roles etc.

Local: Follow numbers of incidences, for example the local police force statistics, number of house calls based on violence and hospital/ER-visits with relevant ICDcodes. See also possible data from child protection services related to domestic violence.

\subsection{Indicator(s) measuring the availability of special services/experts}

Measure the number of special services/ experts available 
National: Follow the number and availability of special services for victims, perpetrators and children exposed to domestic violence. Also follow the number of used special services.

Local: See above. Compare your local situation to relevant counterparts, such as best-performing similar-sized local entities. Measure the number of available experts in the relevant fields, i.e. having received specialized training on domestic violence.

\subsection{Indicator(s) measuring concrete resources}

Measure how much concrete, both human and monetary resources are allocated to the function (i.e. policy/service etc.) at hand.

National: Measure the amount of resources allocated to the implementation of the relevant policies analysing the government budget.

Local: See whether domestic violence work has specified resources on the local budget level, i.e. municipality/ local police force/ health care / social work entity. See how the relevant services allow the staff to allocate time to domestic violence specified work. See, if specializing in domestic violence is made possible in each relevant entity.

\subsection{Indicator(s) measuring the buman rights-based approach}

Base the indicators solidly on the human-rights-perspective in order to avoid national distortions (i.e. the lack of understanding of gendered violence), using external evaluation where available. For the critical understanding of the human-rights based approach to your implementation, see to external/ expert legal evaluation of your performance.

The United Nations Human Rights Office of the High Commissioner (OHCHR) has developed a conceptual and methodological framework of indicators that can be applied and contextualised at the national level. The OHCHR conceptual and methodological framework adopts a common approach to identifying indicators for monitoring civil and political rights, and economic, social and cultural rights. 
The framework recommends the development of structural, process and outcome indicators. This configuration of indicators should help assess the steps being taken by states in addressing their obligations - from commitments and acceptance of international human rights standards (structural indicators) to efforts being made to meet the obligations that flow from the standards (process indicators) and on to the results of those efforts (outcome indicators) ${ }^{4}$.

National: Firstly, see to the recommendations by expert bodies following up the implementation of relevant human rights conventions, secondly, see to extracts from peer review such as the UPR, thirdly, see to findings of national external evaluations of national action plans etc. and fourthly, see to critical expert legal opinions in international sources.

Local: In terms of basing your indicator on the human-rights perspective, see to your national monitoring mechanisms reports on the policy performance at hand, such as the ombudsman's opinions, national bureau level recommendations etc.

\section{Dealing with overlaps}

\subsection{Ensure a systemic and co-ordinated approach}

When drafting and planning the implementation of a policy, make sure the approach is systemic, buman-rights-based and in line with other policies with a similar aim. Policies should be carried out consistenty and in a coordinated fashion with special attention on how different parts relate to each other and the rest of society. Ensure that the chosen approach leads to a combined effect with other policies.

National: When drafting a new policy for the national level, make sure you check other existing policies that relate to your subject, such as other action plans based on human rights conventions or public health promotion.

Local: See above.

\footnotetext{
${ }^{4}$ For more information, see: https://www.ohchr.org/EN/Issues/Indicators/Pages/framework.aspx
} 


\subsection{Ensure the existence of open reporting cycles}

Ensure that the reporting cycle is as open and accessible as possible, and that data is being accumulated and utilized from previous reporting cycles. An open cycle means firstly that the individuals responsible for reporting are aware of each other's and their own responsibilities, thus avoiding double reporting. Secondly, open reporting refers to the responders being aware of the timetables and the bigger picture.

National: Make the reporting cycle plus the actual report(s) public, thus the individuals responsible for reporting may use the information previously collected and can see where their share of reporting adds value to the national picture and points for action. This also enables the use of the reports for other purposes, such as service development.

Local: When gathering information at the local level, make sure they are aware of the national level reporting.

\subsection{Ensure sufficiently frequent reporting cycles}

The individuals responsible for reporting should gather information or experiences from the grassroot level of frontline responders, thus making it visible if resources are too scarce or other problems binder implementation.

National: Keep the reporting cycle sufficiently frequent. This could mean as frequent as once a year, or in the case of an action plan, using mid-term evaluation plus final evaluation. In between the reporting cycles, make sure you gather information from the experiences of the experts as well as grass-root level practitioners.

Local: See above.

3.4. Confirm the existence of a common database.

Build an accessible database of the reports gathered. 
National: The Ministry of Foreign affairs (or equivalent), who is responsible for the reporting internationally, should uphold a database of the national report cycles and their reports.

Local: Individuals responsible for local reporting should be made aware of the national database and how to utilize it in their own reporting. When compiling local reports, ideally, they also should be gathered in a database, i.e., that of the municipality.

\section{How are boundaries crossed?}

\subsection{Ensure the existence of a multi-agency approach on the strategical level}

When there are boundaries, make sure to have a mechanism (structures) where key persons meet and plan together overarching next steps for implementation, noting that some steps may be common. National: Establish a multi-agency working group responsible for drafting national action plans and following up their implementation. Such a national structure may exist already based on Art. 10 of the Istanbul Convention.

Local: Establish a local multi-agency working group responsible for the strategic planning and implementation of national action plans and other relevant norms on the local level. The strategic planning may include safety planning, local action plans related to combatting domestic violence, awareness-raising etc.

\subsection{Ensure the existence of a multi-agency approach on the practical level}

National: Establish national steering groups for major practical multi-agency solutions, such as SARCs (Sexual Assault Resource Centre), MARACs (multi-agency risk assessment conferences) etc.

Local: Establish necessary practical multi-agency solutions for customer work, such as MARAC-teams. Establish local steering groups for supporting practical multiagency solutions, which has managing level participation from each relevant entity involved in the practical solution. 


\section{Theory and Practice}

\subsection{Ensure that policies are made into practical guidelines/tools}

Legal implications need to be made into something very concrete and systematic in order to be fulfilled. Concrete tools; such as risk assessment forms, etc. should be made part of the daily practice and implanted into the professionals' routines. Follow-up should be routine, i.e. gathering registered data of the use of the tools. Thus, also evidence will be gathered of the effectiveness of the chosen tool.

National: Make sure that major international conventions as well as EU and national laws are accompanied with clear and practical guidelines when being implemented at the grass-root level. For example, draft a national tool for the implementation of a specific obligation, such as risk assessment.

Local: Make sure, that treatment/support paths of clients/patients such as emergency rooms, maternity clinics, the police, educational institutes, asylum centres etc. are established on the local level.

\subsection{Ensure that regular training exists on the guidelines/tools}

The importance of systematic and built-in training of the use of the concrete tool(s) cannot be exaggerated. Even when the use of a specific tool is compulsory, it may deteriorate with time if not overseen by regular training. The danger is that without adequate training a tool may be used in a counter-effective manner.

Ideally, all professionals active in the field of domestic violence prevention or intervention receive basic training on the necessary guidelines and tools as well as in-depth training during service.

National: Make sure that available training exists for professionals being trained at universities or polytechnics, as well as police schools. When possible, make sure the training modules are compulsory. For in-service training, create training materials available for all relevant professionals, such as e-training platforms. 
Local: Enable access for professionals to in-service training on a yearly basis. Make sure the training materials and availability is up to standard. Make sure that regular and systematic training is available for tools being used locally, such as risk assessment forms. Demand that new employees always take the training before using the tools in practice.

\subsection{Commit superiors to the use of the guideline/tools}

Even with the most effective and concrete tools, if superiors are not committed to the chosen practice, it will not cause the expected results.

Ideally, policies, goals, objectives and roles are well defined in the organizations' guidelines and superiors are competent to monitor and steer these sectors. Competence consists of knowledge, skills and attitudes, whereupon the competence and motivation in domestic violence related work has to be taken into account already in the recruitment process of superiors. Furthermore, the entities should have local "centres/bubs of excellence" regarding domestic violence, so that designated teams may specialize into domestic violence cases/issues.

National: Make sure that the relevant ministers and other government officials are informed about the level of implementation of each policy. Commit the ministers with regular reporting.

Local: It is of utmost importance, that the management of local entities enable expertise-building and specializing in domestic violence cases, also on the level of management. Another way of committing superiors to the chosen tools is to involve them in steering groups and in the strategic planning of their use.

\subsection{Ensure the use of existing guidelines/tools on the field}

Ideally, domestic violence related tools, used by the frontline responders, are compatible with one another and with the particular information systems of the authorities. Tools are designed to be userfriendly and to make frontline responders' work easier and more efficient.

Furthermore, exact guidelines provide practical and concrete information. Vague or abstract expressions are avoided as they may describe obligations imprecisely and may cause people to interpret them in different ways. The guidelines should provide practitioners with solutions and concrete examples of good practices. 
National: Measure and follow-up on the use of the chosen tools. If the tools are not used extensively and effectively, investigate the reasons for this. Based on the results, improve the tools, skills, abilities, attitudes or professionals' access to training.

Local: See above. Also, regularly ask for experiences of the use of the chosen tools for development purposes.

\section{Specified Resources}

\subsection{Ensure the allocation of specific resources for implementation}

Every action should be accompanied with a financial plan/information on the resources and how to implement them. Financial resources should also include human resources. The specific tasks should be incorporated into the task description of specific professions, thus, the normal mobility of labour will not deteriorate professionalism.

Ideally, financial resources should encourage the authorities to develop preventive measures. Evaluating the efficiency of preventive actions is difficult and may lead to a situation where allocated resources are used only to intervene with violence that has already happened. Financial planning should also include and define preventive measures.

National: Make sure that a sufficient amount of resources is allocated to the implementation of the relevant policies analysing the government budget.

Local: Make sure that local level domestic violence work has specified resources on the local budget, i.e. municipality / local police force / health care / social work entity. Make sure that the relevant services allow the staff to allocate time to domestic violence specified work. Ensure that specializing in domestic violence work is made possible in each relevant entity. Ensure that the person-years allocated to domestic violence work are actual; for example, in case of an absence, a substitute employee is recruited. 


\section{Maturity presentation}

\subsection{Confirm the use of a sufficiently nuanced maturity level presentation}

Often the traditional traffic light presentation of maturity level is too vague. Thus, level(s) of policy maturity could be presented by percentages (of fully implemented). One additional prospect of making the maturity presentation more nuanced is the possibility of dividing one large task into smaller elements and following the implementation of each one separately. Also, possible reporting timetable/ acceleration of time frame of reporting could be considered.

National: For example, when looking at the implementation of the required number of shelter places, first decide what the sufficient number of shelter places is. Then decide on the required distances and accessibility criterion for the required number of places. Thirdly, compare the current situation and see to the percentages by which it meets the chosen criterion.

Local: For example, when looking at domestic violence cases reported to the police, see how many of them were referred to support services. When the required number of cases is $100 \%$, compare the reality to that. Make sure that the local area data collection system is the same, so that situations are comparable.

7.2. Include reporting back to the grassroot level

If maturity is pending, a built-in alarm should go off giving a signal back to the grassroot level that implementation is not complete.

Ideally, information should be gathered on where lack of implementation exist and after an alarm goes off, the specific information is fed back to the grassroot level responsible for finalizing the implementation.

National: The gathering of information should be incorporated into the policy implementation reporting cycle. Thus, the information from a pending task is being fed back to the national entity responsible for the implementation of the function. For example, when looking at the prevalence of multi-agency co-operation, the availability of the multi-agency risk assessment conferences MARACs may imply a decrease in the recognition of domestic violence. Thus, the information will go back to the local level alarming them that sufficient level of implementation is still pending. 
Local: For example, the local multi-agency working group responsible for the strategic planning and implementation of national action plans on the local level should gather data from the local entities, such as hospitals and police stations, on the level of implementation. When the alarm goes off that a task is not completed, for example that a treatment/support path does not exist, the information would be sent back to the entities at hand.

\section{Defining 'fully implemented'}

\subsection{Define 'fully implemented' in the policy}

What is good enough should be agreed upon prior to drafting the policy document and when reporting, comparing the success rate to the set level of "fully implemented" should be carried out (i.e. in the form of the numeric indicators).

Typically, Fully implemented' should be a combination of numeric and areal attributes.

Ideally 'Fully implemented' should be a living and flexible concept: When knowledge on the topic increases, the understanding of what is fully implemented may be redefined.

National: For example, when looking at the full implementation of the policy of having a sufficient number of rape crisis centre places available, the criterion should first be decided as to what are the numeric indicators of fully implemented: (how many places, where they should be located as to be accessible enough to match the geographic realities).

Local: For example, if the policy at hand is the improved recognition of violence at maternity clinics, 'fully implemented' could be measured by asking the clinics on which percentage of cases have they performed universal screening of domestic violence.

For example, the Istanbul convention obligates that the parties shall provide or strengthen the appropriate training of the relevant professionals dealing with victims or perpetrators. For instance, regarding the police forces, this policy is fully implemented when all the police officers who work with clients have received training. 
For example, risk assessment by police should be mandatory for every domestic violence case. When the number of conducted risk assessments equals the reported cases with the classification of 'domestic abuse', the policy of conducting risk assessment can be considered as fully implemented. 


\title{
DOMESTIC ViOLENCE RISK
}

\section{ASSESSMENT AND CASE DOCUMENTATION}

\author{
MARIANNE MELA \& JARMO HOUTSONEN \\ Police University College of Finland, Tampere, Finland. \\ E-mail: marianne.mela@polamk.fi,jarmo.houtsonen@polamk.fi
}

Abstract Risk assessment is a cornerstone of domestic violence prevention and intervention. From the front-line responders' perspective, risk assessment constitutes a process that starts from identifying the factors increasing the likelihood of violence and then continues to plan safety measures to manage the sources of risks and prevent the recurrence of violence. To address some of the shortcomings related to the risk assessment of domestic violence, the IMPRODOVA project developed a Risk Assessment Integration Module, RAIMO. The overall purpose of RAIMO is to bridge the gaps between different risk assessment tools and professional perspectives and thereby to generate a shared understanding of risk assessment in multiprofessional and cooperative contexts. While RAIMO can be utilised in learning, teaching and as a databank, in this chapter, we focus on the key aspects and findings in risk assessment research. The chapter also aims to equip front-line responders with applicable information to revise or remodel the existing risk assessment procedures, networks, and tools.

Keywords:

domestic violence, Risk

Assessment Integration Module, RAIMO, front-line responders, risk

assessment 


\section{Introduction}

Risk assessment is a cornerstone of domestic violence (DV) prevention and intervention (Kropp, 2004). From the front-line responder's (FLR) perspective, risk assessment constitutes a process that starts from the identification of the factors increasing the likelihood of violence and then continues to safety measures to manage the sources of risks and thereby prevent the recurrence of violence. Risk factors can be grouped in several ways. Some factors relate to the perpetrator's psychological characteristics that increase the propensity to recidivism (Svalin \& Levander, 2019), while others relate to social and economic circumstances that may trigger or escalate violence. Furthermore, certain social and psychological features may increase the victim's vulnerability to violence (Ward \& Beech, 2014). Skeem and Monahan (2011) distinguish four components in the risk assessment procedure: identifying, measuring and combining risk factors, and producing a final risk assessment. However, calculating the level of risk in the form of an overall risk score is not enough since the ultimate aim of the risk assessment process is to improve the safety and well-being of the victim by specifically tailored services that DV frontline responders manage cooperatively (Douglas \& Kropp, 2002). The mitigation of risks can include judicial decisions, various social services and therapeutic support focusing on the behaviour and well-being of the perpetrator. Risk assessment should be a dynamic process. After risks have been identified and managed and the safety and well-being of the victim improved, multi-agency cooperation should continue monitoring the case as situations evolve. If the victim's safety and well-being deteriorate, safety measures should be immediately revised.

Risk assessment approaches are often divided into three major types. The least structured of the three approaches is clinical judgement, in which the professional explores factors that entail risks in a particular DV case by consulting his/her professional experience and body of knowledge (Skeem \& Monahan, 2011). Thus, clinical judgment is not equivalent to a simple layman's heuristics likely leading to biased perceptions (Kahneman et al., 1982), but requires strong and diverse professional experience and a deep understanding of DV risks. An actuarial approach is a structured and formal procedure to assess the risks of DV. The assessment of risks is formal because the professional explores a particular DV case with the help of an explicit checklist or guidelines covering items that are regarded in advance as the most salient risk factors. Furthermore, such a checklist is generally 
standardised based on research results and validated by an extensive pilot and testing. Following the specific guidelines, the professional ticks the observed risks, tallies them up and calculates an overall risk score for the case (Hart, 1998). Finally, structured professional judgment aims to combine the best of clinical and actuarial approaches and balances between the structured identification of risks and professional judgement (Nicholls et al., 2013). Several structured and formal risk assessment tools have been developed for professionals whose task is to prevent domestic violence, such as DA (Danger Assessment), VRAG, PATRIARCH and DASH/MARAC. These formal checklists not only help front-line practitioners identify serious DV, but also advance cooperation and shared understanding between different agencies and volunteer organisations. Moreover, the structured instruments enable the agents to reach justifiable decisions.

Currently, risk assessment in the context of DV is also required by legislation and policy, meaning that FLRs are in principle responsible for conducting risk assessment. The Istanbul Convention is the first international treaty that establishes a comprehensive set of legally binding obligations in order to ensure a holistic response to all forms of violence against women, including domestic violence. The Istanbul Convention combines detailed provisions concerning preventing violence, protecting and supporting victims and prosecuting perpetrators, obligating the signed countries to develop a set of comprehensive policies (Council of Europe, 2014). Article 51 of the Convention obliges parties to take the necessary legislative or other measures to ensure that an assessment of the lethality risk, the seriousness of the situation and the risk of repeated violence is carried out by all relevant authorities in order to manage the risk and if necessary to provide coordinated safety and support. Despite the clarity of the wording of the convention, many countries have not yet implemented systematic risk assessment tools and procedures for FLRs. In addition, there are gaps in FLRs' competencies, so basic and further training in assessing and managing the risks of domestic violence is needed (Niklander et al., 2019). 


\section{Domestic violence risk assessment integration module 'RAIMO'}

To address some of the shortcomings in the risk assessment of DV, the IMPRODOVA project developed a Risk Assessment Integration Module 'RAIMO'. The overall purpose of RAIMO is to bridge the gaps between different risk assessment tools and professional perspectives and thereby to enhance the shared understanding of risk assessment in multi-professional and cooperative contexts. Previous research has shown that different FLRs operate within their organisational frames, but effective collaboration requires more flexibility, overcoming professionspecific perspectives and increased awareness of the common purpose (Notko et al., 2021).

The development of RAIMO was based on extensive empirical data gathered from the different frontline responders working in the police, social work or health care in eight partner countries of the IMPRODOVA consortium. This field research collected the perceptions and experiences of almost 300 interviewees on risk assessment tools and procedures. We also explored the challenges, good practices and FLRs' needs for development of DV risk assessment. In addition, the development of RAIMO reviewed and utilised the body of research knowledge on the risk assessment of domestic violence.

The IMPRODOVA study showed large variations in the use of the systematic risk assessment procedures of DV on national, regional and local levels. First, the legislation and governance of the documentation, exchange and sharing of information about the parties of DV differ from country to country. Second, the structures, networks, and procedures for risk assessment vary on national and local levels. In some regions and locations, the processes were supported by clearly organised cooperative structures and official agreements. However, risk assessment systems were more dependent on the skills and commitment of individual professionals without formal organisational support, which left the processes vulnerable (Hera \& Szego, 2020). Therefore, we positioned RAIMO not as a competing tool intended to replace the current or forthcoming national or local risk assessment tools and procedures. Rather, we aimed at producing a set of resources compiling information about the focal risk factors from professional perspectives, the methods and procedures for identifying and documenting risks and steps to be followed in the process of risk assessment. The end product is a set of ideas, 
materials and concepts that can be used for improving local risk assessment tools and procedures and planning professional training. Two premises were underlined in the development of RAIMO. Firstly, the end product should meet the practical needs of the frontline responders, and secondly, it should include the victims' perspective. Hence, we aimed to develop a risk assessment integration module that offers frontline responders both the principles and practices of the various stages of the risk assessment process, complemented with a case scenario to emphasise the victim's perspective.

The IMPRODOVA study showed that FLRs were not particularly well trained in carrying out the risk assessment process or using the risk assessment instruments. Many FLRs did not have adequate competencies to detect and intervene in certain forms of DV such as coercive control and honour-based violence. When developing risk assessment procedures, the practitioners should be consulted and more actively engaged, otherwise the tools will not be well adapted to the conditions and requirements of the work. The lack of clear policy level regulation and local supervision together with disorganised and unsystematic risk assessment processes did not support the uniformed police officers in their work. Furthermore, failures, distortions or misunderstandings in information sharing between different FLRs were identified as possibly compromising the victims' security in certain situations. Finally, the lack of adequate documentation of assessed cases into a well-organised information system meant that valuable information could be scattered all over and the merging of information together was difficult (Hera \& Szego, 2020).

In order to respond to these shortcomings, RAIMO provides a rich resource base for developing risk assessment tools and procedures and for planning training. The content of RAIMO is organised in a conventional risk assessment process. Every stage or step of the process is described carefully and also demonstrated by the case scenario. RAIMO's purpose is to bring about a sense of shared purpose, responsibility, and common language for risk assessment among FLRs and thereby enhance multi-professional collaboration for the victim's benefit.

Several IMPRODOVA partner countries reported that the current risk assessment tools and procedures did not sufficiently address the specific situation of certain vulnerable individuals such as children, immigrant women and the elderly (Hera \& Szego, 2020). To bridge this gap, we added a section on victim vulnerability factors in RAIMO. It is crucial to understand how vulnerability may shape the victim's 
capability to act, their trust in the authorities, how they follow security strategies, leave the abuser or continue to be exploited by the abuser. Thus, RAIMO recommends paying careful attention to the victims' vulnerabilities in risk assessment and management.

As is common in R\&D research, the content and usability of RAIMO were first designed based on research and the body of research knowledge, and then assessed in an evaluation study. The evaluators who offered their criticism and suggested improvements were experienced frontline responders, managers, educators and academic researchers from the sectors of police, health care, social work, NGOs, judiciary and other statutory agencies (Szego \& Hera, 2021).

RAIMO was revised as per the findings and suggestions of the evaluation. RAIMO was converted from PPT format into WordPress to improve usability and visual clarity. Since RAIMO is a training tool for professionals from different sectors in eight EU countries, some very detailed or specific information had to be omitted. Therefore, we encourage the partner countries of IMPRODOVA to complement RAIMO with nationally relevant details in order to better support the work of their countries frontline responders and practitioners.

\section{Domestic violence risk assessment process}

Figure 1 shows the conventional steps of the risk assessment process that are also followed in RAIMO. We will now walk through the content of each step systematically. In the end, we will offer some ideas and suggestions for trainers, managers and frontline responders for improving and strengthening each step. 


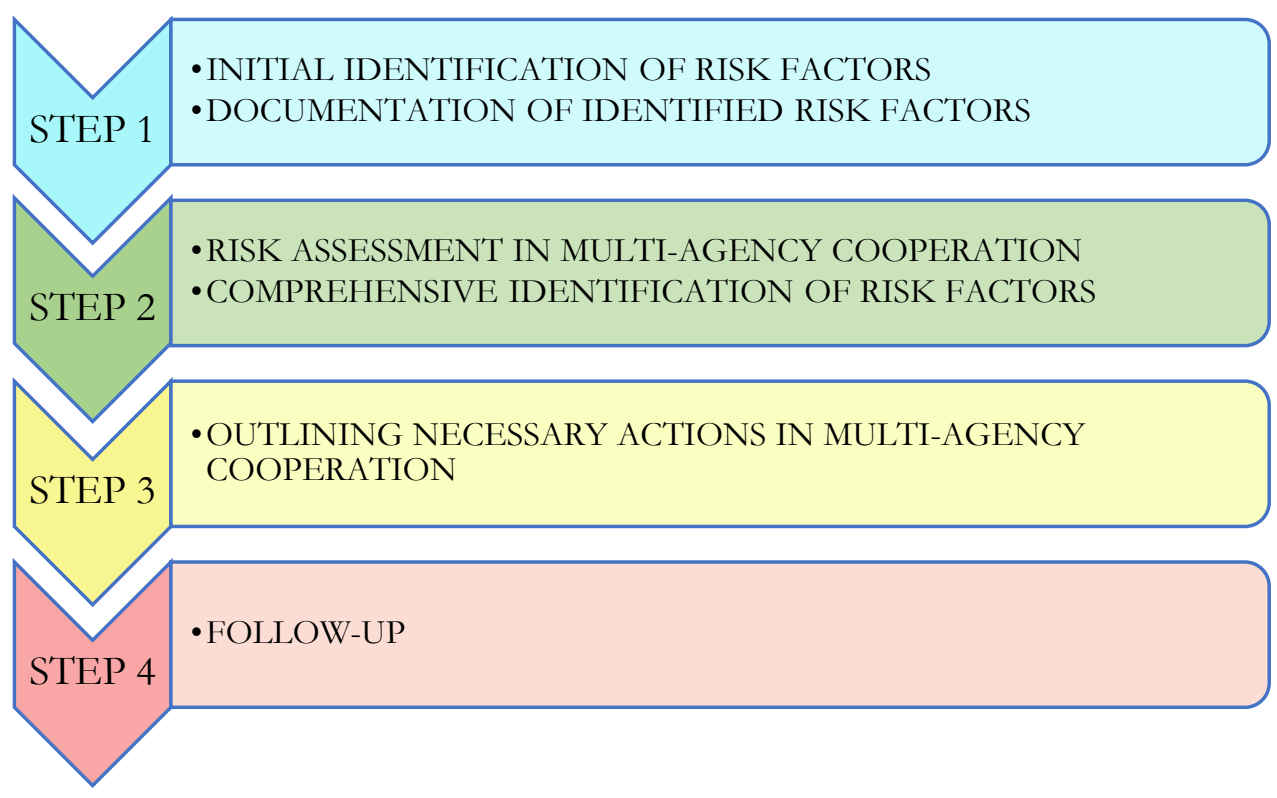

Figure 1: Steps of Risk Assessment Process in RAIMO

\section{Step 1. Risk identification}

The first step of DV risk assessment aims to identify the presence of risk factors. It is quite unrealistic to assume that the likelihood and timing of violence can be predicted exactly. The purpose of risk assessment is to prevent serious violence by protecting the victim and intervening in acts of violence. In addition, it is an exercise in evaluating how serious the consequences would be if violence continues, reoccurs or escalates. Some risk factors may escape the radar because they are not the concern of any particular profession. However, in order to have a comprehensive understanding of the sources of risks, the identification and documentation of all significant risk factors that may undermine the security of the victim are crucial, otherwise some important sources of risks may not be managed properly.

\section{Whose business is it?}

FLRs are the key players in the risk assessment process. By FLR we refer to police officers, social workers, doctors, nurses, paramedics, NGO workers and educators who concretely work in the frontline with the victims, suspects and other parties to domestic violence. The identification of risk factors as early as during the first 
contact with the victim and suspect is important. Later on, however, it is crucial to elaborate on and complement the information obtained during the first encounter with additional data from further interviews of the parties to DV and various registers maintained by FLRs. Some FLRs may have access to people's homes and so may observe in person the living conditions, relationships, resources and health problems of the individuals directly or indirectly involved in DV. In some sense, FLRs are also gatekeepers who have the discretion and responsibility to decide which problems are worthy of more attention and which individuals deserve more help and assistance.

Often FLRs may identify risk factors that do not necessarily relate to their own tasks and job description. Nevertheless, in order to produce a complete and realistic concept of the situation, it is essential for all frontline professionals to first be able to recognise indicators of DV, then record and also share information about risk factors that falls under their partner agencies' jurisdictions. For example, police officers may focus on criminal procedure and are keen on identifying criminal evidence. In parallel, the paramedics may assume that documenting information about criminalised acts such as trespass is the task of the police. If risk assessment is not supported by standardised tools such as a checklist of various risks and is based solely on the professionals' own judgment, there remains a chance that risk factors will not be systematically observed and recorded, unless the professional is trained and well experienced in conducting risk assessments. Moreover, domestic violence risk assessment seeks information about different types of domestic violence such as psychological violence and coercive control that are not necessarily criminalised. Thus, domestic violence risk assessment challenges the concept of domestic violence constructed only as a criminal justice problem.

\section{Risk factors}

Research has pointed out several factors that may indicate a strong likelihood of violence escalating or recurring in the future. Every frontline responder - police officer, social worker, nurse, doctor, educator or NGO worker - should be able to identify such factors. Table 1 lists the most common risk factors in the first column and then explains their importance in the second. The likelihood of violence may increase when a particular set of risk factors such as certain perpetrator characteristics and situational features occur together. For instance, a perpetrator's controlling characteristics in conjunction with access to a weapon and previous 
threats with a weapon should always be taken very seriously (Dawson \& Piscitelli, 2021).

Table 1: Risk factors and their explanation

\section{Risk factor Explanation}

Previous physical violence Previous physical violence is the best predictor of future violence. A history of abusive dynamics predicts intimate partner violence and homicide (Matias et al., 2020).

Violence occurs more frequently or violence is more intensive (harmful, injurious)

Escalation over time is characteristic of some violent relationships, particularly where the offender is persistent and engages in serious behaviours. Note that not all violent incidents are reported to frontline responders, so it is possible that assessments made by victims better account for all acts of violence including both nonphysical behaviours and coercive control (Boxall \& Lawler, 2021).

Coercive control Coercive control is a pattern of behaviour that intimidates and frightens the victim. Stalking and controlling behaviours are risk factors related to abusive couple dynamics together with various threats and abuse during pregnancy (Matias et al., 2020).

Extreme jealousy Extreme jealousy and obsessive thinking are risk factors

Obsessive thinking for domestic violence. Severe jealousy can be a crucial risk factor. Severe cases of jealousy may also meet the diagnostic criteria for delusional disorder. Jealousy in intimate relationships should therefore be assessed as part of psychiatric evaluation (Koskelainen \& Stenberg, 2020).

Victim has left for another Victim leaving an abusive partner for another partner
partner poses a significant risk factor for femicide (Campbell et al., 2003)*.

Perpetrator's stepchild in the Having a child living in the home who is not the abusive home partner's biological child more than doubles the risk of femicide (Campbell et al., 2003)*.

Strangulation Strangulation in the context of domestic violence is a 'red flag' risk factor for future serious harm and death (Douglas \& Fitzgerald, 2014). Prior non-fatal strangulation increases the risk of attempted homicide more than six times and a completed homicide by more than seven times (Glass et al., 2008). Intimate partner violence is often committed in the victim's or couple's household using sharp objects or strangulation (Matias et al., 2020, 10).

Victim is trying to divorce/ The risk of intimate partner femicide increases nine-fold separate or has divorced/ by the combination of a highly controlling abuser and the separated couple's separation after living together (Campbell et al., 2003)*. 


\begin{tabular}{|c|c|}
\hline $\begin{array}{l}\text { Mental healtl } \\
\text { perpetrator }\end{array}$ & $\begin{array}{l}\text { There is a significant relationship between anger } \\
\text { problems, anxiety, depression, suicidal behaviour, } \\
\text { personality disorders, alcoholism or problem gambling } \\
\text { and perpetration of domestic violence (Sesar et al., 2018). }\end{array}$ \\
\hline $\begin{array}{l}\text { Substance abuse issues of } \\
\text { perpetrator/victim }\end{array}$ & \multirow[b]{2}{*}{$\begin{array}{l}\text { Both the abuser's access to a firearm and their use of illicit } \\
\text { drugs are strongly associated with intimate partner } \\
\text { femicide. Neither alcohol abuse nor drug use by the } \\
\text { victim was independently associated with her risk of being } \\
\text { killed (Campbell et al., 2003)*. However, the substance } \\
\text { abuse issues of a victim may prevent them from seeking } \\
\text { or receiving help as they may not be considered 'ideal } \\
\text { victims' (Christie 1986). The likelihood of intimate } \\
\text { partner violence increases when there is a history of an } \\
\text { abusive relationship. Especially if the perpetrator has } \\
\text { access to weapons and has previously threatened to harm } \\
\text { or kill the victim with or without a weapon are strong risk } \\
\text { factors for male intimate partner violence or homicide } \\
\text { perpetration (Matias et al., 2020). }\end{array}$} \\
\hline $\begin{array}{l}\text { Perpetrator's access to a } \\
\text { firearm }\end{array}$ & \\
\hline Socia & $\begin{array}{l}\text { Social isolation has been linked to the risk of being abused } \\
\text { (Farris \& Fenaughty, 2002). Social isolation may also be a } \\
\text { consequence of an abuser's controlling behaviour. }\end{array}$ \\
\hline $\begin{array}{l}\text { e life changes } \\
\text { tor and econc }\end{array}$ & $\begin{array}{l}\text { For example, unemployment or bankruptcy. Economic } \\
\text { stress may increase the risk of domestic violence but } \\
\text { domestic violence may also cause financial problems for } \\
\text { victims and entrap them in poverty and an abusive } \\
\text { relationship (Center for Research on Violence Against } \\
\text { Women, 2009). }\end{array}$ \\
\hline $\begin{array}{l}\text { Other forms of domestic } \\
\text { abuse }\end{array}$ & $\begin{array}{l}\text { Including, for example, economic, sexual, psychological, } \\
\text { chemical and online violence, negligence, forced } \\
\text { marriage, FGM and human trafficking. }\end{array}$ \\
\hline $\begin{array}{l}\text { Victim is pregnant or has a } \\
\text { baby }\end{array}$ & $\begin{array}{l}\text { Abuse during pregnancy is a significant risk factor for } \\
\text { future femicide (Campbell et al., 2003)*. }\end{array}$ \\
\hline Violence towards pets & $\begin{array}{l}\text { There is a correlation between cruelty to animals and } \\
\text { family and domestic violence. Abuse or threats of abuse } \\
\text { against pets may be used by perpetrators to control and } \\
\text { intimidate family members. }\end{array}$ \\
\hline Threatening to kill & n intimate partnerships, threats to kill are often genuine. \\
\hline
\end{tabular}

$*=$ when comparing victims of femicide $(\mathrm{n}=220)$ and randomly identified abused women $(\mathrm{n}=343)$.

Research has pointed out several factors that may indicate a strong likelihood that violence will escalate or recur in the future. Every frontline responder - police officer, social worker, nurse, doctor, educator or NGO worker - should be able to identify such factors. Table 1 lists the most common risk factors in the first column and then explains their importance in the second. The likelihood of violence may increase when a particular set of risk factors such as certain perpetrator 
characteristics and situational features occur together. For instance, a perpetrator's controlling characteristics in conjunction with access to a weapon and previous threats with a weapon should always be taken very seriously (Dawson \& Piscitelli, 2021).

Table 2: Profession-specific risk factors

\begin{tabular}{lll} 
POLICE & $\begin{array}{l}\text { SOCIAL } \\
\text { WORK/EDUCATION }\end{array}$ & HEALTH CARE \\
$\begin{array}{l}\text { The perpetrator has access } \\
\text { to firearms. }\end{array}$ & $\begin{array}{l}\text { The victim is not allowed to } \\
\text { meet a social worker alone. }\end{array}$ & $\begin{array}{l}\text { The victim has symptoms } \\
\text { of strangulation. }\end{array}$ \\
\hline $\begin{array}{l}\text { The perpetrator has used/ } \\
\text { threatened to use a } \\
\text { weapon in the most recent } \\
\text { event. }\end{array}$ & $\begin{array}{l}\text { Signs of substance or non- } \\
\text { substance addictive } \\
\text { behaviour including co- } \\
\text { addiction (by partners or } \\
\text { family members) }\end{array}$ & $\begin{array}{l}\text { The victim is not allowed to } \\
\text { see the nurse/doctor alone } \\
\text { or the victim seems fearful. }\end{array}$ \\
$\begin{array}{l}\text { The perpetrator has a } \\
\text { previous criminal record, } \\
\text { especially of violent } \\
\text { crimes. }\end{array}$ & $\begin{array}{l}\text { Signs of conflict behaviour } \\
\text { that may lead to potential } \\
\text { escalation of conflict. }\end{array}$ & $\begin{array}{l}\text { There are prior (partly } \\
\text { healed) injuries on the } \\
\text { victim caused by trauma. }\end{array}$ \\
\hline $\begin{array}{l}\text { The perpetrator has } \\
\text { previously violated a } \\
\text { restraining order. }\end{array}$ & $\begin{array}{l}\text { The perpetrator is } \\
\text { experiencing high levels of } \\
\text { stress. }\end{array}$ & $\begin{array}{l}\text { Victim's or/and } \\
\text { perpetrator's depression or } \\
\text { symptoms of PTSD in the } \\
\text { victim. }\end{array}$ \\
\hline $\begin{array}{l}\text { More than three house- } \\
\text { calls to the same address } \\
\text { within one year. }\end{array}$ & & $\begin{array}{l}\text { Victim's or perpetrator's } \\
\text { suicide attempts. }\end{array}$ \\
\hline
\end{tabular}

Research has pointed out several factors that may indicate a strong likelihood that violence will escalate or recur in the future. Every frontline responder - police officer, social worker, nurse, doctor, educator or NGO worker - should be able to identify such factors. Table 1 lists the most common risk factors in the first column and then explains their importance in the second. The likelihood of violence may increase when a particular set of risk factors such as certain perpetrator characteristics and situational features occur together. For instance, a perpetrator's controlling characteristics in conjunction with access to a weapon and previous threats with a weapon should always be taken very seriously (Dawson \& Piscitelli, 2021). 
Table 3: Victim's vulnerability factors and their explanation

\section{VULNERABILITY EXPLANATION (WHY THIS CAUSES FACTOR VULNERABILITY AND HOW ABUSE MAY OCCUR)}

A victim may be dependent on a violent family member or the victim may be the only responsible caregiver for a violent family member. Thus, leaving a violent family member may not be an option for the victim. The victim may already be socially isolated. Leaving may require moving to a new address and concealing the contact information.

A perpetrator may have experienced caregiver burnout.

Elderly person An elderly person may experience overwhelming shame about the situation especially if the perpetrator is an adult child.

Abuse can occur in many forms such as physical, sexual, emotional or financial abuse, negligence, isolation and abandonment. There may also be signs of dignity deprivation (e.g. untidy appearance, soiled clothes) or choices concerning daily life, signs of insufficient care (e.g. pressure sores) or overor under-medicating (WHO, 2014).

Minors are nearly always dependent on the perpetrators.

Growing up in a hostile environment normalises the experiences of violence and thus the victims may not perceive their experiences as violence.

Minors may think that their experiences will not be believed by outsiders.

The patterns of coercive control such as restriction, isolation and a deprivation of personal freedom may be difficult to

Minor discriminate from parental upbringing and protective measures. Note: In some immigrant or otherwise socially or religiously strongly controlled families, differences between cultural values, lifestyles and views may cause conflict between the minors and their parents. Undiplomatic handling by the authorities or rash measures may increase the risk of the parents sending the child to their native country to a boarding school or having them raised by relatives. This may increase the risk of FGM, child marriage and breaks in education, social relations and integration.

Disabled persons may be functionally dependent on the perpetrator in everyday life, needing assistance in moving, eating, communicating and medicating.

A violent family member or caregiver may experience caregiver

Disabled person burnout.

Victims may have difficulties in making themselves heard, understood or believed.

A perpetrator may explain injuries as accidents caused by dyskinesia. 
There are several forms of dependency such as financial and emotional dependency. Also, structural reasons such as

Dependent on perpetrator hierarchical gender relations or rural disparity contribute to dependencies; for instance, when compared to urban women, rural women experience higher rates of DV yet live farther away from available resources (Peek-Asa et al., 2011).

The rates of mental health disorders such as anxiety disorders, PTSD and depression are higher among refugee populations in comparison to the general population. This increased

Refugee background vulnerability is linked to experiences prior to migration, such as war exposure and trauma (Hameed et al., 2018). In addition, language barriers or negative experiences of the police and distrust towards authorities may prevent the victims from seeking help.

Homelessness can also be a consequence of domestic violence and often increases the vulnerability and dependency of the victim. Social marginalisation may prevent the victims from seeking help.

Language barriers, negative or discriminative experiences of the

Belongs to an ethnic police, fear of not being believed, experiences of racism, social minority marginalisation or the power of parallel societies may prevent the victims from seeking help.

A victim may fear of being 'outed' to family members, friends

Belongs to sexual or gender minority and co-workers if they report domestic violence to the police. A victim may fear discrimination or disrespectful treatment by the police.

Fear of an abusive partner may weaken women's ability to improve their life situations (Sabri et al., 2014). An atmosphere

Strong fear of fear is likely to increase maladaptive thinking patterns, inhibiting problem-solving and increasing denial and avoidance (Calvete et al., 2007).

Apart from being a consequence of domestic violence such as post-traumatic stress disorder (PTSD), mental health issues can also be a risk factor for IPV revictimisation (Kuijpers et al., 2012).

If the family or community of the victim approves of and

Family or community justifies violence based on honour/culture/ religion justifies violence, the victim may be extremely scared, isolated, coerced and controlled. The victim may feel powerless to seek help. For many victims, it may be unthinkable to abandon their entire community to live without violence, and even if they did so, leaving the family or community may escalate the violence. 


\section{Case documentation}

Since risk assessment and the management of the sources of risks are dynamic processes, they need to be adjusted when the risk situation changes. Revisions in the management of risks is not possible, however, without clear case documentation of domestic violence and its risk factors. Careful case documentation that is systematically recorded and filed in an information system ensures that FLRs can easily search for and find information documented in the past and revise it if the changing situation requires it. Standardised risk assessment tools and checklists support the documentation efforts because they offer the criteria for what information needs to be recorded and when and how. Obviously, all FLRs must follow general and field-specific legislation, regulations and guidelines that set the terms for the collection, storage, processing, sharing and deletion of personal and private information.

It is vital for risk assessment, case documentation, and information sharing between authorities to avoid endangering victims' safety at any point. Thus, there should be plain and unequivocal protocols and security restrictions for documenting the assessed risk factors and the measures taken to improve the victim's safety. For example, documented risk assessment data should not be included in pre-trial investigation records that are part of the judicial process, thus giving the defendant access to the material. The perpetrator should not have access to the victim's risk assessment documentation, which should be kept separate from a possible criminal procedure. Data protection, confidentiality and the victim's consent to share information are key issues when intervening in domestic violence and abuse (Albuquerque et al., 2013).

Systematic case documentation supports FLRs work, fulfils legal requirements and ensures the continuity of risk management and service delivery. However, documenting the case is not as simple as it may sound. There is no consensus in literature or among the professionals about what risk factors are significant, what should be done about these risk factors and by whom. Risk assessment tools are not commensurable so the development of a shared understanding and common riskrelated language among frontline responders are required (Backhouse \& Toivonen 2018; McCulloch et al., 2016). 


\section{Step 2. Risk assessment}

Risk assessment is the phase, during which the professionals consider the level of risk using relevant information regarding risk factors and the victim's own assessment of the situation. Risk assessment is not a mechanical calculation of a risk score, but the professional has to use his/her professional judgement to reach a conclusion about the seriousness of the situation. A comprehensive and reliable risk assessment process requires all pertinent information to be collected, available and documented properly.

The risk assessment needs to address both the adult victim and their children. In addition, the risk assessment should be done with the victims, not to them. Ideally, with the consent of the victim, information is shared, for example with the police, prosecutor, social work, health care sector and relevant NGOs.

\section{Risk assessment tools ${ }^{1}$}

There are several risk assessment tools designed to detect and assess the risks of domestic violence. The DASH questionnaire and MARAC (multiagency risk assessment conference), for example, focus on intimate partner violence. Danger Assessment (DA) consists of a calendar to assess the severity and frequency of battering during the past year and a 20-item scoring instrument. DA focuses on intimate partner violence, but there is also a revised version of the questionnaire that can be used to predict re-assault in abusive female same-sex relationships (Danger Assessment website, n.d.). The violence risk appraisal guide (VRAG) is a 12-item actuarial instrument that assesses the risk of further violence among men who have recently committed criminal violence. It is an empirically validated actuarial method for the assessment of the risks of violence by persons with a psychological diagnosis or clinical status. The recommended material for scoring the VRAG both in research and individual assessment comes from a person's comprehensive psychosocial history addressing, for example, his/her childhood conduct, anti-social and criminal behaviour, psychological problems and details of offences (Criminal Justice, n.d.). PATRIARCH is a victim-focused checklist and risk assessment tool that applies professional judgment to honour-based violence and forced marriage risks. The

\footnotetext{
${ }^{1}$ For a list of countries that use different approaches and methods to assess the risks of domestic violence, see Hera \& Szego (2020).
} 
ultimate aim of PATRIARCH is safety planning. It comprised 15 items covering the perpetrator's behaviour, attitudes and life's circumstances and the victim's vulnerabilities (Sundsvall Forensic Psychiatric Hospital, 2005).

There are certain limitations to the risk assessment tools. For example, MARAC is not fully and directly applicable to the case of children (SafeLives, 2019). The use of VRAG requires clinical expertise since compiling answers to assess someone's psychosocial history is a clinical task (Criminal Justice, 2021). The proper application of the risk assessment tool based on structured professional judgement (e.g. MARAC and PATRIARCH) requires experienced and qualified practitioners who have undergone specific and specialised training (EIGE, 2019; Belfrage, 2005). Some risk assessment tools are considered time-consuming and require access to and analysis of a large amount of information (e.g. see Respect, 2010). The actuarial risk assessment tools have performed somewhat better than structured clinical judgment in predicting violence (Put et al., 2019). However, the limitation on using only an actuarial tool is that decisions on the level of risk may not take into account other sources of information and, as the tools focus on static risk factors, they do not capture how risk can change over time as a result of perpetrator management or victim safety interventions (EIGE, 2019). Put et al. (2019) therefore suggest that actuarial tools should be further developed and strengthened by distinguishing between risks and needs assessment, integrating risk assessment into case management and extending actuarial tools with a broad array of dynamic risk factors.

\section{High-risk moments}

FLRs should always be aware of so-called high-risk moments and potential triggers for increasing risk. During the situations and events that may increase risks, agencies should be alerted to upgrade their safety planning and provide the victim with extra support. Some common high-risk moments are listed in Table 4. 
Table 4: High-risk moments

\section{HIGH-RISK MOMENTS}

- The perpetrator is given a (court) decision of

- a restraining order

- a divorce/obligation to share assets

- a negative residence permit

- a negative child custody decision/child contact arrangements

- The perpetrator realises that the situation was reported to police

- The perpetrator is released from custody or a prison sentence

- The perpetrator is being charged

- Trial is scheduled/has occurred

- Lead-up to a trial

- Sentence reading is scheduled/has occurred

- Expiry of a court order

- The perpetrator discovers the new address of the victim

- The victim declares the intention of leaving/separation

- The victim attempts to leave for separation

- The victim starts a new relationship

\section{Towards a systematic risk assessment process}

From the perspective of a systematic risk assessment process, the chain is only as strong as its weakest link, so we would also highlight here the process and procedures of how the cases are entered or find their way into the risk assessment process. During the fieldwork of the IMPRODOVA research and innovation project, we learned that different types of methods are used and various types of cooperative networks have been established among FLRs for risk assessment at the local level. Furthermore, even though the personnel in charge of the risk assessment of DV may be highly skilled, their organisations did not support the function with formal structures and arrangements. Moreover, these well-motivated individuals were often trying to manually identify the high-risk cases from the masses of crime reports. This type of work may be effective but as a process it is flawed and time-consuming.

In order to be effective, a risk assessment process should start during the very first encounter with the victim. Depending on the situation, an initial assessment could be carried out by the first police officer, social worker, paramedic or teacher, whoever is in contact with the victim. FLRs should have the necessary skills, knowledge, tools and organisational support to identify and document risk factors at the earliest stage. In addition, an adequate understanding of domestic violence risk factors would help FLRs to assess the victim's acute need for support and safety. 
Consistent practice in case documentation and easy access to the documented information can facilitate a systematic risk assessment process.

\section{Need for a tailored risk assessment tool?}

To strengthen the risk assessment process from below, we recommend that FLRs be offered a tailored risk assessment tool. By 'tailored', we mean that the tool is adapted to local risk assessment procedures, networks and digital solutions. A tailored tool should support the structures and procedures that have already been locally established and not completely replace what is already functioning well. The use of the tool should not substantially increase the workload of FLRs, but rather the professionals should be able to experience its benefits in practice. Nevertheless, FLRs should have a sufficient understanding of the purpose and importance of risk assessment so that the 'preliminary risk assessment' would become a natural and significant part of their daily work. This requires training to build a thorough understanding of why some situations and events increase the risk of high-impact domestic violence. Moreover, locally adapted risk assessment tools should recognise and overcome possible cultural and managerial barriers impeding the cooperation between FLRs agencies, and thus resonate, for instance, with the languages and concepts used by different FLRs (Grant \& Rowe, 2011).

\section{Step 3. Outlining necessary actions}

Identifying the sources of risks and calculating the likelihood of grave/serious violence are good starting points, but in order to effectively promote the victim's safety, the sources of risks need to be managed carefully (Myhill \& Hohl, 2019; Cattaneo, Goodman, 2007). Multiagency cooperation is the most effective way to respond to domestic violence at both an operational and strategic level. Each agency approaches domestic violence from their professional perspective (Notko et al., 2021) and they have access to different types of information. By combining these professional perspectives and information, a more complete and detailed picture of DV and its risk factors can be constructed. Outlining necessary actions and measures is a crucial phase where the professionals in close cooperation with each other and the victim develop a plan of measures to strengthen the victim's safety. 


\section{Protective measures}

Several aspects need to be considered to avoid any situation in which the professionals' actions aimed at improving the safety of the victim actually make things worse. Firstly, the action planning should be coordinated. Scattered and uncoordinated measures may be ineffective as they may not support each other. Secondly, the actions should be timed right so as not to compromise the safety of the victim. Some moments may trigger and escalate violence (see Table 4). Thirdly, the victim and the professionals should be aware that some actions and decisions may actually increase the risk of high-impact domestic violence. This is especially the case when the perpetrator has been controlling the victim and the professionals' actions reduces the perpetrator's power over the victim. Fourthly, effective management of risks cannot be achieved with a 'one-size-fits-all' response as the context and severity of violence, degree of coercive control and the life circumstances of the victim and the perpetrator vary (Battered Women's Justice Project, n.d.). Finally, according to some studies, the risk of recidivism is heightened within the first year after the police report, hence risk management interventions need to be implemented quickly during this critical period (Petersson, 2020).

Below is a list of protective measures that can be taken to strengthen the safety of the victims and their children.

Table 5: Examples of protective measures

\section{POLICE}

- Inform the victim about shelters and guide the victim to a shelter if needed.

- Initiate child protection procedures if not yet done.

- File a crime offence report if not yet done

- With the victim's consent, contact the victim support services.

- Document information produced by risk assessment and keep it confidential.

- Inform the victim about a restraining order or issue a temporary restraining order.

- Inform the victim of possible moments when the police will contact the perpetrator.

- Create a safety plan for the victim - co-produced with the victim.

- In case of physical injuries, guide the victim to health care services to have them treated and documented.

- Guide the victim to Social Services based on their needs for support.

- Make sure all relevant NGOs are invited to participate in the risk assessment process.

- Assist the victim in protecting their personal data. 
- Take into account the risks of digitally assisted stalking and cyberstalking and help the victim in protecting their digital devices.

- Depending on the legislation, the police can also consider secret means of gathering intelligence to prevent crimes or avoid danger.

- Consider the benefits of a portable alarm system for the victim.

- Assist the perpetrator in joining a perpetrator programme, if this duty does not belong to another agency.

\section{SOCIAL WORK}

- If there is an immediate or even likely risk to the safety of the client or any children, consider contacting the police.

- Initiate child protection procedures if not yet done.

- Inform the victim about shelters and guide the victim to a shelter if needed.

- Help the victim to solve financial problems.

- Secure safe housing for the victim.

- Assist the victim in protecting their personal data.

- Assist the victim in getting immediate crisis help and psychosocial support.

HEALTH CARE

- Always examine the patient without their family members or spouse being present.

- Assist the victim in receiving immediate crisis help and psychosocial support.

- If there is an immediate risk to the safety of the patient or any children, consider contacting the police.

- Initiate child protection procedures if not yet done.

- Ask for the victim's consent before admitting any visitors .

\section{Step 4. Follow-up}

Despite effective intervention, an abuser may continue being violent and oppressive towards the victim. There are many reasons why a victim of domestic violence may not be able to leave the abuser, (mutual) dependency and fear or financial issues to name but a few. Usually, it takes several attempts by the victim to leave an abuser before being able to establish a new life and stay away for good.

Sometimes separation or even an attempt or voiced wish to separate may escalate the violence. In some cases, the victim may try to control the violence by staying in the relationship. In other cases, the victim may leave the abuser, but the abuser may start stalking and harassing the victim. Child contact arrangements may be used as a means to carry on subjecting the victims to violence. FLRs must monitor the situation and keep a trustful and safe relationship with the victim. If the victim's situation changes substantially, the risk assessment must be revised and the professionals must construct new appropriate safety measures. Ideally, risk 
assessment is a dynamic process, because risk factors constitute a dynamic and evolving totality (Ward \& Beech, 2014). If the threat of violence continues, the process of risk assessment must be reiterated from time to time. Effective prevention of DV and breaking the cycle of violence may require several interventions.

\section{Tables of guidelines and suggestions}

\section{POSSIBLE CHALLENGES IN THE RISK ASSESSMENT PROCESS}

- The consequences of incompetence due to lack of training.

- Insufficient identification of risk factors.

- Justification of non-intervention with 'lame' risk factors such as the victim's substance abuse, repeated violence and the victim's unwillingness to cooperate, language and cultural barriers.

- Formalised risk assessment tools may narrow the perception of frontline responders or may result in mechanical 'ticking of boxes', leading to exact yet incomplete and erroneous judgement of risks. Standardised and formal risk assessment tools should not exclude the art of professional judgement, but rather support it (Hera, Szego, 2020).

- The consequences of unsystematic assessment without a structured risk assessment questionnaire or checklist may produce an incomplete picture of the situation; the professional may not perceive all risk factors systematically and comprehensively, and various cognitive biases may distort the perception of risk factors.

- Multiple and unconnected information systems with disparate records:

- Fragmented information in multiple registers.

- Documentation of information is laborious.

- Searching and merging information is challenging.

- Information exchange and cooperation between FLRs is inflexible.

- When a victim discloses risk information, but an FLR does not record it, the victim is left under the misconception that their account has been registered and need not be retold again later. Therefore, the documentation of risk factors should be systematic and based on structured questionnaires.

- Different FLR agencies do not necessarily communicate and share risk-related information with each other; the victim may already be a client of some service provider, but that party is not invited into the risk assessment process because the agencies that carry out risk assessment may have no experience of cooperation with the other service providers. Involving the actors with which the victims have a relationship of trust may support the victim's confidence in cooperating with other professionals and agencies.

- The responsibilities and roles of other agencies are unclear for the cooperative professionals.

- The risk assessment work is profiled only for a few motivated individuals in the organisation, so the identification of high-risk cases is not systematic but rather coincidental. 


\section{SUGGESTIONS FOR STRENGTHENING THE RISK ASSESSMENT}

\section{PROCESS}

- Make sure that the risk assessment tool takes adequate account of the risk posed by psychological violence and coercive control and the history of abuse, and recognises additional risks faced by those with protected characteristics (e.g. minority ethnic women, sexual and gender minorities, disabled persons, elderly or those with additional support needs).

- Make sure that the professionals who work in the chain of the risk assessment process have adequate resources/funding for their work.

- Make sure that there is a set of common values (gender-based understanding of domestic abuse; victim centeredness; embedding of inter-sectional approach; informed by lived experience).

- Offer FLRs in-service training about risk assessment and the use of its tools.

- Provide FLRs with a clear pathway or modus operandi - all the actors should know who they need to contact and what is expected of each person.

\section{GUIDELINES FOR FRONTLINE RESPONDERS}

- Ask your supervisor for a risk assessment tool and appropriate training.

- Use an adequate and validated risk assessment tool.

- Ask systemically about all pertinent risk factors.

- Document all identified risk factors.

- Document your own assessment as well as the victim's assessment of the risk situation.

- Remember confidentiality and data security.

- Request the victim's consent for multi-agency information sharing.

\section{GUIDELINES FOR MANAGERS}

- Provide your staff with ongoing in-service training and organisational support for risk identification, risk assessment and risk management.

- Provide your staff with modern and effective risk assessment tools and working tools, including information systems for documentation.

- Make sure that the documentation of risk factors is user-friendly, integrated into other relevant processes and information systems, and enables the searching and sharing of documented risk factors.

- $\quad$ Risk identification should start during the first encounter with the victim.

- In order to motivate the FLRs to initial risk assessment, they should understand the purpose of the risk assessment process and why the identification and documentation of certain risk factors is important. This may require FLRs to understand their role as gatekeepers in the chain of multi-professional collaboration.

- For example, uniformed police officers and detectives focus on seeking evidence for crime investigation. However, an understanding of multi-agency cooperation and the police's responsibilities in preventing domestic violence would motivate them to identify and document risk factors that do not necessarily constitute a crime or relate to criminal investigation.

- For example, paramedics may believe that the victim will talk to the police about the domestic violence incident just as they have talked to the paramedics. However, often victims do not want or are frightened to confide in the police. If the paramedics do not document what their patients disclose in addition to injuries and the mechanism of injuries, the victims' reported information on, for 
example, the repetitiveness of the violence and coercive control may remain in the dark. Thus, paramedics can be gatekeepers in the risk assessment.

- Motivate and your staff and ensure that they follow established procedures and best practices.

- Update guidelines from time to time and encourage staff to follow new good practices.

- Acknowledge good practices so that they become part of the organisational memory.

- Assess the effectiveness and impact of risk assessment procedures and make changes if needed.

- Support your staff in understanding their own roles and responsibilities, but also the roles and responsibilities of partner agencies. Mutual understanding and a common purpose would help parties avoid an ambiguous situation where no particular agency seems responsible for the risk assessment process. In a worst-case scenario, the victim is left alone or their safety is compromised.

- Cooperation with other agencies should also occur at a managerial level. Formal agreements with other agencies for effective and mutual cooperation are often required.

\section{RECOMMENDED FURTHER READING}

- EIGE: A guide to risk assessment and risk management of intimate partner violence against women for police https://eige.europa.eu/gender-based-violence/riskassessment-risk-management

- European Manual of Risk Assessment https:/ /e-maria.eu/wp-content/uploads/2011/10/Manual-latest-version-lightcolours.pdf

- Digital Stalking: A guide to technology risks for victims https://www.womensaid.org.uk/wpcontent/uploads/2015/11/Digital_Stalking_Guide_V2_Nov_2012.pdf

\section{References}

Albuquerque, M., Basinskaite, D., Medina Martins, M., Mira, R., Pautasso, E., Polzin, I., Satke, M., Shearman de Madeco, M., Alberta Silva, M., Sliackiene A., Manuel Soares, M., Viegas, P. \& Wiemann, S. (2013). E-MARIA: European manual for risk assessment. Bupnet, Göttingen. https://e-maria.eu/wp-content/uploads/2011/10/Manual-latest-version-light-colours.pdf

Backhouse, C. \& Toivonen, C. (2018). National Risk Assessment Principles for domestic and family violence: Companion resource. A summary of the evidence-base supporting the development and implementation of the National Risk. Assessment Principles for domestic and family violence (ANROWS Insights 09/2018). NSW: ANROWS. https://apo.org.au/sites/default/files/resourcefiles/2018-07/apo-nid189371_6.pdf

Battered Women's Justice Project. (n.d.). Coordination Models. https://www.bwjp.org/ourwork/topics/ccr-models.html

Boxall, H. \& Lawler, S. (2021). How does domestic violence escalate over time? Trends \& issues in crime and criminal justice, (626), 1-7. https://doi.org/10.52922/ ti78139

Calvete, E., Susana, C. \& Este'Vez, A. (2007). Cognitive and coping mechanisms in the interplay between intimate partner violence and depression. Anxiety, Stress, Coping, 24(4), 369-382.

Campbell, J. C., Webster, D., Koziol-McLain, J., Block, C., Campbell, D., Curry, M. A., Gary, F., Glass, N., McFarlane, J., Sachs, C., Sharps, P., Ulrich, Y., Wilt, S. A., Manganello, J., Xu, X., Schollenberger, J., Frye, V. \& Laughon, K (2003). Risk factors for femicide in abusive 
relationships: results from a multisite case control study. American journal of public bealth, 93(7), 1089-1097. https://doi.org/10.2105/ajph.93.7.1089

Cattaneo, L. B. \& Goodman, L (2007). New directions in risk assessment: An empowerment approach to risk management. In K. Kendall-Tackett \& S. Giacomoni (Eds.), Intimate partner violence. Civic Research Institute, 1-17.

Christie, N. (1986). The ideal victim. In: Fattah, E. A (Ed). From Crime Policy to Victim Policy. MacMillan, 17-30.

Council of Europe (2014). Council of Europe Convention on preventing and combating violence against women and domestic violence. https://rm.coe.int/168008482e

Criminal Justice. (n.d.). Violence Risk. Appraisal Guide (VRAG). http://criminaljustice.iresearchnet.com/forensic-psychology/violence-risk-appraisal-guide-vrag/

Danger Assessment (n.d.). What is the Danger Assessment? https://www.dangerassessment.org/about.aspx

Dawson, M. \& Piscitelli, A. (2021). Risk Factors in Domestic Homicide: Identifying Common Clusters in the Canadian Context. Journal of Interpersonal Violence, 36(1-2), 781-792. https://doi.org/10.1177/0886260517729404

Douglas, H. \& Fitzgerald, R. (2014). Strangulation, Domestic Violence and the Legal Response. The Sydney law review, (36), 231.

Douglas, K. S. \& Kropp, P. R (2002). A Prevention-Based Paradigm for Violence Risk Assessment: Clinical and Research Applications. Criminal Justice and Behavior, 29(5), 617-658. https://doi.org/10.1177/009385402236735

European Institute for Gender Equality (EIGE) (2019). A guide to risk assessment and risk management of intimate partner violence against women for police. https://eige.europa.eu/sites/default/ files/documents/20191701_mh0119277enn_pdf.pdf

Farris, C. \& Fenaughty, A. (2002). Social Isolation and Domestic Violence Among Female Drug Users, The American Journal of Drug and Alcohol Abuse, 28(2), 339-351, https://doi.org/10.1081/ADA120002977

Glass, N., Laughon, K., Campbell, J., Hanson, G., Sharps, P. \& Taliaferro, E. (2008). Non-fatal strangulation is an important risk factor for homicide of women. Journal of Emergency Medicine, 35(3), 329-335. https://doi.org/10.1016/j.jemermed.2007.02.065

Grant, S. \& Rowe, M (2011). Running the risk: Police officer discretion and family violence in New Zealand. Policing \& Society, (21), 49-66. https://doi.org/10.1080/10439463.2010.540662

Hameed, S., Sadiq, A. \& Din, A. U. (2018). The Increased Vulnerability of Refugee Population to Mental Health Disorders. Kansas journal of medicine, 11(1), 1-12.

Hart, S. D. (1998). The role of psychopathy in assessing risk for violence: Conceptual and methodological issues. Legal and Criminological Psychology, 3(1), 121137. https://doi.org/10.1111/j.2044-8333.1998.tb00354.x

Hera, G. \& Szego, D. (2020). Deliverable report for IMPRODOV A (D2.3). https://improdova.eu/pdf/IMPRODOVA_D2.3_Risk_Assessment_Tools_and_Case_Do cumentation_of_Frontline_Responders.pdf? $\mathrm{m}=1585673380 \&$

Kahneman, D., Slovic, P. \& Tversky, A. (1982). Judgement under uncertainty: Heuristics and biases. Cambridge, Cambridge University Press.

Kropp, P. R. (2004). Some Questions Regarding Spousal Assault Risk Assessment. Violence Against Women, 10(6), 676-697. https://doi.org/10.1177/1077801204265019

Koskelainen, M. \& Stenberg, J-H. (2020). Mustasukkaisuudesta harhaluuloisuushäiriöön: tunnistaminen ja väliintulot osana lähisuhdeväkivallan estämistä. Duodecim, 136(6), 611-616.

Kuijpers, K., van der Knaap, L. \& Winkel, F. (2012). PTSD symptoms as risk factors for intimate partner violence revictimization and the mediating role of victims' violent behavior. $J$ Trauma Stress, 25(2), 179-186. doi: 10.1002/jts.21676

Matias, A., Gonçalves, M., Soeiro, C. \& Matos, M. (2020). Intimate partner homicide: A meta-analysis of risk factors. Aggression and Violent Behavior, 50, 101358. https://doi.org/10.1016/j.avb.2019.101358

McCulloch, J., Maher, J., Fitz-Gibbon, K., Segrave, M. \& Roffee, J. (2016). Review of the Family Violence Risk. Assessment and Risk Management Framework (CRAF). Monash University. 
Myhill, A. \& Hohl, K. (2019). The "Golden Thread": Coercive Control and Risk Assessment for Domestic Violence. Journal of Interpersonal Violence, 34(21-22), 4477-4497. https://doi.org/10.1177/0886260516675464

Nicholls, T. L., Pritchard, M. M., Reeves, K. A., \& Hilterman, E. (2013). Risk assessment in intimate partner violence: A systematic review of contemporary approaches. Partner Abuse, 4(1), 76168. https://doi.org/10.1891/1946-6560.4.1.76

Niklander, E., Notko, M., \& Husso, M. (2019). Intervening in domestic violence and training of professionals in social services and health care and the police: Evaluation of the EPRAS project. http://urn.fi/URN:ISBN:978-952-343-413-4

Notko, M., Husso, M., Piippo, S., Fagerlund, M. \& Houtsonen, J. (2021). Intervening in domestic violence: interprofessional collaboration among social and health care professionals and the police. Journal of Interpersonal Care, 1-9. https://doi.org/10.1080/13561820.2021.1876645

Peek-Asa, C., Wallis, A., Harland, K., Beyer, K., Dickey, P. \& Saftlas, A. (2011). Rural disparity in domestic violence prevalence and access to resources. Journal of women's health, 20(11), 17431749. https://doi.org/10.1089/jwh.2011.2891

Petersson, J. (2020). Identifying risk for recidivism among partner violent men reported to the Swedish police. Doctoral Thesis. Mid Sweden University doctoral thesis. Sundsvall: Mid Sweden University. http://oru.diva-portal.org/smash/get/diva2:1500215/FULLTEXT01.pdf

Respect. (2010). Expert Domestic Violence Risk. Assessment in the Family Courts. Recommendations. http://www.fsa.me.uk/uploads/7/6/5/6/7656227/respect_dv_risk_assessment_review__c_newman_c_bell.pdf

Center for Research on Violence Against Women. (2009). Economic stress and domestic violence. https://uknowledge.uky.edu/crvaw_reports/1

Sabri, B., Stockman, J. K., Campbell, J. C., O'Brien, S., Campbell, D., Callwood, G. B., Bertrand, D., Sutton, L. W. \& Hart-Hyndman, G. (2014). Factors associated with increased risk for lethal violence in intimate partner relationships among ethnically diverse black women. Violence and victims, 29(5), 719-741. https://doi.org/10.1891/0886-6708.VV-D-13-00018

SafeLives. (2019). SafeLives Dash risk checklist. Quick start guidance. https://safelives.org.uk/sites/default/files/resources/Dash\%20risk\%20checklist\%20quick $\% 20$ start $\% 20$ guidance $\% 20$ FINAL_1.pdf

Sesar, K., Dodaj, A. \& Simić, N. (2018). Mental health of perpetrators of intimate partner violence. Mental Health Review Journal, 23(4), 221-239. https://doi.org/10.1108/MHRJ-08-2017-0028

Skeem, J. L. \& Monahan, J. (2011). Current Directions in Violence Risk Assessment. Current Directions in Psychological Science, 20(1), 38-42. https://doi.org/10.1177/0963721410397271

Sundsvall Forensic Psychiatric Hospital. (2005). PATRLARCH, Checklist for the assessment of risk for patriarchal violence with honor as motive. http://www.rpksundsvall.se/wpcontent/uploads/2009/05/PATRIARCH-4.pdf

Svalin, K. \& Levander, S. (2019). The Predictive Validity of Intimate Partner Violence Risk Assessments Conducted by Practitioners in Different Settings-a Review of the Literature. Journal of Police and Criminal Psychology, (35), 115-130. https://doi.org/10.1007/s11896-01909343-4

Szego, D., \& Hera, G. (2021). Assessment of RAIMO: IMPRODOV A Integration Module for HIDV Risk Assessment Tools and Case Documentation (D4.3). https://improdova.eu/pdf/IMPRODOVA_D4.3-

Evaluation_Report_HIDV_risk_assessment_Case_documentation_website.pdf?m=161702 $8917 \&$

Ward, T. \& Beech, A. R. (2014). Dynamic risk factors: a theoretical dead-end? Psychology, Crime \& Law, 21(2), 100-113. https://doi.org/10.1080/1068316X.2014.917854

World Health Organisation (WHO). (2014). Elder abuse. https://www.who.int/news-room/factsheets/detail/elder-abuse 


\section{INTER-AGENCY COOPERATION}

AND COORDINATION: THE

CharaCteristics OF A "GOOD

PARTNERShip" Against

DOMESTIC VIOLENCE

\section{THIERRY DELPEUCH \& FRANÇOIS BONNET}

Université Grenoble Alpes, Sciences po Grenoble, CNRS - UMR PACTE, Saint-Martin-d'Hères, France.

E-mail: thierry.delpeuch@umrpacte.fr; francois.bonnet@umrpacte.fr

Abstract In the past, the feminist movement exposed a sexist police culture as the main cause for police apathy in the face of domestic violence. This critique led to an ongoing transformation of police organisations. This transformation is composed of two main processes. The first process is a movement to constrain police activity, force police officers to take domestic violence seriously by enacting laws and rules that aim to reduce police officers' discretion. The second process also aims at transforming police activity, not by constraining it, but by improving the skills of police officers and making them work in partnerships with other stakeholders from medical or social service professions in the best interest of the victim. These partnerships may be within the police organisations or between the police and other stakeholders - typically social workers, magistrates, social housing representatives, NGOs, city administrators, etc. This chapter focuses on this second transformation process and aims at drawing comparative lessons from case studies in eight countries to document the characteristics of a "good partnership" against domestic violence.

Keywords: domestic violence, police, victims, interagency cooperation, good practice 


\section{Introduction}

In the 1970s, the feminist movement exposed a sexist police culture as the main cause for police apathy in the face of domestic violence (Ferraro, 1989, Hirschel \& Buzawa, 2002). This critique led to an ongoing transformation of police organizations. This transformation is composed of two main processes. The first process is a movement to constrain police activity, to force police officers to take domestic violence seriously by enacting laws and rules which aim at reducing the discretion of police officers (Goodmark, 2018). This was done with policies such as mandatory arrest and no-drop prosecution, under which police officers have to follow strict rules so as to make sure they will be lenient with domestic violence perpetrators. This first process has been widely implemented since the 1990s and aspects of it still are pursued by domestic violence reformers; for instance, riskassessment tools typically are devices aimed at minimising human error in the treatment by reducing the discretion of police officers.

The second process also aims at transforming police activity, not by constraining it, but by improving the skills of police officers and making them work in partnerships with other stakeholders from medical or social service professions, in the best interest of the victim (Meier, 2003; Mirchandani, 2005; Grant \& Rowe, 2011; Horwitz et al., 2011; Myhill \& Johnson, 2016). These partnerships may be within the police organizations (such as the psychiatric nurse embedded with Finnish police officers, or the social worker embedded with French police officers), or between the police and other stakeholders - typically social workers, magistrates, social housing representatives, NGOs, city administrators, and so on. The underlying idea of this second process is that police officers need to be educated about domestic violence, and once they are, they can be reliable partners of a wider network of agencies which will help with the multifaceted needs of a given victim (for instance needs related to housing, children, legal services, counselling, etc.). This chapter focuses on this second process of transformation and aims at drawing comparative lessons from case studies in eight countries-Austria, Finland, France, Germany, Hungary, Portugal, Scotland and Slovenia-to document the characteristics of a "good partnership" against domestic violence. 
Partnerships are inter-institutional structures that bring together fragments of partner organisations. Partners are chosen for their expertise and the resources they can bring to the collaboration to deliver specific services that no single partner would be able to provide on their own. This is to achieve a beneficial change for victims or a more appropriate treatment for perpetrators. The collaboration between agencies serves a greater purpose than any of the individual organisations can achieve by their specific tasks alone. For instance, finding a common purpose, protecting and helping the victim provides a shared mission and identity, bonding various partners together.

However, successful partnerships cannot be taken for granted for several reasons. First of all, partnerships against domestic violence require the collaboration of different professional stakeholders who do not have the same understanding of domestic violence or the same agenda to fight this phenomenon. Depending on the profession, organisation, and institution, each participant tends to defend their own vision of what is problematic, what should be prioritised, and what constitutes an acceptable and effective solution. Such disagreements can lead to mutual mistrust, conflict, reserve or avoidance attitudes. Another obstacle to developing a partnership organisation is partner organisations' reluctance to comply with the constraints involved in engaging in joint initiatives of an operational nature. Indeed, taking part in a collective project to combat domestic violence require that each participant question one's way of seeing things, subordinate their freedom of action to common decisions, adapt practices, accept partners' right to control their activities and take their share of the expenses incurred in the implementation of the project. Some partner organisations reject the interplay of reciprocal obligations, mutual interference and the additional costs associated with partnership action. They are then tempted to withdraw from the partnership. Case studies contain numerous examples of divergent views that lead to conflicts or inabilities to cooperate: tensions between prosecutors and associations offering educational programmes for violence perpetrators in Slovenia, for example, or conflicts between police and social workers on risk assessment in the case of the Austrian MARAC.

These obstacles to multi-agency cooperation mean that many partnerships decline rapidly once the initial enthusiasm phase is over. In the fight against domestic violence, as in other areas of security policy, few partnership initiatives can become permanently institutionalised to develop and improve their range of services over time. So, what makes a partnership more likely to be successful? In short: 
- First, it takes targeted actions with an intended outcome. It targets specific types of perpetrators or acts to mitigate or manage risks posed to victims.

- Second, it has a system for managing its action that is capable of performing a range of functions and imposing its authority on system members.

- Third, information management facilitates inter-institutional sharing and ensures feedback from partner organisations to the partnership mechanism.

- Fourth, the partner organisation has specialised relays in each partner organisation. These specialised units or staff, who represent, promote and implement the partnership in their respective organisations, enjoy high status within their partner organisations.

- Fifth, the partnership mechanism and partner organisations make a significant effort to train the staff involved in the collaboration and codify and produce professional valuable knowledge for the proper functioning of the partnership.

\section{An action that targets priority audiences}

The first comparative lesson learnt from the Improdova project is that working partnerships usually take focussed action, aimed primarily at a number of welldefined categories of victims or perpetrators of domestic violence. Such targeting allows the system to focus its attention and resources on a limited range of situations. It helps to set up services suited to the specific nature of the cases handled. It is made necessary by the pressing social demands requiring that the institutional care of domestic violence situations must be a tailored solution adapted to the uniqueness of each case.

Overall, measures tend to focus on those victims most at risk in their physical integrity and on the most dangerous perpetrators. For example, the Scottish Domestic Abuse Task Force (DATF) treats "high-tariff" (prolific) perpetrators, those who commit the most serious crimes and who present the greatest danger to their victims.

The counterpart of this requirement for individualized public action, and the resulting need for targeting, is the risk of leaving out or mismanaging non-priority populations. In fact, in many of the case studies, partnerships paid less attention to victims perceived as being at low risk and less to those who suffer attacks of or 
including psychological, emotional and economic abuse than those victims who suffer violent physical abuse.

The most encompassing partnerships, such as the Berlin Initiative Against Violence to Women (BIG), simultaneously pursue several targeted programmes that address various issues such as, for example, domestic violence among migrants and refugees, the protection of children and adolescents who witness violence, forced marriages and honour crimes. Each of these problems is addressed by means of a customised system, which is based on a specific configuration of stakeholders involved, dedicated working groups and appropriate means of intervention. This type of multipriority, multi-project partnership has the disadvantage of imposing heavy workloads on participating organisations. They no longer keep pace and see partners withdraw from some of the partnership lines of action.

\section{An extended steering body that is an authority}

The second lesson is the need for one of the partners to take the lead in coordinating the partnership. In the case studies, the different partners are coordinated by a clearly designated body to establish a strategy and take the lead. The body's authority is recognised by all participants, who agree to follow its guidelines and implement its recommendations, in particular when it comes to assigning concrete tasks to the partners and monitoring their implementation. This is worth underlining, as the consolidation of their authority is a difficult ordeal for multi-agency cooperation against domestic violence.

This is related to the fact that the authority of the steering body of a partnership in this field-its ability to ensure that partners comply with its directions and decisions-is inevitably fragile. Indeed, the means of intervention of such a partnership generally depend on participating organisations. The steering body has no hierarchical power over the organisational actors expected to implement the partnership action. The piloting team depends on each partner's political choices and decision-making processes. The requests addressed by the steering body to participating organisations often compete with the priorities and missions set by these same organisations' management, resulting in ongoing tensions and negotiations between the intra-organisational and partnership work and priorities, often against the favour of partnership efforts. 
The cases we have reviewed show that several factors are likely to strengthen the authority of a steering body: openness; quality and equity of the deliberation procedures that prepare the decision-making process; concern for rational argumentation and consensus-building in decision making forums; enjoying financial independence from partners, for example through budgets allocated by national programmes or international donors; precise agreements that define participants' rights and duties with regard to the partnership mechanism; the existence of protocols that clearly and in detail determine the modalities for implementing the most common partnership actions. The most developed partnerships in our sample, such as the Berlin Initiative against violence to women German (BIG) and Hanover's Intervention Project Against domestic violence (HAIP), combine all these features.

There is a contradiction between, on the one hand, the openness of the steering system to all the organisations involved in partnership actions-which is a necessary condition for all to agree to participate in collective efforts—and, on the other hand, this system's ability to take strategic and operational decisions within a reasonable time frame. A contradiction between broad participation in partnership management and decision-making effectiveness is partly resolved by the multiplication of steering bodies, some of them broadened and others restricted. Such juxtaposition can be found between plenary committees-generally plethoric-and restricted committees in several of the mechanisms studied. For example, the governance of the German HAIP is ensured by a complex structure of decision-making committees which includes a strategic "round table" involving the 40 partners, operational committees (called "building blocks") where only the stakeholders directly concerned participate, and thematic working groups involving actors recognized for their expertise on the issue. This management method promotes the cohesion of the partnership, insofar as each actor feels that they have a say in the decisions that affect them, but it forces partners to spend considerable time in meetings and entails significant coordination costs between committees. This puts organisations that have smaller resources in a tight position. Bigger organisation can, for instance, find different individuals for each committee, but for a small organisation, one individual may have to serve in several roles. 
One of the main determinants of the effectiveness of piloting partnerships is the quality of the leadership exercised by the people responsible for facilitating dialogue between partners, coordinating joint activities and resolving conflicts. In all the systems studied, these people are distinguished by a higher hierarchical position in their home organisation. In other words, they have a rank of some seniority in their own institution to impose their leadership on an inter-institutional scene. These people are also characterised by a great deal of experience and recognised expertise in the field of combating domestic violence. In short, they combine social status and functional authority. In addition, these people have skills - often acquired through training -in inter-organisational diplomacy. For example, they have learned to bring together different professional perspectives; reconcile conflicting organisational interests; harmonize agendas; prevent and manage conflicts; facilitate negotiations; promote and monitor collaborative projects. Mastering such skills is absolutely essential for the coordinator because, as already pointed out, this individual does not have control over the resources needed to implement partnership activities and strategies.

The clarification and formalization of the main intervention methods are necessary, insofar as they make it possible to avoid conflicts between partners at the stage of the concrete implementation of multi-agency cooperation programmes. Indeed, partnership work is conducive to mix-ups and misunderstandings, especially when the participants do not share the same thinking frameworks or the same action rationales. This is why partnerships that strive to clarify, shape and rationalize their "ground rules" derive many benefits from it: increased steering efficiency; better integration and complementarities of the contributions made by the various participants; a higher degree of partner satisfaction with the collaboration.

In this respect, one of the most crucial working processes is the organisation and conducting of decision-making forums, in particular those during which partners agree on responses to concrete cases of violence. Good practices in this area are defined by compliance with preparatory procedures, such as the collection of information and the compilation of files on cases on the agenda, or then again maintenance of a record to monitor developments and partners' responses from one time to the next. They also stand out for their use of meeting facilitation techniques that promote inter-professional dialogue, the formation of a common vision of situations and the joint development of operational solutions. Finally, each 
participant recognizes that others have a right of control over their actions accepting, for example, that compliance with commitments made in one meeting be monitored at a subsequent time.

The most developed partnerships are characterised by possessing their own management and human resources. They are staffed, as appropriate, with a coordinator and a secretariat; they also provide comprehensive action programmes and reviews; activity and results indicators; digital tools for internal and external communication; means for training speakers; feedback procedures; quality procedures to improve services; research and development projects to renew working methods and tools. Partnerships that benefit from such capacities are marked not only by their better management of joint activities and greater versatility to the target audiences' needs, but also by their steering body's greater weight vis-àvis partner organisations, and hence by a better capacity to implement partnership decisions. Finally, very large partnerships, such as the German BIG or HAIP, have also acquired political and media lobbying capacities that enable them to promote legislative or regulatory changes, launch awareness campaigns aimed at the general public or targeted audiences and increase their chances of obtaining government subsidies. In addition, these partnerships have developed an advice and expertise proposition to promote the action models they have devised.

Partners in leadership positions in the cooperation system may differ from place to place. The police still play an important role in steering since they detect the largest number of violent situations. Indeed, emergency calls, police interventions in the home, and the reception of victims at the police station are still the main ways domestic violence cases come to institutions' attention. Depending on the case, the structure that takes the greatest part in the coordination - and bears a large part of both the costs and responsibilities thereof - may be a municipality, an NGO, a state administration, or a national programme, or then again the police. Each of these institutions has strengths and weaknesses in achieving leadership. Cities have more financial resources and are experienced in multi-agency project management, but they are vulnerable to electoral uncertainty. NGOs have greater political independence and activist support, but they have no guaranteed resources and enjoy less professional legitimacy. According to most of our case studies, the police are the first entry point of a large proportion of domestic violence victims in the partnership organisation and have more complete information on violence 
perpetrators (via criminal records and event registers), but they are overwhelmed by many and diverse demands (from road safety to terrorism) and are therefore struggling to keep domestic violence as a priority in a sustainable manner.

\section{An extensive organisation for information sharing and use}

Partnerships are based on procedures for collecting, sharing, managing, analysing and making decisions based on information on domestic violence cases. Successful partnerships develop information-sharing systems that seek to ensure, as far as possible, early identification of victims and perpetrators, particularly in the context of serious violence. These systems are also intended to gather the information necessary to analyse the situations that have been detected, to choose the course of action and to monitor victims' and perpetrators' trajectories.

Establishing "good management" of information in a partnership framework is no small task, because it does not only mean organizing the circulation and sharing of information between partners, but also modifying and rearranging all participating organisations so their representatives in the partnership are supplied with the required data in a timely manner. In other words, it is not good enough to implement information sharing arrangements within the partnership. Each partner must also agree to carry out adjustments so that its own information system can properly feed the partnership information system.

Three major challenges justify making efforts to improve information sharing between the system stakeholders. First, cases detected by one partner are quickly reported to others, allowing each partner to take appropriate action in their own area of expertise in a timely and informed manner. Secondly, it avoids victims having to repeat their story several times to the succession of workers they meet: sharing a file containing what each partner needs to know -and has the right to know - about the situation being treated reduces this form of "secondary victimization" due to being constantly re-interviewed. Finally, sharing a variety of data allows for a more detailed analysis of the cases discussed in partnership meetings (all case studies concur on these matters). 
From the point of view of information management, a common point of practices studied is the intensive use of tools and procedures helping decision-making, intended to provide steering bodies with both multidisciplinary and in-depth knowledge of cases handled.

These instruments include, in particular, devices to diagnose the extent of domestic violence in a given territory (such as the French "observatories"), expert committees to better understand its underlying logics and dynamics (such as the think tanks set up under the Berlin initiative); working groups to bring closer together the different partners' professional views (such as in the German HAIP programme or the Slovenian Association for Nonviolent Communication); and procedures to assess particular situations from the perspective of the risks faced by victims.

In several "best practices" cases, the central element of cooperation is the risk assessment procedures and instruments: the risk posed by the perpetrator in the case of law enforcement oriented collaborations; or faced by the victim in the case of victim-oriented partnerships.

In Scotland, Multi-Agency Tasking and Coordinating (MATAC) meetings are organised and hosted monthly by the police in each of Scotland's 13 police divisions. They bring together social and health services, housing associations, public prosecution representatives, specialised police staff, as well as NGOs in some areas. The purpose of these meetings is to share information on the violence histories of individuals suspected of being domestic violence perpetrators and intelligence of their relationships, criminal activities, and people they associate with. Participants share information and analysis to assess risks and jointly develop action strategies to disrupt the activities of individuals identified as "high tariff" perpetrators. This may involve judicial or administrative proceedings unrelated to suspected domestic violence offences, but which deal with other offences committed by them, such as rent or tax arrears, lease contract violations, tax or social security fraud, or traffic offences.

Furthermore, during the MATAC, participants assess this danger to determine whether the case should remain for investigation at a divisional or national. Perpetrators considered particularly threatening (prolific abuse, and/or multiple partners) are passed to a national investigation unit - the Domestic Abuse Task 
Force (DATF) - that has a specialized domestic violence remit. DATF officers screen the suspect's life for evidence of past violence to increase the prosecution's burden. An assessment is carried out using a scoring system that takes into account criteria such as recent developments (recency), the repetition and severity of violence (frequency) and the number and profile of victims (gravity) to create an "RFG" score, as well as undertake the examination of information shared by the suspect on social networks; worrying elements and warning signals identified by the various partners.

Similar systems - i.e. organised around a partnership-based risk assessment procedure - are used to improve the safety of victims in Scotland, Austria and Finland. These countries implement a system called Multi-Agency Risk Assessment Conferencing (MARAC), which aims to identify victims who are at serious risk by combining information from a wide range of partners. The system involves the following services: police, social, childcare, educational, health, integration probation, social housing, victim support and access to rights. The central element of MARAC is a partnership meeting during which participants share information and compare their professional expertise to complete or supplement a risk analysis questionnaire (DASH/DAQ) and define a series of action points to manage and mitigate the risk based on this questionnaire.

In Scotland, there is also a mechanism to warn potential victims of their current partner's history of abuse, known as the Disclosure Scheme for Domestic Abuse Scotland (DSDAS). This scheme responds to requests of a spouse, partner, friend or family member, NGO worker, or statutory worker who wishes to check an individual's history of domestic violence (Right to Ask), or at the initiative of a police officer (Power to Tell), where there is a concern or belief of domestic violence history or activity. Following such applications to the scheme, verifications are conducted by the police, and where there is evidence or concern, a multi-agency decision-making forum is held to decide whether or not to disclose a perpetrator's violent past to their current partner.

Of course, the more sophisticated the partnership systems for information sharing, situation diagnosis and risk assessment, the more work they require from partner organisations upstream. Increasing the quality of decision-making in partnership bodies is costly and may lead some participants to disengage or withdraw from multi- 
agency cooperation, particularly when the issue of domestic violence becomes less prominent in the media and political debate.

\section{The presence specialization in each partner organisation}

One of the most effective ways of extending cooperation within a partner organisation involves a specialised unit or staff, i.e. a staff member specifically responsible for dealing with domestic violence, with instructions to carry out tasks related to partnership actions as a priority. There are specialized domestic violence units that have been set up within a large organisation with more a general mission, such as law enforcement agencies, hospital centres or municipalities (local government). In our sample, specialization and partnerships are often intertwined and complementary. Organisations - police departments, courts, hospitals, city administrations, social services, victims' aid association, etc. - that participate in inter-institutional partnerships often do so through their specialised domestic violence units. All the partnerships in our sample use specialized units as the main communication channel and grassroots implementer of their actions against domestic violence. Conversely, all the specialised units in the same sample participate in one or more multi-agency cooperation(s). This configuration makes it easier to integrate the staff concerned into the partnership network as well as teaching them the practices that enable cooperation to work. More broadly, it promotes their professionalization in dealing with domestic violence.

The most dynamic partnerships in our sample (BIG and HAIP in Germany, BPF in France, GAIV in Portugal, OKIT in Hungary, ANKKURI in Finland, the Interinstitutional Group for Prevention of domestic violence in Slovenia) are those that can rely on a small core of highly involved cooperation relays. These partnerships have developed a strong sense of belonging and loyalty to the system, and the specialized stakeholders play a leading role vis-à-vis less involved actors.

The case of victim protection units in Austrian hospitals illustrates the multiple advantages of building cooperation as an assembly integrated contact in organisations. These dedicated units tend to advocate for better care for victims by the organisation as a whole, namely through the creation of procedures and tools common to all services or the training of non-specialist colleagues. In addition, these units become internal "competence centres", whose expertise is sought whenever 
the organisation or one of its components is confronted with a domestic violencerelated problem. These units constitute, in addition, an easily identifiable point of contact for external actors who wish to contact the organisation regarding domestic violence. Their most important contribution is currently the strengthening of the medical sector sensitivity for cases of domestic violence, improving its unique potential for early detection and as an entry point for specific types of victims not entering the networked response system via the police or social services (i.e. domestic violence victims experiencing neglect or heavy coercive control).

The more complex a partnership, i.e. the more numerous and varied its partners and the more it provides a diversified range of services, the more it needs to have specialised and professional contacts in each participating organisation.

These "partnership relays" are all the more motivated to invest in multi-agency cooperation as their respective organisations give them high status and adequate resources. In this respect, one of the main status symbols is access to means of action that are usually reserved for cases considered important. For example, dedicated Domestic Abuse Investigation Units, which are present in some police divisions in Scotland, can use the same tools and working methods used to investigate organized crime, anti-fraud, serial crime, or homicide. This requires that the organisation managers regard this type of unit as very important and have given the unit a real mandate. Most likely, there is also strong political pressure behind it.

To make a useful contribution to cooperation, partnership relays must have operational autonomy and influence with their management. They must ensure that their organisation works in a spirit of multi-agency cooperation and plays its part in the implementation of partnership services. When they receive a justified request from an external partner, they must be able to activate their organisation to respond satisfactorily.

By contrast, a partnership is unlikely to work effectively when partnership relays are saturated with tasks unrelated to combating domestic violence when the work they do for the partnership is less rewarded than what they do for their organisation, or when they have no leverage to ensure their organisation fulfils its partnership obligations. 


\section{An effort to train professionals and produce knowledge}

The comparison of multi-agency cooperation's "good practices" reveals another similarity: the organisations involved make substantial investments in training their staff responsible for carrying out partnership missions.

This training effort is multi-faceted. One is the transmission of knowledge about domestic violence as a criminological fact, a legal notion that gravely affects victims' well-being physically, psychologically, and socially. A second is training staff to learn skills to support and protect victims and their children, provide care and treatment for perpetrators, and develop policies to combat domestic violence. A third is learning methods designed to facilitate inter-organisational cooperation, such as communication in meetings, working-group facilitation, project design, promotion and management, and shared evaluation of results. The actors who are given priority training are those with a coordinating role and those who ensure the coupling between the partnership mechanism and partner organisations (and often are the specialized staff mentioned above).

Different methods are used to strengthen partnership relays' skills. In addition to training, some schemes encourage their members to read professional journals and scientific publications, participate in symposiums and seminars, engage in dialogue on specialised online forums, visit organisations known for their good practices, meet associations, etc. (This is particularly the case in German practice, French BPF and the Inter-Institutional Group for Prevention of domestic violence in Slovenia).

The most developed partnerships have knowledge production activities. Such initiatives may consist of setting out, specifying and codifying the practices of actors in the system, in manuals, practical guides, and operations blueprints. This is designed to clarify, stabilise, rationalise and systematise working procedures necessary for good cooperation between stakeholders and properly handling the cases under treatment. Standardising partnership relays' practices is a way of integrating the system's activities into the operating routines of participating organisations, which are then less likely to question them. In addition, codifying practices makes it easier for newcomers to learn their role in the partnership. In addition, codification work requires implementing reflexivity approaches, such as identifying and analyzing dysfunctions, pinpointing shortcomings in provisions (e.g. 
through victim satisfaction surveys), devising outcome evaluation programs, etc. On the other hand, this kind of standardization renders partnership and practices public, formal and official. It may set a path on which the future of the partnership will be dependent. It is more difficult to change and reform structures and practice once they have become official.

Knowledge production can also take advisory and expert activities, participation in studies and research projects, contribution to professional or scientific publications, invention and experimentation with new instruments or new methods, as do the German, Austrian and Hungarian systems.

\section{Conclusion: The development of "good cooperation" is not just an organisational matter}

This chapter has shown that police action towards domestic violence can be improved not only by forcing police officers to take domestic violence seriously but also by educating them about the subject, specializing them on it, and above all make them work in partnerships with other professions_-magistrates, social workers, city administrators, etc.

Identifying five organisational features found in all "good" inter-agency partnerships against domestic should not suggest that these features would be sufficient to set up the "right organisation", i.e. to generate dynamic, productive and sustainable interinstitutional cooperation.

The analysis of the 18 case studies in 8 countries for the IMPRODOVA project suggests that the consolidation of a partnership against domestic violence depends on many factors that have nothing to do with the partnership organisation's design and management. By consolidation, we mean the institutionalisation and systematic use of working procedures by which partnership bodies and partnership relays contribute together and in an integrated manner to provide efficient partnership services. These factors include:

- The existence of a legal framework or public policy that encourages or even forces partner organisations to engage in the partnership and to consider it a priority. These incentives can be negative (regulatory obligation, 
hierarchical order, etc.) or positive (granting of subsidies, allocation of additional resources, etc.).

- Increased social, political and media pressure to do something about domestic violence. These pressures are often linked to highly publicized media stories, advocacy or the adoption of international standards.

- Strong involvement of institutional entrepreneurs and change agents in the design and promotion of the partnership mechanism, and their ability to build alliances with influential partner organisations' members.

- Securing political support, especially from local authorities.

- Reference to models applied elsewhere - on the national territory or abroad - that are already acknowledged as "good practices". Such recognition is rarely linked to the availability of rigorous evaluations of "good practice" effectiveness. It often results from the fact that well-known institutions have pioneered the practice or are working to disseminate it. For example, the MARAC approaches applied in Austria, Scotland and Finland are modelled on a model advocated by the European Union, and the work of the Slovenian Association for Nonviolent Communication is based on an American approach.

One of the most decisive factors seems to be how long a partnership has been in existence. Indeed, the long-standing nature of a device allows a whole set of incremental changes to produce their effects. For example, partnership practices are gradually being integrated into participating organisations' culture and structure. In the long run, they become constitutive elements of partners' identity and routine functioning. Members appropriate partnership work to the point of no longer differentiating it from their own practices. These partnerships are enshrined in their organisation chart, internal regulations, official procedures, management and work tools, recruitment and training plans, etc. As a result, partner organisations build capacity, standard operating routines, and interests in their ranks to contribute to the partnership, leading to institutional inertia or even to irreversible involvement in the partnership mechanism.

Other positive effects of the longstanding nature of a scheme are linked to socialization dynamics that gradually strengthen social ties between participants. This ensures that they all have realistic demands and expectations from each other, which limits grounds for conflict. On the other hand, the multiplication of personal 
relationships and the establishment of a climate of trust between stakeholders are conducive to the informal circulation of information as well as quicker and concrete solutions to urgent situations (typically: the issue is immediately resolved by telephone exchanges, rather than waiting for the next meeting). Finally, the sense of mutual respect that binds partners promotes the expression of mutual criticism in a constructive way rather than "passing the blame onto others" or dismissing it altogether.

\section{References}

Ferraro, K. J. (1989). Policing Woman Battering. Social Problems, 36(1), 61-74.

Goodmark, L. (2018). Decriminalizing domestic violence: a balanced policy approach to intimate partner violence. Oakland, California: University of California Press.

Grant, S. \& Rowe, M. (2011). Running the Risk: Police Officer Discretion and Family Violence in New Zealand. Policing and Society, 21(1), 49-66.

Hirschel, D., \& Buzawa, E. (2002). Understanding the Context of Dual Arrest With Directions for Future Research. Violence Against Women, 8(12), 1449-1473. https://doi.org/10.1177/107780102237965

Horwitz, S.H., Mitchell, D., Larussa-Trott, M., Santiago, L., Pearson, J., Skiff, D.M., \& Cerulli, C. (2011). An Inside View of Police Officers' Experience with Domestic Violence. Journal of Family Violence, 26(8), 617-625.

Meier, J. (2003). Domestic Violence, Child Custody, and Child Protection: Understanding Judicial Resistance and Imagining the Solutions. The American University journal of gender, social policy \& the law, 11(2), 657-730.

Mirchandani, R. (2005). What's So Special about Specialized Courts? The State and Social Change in Salt Lake City's Domestic Violence Court. Law \& Society Review, 39(2), 379-418.

Myhill, A., \& Johnson, K. (2016). Police Use of Discretion in Response to Domestic Violence. Criminology \& Criminal Justice, 16(1), 3-20. 


\title{
RISK-ASSESSMENT AND VICTIM-
}

SUPPORT RECOMMENDATIONS

DURING THE COVID-19-RELATED

\section{LOCKDOWNS}

\author{
JoAChim Kersten, ${ }^{1}$ Catharina Vogt, ${ }^{1}$ \\ Michele Burman, ${ }^{2}$ Jarmo Houtsonen, ${ }^{3}$ \\ NORBERT LEONHARDMAIR ${ }^{4} \&$ PAUl HERBINGER $^{4}$ \\ ${ }^{1}$ German Police University, Criminology and Interdisciplinary Crime Prevention, \\ Münster, Germany. \\ E-mail: joachim.kersten@t-online.de; catharina.vogt@dhpol.de \\ 2 University of Glasgow, Scottish Centre for Crime and Justice Research, Glasgow, \\ Scotland. \\ E-mail: michele.burman@glasgow.ac.uk \\ ${ }^{3}$ Police University College, Tampere, Finland. \\ E-mail: jarmo.houtsonen@polamk.fi \\ ${ }^{4}$ Vienna Centre for Societal Security, Vienna, Austria. \\ E-mail: norbert.leonhardmair@vicesse.eu; paul.herbinger@vicesse.eu
}

Abstract This chapter covers the effects of the COVID-19 crisis on the incidence and severity of domestic abuse cases in Europe. First, the manifestation of the COVID-19 lockdown and its adverse effects on private life are described. Building upon this description, co-occurring risks factors with a high potential to initiate or intensify domestic abuse (e.g., cramped living conditions) are discussed. Responding to various calls on investigating the impact of COVID-19 on domestic abuse incidents, IMPRODOVA research on the first lockdown shows that the related concerns for various reasons are inconsistently reflected in domestic abuse-related statistics. In some IMPRODOVA partner countries, however, victimisation numbers went up, after the lockdown ended. Consequently, the complexity of detecting domestic abuse cases during lockdowns are discussed. In line with the strong concern about intensified victimisation, innovative responses by front-line professionals to detect and manage domestic violence and abuse cases are presented. Building on the beforehand presented assumptions, findings and explanations, the chapter closes by highlighting eighteen recommendations regarding risk assessment and victim support during pandemics.

\footnotetext{
Keywords:

domestic

violence,

IMPRODOVA, COVID-19, pandemic, risk assessment, victims
} 


\section{Manifestation of the COVID-19 lockdowns}

Since March 2020, in Europe and around the world the lockdowns impelled by COVID-19 have brought economic and work life, culture, education and childcare, travel, and various other routine facets of social life to an abrupt halt. Across the European continent, in North and South America, and elsewhere citizens have gone through first, second and third waves of widespread infection with the corona virus and its mutant forms. At the start of the pandemic-related quarantine and lockdown measures, many experts and commentators predicted there would be a 'tsunami-like' increase in domestic abuse victimisation as a likely outcome of families and couples being confined to their living spaces.

Now, more than one year later, what reliable evidence can be found to test this prediction? This chapter addresses this and other questions. The primary focus is directed to the repercussions held by the COVID-19 lockdowns in the context of intimate partnerships and families based on analyses in eight European member states.

By late spring 2020, it was feared in Austria, Finland, France, Germany, Hungary, Portugal, Scotland and Slovenia that the lockdowns would significantly increase intimate partner violence and violence against children. In many states and cities, people had to spend most of their days and nights at home. No childcare was available, and schools were closed; home schooling was required, and so was working from one's 'home office' for those still with employment. In difficult social conditions, citizens with menial jobs often lose them. Such precarious employment situations, financial difficulties and similar stress factors may have introduced a ticking time bomb of emotions in the home.

\section{Potential impact of COVID-19 on domestic violence prevalence rates}

Following the February 2020 outbreak of COVID-19 disease in Italy, people in the European Union have faced health challenges not seen since the end of World War II. After the World Health Organization (WHO) declared the then widespread virus a pandemic on 11 March 2020, national governments across Europe began efforts to protect their populations from infection and maintain healthcare delivery. The most influential governmental measures were 'lockdowns', namely, periods of 
several weeks during which all educational institutions, nearly all sports, entertainment and recreational facilities, and businesses other than grocery stores and petrol stations were closed. Citizens were asked to wear masks in public spaces, to stay at home, to work from home, to minimise their social contacts and, if they were out of town, to remain in local quarantine. As a result, couples and families limited their entire daily routines to an unfamiliar environment: working at home, cooking at home every day, and schooling or caring for children at home. For many citizens and families, the individual stress levels created by these changes were coupled with a fear of job loss and the associated financial burden, concern for one's own health or that of loved ones, and fear of societal changes in general. In these circumstances, the predictions of a bigger incidence of violence in homes seemed reasonable.

Across EU member states, resources like social support or easy access to healthcare services were lacking and/or under growing pressure. Accordingly, professionals active in the field of domestic violence (DV) prevention called for efforts to ensure that DV victims were not left unprotected from their perpetrators at home. The expected tensions between couples or parents and children in crowded family homes under stress led to forecasts of a huge rise in DV numbers. At the same time, the prevention and detection of DV and respective interventions and interagency cooperation were anticipated to become more complicated during the lockdown conditions. The European Institute for Gender Equality (EIGE) backed calls made to the Union and the member states to use the coronavirus pandemic as an opportunity to step up their efforts to protect women's rights (e.g. EIGE, 2021). In the same vein, the WHO and the organisations of UN Women stressed the important need to collect data during COVID-19 as a critical tool for reducing adverse effects on women and girls experiencing violence and to inform prevention strategies during future crises (UN Women \& WHO, 2020; WHO, 2020).

In some cases, the measures to protect citizens from being infected with COVID19 led to certain individuals facing an increase in DV risk factors. Vulnerable persons were expected to become more vulnerable to DV victimisation. Abusers were expected to have greater opportunities and encounter lowered detection thresholds for first-time or repeated DV. Accordingly, DV risk factors encompass dimensions like mental health, financial precariousness, insecurity, and isolation. These factors affect the persons chiefly concerned (victims, perpetrators, children, witnesses) as 
well as frontline responder services, and members of the general public. Different types of impact affect all of the above-mentioned levels: prevalence, phenomenology, risk factors, reporting, access to services, processing of cases, and awareness of witnesses like neighbours, general practitioners, teachers, as well as the public at large.

\section{IMPRODOVA research on COVID-19-related domestic violence}

Internationally, the expected worldwide rise in DV incidents was a serious concern. These concerns were shared by the IMPRODOVA research project partners studying frontline responses to domestic abuse in eight European countries (see Kersten et al., in press): In Hungary, in March 2020, for example, domestic violence incidents reported to the police rose by $50 \%$ compared to March 2019. Since the start of the formally declared epidemic, Slovenian police recorded a $20 \%$ rise in domestic violence over the same period in 2019. For the police in Finland, family violence emergency tasks increased $13 \%$ in March and April 2020 compared to the same period in the previous year. In response, IMPRODOVA teams aimed to map the available data (crime statistics, surveys), complemented with an expert assessment (interviews) of COVID-19's impact on the project's participating countries. The IMPRODOVA project's cooperation with first-line responders, police, bealth, shelters, and other victim services meant that the data sources available from these organisations could be used, and the findings compared across borders (Kersten et al., in press). More specifically, the country reports are based on available data assembled from the participating countries' law enforcement agencies and criminal justice system sources, from helpline and victims' shelter agencies, the medical sector, policy measures, and media coverage. Victim survey data were also included where available. Since the countries differ substantially with respect to policing, legal systems, social and cultural factors, the trends in DV cases reported to law enforcement must be interpreted in the light of such differences. Below are some examples:

- in France, DV victims must report to a police station; this is likely to affect reporting rates;

- cities in Portugal like Porto operate a special police unit for DV cases, which may make it easier for victims to report and seek assistance;

- in German cities and in the countryside, police patrol officers drive to residences where domestic abuse cases have been reported; 
- in Finland, outside of the more densely populated areas, the distances are too vast to send patrol cars to affected residences;

- trust in the police varies between Northern (high trust) and other parts of the European continent, with this affecting reporting behaviour;

- during 2019 and 2020, in several of the participating countries DV awareness grew due to the rise in numbers of femicides together with a number of horrific domestic abuse cases. These were widely debated by the media, public and politicians. Together with media and activist campaigns, this has arguably influenced the likelihood of DV reporting by victims, their family members, and neighbours.

Our IMPRODOVA analyses suggest an increase in domestic violence phenomena and evident stronger demand by victims for online and phone counselling. However, during the project, the prediction of a huge rise in domestic violence victimisation could not be verified. Increased numbers of calls and reports to law enforcement were seen in some countries, plus greater demand for counselling and support, mostly after the start of the 2020 lockdown measures. Yet, in some instances, the numbers actually rose after the restrictions had been lifted and people were able to move around more freely. Such variations make it difficult to clearly identify causal factors, or even correlations.

Table 1: Impact of Covid-19 measures on prevalence, reporting, processing and practices of DV cases by frontline responder organisations, media reporting, and public authorities across eight member states

\begin{tabular}{|c|c|c|c|c|c|c|c|c|}
\hline & AT & FI & FR & GE & HU & PO & SL & SCT \\
\hline Police/CJS sector & {$[1][2]$} & & & & & & & \\
\hline DV offences & $\frac{1}{21}$ & $\Downarrow$ & 个 & $\Rightarrow$ & $\uparrow$ & $v$ & तर & $\uparrow$ \\
\hline Restraining orders & 2 & $\psi$ & & $\Rightarrow$ & $\Rightarrow$ & $\uparrow$ & $v$ & \\
\hline Emergency calls & $\mathrm{N} / \mathrm{A}$ & $\uparrow$ & $\uparrow$ & $\Rightarrow$ & $\uparrow$ & $v$ & $v$ & $\uparrow$ \\
\hline Court processing & 2 & & & & $N / A$ & 2 & $N / A$ & $v$ \\
\hline Intensification of DV? & & & & $\mathrm{N} / \mathrm{A}$ & $\uparrow$ & +1 & $N / A$ & \\
\hline Social sector & [1] [4] & & & & & & $\begin{array}{l}{[1]} \\
{[4]}\end{array}$ & \\
\hline Hotline calls & 个 & 个 & $\uparrow$ & $\uparrow$ & $\uparrow$ & $\uparrow$ & T & $\uparrow$ \\
\hline $\begin{array}{l}\text { Contacts with } \\
\text { victims }\end{array}$ & 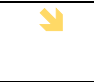 & $\psi$ & & & $\mathrm{N} / \mathrm{A}$ & $v$ & $v$ & $\uparrow$ \\
\hline DV cases & $\Rightarrow$ & & & $\Rightarrow$ & $\uparrow$ & $v$ & $\uparrow$ & $\uparrow$ \\
\hline Shelter referrals & $\pi$ & $\psi$ & & $\Rightarrow$ & $\Rightarrow$ & $v$ & 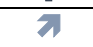 & $\uparrow$ \\
\hline Medical sector & [1] [4] & & & & & & & \\
\hline
\end{tabular}




\begin{tabular}{|c|c|c|c|c|c|c|c|}
\hline & $\mathbf{A T}$ & FR & GE & $\mathrm{HU}$ & PO & SL & SCT \\
\hline DV cases & $y$ & $\Rightarrow$ & $\mathrm{N} / \mathrm{A}$ & $\mathrm{N} / \mathrm{A}$ & $\mathrm{N} / \mathrm{A}$ & $\mathrm{N} / \mathrm{A}$ & \\
\hline Adapted policies & $\checkmark$ & $\checkmark$ & & $\Rightarrow$ & $\uparrow$ & $\Rightarrow$ & \\
\hline Policy sector & [4] & & & & & & \\
\hline Specific measures & $\checkmark$ & $\checkmark$ & & $\Rightarrow$ & 个 & $\uparrow$ & $\Rightarrow$ \\
\hline $\begin{array}{l}\text { Additional } \\
\text { resources }\end{array}$ & $\checkmark$ & & & $\Rightarrow$ & $\uparrow$ & $\uparrow$ & 个 \\
\hline $\begin{array}{l}\text { Awareness } \\
\text { campaigns }\end{array}$ & $\checkmark$ & & $\checkmark$ & $\Rightarrow$ & $\uparrow$ & $\uparrow$ & 个 \\
\hline Media sector & [4] & & & & & & \\
\hline Reports on DV & $\uparrow$ & & $\uparrow$ & 个 & $v$ & $\uparrow$ & 个 \\
\hline $\begin{array}{l}\text { Press releases on } \\
\text { DV }\end{array}$ & $\uparrow$ & & T & $\uparrow$ & $v$ & $\uparrow$ & 个 \\
\hline $\begin{array}{l}\text { (Local) Initiatives/ } \\
\text { practices }\end{array}$ & [1] & & & & & & [4] \\
\hline $\begin{array}{l}\text { Supermarket safe } \\
\text { space }\end{array}$ & & & & $\mathrm{N} / \mathrm{A}$ & $\mathrm{N} / \mathrm{A}$ & $\checkmark$ & $\mathrm{N} / \mathrm{A}$ \\
\hline Pharmacy safe space & & & $\mathrm{N} / \mathrm{A}$ & $\mathrm{N} / \mathrm{A}$ & $\mathrm{N} / \mathrm{A}$ & $\checkmark$ & $\mathrm{N} / \mathrm{A}$ \\
\hline Digitalisation of CJS & $\checkmark$ & & & $\mathrm{N} / \mathrm{A}$ & $\checkmark$ & $\checkmark$ & $\checkmark$ \\
\hline $\begin{array}{l}\text { Note. Types of sources: } \\
\text { victimisation/prevalence) su }\end{array}$ & $\begin{array}{l}\text { [1] } \quad(\exp \\
\text { irveys, }[4\end{array}$ & $\begin{array}{l}\text { ert/practitioner) int } \\
\text { (media/government }\end{array}$ & $\begin{array}{l}\text { ws, [2] } \\
\text { ports }\end{array}$ & ficial (cri & e/procec & ral) st & tics, [3] \\
\hline \multicolumn{8}{|c|}{ Legend for the above table: } \\
\hline A Increase & 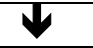 & Decrease & & & & & \\
\hline $\boldsymbol{n}$ Slight increase & $y$ & Slight decrease & & & & & \\
\hline$\Rightarrow$ Stagnant & $\mathrm{N} / \mathrm{A}$ & Not applicable & & & & & \\
\hline$\checkmark \quad$ Yes & $\mathbf{x}$ & No & & & & & \\
\hline
\end{tabular}

Table 1 presents figures for an on-going, still-unfolding situation, further complicated by some countries' renewed declarations of lockdown restrictions during 2020 and 2021. Based on the collection of IMPRODOVA participant country reports, it is safe to assume that the lockdown measures after March 2020 had an influence on reported DV incidents, in some countries more, in others less. In most of IMPRODOVA's participating countries the forecasts of an imminent and huge wave of domestic violence due to the lockdowns are difficult to confirm. Similarly, the results still have a snapshot quality, a picture based on available data sources, expert opinions, practitioner reports and comparable sources. Reliable data were limited by their availability, while in some cases the country reports contained inconsistencies. Since processing reported domestic violence data takes varying lengths of time to properly assess the trends (increase, decrease or stagnation), the trends shown in Table 1 are no basis for broad conclusions or policy strategies. 


\section{Complexity of detecting domestic violence cases during lockdowns}

Across Europe, it was found that isolation and confinement within the home gave violent partners opportunities to further exercise power and control over their partners (Kersten et al., in press). The lockdowns also impacted victims' opportunities to contact authorities and other informal networks that may have provided assistance and support, while the diminished access to services increased the risks of those experiencing violence. The extra attention the Covid-19-SARS2 suppression measures demanded from the authorities limited their ability to continue preventing and intervening in domestic violence incidents and to provide the conventional forms of services to the victims and perpetrators.

These lockdowns and social isolation created anxiety, mental health problems, greater substance abuse and financial stress, all of which are known to add to the risk of escalated domestic abuse. A significant factor during lockdowns is the increased capacity of perpetrators to control the victim and thereby contribute to the victim's restricted access to family, friends and other forms of support. Indeed, some information given to us by experts shows that the coercive control exercised by some violent partners made it very hard for certain victims to leave the abusive relationship. At the same time, victims' access to services provided by authorities and non-governmental organisations (NGO) was limited by the restricted mobility and physical contacts. Moreover, in addition to structural and situational changes, the uncertain circumstances coupled with the inability to predict the future may prevent victims from leaving the abusive relationship and seeking help outside the household or partnership. Victims may be forced to stay in an abusive relationship and endure violence, postponing considerations of leaving until the situation has become more stable and predictable. Vulnerabilities are heightened especially among disabled, immigrant and ethnic minority women, in particular among those living in a confined residence with many family members.

There was a range of best practices to prevent the exceptional conditions resulting from the Covid-19 lockdowns from undermining victims' security and frontline responders' (FLR) capacities to provide services and curb domestic violence in the IMPRODOVA participating countries. Effective prevention and intervention presuppose that FLRs and policymakers can maintain a valid picture of the prevalence of domestic violence through various registers and data sets. It should be 
acknowledged that Covid-19 has affected the collection of much service-based data while preventing the collection of data in particular sectors. Police-recorded crime statistics that allow year-on-year comparisons to be made of numbers of DV incidents registered by police were only available in Scotland and Finland.

\section{Innovative responses by frontline professionals to detect and manage cases of domestic violence and abuse}

The social isolation and restrictions on free movement prevented face-to-face contact with clients, including those under a serious risk of domestic violence. However, multi-professional risk assessment procedures and meetings, such as the Multi-Agency Risk Assessment Conference (MARAC) were maintained in Scotland and Finland, and the Multi Agency Tasking and Coordination (MATAC) in Scotland. MARAC allows agencies to appraise the security needs of victims of serious domestic violence whereas MATAC assesses threats posed by the most serious DV perpetrators. In France, law enforcement agencies initiated innovative ways to stay in contact with victims and intervene in homes, for example through the use of code words left by victims or witnesses at contact points like supermarkets and pharmacies. Such unconventional means helped to maintain a picture of the situation, keep track of DV cases and clients, and identify possible new victims. The strengthening of such collaboration and the finding of a common purpose among the public agencies, private enterprises and NGOs was an extremely positive outcome. This collaboration led for instance to the establishment of new physical contact points for social and medical services and support outside of conventional settings.

Agencies and NGOs were attentive to the lockdowns' possible impact on the changing needs of victims. In many countries, authorities reacted quickly to these changing conditions and the potentially increasing number of more serious DV cases. Some governments started to provide the NGO sector with greater funding to deal with the stronger demand for services and support during the pandemic. In addition, authorities and NGOs rapidly activated existing online channels of help and innovated new forms of communication, such as hotlines, helplines and chatlines to communicate between the service providers and victims. For instance, the Commission of Citizenship and Gender Equality in Portugal created a new additional helpline SMS number and email address. In France, NGOs joined forces with private enterprises and public agencies and established helplines and hotlines. 
Smartphones and other digital devices were also offered to individuals under serious danger of domestic violence so they could contact authorities more quickly and securely. Government funding was made available to expand helplines and available support in Scotland and the rapid shift to online provision by NGOs allowed contact to be maintained with many victims.

Moreover, in Germany it was realised that those working in the critical professions, like healthcare, security and education, were under severe strain. Those working in positions crucial for the system received emergency childcare and day-care support in certain locations. The availability of existing and new services was advertised through public campaigns and various media in all countries. In some countries, services were available in several languages to provide people with accurate and factual information about the services still functioning. Countering false information with facts was a valuable function. In Austria, language barriers were overcome by interpreters recruited to assist the response of helplines, which could then pass victims' questions on to expert social workers. In many countries, shelters did not receive new clients during the lockdowns, while in certain countries alternative accommodation for victims and perpetrators such as hotel rooms was provided by the authorities.

\section{Recommendations for risk assessment and victim support during a pandemic}

Based on findings about best practices and deficiencies in service delivery, the following actions and policies are recommended:

- Priority should be given to targeting resources to ensure that DV victims have access to high-quality services and support, and to make certain that their safety is assured.

- In order to maintain services, governments should offer extra financial support not only for FLR agencies, but also to those NGO service providers with a good record of effective work with victims and perpetrators of domestic violence.

- It is critical to maintain contact with clients, both the victims and suspected perpetrators. New means and channels for secure communication must be created to take advantage of various secure online solutions like helplines 
and chatlines. Because digital devices and online tools can be hacked and abused by perpetrators, safety standards must be clearly specified.

- Since victims' use of smartphones, landline phones and computers can be restricted by perpetrators, and to ensure access for those who are digitallyexcluded, new channels for secure communication and help-seeking must be created as alternatives; these could include diverse contact points, such as through neighbourhood markets, pharmacies, post offices etc., as well as through health and legal clinics.

- Special care is needed with vulnerable individuals and immigrants who have cultural and language deficiencies, for instance, by providing accurate written and online information in relevant languages and interpreters and services in such languages.

- Effective public campaigns and awareness-raising initiatives should be established to provide accurate information about the circumstances, the possible effects of the pandemic situation on domestic violence, and the availability of offline and online services, and made available in relevant languages.

- Well-coordinated cooperation between public authorities, private enterprises and NGOs and the pooling of appropriate resources is essential. This might include the following activities: cooperation in the construction of online infrastructure, the design and provision of communication devices, offering shelter placement, establishing and maintaining new online and off-line contact points, organising awareness campaigns, compiling information about domestic violence and Covid-19, its consequences and the services available.

- In order to produce a reliable and rapid picture of the prevalence of domestic violence in exceptional circumstances, authorities should create consistent information systems that rely on harmonised definitions and classifications of domestic violence on the country level. In addition, greater data standardisation is needed to allow comparisons between countries during a pandemic.

- Gathering robust data on domestic violence during a pandemic or other crisis is very important. However, all data collection must comply with ethical and safety principles, and assure the safety of victims at all times.

- Information should be accurately and immediately registered in various information systems maintained by a range of public agencies and NGOs. 
Further, such data should be relatively straightforward to analyse. This may require improved digital information and intelligence systems with harmonised definitions and versatile analytical, processing and mining features. This would increase understanding of how different factors interact and which mechanisms are at work in exceptional circumstances.

- Data on calls and reports to the police, helplines, shelters or other services should be triangulated with data coming from medical and social service providers and NGOs.

- It is useful to examine patterns and trends arising from pre-, during and post-COVID-19 reports (to police, shelters or other services) to inform policy and programme responses.

- Multi-professional risk and threat assessment procedures and related safety planning should be established and continue to function in order for agencies to assure the security of those under the greatest threat of highimpact domestic violence.

- Risks should continue to be monitored and safety plans should be adjusted to new conditions. Risk factors established and validated in 'normal conditions' may produce different outcomes in atypical conditions. Therefore, parties to risk assessment procedures should be aware of this possibility and be ready to adjust their measures, assessments and safety plans accordingly.

- The pandemic has affected many organisational protocols and procedures, as well as individual workers' coping strategies. The well-being and resilience of professionals working in critical services should be prioritised by offering structured support, along with the putting in place of mechanisms to help staff recover from the extra pressure from work caused by the virus and lockdown.

- Managers and supervisors should develop virtual support measures that maintain the dynamics and essence of staff well-being.

- It is especially important to acknowledge the demands placed on female workers who bear the burden of caregiving and workload in the domestic sphere whilst also supporting vulnerable and isolated victims during the time of a pandemic.

- Evaluations are required of the effectiveness and impact of awareness campaigns and new methods of communication and contact points. 


\section{References}

European Institute for Gender Equality (EIGE). (2021). The Covid-19 pandemic and intimate partner violence against women in the EU. https:// eige.europa.eu/publications/covid-19-pandemicand-intimate-partner-violence-against-women-eu

Kersten, J., Burman, M., Houtsonen, J., Herbinger, P., \& Leonhardmair, N. (eds., in press). Domestic Violence and COVID-19 - The 2020 Lockdown in the European Union. Springer.

UN Women \& WHO/United Nations Entity for Gender Equality and the Empowerment of Women \& World Health Organization. (2020). Violence against women and girls. Data collection during COVID-19. https://www.unwomen.org/en/digital-library/publications/2020/04/issuebrief-violence-against-women-and-girls-data-collection-during-covid-19

World Health Organization (WHO). (2020). Naming the coronavirus disease (COVID-19) and the virus that causes it. https://www.who.int/emergencies/diseases/novel-coronavirus-2019/technicalguidance/naming-the-coronavirus-disease-(Covid-2019)-and-the-virus-that-causes-it 


\section{FRONTLINE RESPONSE TO DOMESTIC VIOLENCE IN EUROPE}


4 ist

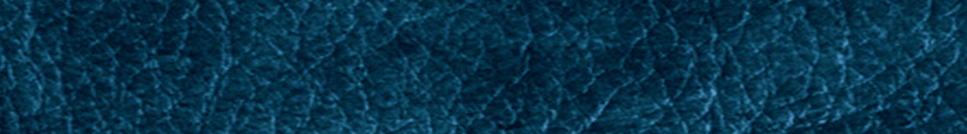

3.1.2.

(1)

W.7.

$$
\text { (1) }
$$

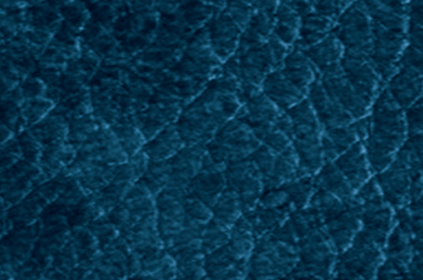

aris

$\cos 2$

1. 3 ?

13:

28.

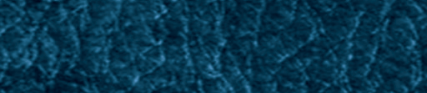

(1)

1)

3

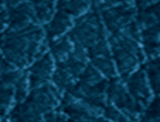

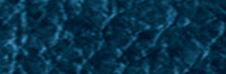

to

(⿻)

xtrat

3.

(1) 


\title{
FrontLine RESPONSE TO High IMPACT DOMESTIC VIOLENCE IN AUSTRIA
}

\author{
PAUl HERbinger, MARION NEUNKIRCHNER \& \\ NORBERT LEONHARDMAIR \\ Vienna Centre for Societal Security, Vienna, Austria. \\ E-mail: paul.herbinger@vicesse.eu; marion.neunkirchner@vicesse.eu; \\ norbert.leonhardmair@vicesse.eu
}

Abstract The networked response to cases of high-impact domestic violence in Austria predominantly involves four groups of actors, who share both formal and informal modes of interagency cooperation, and each function as independent entry points to a networked intervention. These groups consist of specialised and non-specialised police officers, a number of NGOs in the social sector, regional administration and municipal authorities, as well as the medical sector, predominantly involving hospital staff. The most important legal measure in place for the protection of victims by police is the restraining order in the Security Police Act, which was introduced as part of the victim protection guidelines. A unified and universally applied definition of domestic violence does not exist in Austria. As a result, there is no cross-sectoral standardisation when identifying violent acts. Nevertheless, the networked response in Austria is characterized by a robust system of inter-agency referrals and formalized cooperation.

Keywords: domestic violence, Austria, interagency cooperation, victims, first responders, police 


\section{Short description of country and legislation regarding domestic violence}

The networked response to cases of high-impact domestic violence in Austria predominantly involves four groups of actors, who share both formal and informal modes of inter-agency cooperation, and each function as independent entry points to a networked intervention. Broadly categorized, these groups consist of specialized and non-specialized police officers, a number of NGOs in the social sector, regional administration and municipal authorities, as well as the medical sector, predominantly involving hospital staff. Each group's role within the networked response is shaped firstly, by their respective legal mandate and competencies, and secondly, by the specific insight they have into cases of domestic abuse as well as the central addressees of their interventions.

\section{Domestic Violence Legislation and Police}

International policies to combat domestic violence and abuse was first implemented in Austria in 1997 and subsequently expanded and revised in the context of the Directive of the European Parliament and of the Council on the European Protection Orders in 2011. (cf. Directive 2011/99/EU) (European Parliament \& of the Council of the Europeam Union, 2011). In accordance with these international guidelines and directives, the major goal of the National Action Plan to protect Women against Violence 2014-2016 (NAP, Der Nationale Aktionsplan zum Schutz von Frauen vor Gewalt 2014 - 2016) was defined as the protection of women, children and other people who might become victims of violent crimes in the context of domestic violence. The national action plan entails both tasks and strategies to be employed by federal ministries to fulfilling this aim. Entering into force in 1997 and last amended in 2019 (cf. BGBl. I Nr. 105/2019; Stadt Wien, n.d.), the Protection Against Violence Act (Gewaltschutzgesetz) represents the central piece of legislation underlying the national response to domestic violence as a public problem. It regulates certain parts in the Austrian Security Police Act (SPG-Novelle: \$38 SPG, 1.9.2013), in the General Civil Code (Allgemein Bürgerliches Gesetzbuch) and in the Execution Code (Exekutionsordnung), and recently also facilitated amendments to the Penal Code (Strafgesetzbuch), as well as in various professional laws. (cf. Violence Protection Act, 2019) 
The most important legal measure in place for the protection of victims by police, is the restraining order in the Security Police Act (SPG), which was introduced as part of the victim protection guidelines. In early 2020, the restraining order under section 38a of the SPG has been amended and replaced by a broader prohibition of approach. The police are now authorized not only to expel a dangerous person from the victim's home (ban on entering). Such a ban now includes a prohibition of approach set at one hundred meters valid and for the duration of two weeks, though local and temporal exceptions to areas covered by the ban on entering and approaching are also still possible. Previous regulations on notifying the child and youth welfare agency in cases where minors are involved, informing them about suitable victim protection facilities, and informing them about the possibility of a restraining order have remained the same. A final substantial amendment to section 38a now stipulates, that all persons a restraining order has been issued against, must contact a violence prevention centre within five days of being issued the ban on entry and approach, where he or she must then complete violence prevention counselling within 14 days (cf. Österreich.gv.at, 2021).

\section{Domestic violence Legislation in the social sector}

In recent years, work with both victims and perpetrators has been increasingly understood to be necessary for the successful response to domestic violence and abuse. This has resulted in the development and proliferation of victim-oriented offender work (cf. Kaiser \& Glaeser, 2013). Today, a broad range of social welfare organizations provide support for victims on the one hand, and work with perpetrators the other. The development and strengthening of these types of services, notably, goes hand in hand with the reinforcement of a dichotomous categorisation of those affected by such interventions. The emergence of both organisational foci and the subsequent establishment of the fields of victim protection and offender work, have a long tradition within social work in Austria, as well as a clear forward trajectory through developments such as the latest Violence Protection Act (2019) described above.

The strategy to protect children and young adults is rooted in the specific vulnerability of this group. Therefore, their endangerment through violence is punished by criminal law and is predominantly assessed by the sovereign task of child and youth welfare. In addition to its control function, they also offer voluntary 
assistance and counselling to support parents. However, their main task for the protection of children in relation to domestic violence is to clarify the risk of the endangerment of the child's well-being. In addition to legal consequences for the parents, their risk assessment can also result in the removal of the child or the imposition of official conditions to the parents. The Federal Child and Youth Welfare Act (Bundes-Kinder- und Jugendhilfegesetz) and the Penal Code (Strafgesetzbuch) are essential foundations for work in the field of child protection (cf. Bundes-Kinderund Jugendhilfegesetz 2013; STGB 1974).

\section{Domestic violence in the medical sector}

Improved interventions into cases of domestic violence by the medical sector are being driven by an increased awareness, institutional and societal pressures, as well as positive policy changes. On the one hand effects of domestic violence result in significant treatment costs in short and long term (cf. Haller \& Dawid, 2006) on the individual, institutional and societal levels. On the other hand, the legal framework medical and health professionals operate under, stipulates a responsibility for vulnerable persons and reporting obligations in case of suspected criminal acts. Such statutory regulations on notification obligations are regulated in the Health Care Act and the Nursing Care Act as well as in the specific professional laws. Due to the new Protection against Violence Act 2019 (Gewaltschutzgesetz) an extension of the notification requirements was introduced and tightened for health professions (cf. Violence Protection Act, 2019).

Furthermore, early detection of domestic violence and forensic evidence preservation (for further criminal proceeding) are also central responsibilities of the medical sector. A guideline to address this issue was developed over the course of the project "Living Free of Violence" (GewaltFREIleben). As a result, victim protection groups were implemented in hospitals in 2011 to provide expertise on issues in the field of domestic violence, to contribute to security within hospitals, and to organize trainings for hospital employees (cf. GewaltFREIleben, 2014). 


\section{Limits to legal framework}

The IMPRODOVA field research published in Deliverable Report D2.2 (2019) showed, that a unified and universally applied definition of domestic violence (DV) does not exist in Austria. As a result, there is no cross-sectoral standardization when identifying violent acts as cases of "violence in domestic context", "violence within families" or "intimate partner violence". Different Frontline Responders (FLRs) in Austria use various definitions for the phenomenon of domestic violence, their definitions frequently varying even within the same sector. This can lead to misunderstandings between the institutions and, in the worst case, affect their cooperation to such an extent that a solid case management no longer works. A common understanding of domestic violence as a problem that reflects social inequalities in the private sphere , thereby partially shifting. The responsibility for the acts of violence and their prevention to the public sector and thus makes it a matter for the police, for the health sector and for social work organizations.

Even when legal provisions are comprehensively developed, not all cases of domestic violence can be prevented or solved in the long term. It is unavoidable that various human factors play a causal role for challenges that arise in responding to domestic violence and abuse. Solving such challenges, requires the cooperation and participation of all relevant authorities and private individuals. Legal regulations can only provide the framework and scope of discretionary powers of all acting parties. The rights of the victims and the accused are included in this scope of action and determine the discretionary scope for Frontline Responders (FLRs). However, since domestic violence remains a problem in the special privacy of a relationship despite being a public issue, the victim's long-term decisions relating to a possible separation from a dangerous person also remains a private matter. The manifold dependencies existing within relationships makes it very complex for all parties involved to deal with the problem and, for the same reason, it makes such confrontations with the it necessary. In this way, fundamental inequalities relating to sex and gender, and their causal relationship with violence and abuse, must be understood as limits to legislation to combat to latter. Substantial and sustainable responses to domestic violence and abuse must therefore encompass both legislation for direct interventions for victims and perpetrators, as well as measures and fundamental conditions that aim to eliminate the social inequalities between men and women forming the foundation of such abuse. 


\section{Reporting rates about domestic violence}

As in most European Member States, there is not one indicative data set designed to consistently and scientifically measure the prevalence of domestic violence in Austria. A variety of differently collected data are available, which each provide different snapshots into the phenomenon, and each reflecting sections of the respective context within which they are collected. This chapter attempts to provide an overview of the available data sources for Austria, discussing their limitations and emerging trends. Most commonly, Domestic abuse is counted and compared by bureaucratically collected data such as restraining orders issued by police. This often is complemented with crime reports linked to a domestic context. Here Domestic Violence is determined by the documented victim-perpetrator relationship and household status. Data on emergency calls to police linked to Domestic Violence are not available for Austria, in contrast to other EU Member States.

Overview of data types:

\section{A / Continuously collected data:}

Bureaucratic statistics:

1. Crime statistics, published annually

2. Procedural statistics (restraining orders), published annually

3. Public prosecutor statistics, not published (no link to DV)

4. Court statistics, published annually (no link to DV)

5. Incarceration statistics, not published (no link to DV)

\section{B / Continuous or single studies:}

(Inter-)national victimisation surveys

1. European Social Survey: continuous (no link to DV)

2. Fundamental Rights Agency: single study (special issue for DV)

3. National Ministries: single study (special issue for DV)

4. Qualitative studies: providing no indication of prevalence 
Table 1: Restraining orders issued by police 2011-2019

\begin{tabular}{lccc} 
& & \multicolumn{2}{c}{ Annual change } \\
Year & Restraining order & absolute & relative \\
\hline 2011 & 7993 & & $1 \%$ \\
\hline 2012 & 8063 & +70 & $3 \%$ \\
\hline 2013 & 8307 & +244 & $2 \%$ \\
\hline 2014 & 8466 & +159 & $-2 \%$ \\
\hline 2015 & 8261 & -205 & $4 \%$ \\
\hline 2016 & 8637 & +376 & $1 \%$ \\
\hline 2017 & 8755 & +118 & $-8 \%$ \\
\hline 2018 & 8076 & -679 & $8 \%$ \\
\hline 2019 & 8748 & 672 & \\
\hline \multicolumn{4}{c}{}
\end{tabular}

Source: Interventionsstelle Wien (2019) Jahresbericht.

The identified studies and the crime statistics and security reports of Austria conceptualising DV primarily as "violence against women", mostly focussed on physical violence with only a few examples taking into account other forms of violence. In Austria, there is no comparative data for the period prior to 1997 available, which is the date where the Protection against Violence Act (Gewaltschutzgesetz) came into force.

Despite the lack of data in case of DV, there are some figures available, primarily based on the afore mentioned studies, as well as crime statistics and evaluations conducted by victim protection centres themselves. These figures are often referred to violence against women. In this regard, $20 \%$ of women, which means every fifth woman in Austria, experienced bodily and/or sexual violence; $15 \%$ experienced stalking since the age of 15 years and $38 \%$ experienced psychological violence by their (ex-)partners since the age of 15 years (see FRA study, 2014) ${ }^{1}$.

The only Austrian national prevalence study on the subject of violence in families and close social relationships was conducted by the Austrian Institute for Family Studies of the University of Vienna in 2011, commissioned by the Ministry of economy, youth and family. This study surveyed experienced violence of both women and men, including their own perpetration. Additionally, they combined face-to-face interviews and an online survey, which was successful in terms of

\footnotetext{
${ }^{1}$ For numbers on violence against women see also

https://www.wien.gv.at/menschen/frauen/stichwort/gewalt/zahlen.html\#oesterreich
} 
making visible areas of experienced violence that had been hidden previously from view (for more see Kapella et al. 2011).

This study shows that 56,8\% of women suffered bodily harm in Austria and 29,5\% of the interviewed women had been victims of sexualized violence, including rape, attempted rape or sexual assault (Kapella et al. 2011). Moreover, every fifth woman experiences abuse by her spouse or companion (see Kapella et al., 2011).

The prevalence study from the European Agency for Fundamental Rights (FRA) on Violence against women, an EU-wide survey (2014) covers the whole 28 Member States and considered the situation of 42.000 women in total (aged between 18 to 74 years). In Austria, they conducted a total of 1.500 interviews with women, which also validated the well-known fact that every fifth woman experiences a form of violence (see FRA study, 2014).

The main police database on DV incidents is the annually produced security report and crime statistics "Polizeileiche Kriminalstatistik Österreich" (PKS) provided by the Bundeskriminalamt (2016). The detailed annual security report is prepared and published by the Ministry of Interior (BMI) together with the Ministry of Justice (BMJ). The statistical and analytical part maps the reported crime rates and covers the following offence types: offences against body and life, offences against personal integrity and offences against sexual integrity, all of which are defined as acts in the Criminal Code and which are relevant with regard to DV incidents. However, those offences are not specifically referred to cases of DV. Also, the report does not cover a single section on DV.

It allows only to analyse trends in crime reporting and does not indicate legal changes over time and DV across all potential offences. It constitutes limited information on the victim-perpetrator relationship and its situational factors that can lead for instance to escalating situations.

Only one study conducted in Austria has the explicit focus on high-risk cases of DV. The study is called "High-Risk Victims - homicides in couple relationships, convictions 2008-2010" (see Haller 2012). The author of the study carried out a quantitative and qualitative analysis of all court files in Austria in which homicides in partner relationships were the striving factor for such an incidence. From a total 
of 130 convictions in the timespan between 2008-2010, the author detected 39 convictions in case of (attempted) homicides in partner constellations along sociodemographic factors and others, which can lead in combination to escalating, or in other words high risk situations, for instance a pre-history of violence within the partner relationship associated with the announcement of divorce and maybe also alcohol abuse. The study shows that every second couple was in a process of separation. The study considers both women and men as possible perpetrators because it covers all court files/convictions where (attempted) homicides in partner relationships occurred (see ibid.).

In sum, similar to other Member States' data gathering in DV cases, the studies and crime reports in Austria can only represent particular sections of DV, which means that there is a clear lack of data and knowledge regrading comprehensible and longterm development of the phenomenon of DV. Generally, raw data is difficult to access, most of the studies are conducted as secondary surveys.

\section{The role of police, other front-line and first-responder agencies, and pertinent stakeholders in responding to high impact domestic violence}

\section{The Role of Police}

While no single criminal offence for domestic violence or abuse exists in Austria, the majority of criminal offences occurring in cases of high impact domestic violence (such as homicide, bodily injury, dangerous threats, coercion, stalking, rape, and molestation) are considered ex-officio crimes in Austrian law. Law enforcement is therefore obligated to prosecute such offences and is able to do so without authorization by a victim, lowering the threshold for police interventions and diminishing the relevance of reporting compared to other countries.

The overwhelming majority of police responses are conducted by non-specialized uniformed officers, whose central task consists of the immediate intervention into ongoing disputes and the assessment of the risk-level during the relatively brief period of time spent at the scene. These assessments are predominantly based on penal law (Strafrecht - StGB), criminal procedural law (Strafprozessordnung - StPO), and the security police act (Sicherheitspolizeigesetz - SPG). Alongside the criminal charges, a central competence of police officers in Austria, is the ability to issue 
restraining orders (Betretungsverbot) on site. If issued, a restraining order will prohibit the person in question from entering the premises of the victimized party under any circumstance for the duration of two weeks. A revision of the security police act (\$38a), entering into force in the beginning of 2020, saw an amendment of the restraining order to include a general prohibition for the accused to approach the victim with a boundary set at one hundred meters and over the entire two-week period.

The issuance of restraining orders lies within the purview of individual police officers on site, it is included under administrative law, and is one of the only cases in which no judicial mandate or approval is required in advance of such police action. While restraining orders are subject to post-facto verification by district administration, these are almost never overturned after the fact. The decision to issue such a restraining order is based on the officer's assessment that a dangerous attack on the life, bealth or freedom of a person is immanent ${ }^{2}$ (SPG 1991 \$38a). The ability to issue restraining orders, therefore, instils police with the mandate to intervene on the basis of actions and offences that have not (yet) occurred, beyond criminal acts that have already taken place.

The majority of police interventions are, as afore mentioned, conducted by nonspecialized uniformed officers. Mandatory sensitivity training is very limited and varies between one or two days during basic training. The training focuses primarily on the legal foundation and necessary case-documentation for the issuance of restraining orders, although some regions have long-standing cooperation agreements with social workers from specialist NGOs, offering a more theoretical introduction to the complex phenomenon of domestic abuse. Due to the comparatively short window of insight into cases and low levels of training, officers predominantly rely on physical signs of violence which has already occurred, on 'gutfeeling', and past experience to guide their interventions. The relative infrequency with which restraining orders are issued by individual officers, and the substantial complexity of the necessary case and procedural documentation, may inadvertently negatively influence the decision to make use of this measure.

\footnotetext{
2 SPG 1991 \$38a "Wegweisung und Betretungsverbot sind gleichermaßen an die Voraussetzung geknüpft, dass auf Grund bestimmter Tatsachen (Vorfälle) anzunehmen ist, ein gefährlicher Angriff auf Leben, Gesundheit oder Freiheit einer gefährdeten Person stehe bevor. Welche Tatsachen als solche im Sinne des $₫ 38$ a SPG in Frage kommen, sagt das Gesetz nicht (ausdrücklich).[...]”
} 
Beyond non-specialized uniformed officers, several specialized units exist within Austrian law enforcement: In the context of the initiative Gemeinsam.Sicher (Safe.Together), a select number of ground-level uniformed officers at district level receive additional training as 'prevention officers' on topics including 'violence-prevention'. These officers are allotted a portion of their working hours in which they may act as liaison officers between the public and police, give lectures on the topic of prevention to relevant audiences, and act as internal ground-level experts on district level. On state-level, the state criminal office (LKA) entails a department on crimes prevention (AB04) including a dedicated unit for victims-prevention (Opferschutz), focused solely on cases of domestic violence and stalking. Their central tasks consist of reviewing cases in which restraining orders were issued and conducting a rough categorisation along the probable severity of risk. Low-risk cases are referred back to non-specialized officers at district level for processing and follow-up, while medium-risk cases are handled by the unit itself. Lastly, for high-risk cases, this unit acts as a gate-keeper for referral to the last specialized unit within law-enforcement. A very small number of cases (usually less then ten cases a year) are referred to the unit VHR (Victims at Highest Risk), subordinate to the federal criminal police office and comprised of officers trained in witness protection. This unit is equipped with substantial resources, able to provide new identities and temporary subsistence to highest-risk victims of domestic violence and abuse. Finally, VHR is set apart from all other law enforcement units by the fact that their interventions uniquely address victims of high-impact domestic violence directly, rather than through measures focused on perpetrators as is standard throughout all other police interventions.

\section{The role of social sector organisations}

Where the role of police is chiefly focused on acute interventions in cases of domestic violence and directed mainly at perpetrators of criminal acts (or probable immanent criminal acts) occurring during such violence, Austrian NGOs in the social sector are primarily focused on victims and offer interventions which accompany cases for longer periods of time. Though the NGOs are primarily statefunded, they maintain a significant degree of autonomy, while simultaneously having established and formalized ties to law enforcement and organizations from the medical sector, regional administration and municipal authorities. 
A central institution within the social sector are the Centres for Protection Against Violence (Gewaltschutzzentren/Wiener Interventionsstelle). Existing in all federal states, these Centres offer their services to all victims, regardless of gender, while the overwhelming majority of cases nevertheless involve male perpetrated violence in heterosexual relationships. The victim-oriented interventions are mainly focused on women and grounded in an analysis of patriarchal gender relations, which can be traced back both to the empirical dimension of (high-risk) domestic abuse being overwhelmingly male-perpetrated abuse of women, as well as the history of this institution arising from the Austrian women's shelter movement of the 1970s.

Centres for Protection Against Violence share strong formalized cooperation agreements with law enforcement in Austria. Specifically, police officers are required to share the contact information of all victims involved in cases where a restraining order has been issued to the regional Centre. In this way, social workers are able to contact such victims and accompany the police measures with counselling (see section d. below for more detailed description). These formalized cooperation agreements with law enforcement result in a high volume of referrals to Centres for Protection Against Violence. In 2019, for example, the Centre in Austria's most populous city, Vienna, received 3,193 referrals from police, compared to 945 new clients seeking services autonomously and 1,994 existing clients continuing their service uptake from the previous year ${ }^{3}$.

Compared to law enforcement, social workers at these centres are able to approach domestic violence and abuse as a more complex phenomenon, accompanying cases for longer periods of time and addressing more intangible forms of violence. Interventions conducted by Centres for Protection Against Violence are rooted in social work methodologies and usually encompass a more holistic approach to countering violence. Interventions can include assistance in most areas of daily needs and assistance with the goal of (re)gaining a state of well-being, security and autonomy. The central tools employed in these interventions are counselling, legal and psychosocial trail support, as well as the referral to other, more specialized actors such as women's shelters, healthcare providers, and regional administration.

\footnotetext{
${ }^{3}$ https://www.interventionsstelle-wien.at/download/?id=Statistik-Wien.pdf
} 
Similar mandates and competencies are held by social workers in the twenty-six women's shelters existing throughout Austria, which provide emergency accommodation and counselling to female victims of domestic violence and abuse. In 2020, approximately 3,000 women and children sought help at a shelter for durations between one and three days $(15 \%)$, four days and a month $(24 \%)$, one to six months (31\%), or longer $(29 \%) .{ }^{4}$ This extended residence of victims of domestic abuse at a women's shelter has a significant impact on the insight gained by social workers into individual cases. While other NGOs also maintain interactions with some clients over extended periods of time, social workers at shelters are afforded time to develop relationships and build trust with clients. Similar to Centres for Protection Against Violence, social workers in women's shelters provide counselling and assistance on a wide range of topics beyond the violence experienced by their clients. This includes questions of subsistence (such as housing, (un)employment, public welfare, personal dept counselling), psycho-social support for legal and bureaucratic proceedings, as well as questions relating to childcare.

Over thirty Child-Protection Centres (Kinderschutzzentren) in Austria also offer services specifically to children and minors who have become victims or witnesses of domestic abuse. These Centres are staffed primarily with social workers, therapists and psychologists and offer services in individual or family counselling and therapy. On national level, Child-Protection Centres provide services to approximately 10,000 cases per year ${ }^{5}$, though not all of these cases involve domestic abuse. The competencies held by employees are deeply rooted in social-work and therapeutic methodologies and entail a thorough understanding of the dynamics of domestic abuse, including a sensitivity for dimensions and indicators of violence that are not immediately apparent to other actor groups. Frequently, Child-Protection Centres act as an entry point for cases of domestic abuse into a wider networked response, as the identification of such cases by means of referrals by schools or kindergartens represent a unique and highly relevant identification mechanism.

\footnotetext{
${ }^{4}$ https://www.aoef.at/index.php/statistiken-der-aoef-2 Accessed: 07/04/2021 16:46

${ }^{5}$ http://www.oe-kinderschutzzentren.at/bundesverband-2/zahlen-und-fakten/
} 
The NGO NEUSTART fulfils an equally crucial role within the networked response in Austria, providing support services for perpetrators during probation, parole, and diversionary measures, as well as being tasked with management of victim-offender mediations. Similar to Centres for Protection Against Violence, NEUSTART holds a monopoly position as the only NGO tasked with these activities. The NGO follows a victim-oriented approach when working with perpetrators, and employees of NEUSTART are predominantly social-workers, therapists, and psychologists, holding additional qualifications relevant to probationary work, or stem from legal professions. Analog to the other social sector organisations, NEUSTART follows a broad conception of domestic violence, including less tangible elements such as coercion and control.

Several Men's Counselling Centres exist in each federal state, tasked with violence prevention and focusing on perpetrators of domestic abuse. Notably, a shift in the methodological approach employed by therapists and other professionals predominantly working at these centres can be observed over the last decade. While the roots of these services often lay in a psychoanalytical and therapeutic approach, attempting to overcome violent behaviour by focusing on the perpetrator's own perceptions, conceptions and contradictions, this approach is being steadily supplanted by a victim-oriented approach that privileges the confrontation of the perpetrator with his previous violent acts and the victim's experience of the same. While conflict still exists between proponents of both approaches, the victimoriented approach has facilitated easier cooperation between existing Counselling Centres and victim organisations. With the introduction of the new Protection Against Violence Act (Gewaltschutzgesetz) in 2020, counselling for all persons issued a restraining order has become mandatory and the establishment of new institutions for such counselling has been decided.

Finally, it is important to note the role of regional administration and municipal authorities in the context of domestic violence and abuse. Within the district administration, the position of Security Administrator is tasked with the post-facto verification of all restraining orders issued by police officers. Though this very seldomly occurs in practice, Security Administrators are able to withdraw restraining orders in all cases the condition of proportionality is not deemed to be met. 
Also housed within district administration, Child and Youth Welfare (Kinder- und Jugendhilfe) holds the mandate ensuring the safety and security of underage victims of domestic abuse. A system of mandatory referrals from police to Child and Youth Welfare is in place whenever a restraining order involves underage parties.

\section{Medical Sector}

While the medical sector plays a key role in the networked response to domestic violence and abuse in Austria, its response is in many ways the least established. Beyond its function of health-care provision, the medical sector (and hospitals in particular) are central to the identification of victims of domestic abuse, the referral of these cases to other institutions, as well as the forensic documentation of cases of sexual assault and rape. The relevance of the medical sector's role in identification stems primarily from two factors: victims of domestic abuse who are reluctant to contact other institutions may nevertheless seek medical attention, and secondly, medical practitioners may see forms of violence and abuse (such as neglect) that other institutions are seldomly confronted with. The referral of cases by medical sector employees is formalized in $\$ 7$ of the Health Care Act (GuKG - Gesunheitsund Krankenpflegegesetz), which stimulates the mandatory reporting of criminal offences suspected to be the cause of any grievous bodily harm or death of a patient. A central challenge to the fulfilment of this task lies in the lack of sensitivity training for medical staff. Though steps are being taken to increase awareness, only small portions of doctors and nursing staff have received such training, partially resulting in a failure to identify cases of domestic abuse or resulting in a reluctance to address this topic with patients. On an institutional level, this lack of awareness has, in the past, led to failures on a bureaucratic level, by which cases were not referred to police or other institutions despite reports having been filed by medical practitioners. In an effort to professionalize the medical sector response, Child- and Victim's Protection Groups have been implemented in hospitals throughout Austria (though no full coverage exists). These are tasked with acting as support units, providing internal sensitivity training and acting as internal competence centres on the topic of domestic violence and abuse. Child Protection Groups consist of one doctor from the field of paediatrics or paediatric surgery, a specialist from the field of psychological care, and a member of the nursing staff, while Victim's Protection is staffed with doctors from the fields off gynaecology and trauma surgery in the place of paediatrics. While the nation-wide roll-out of these groups is still ongoing, the most 
established function of the medical sector in the wider networked response lies in their task of forensic documentation in cases of sexual assault and rape. A formalized procedure and case documentation is in place for the collection evidence, which is stored for the duration of at least six months, regardless of whether the case of assault or rape is reported.

\section{Good practices of co-operation between police, other front-line responder agencies, and pertinent stakeholders}

The Austrian networked response to domestic violence is characterized by a series of established formalized co-operation practices between police and other front-line responder agencies. These good practices of co-operation are grounded in policies that regulate and reinforce the interaction between different actors, and are well established within operating procedures of each of the agencies involved.

A principal example of effective formalized cooperation between police and social sector NGOs, is the standardized practice of referral by law enforcement to the regional Centre for Protection Against Violence, of all cases in which restraining orders have been issued. Within forty-eight hours of such a case referral, social workers from a Centre for Protection Against Violence will attempt to contact the victims and offer a range of support services, whose duration varies depending on the severity of the violence or threat, and the demand voiced by the victims. This frequently includes violence-counselling, but also assistance regarding questions on subsistence, housing, residency, child-care and (un)employment. In this way, the response to violence and abuse experienced by clients is approached as a more fundamental and systemic conflict, embedded in broader structures of dependency and (in)security. In all cases in which underage victims or witnesses are involved, similar mandatory referrals occur from all agencies involved to the Cbild-and Youth Welfare.

As a result of the 2020 Protection Against Violence Act, this system of mandatory referrals to social sector institutions will be expanded in the near future. In addition to the referral of victim's contact information to social sector institutions, perpetrators will be required by law to attend violence prevention counselling. To accommodate this new formalized procedure, a network of Violence Prevention Centres will be established nationally. Similar formalized cooperation exists as it relates to perpetrators recently released from prison or on parole. A well-established system 
of referrals is in place, by which the NGO NEUSTART offers a range of services and counselling in all such cases.

Finally, the aforementioned Child- and Victim's Protection Groups in hospitals, though comparatively smaller and less established than other actors, represent a goodpractice in cooperation between the medical sector and other agencies involved in the response to domestic violence and abuse. Their role as internal competencecentres also includes the task of liaising with other agencies. The presence of these groups within the medical sector represents the existence of clear contact points for outside agencies to approach and cooperate with a sector that is typically poorly integrated into a networked response.

The interviews conducted in three case-locations in Austria during the IMPRODOVA-Project revealed an important dimension of interagency cooperation beyond formalized structures: regardless of the specificities of each of the case locations (rural/urban settings, density of services, population size, etc.), formalized cooperation between agencies in each location was always accompanied by informal structures existing in parallel, and often underlying the smooth operation of formalized arrangements. These were primarily the products of efforts by single individuals within police, social sector organisations and the medical sector, relying on the good working relationships of single persons. Beyond improving communication and coordination, these non-formalized structures frequently included regular interagency meetings, case-conferences (or calls), and even joint services which no single agency was tasked with providing (such as regular meetings for relatives providing long-term care at home). Though these forms of informal cooperation are faced with a series of challenges (described below), it became abundantly clear, that they represent a major asset, if not a condition for the effective functioning of formalized cooperation. What can be described as a good practice in this context, are all instances in which employees of different agencies are granted the relative autonomy, or are expressly encouraged, to pursue such forms of nonformalized cooperation.

Finally, with the 2020 reform of the Protection Against Violence Act, a formalized mode of inter-agency case conferences was established. Though a critique of some aspects of this new form of cooperation will be formulated below, it is important to highlight these new Sicherheitspolizzeiliche Fallkonferenzen as good practices for inter-agency 
cooperation as attempts to overcome long-standing barriers. Broadly resembling the MARAC model of joint risk-assessment conferences, Sicherbeitspoliizeiliche Fallkonferenzen were created as multi-agency case-conferences in which pertinent information can be shared between different frontline responders to better assess the level of risk in particular cases and better coordinate interventions. The implementation of these conferences address two major challenges in inter-agency cooperation in particular: Firstly, the implementation of the Sicherbeitspoliizeiliche Fallkonferenzen on policy level included a new legal framework that allowed different agencies to share relevant information on a case while safeguarding victim's and perpetrator's rights relating to GDPR. Though Multi-Agency Risk Assessment Conferences (MARAC) had taken place in some case locations in the past, these had been lacking official rulings and a clear legal framework for the sharing of sensitive information. Secondly, previous attempts at case conferences often encountered the challenge of unclear mandates for participating actors. The police in particular frequently criticized the lack of a clear role and procedures in past models. The formalisation of such conferences within the 2020 Protection Against Violence Act successfully addressed this issue and strengthened the role of police within this form of cooperation.

\section{Main challenges and issues to be anticipated}

The central challenges Police will be confronted with in the short term relate to the frequency of changes to the Protection Against Violence Act and their implications for standardized procedures within police work. Specifically, the most recent revision of the act, entering into force in early 2020, will no doubt require some time to be adopted on a broad scale by ground-level police officers. This same challenge was regularly reported during the IMPRODOVA field study, particularly in the context of the relative infrequency with which individual officers are involved with the issuance of restraining orders. In some less densely populated case locations, police reported that individual officers may be involved in the issuance of a restraining order as seldomly as once a year, representing a serious barrier to the development of experience and expertise through police work in practice. The systemic nature of this challenge suggests, that it will also present in the medium and long term, and have relevant implications in the context of the strengthening of the role of police as the central formalized actor in the networked response to domestic violence. This becomes particularly evident in the new multi-agency case conferences 
(Sicherheitspolizeiliche Fallkonferenzen): unlike previous models, only law-enforcement is able to convene the new form of case-conferences and selects the participating agencies and organisations on a case-by-case basis. This approach runs the risk of replicating existing biases and blind spots of the institution and may reduce the efficacy of this form of multi-agency cooperation. This risk is increased by a further medium and long-term challenge faced by police: Though all police officers receive mandatory training on the topic of domestic violence, this training is focused predominantly on the legal grounds and operational procedures for issuing restraining orders. A significant gap still remains in general sensitivity and awareness for the phenomenon of domestic violence and domestic abuse in particular (Neustart, 2021).

Short term challenges faced by the social sector in the short term also stem from the revision of the Protection Against Violence Act. The most prominent challenge lies in the establishment of the new Violence Prevention Centres on national level. The organisational challenge of implementing a nation-wide network of such institutions will be followed in the medium and long term with the challenge of integrating these into the wider network of social sector organisations. As we have pointed out, good inter-agency cooperation fundamentally relies on the informal cooperation between individuals in the sector. It will take time to establish such ties, and the mode in which these new Centres will be established will play a major role in the successful implementation. It is to be seen, which shape these new institutions will take, and how they will be integrated into a network of existing organisations already providing the same services. The possible overlap in services and resulting competition between this new institution and existing ones is likely to represent a significant hinderance to cooperation in the response to domestic violence. Similarly, the fact that the mandatory violence counselling for perpetrators at these centres requires the former to pay for this counselling out of their own pocket representsin some cases a structural barrier to this measure's efficacy and is discriminatory towards lowincome groups.

Finally, a structural long-term challenge faced by the Social Sector in general relates to the ratio between level of funding and caseload. At the Centres For Protection Against Violence, for example, social workers are able to expend an average of only 5 hours per client. As this amount of time does not suffice to accompany a case over time, it necessarily leads to the concentration of efforts and funds on high-risk cases. 
While focusing on these cases is undoubtedly relevant, the sparse resources for interventions at earlier stages of a violent relationship leave many victims disappointed and feeling abandoned in phases of an abusive relationship where counselling may be more effective. The problem of limited funding also relates to the relevance of informal cooperation outlined above, coupled with the dependence of these informal networks on specific motivated individuals. Insofar as no funds exist to prove the structures for such informal cooperation, no sustainability for these essential informal, non-scalable aspects of co-operation can be achieved.

The main challenge faced by the Medical Sector in the short and mid-term pertains to the continuing roll-out and implementation of the Victim's Protection Groups in Hospitals. Structural challenges faced by these Groups relate to their size (usually three members per hospital) and the limited time resources. Structural barriers also stem from the limits to the departmental sharing of information. Addressing this, first attempts are being made to establish a virtual department for victim's protection, which would allow Protection Groups to access relevant information on cases of DV between departments without disrupting the status quo of documentation procedures. Finally, the medical sector will continue to be faced with the significant challenge of a general lack of awareness and sensitivity training amongst medical staff. While some hospitals have implemented mandatory training on the topic, this varies strongly from hospital to hospital. The integration of the topic of domestic abuse as a mandatory part of medical training remains a long-term goal.

\section{References}

European Parliament \& of the Council of the European Union. (2011). Directive 2011/99/EU of the European Parliament and of the Council of 13 December 2011 on the European protection order, (338), 2-18. https://eur-lex.europa.eu/legalcontent/EN/TXT/?uri=celex\%3A32011L0099

GewaltFREIleben. (2014). Living FREE of violence - A campaign to prevent violence against women and cbildren. http://gewaltfreileben.at/en/

Gewaltschutzgesetz. (2019). BGBI, (105/2019). https://www.ris.bka.gv.at/Dokumente/BgblAuth/BGBLA_2019_I_105/BGBLA_2019_I _105.html

Haller, B. (2012). "High-Risk victims". Tötungsdelikte in Beziehungen, Verurteilungen 2008-2010, BMFG. Medieninhaberin, Verlegerin und Herausgeberin: Bundesministerin für Frauen und Öffentlichen Dienst im Bundeskanzleramt Österreich.

Haller, B., \& Dawid, E. (2006). Kosten bäuslicher Gewalt in Österreich. Institut für Konfliktforschung. http://www.ikf.ac.at/pdf/kosten.pdf 
IMPRODOVA. (2019). Country Reports and Cross-National Comparison on the Implementation of International Norms and National Best Practices of Frontline Responders.

https://www.improdova.eu/results/reports/index.php

Kapella, O., Baierl, A., Rille-Pfeiffer, C., Geserick, C., Schmidt, E.-M. (2011). Gewalt in der Familie und im nahen sozialen Umfeld. Österreichische Prävalenzstudie zur Gewalt an Frauen und Männern, 2011. BMWFJ

Kaiser, J. \& Glaeser, B. (2013). Opferorientierte Täterarbeit. Neustart. https://www.neustart.at/at/de/blog/entry/3479

Neustart. (2021). Leben obne Kriminalität. Hilfe nach der Haft, für Opfer \& Prävention - Angebote in Österreich. https://www.neustart.at/at/de/index.php

Österreich.gv.at. (2021). Sofortiges Betretungs- und Annäherungsverbot zum Schutzv vor Gewalt. https://www.oesterreich.gv.at/themen/gesundheit_und_notfaelle/gewalt_in_der_familie/ 5/Seite.299420.html

SPG §38a (Betretungsverbot); Decree: P4/436620/1/2014, 25.02.2015, LPD (Erlass zum Gewaltschutzgesetz, SPG).

Stadt Wien. (n.d.). Gewaltschutrgesetz - Gewalt gegen Frauen.

https://www.wien.gv.at/menschen/frauen/stichwort/gewalt/recht/gewaltschutzgesetz.ht $\mathrm{ml}$ 


\title{
FRONTLINE RESPONSE TO HIGH IMPACT DOMESTIC VIOLENCE IN BULGARIA
}

\author{
MARgarita VASSILEVA \& THIERry DELPEUCH \\ Université Grenoble Alpes, Sciences po Grenoble, CNRS - UMR PACTE, \\ Saint-Martin-d'Hères, France. \\ E-mail: margarita.vassileva@umrpacte.fr; thierry.delpeuch@umrpacte.fr
}

Abstract According to the NGO Women Against Violence Europe, an estimated 30 per cent of women in Bulgaria suffer from domestic abuse every year. Thirty-five women were murdered in the context of domestic violence in 2018. The mistrust of law enforcement and the justice system inherited from the communist regime discourages victims from seeking assistance from the police and the judiciary. The issue of violence against women surfaced in the government's agenda due to the debates around the ratification of the Istanbul Convention, which was ultimately rejected. The country policies are characterised by a lack of change in the legal frameworks, a lack of official data, a lack of sufficient financing from the state budget, and a lack of established procedures for handling domestic violence cases. Ineffective coordination between institutions, the failure to make official statistics publicly available, the lack of a national register of acts of domestic violence, the requirement of proof of systemic violence to initiate criminal proceedings, and the lack of resources to support NGOs are all obstacles that result in a high number of acts of domestic violence that goes unaddressed by the courts. NGOs are at the forefront of the fight against domestic violence.

Keywords:

domestic violence, Bulgaria, interagency cooperation, victims, NGO, police 


\section{Description of the country regarding domestic violence}

In Bulgarian society, domestic violence (DV) is a problem that is frequently encountered. According to NGO data, 1 million (i.e. one out of every three) women in the country have been victims of domestic violence. However, only $14 \%$ report their assaults to the police, and they do not believe they will receive any support. The challenges in the field of DV also stem from the fact that gender difference ${ }^{1}$ is firmly entrenched wherever traditional roles persist. Thus, according to a survey by Eurobarometer (2017), respondents in Bulgaria are the most likely in Europe to stereotype based on gender: $81 \%$ think that the most important role a woman has is to take care of her home and family and that a man's most important role is to earn money; $32 \%$ think it is not acceptable for men to cry. According to the Women Against Violence Europe organisation, an estimated 900,000 women (30\%) in Bulgaria suffer from domestic abuse every year. Thirty-five women were murdered in the context of domestic violence in 2018.

Largely ignored by the state for many years, the issue of violence against women surfaced in the government's agenda due to the planned ratification of the Istanbul Convention. On 21 April 2016, Bulgaria signed the European Council's Action against violence against women and domestic violence (Istanbul Convention), although it has not ratified it. After long months of heated discussions in the public arena, conservative and nationalist circles and Orthodox and Muslim religious leaders joined forces against the text accusing it of relying on gender theories. On 27 July 2018, the Bulgarian Constitutional Court declared that the Istanbul Convention does not conform to the Bulgarian Constitution because the convention's definition of "gender" as a social construct " relativizes the borderline between the two sexes male and female - that is biologically determined". "If society loses the ability to distinguish between a woman and a man, the fight against violence targeting women will remain a formal but unachievable task", the statement read.

\footnotetext{
1 "If a man can't slap his wife, he's not a man": Man interviewed in Sofia, February 2019.

2 Constitutional Court of the Republic of Bulgaria (Конституционен съд на Република България), Decision No 13 of 23 July 2018: http:// constcourt.bg/bg/Acts/GetHtmlContent/f278a156-9d25-412d-a064-6ffd6f997310
} 
Since then, European ideas and initiatives in the field of women's rights have been seen by a large part of the population as the result of a degraded and harmful Europe. Many demonstrations were organised against the Istanbul Convention and the Strategy for the Protection of Children. The protagonists of these movements declared themselves opposed, on the one hand, to the rise of alternative concepts targeting sexual orientation and, on the other hand, to the intervention by the state in the family sphere and, in particular, to the prerogatives to place a child in a social structure. A whole reactionary vocabulary has appeared in the public space: The word "gender" has been imported into the Bulgarian language as "Ажендър" [djendar] but means a person with an "abnormal" sexual orientation. Its connotation has become extremely negative. The way the non-ratification of the IC was viewed has divided the country into two opposing camps. This discord has pitted the city against the countryside, the people belonging to the LGBTQ community against those who do not tolerate them. As a result, institutions and non-governmental organisations working in the field of the family have difficulty finding partners and participants to support their activities.

The lack of reliable official data on violence against women is considered one of the most significant problems of Bulgarian criminal procedure and policy. The main reason is that Bulgaria does not have an automatic information system to collect and process data on domestic violence. This function is part of the Integrated Information System for Action against Crime, which is currently being developed. Various institutions use their own information systems. For example, the Ministry of the Interior collects data on crimes such as murder, rape, sexual violence, bodily harm and other forms of violence that can be based on gender. Surveys on DV are generally conducted as part of research projects and are, therefore, not long-term. Projects are carried out by partners, but competition may also hinder the flow of exchanges. In the end, the information is insufficient and poorly organised on the Internet. Bulgaria is one of the countries for which Eurostat has no data on femicides. 


\section{Legal changes regarding domestic violence}

\section{Law on Protection against Domestic Violence: the protection of victims through civil proceedings}

The Bulgarian Law on Protection against Domestic Violence (LPDV) ${ }^{3}$ was adopted in 2005 and is considered a breakthrough in countering this growing phenomenon. ${ }^{4}$ The law offers direct remedies against acts of domestic violence by means of a civil law procedure before civil courts within relatively short time frames. Authorities cannot act in an ex officio capacity, and the launch of proceedings greatly depends on the victim's willingness to lodge a complaint. All victims of domestic violence may seek protection under the law from the regional court.

Court proceedings must be initiated by the victim, who must submit a written motion which contains a personal declaration regarding the violence committed. The motion is submitted within one month of the act of domestic violence, and on the day of submission the court schedules an open hearing to take place within one month.

Admissible evidence during the proceedings includes actions taken by the Social Assistance Directorates, consulting doctors and/or psychologists, as well as documents from social service providers and certified copies of written evidence from the police and other authorities. If there is no other evidence, the court issues a protection order based solely on the victim's declaration.

The law provides for psychological consultation and practical aid, which are offered primarily by NGOs, as well as medical and legal aid, which are regulated by special laws. The law does not require victims to receive legal representation or advice. In practice, victims are most often represented or advised by attorneys in the proceedings on protection orders against domestic violence and interim measures. State-provided legal aid in the strict sense is regulated by the specific Law on Legal

\footnotetext{
${ }^{3}$ National Assembly of the Republic of Bulgaria (2005). Закон за защита от домашното насилие [Law on Protection against Domestic Violence] (State Gazette (SG) 27 of 29 March 2005). Sofia, National Assembly of the Republic of Bulgaria.

${ }^{4}$ Number of victims of DV who have obtained a protection order: 2,121 (2015), 2,323 (2016), 2,440 (2017), 2,981 (2018). Source: GDNP, April 2019.
} 
Aid. ${ }^{5}$ Recently, its scope prior to the start of proceedings (consultation and preparation of documents) was significantly broadened to include, in addition to indigent persons and families, children at risk and victims of domestic violence who do not have sufficient funds but would like to be represented by an attorney.

Members of NGOs point out several problems with victims contacting the police as the first authorities: In some cases, police authorities refuse to accept oral or written complaints about domestic violence and directly refer the victims to NGOs or the court; in many cases, registration numbers of complaints are not given or are significantly delayed, which hampers the protection order procedure, since complaints to police are important evidence to be attached to the motion in court.

The directors of local Social Protection Directorates, who can petition the court for protection orders, rarely use this opportunity. By contrast, some police departments prepare petitions for protection orders, even though they are not one of the entities that can submit such petitions, which delays court proceedings. Social workers' reports, which are prepared as part of protection order proceedings, often contain general information on the families' social situation that is not relevant to those specific proceedings, which further hampers victims' protection.

Medical certification of sustained trauma is an important element of proving domestic violence committed during protection order proceedings, but general practitioners, who are specifically empowered by law to issue such certificates, often refuse to do so, while forensic doctors' certificates are expensive, and allegedly no specialists on duty are available over weekends and during holidays. At the same time, certificates by general practitioners are sometimes ignored by the court, and psychological violence is frequently punished less severely in terms of the length of protection measures. If the partners do not live in cohabitation, the victim cannot practically obtain a protection order. In addition, cohabitation can be difficult to prove. In addition, LGBTI partnerships do not enjoy legal recognition in Bulgaria, so they do not fall under the scope of the law.

\footnotetext{
${ }^{5}$ Law on Legal Aid (Закон за правната помощ) (2005). Promulgated in SG 79 of 4 October 2005, in force since 1 January 2006, latest amendments in March 2013. http://lex.bg/bg/laws/ldoc/2135511185
} 
If the court honours the motion, it issues a protection order with one or more of the following protection measures:

- the perpetrator is obliged to refrain from committing domestic violence,

- the perpetrator is removed from the co-habited home for an amount of time determined by the court,

- the perpetrator is prohibited from approaching the victim, his/her place of living, work of social contacts and recreation under terms and conditions determined by the court,

- the child is temporarily placed with the victimised parent or the parent who is not alleged to have committed the violence under terms and conditions determined by the court, provided this does not go against the interests of the child,

- the perpetrator of the violence is obliged to take part in specialised programmes,

- victim is referred to rehabilitation programmes,

- a fine of 200 to 1,000 leva (€100-€500) is also imposed.

Bulgarian law also has an order for immediate protection, which is issued within 24 hours after a motion is submitted if the latter contains evidence of direct, immediate or subsequent danger to the victim.

In court, offenders and victims are often invited to reach an agreement, as in an ordinary civil case, which eliminates the victim's motivation to seek protection via a protection order. Sometimes, in procedures for orders for immediate protection, the measure of temporarily housing the child with the victimised parent (the parent who has not committed the violence) is allegedly not imposed because of a lack of data on the violence directed at the child, despite the latter being a witness to the violence and, therefore, a victim. Thus, victims are left with the alternative to stay with the children or take care of their own security.

Practitioners argue that many courts require domestic violence to be proved beyond a reasonable doubt, which is an excessively high burden of proof that puts the onus entirely on the victim. 
One explanation for this situation would be the abuse of victims' rights, which some complainants would like to benefit from. For example, according to the family judges we met in Sofia, a significant percentage of complainants (between $50 \%$ and $60 \%$ in divorce proceedings use the charge of domestic violence. Often, it is the lawyers who advise their clients to take this approach in order for them to win their cases.

As noted by NGO professionals, a common problem for all protection orders is that they very often simply repeat the provisions of the respective law without any specification, which makes it difficult to enforce them. Judges also note that the measures that protection orders, such as obliging the offender to attend specialised programmes, are inapplicable in practice because of a lack of such programmes and the insufficient number of professionals in that field.

Protection orders are subject to immediate execution. The initiative to notify and prove the potential violation of an order lies wholly with the protected persons.

There is no central register of protection orders for domestic violence in Bulgaria; thus, police officers who are called to the scene do not have advance information about them or that they have been violated.

The police are insufficiently aware of its powers and obligations related to monitoring protection orders. According to NGO professionals, the police often refuse assistance to victims in cases of orders for immediate protection and, instead, wait for the original of the order to be sent officially to them or for the offender to be served with a copy. Reportedly, the police are also uncooperative in cases repeated abuses. NGO professionals claim that non-compliance rarely leads to serious consequences for the offender. The police do not use its powers effectively enough and consider violations a "private" or "family" matter, especially in smaller towns or villages where people know each other, and the protection offered to such victims is largely insufficient.

In the view of a number of practitioners, the sanctions in response to violations of protection orders against DV are not effective in terms of severity and execution. Non-compliance with such orders is criminalised, but criminal proceedings are not frequent, and punishment is not serious enough. 


\section{Reforms of the criminal justice system}

Crimes are prosecuted by the State through the public prosecutor, who collects evidence and brings charges. There, however, systematic violence is required. That is, evidence of three prior acts of domestic violence must be collected. Often victims do not complain to the police and there may have been a pattern, but no evidence was collected. The Criminal Code treats the murder of a mother, father, biological child, pregnant woman or minor as an aggravated case of murder. Any bodily injury of a mother, father, pregnant woman or minor in a manner that is especially torturous for the victim is also an aggravated case. However, light bodily injuries, even in the cases mentioned above, as well as light and medium bodily injuries, are tried only if the victim lodges a complaint. Sexual crimes stemming from acts of domestic violence can also be prosecuted and tried. Bulgarian law does not define rape in the marital context.

As the Bulgarian Constitutional Court judged the Istanbul Convention to be unconstitutional, legislative amendments were adopted by Parliament to strengthen women's protections against violence. Acts of domestic violence as such were criminalised under the Bulgarian Criminal Code. ${ }^{6}$

The most important amendments to the Criminal Code concerned the significant increase in prison sentences and fines for failing to comply with the court decision. These amendments were a step towards the ex officio penalisation of all medium bodily injuries that affect relatives and spouses. Stalking and forced marriages were also criminalised. The amendments made it possible to inform a victim who has special protection needs if the suspect/accused is released or escapes from detention in custody or in prison. Non-compliance with domestic violence protection orders became subject to aggravated punishment.

In cases in which the requirements of the law for crimes committed under the condition of domestic violence are not met, the prosecutor's office shall instruct the victim to initiate proceedings by complaint. This delays the proceedings against the perpetrator. This creates additional risks for the victim and discourages the victim.

\footnotetext{
${ }^{6}$ National Assembly of the Republic of Bulgaria (2019). Amendments and Supplements to the Criminal Code Act (Закон за изменение и допьлнение на Наказателния кодекс), 22 February 2019. Available at http://dv.parliament.bg/DVWeb/showMaterialDV.jsp?idMat=134676
} 
The burden of proof falls on the victim. Victims often do not have the economic means to do so.

As the first actor in contact with victims and perpetrators of DV, the police suffer from weaknesses that prevent them from effectively solving DV cases. According to one police officer, these weaknesses are: "the lack of regulations on the coordination of institutions concerned with the Law on Protection against DV; the need for amendments in the Law on Protection against DV, the Penal Code and the Code of Criminal Procedure in order to criminalize certain DVs; the lack of officers specialized in working with DV victims ; the lack of methodology and training in risk assessment; the lack of targeted funding for DV protection projects; the lack of work programs for DV perpetrators; the lack of shelters for DV victims.

Concerning the risk assessment of DV, currently neither the police nor NGOs have the tools to evaluate the probability of a violent situation. The qualification and skills of the police officers who go to the address where the domestic violence was committed are relied on. In fact, the police officers' expertise in handling collected and existing information is the decisive factor.

The Regulations on the Organisation of the Work of the Prosecutor's Office signed by the Attorney General on 30 April 2018 specify how to conduct preliminary investigations to assess the risk of the perpetrator committing murder or repeating the acts of violence. These are internal notices whose application remains ineffective.

Victims of criminalised acts of domestic violence would most often fall within the scope of the Law on Assistance and Financial Compensation to Victims of Crime $(\mathrm{LAFCVC})^{7}$ in case of murder; intentional grave bodily injury; carnal abuse and rape that resulted in serious health problems; as well as other serious intentional crimes resulting in death or grave bodily injury. The LAFCVC has been criticised for being too restrictive in how it regulates the provision of financial compensation. The latter is only given after the entry into force of the sentence or after proceedings have been terminated, and it does not provide for any pre-payments for urgent expenses. The financial compensation request is submitted to the regional governor for the place

\footnotetext{
${ }^{7}$ National Assembly of the Republic of Bulgaria (2006): Закон за подпомагане и финансова компенсация на постраАали от престьпления [Law on Assistance and Financial Compensation to Victims of Crime] (SG 105 of 22 December 2006), Sofia: National Assembly of the Republic of Bulgaria.
} 
where the victim currently resides or to the National Council for Assistance and Compensation for Victims of Crime within two months of the entry into force of the sentence. It is accompanied by supporting documents, which often create evidentiary difficulties for the victims. It is reviewed by the council's expert committee, and the council adopts a decision that cannot be appealed.

The LPDV stipulates that the court may decide on measures for the perpetrator of domestic violence by requiring him or her to participate in specialised programmes, but in practice, after the court decision, the perpetrator is expected to visit the centres offering this type of service. If the perpetrator of domestic violence is absent from these courses on two occasions, the NGO must immediately refer the matter to the Prosecutor's Office so that it can initiate preliminary proceedings: Under Article 296 of the Criminal Code, failure to comply with the court's decision is a criminal act. The Ministry of the Interior has no information on this subject because participation in programmes for perpetrators of domestic violence is de facto voluntary with the presumption that the programme is effective and the perpetrator will no longer commit such acts. Thus, if there is no report of the perpetrator committing another act of DV, the police do not receive any further information on him. Usually, the obligation for perpetrators to attend psychologists does not change the former's self-perception. According to the victims, systematic violators require not psychological but psychiatric treatment.

\section{National policy and inter-agency coordination}

The main institutions involved in combatting domestic violence:

- Ministry of Interior, through the Prevention Directorate in the Security Police General Directorate, as well as regional directorates (28) and district police departments,

- Ministry of Justice, through its legislative activity and the domestic violence-related project funding of NGOs,

- Courts, involved in adopting protection measures through their civil panels and, through their criminal panels, in trying DV-related criminal acts and violations of DV restraining orders,

- Prosecutor's Office, involved in prosecuting violations of DV restraining orders and DV-related criminal acts, 
- Ministry of Labour and Social Policy,

- Social Assistance Agency and its local directorates,

- State Agency for Child Protection, responsible for coordinating all child protection policies and actions,

- Ministry of Health.

Each year, the Council of Ministers adopts a National Programme for Prevention and Protection against Domestic Violence based on the Law on Protection against Domestic Violence. The programme was first initiated in 2011 and includes actions planned for the coming year, organisations responsible for implementing them, funding sources, implementation timeframes and expected results.

Since 2011, the National Programme for Prevention and Protection from DV has required an annual report on its implementation. However, no official document has been published. Despite the requirement to gather and analyse in detail the data on work with the Law on Protection against DV, there are no statistics under uniform criteria on that topic. This failure is partly remedied by the NGOs' activity reports and European projects in which Bulgarian institutions and NGOs participate. The Animus Association Foundation, the Bulgarian Gender Research Foundation and the Centre for the Study of Democracy have published the most important surveys in this regard. They are all primarily supported by European funds. These are multidisciplinary studies in which the legal approach predominates. Other more targeted studies analyse measures against DV in the context of business, schools, honour crimes, etc.

The official Internet sites of the institutions involved in implementing the National Programme contain no published reports, analyses or independent monitoring reports on the implementation of the programme.

The National Programme is developed by the National Police General Directorate and falls under the responsibility of the national coordinator of policy against DV. Other institutions play a very small role in how the programmes are drafted, and the national coordinator ${ }^{8}$ carries out this task without the full support of the public stakeholders concerned in the fight against DV.

\footnotetext{
${ }^{8}$ Interview, Sofia, February 2019.
} 
In 2015, the National Programme incorporated the creation of a workgroup tasked with drafting amendments to the methodological instruction set in the Law on Protection against Domestic Violence for police authorities. The goal was to introduce a unified approach to the work of police officers in applying the Regulation for Implementation of the Law on Protection against Domestic Violence. This initiative has not been implemented either.

According to the law, there should be cooperation between the Ministry of the Interior and the Ministry of Labour and Social Policy, which should take place through an exchange of information on domestic violence protection requests and on the execution of protection measures and programmes on the prevention of and protection against domestic violence, as well as common actions. Under common actions, each local social assistance director should notify police authorities about the location of each act of domestic violence or violation of a domestic violence restraining order. Police authorities must notify the local social assistance director of every domestic violence case involving a minor or juvenile, a person of limited legal capacity or with disabilities. Twice a year, social assistance structures under the Ministry of Labour and Social Policy provide police authorities with information regarding the registered social assistance providers best suited to treating DV victims on the territory they are responsible for.

In 2012, a multi-agency working group with the Ministry of Justice, supported by Animus Association Foundation, developed a draft coordination mechanism to support victim of DV. The group involved representatives from the Ministry of the Interior, the Ministry of Labour and Social Policy, the Ministry of Education and Science, the Ministry of Youth and Sport, the Ministry of Health, the State Agency for Child Protection and the Agency for Social Assistance. The draft coordination mechanism suggests a framework for cooperation between state institution professionals, NGOs and municipalities in order to standardise, combine and coordinate their respective interventions.

The coordination mechanism includes measures in three areas:

- notification and referral, including identification of the victim, risk assessment and safe referral, 
- protection measures, e.g. through the involvement of the police and child protection departments, medical aid, crisis interventions, placement in crisis centres and so forth in the case of direct and imminent danger and consultation on victims' rights, psychological aid and social advocacy in the case of potential risk,

- social inclusion, i.e. long-term support after the violence has stopped, including psycho-social consultation and psycho-therapeutic work, building skills for the labour market, social consultation, advocacy and active social work.

Elaboration of the coordination mechanism should have been a significant step in the policy response to domestic violence, but the document has still not been signed by the ministers of the responsible institutions. In drafting the mechanism, the Ministry of Health insisted on removing text related to the medical specialists' responsibility for: assessing the risks; alerting any DV victims; filling in the DV report form or taking concrete action when witnessing domestic violence. Evidence suggests that women who have been subjected to violence seek health care and identify medical specialists as the professionals they would trust most when disclosing the abuse. Improvement of existing policies can be achieved only if the Ministry of Health plays a significant role in the process of supporting domestic violence victims.

Lack of a full-scale evaluation of existing policies and strategies hinders the assessment of the policies mentioned above. However, it can be seen that domestic violence policy is implemented in very different ways depending on the institution and on the location. Fragmented and uneven services and regional discrepancies result in varying levels and quality of the response to DV victims.

\section{NGO as main stakeholders in responding to high impact domestic violence}

NGOs are at the forefront of the fight against DV, and thanks to their activities the phenomenon is starting to be taken seriously. They are also the main providers of services, training and analysis related to DV. NGOs working on domestic violence issues keep well-updated databases of relevant information and advice for DV victims, as well as current methodologies and surveys for use by professionals in the 
field. The functioning of NGOs is largely based on European grants, which focus on partnership projects.

Victims should first turn to NGOs such as Animus, Bulgarian Lawyers for Human Rights, etc. to receive psychological, moral and material support, as well as shelter. In this way, cases can be registered so that there is evidence of systematic violence. Such a non-profit association should be able to file a report with the court to initiate proceedings to protect the victim under the PLDV. ${ }^{9}$

An interdepartmental workgroup of the Agency is developing a methodology for providing crisis centre services for Social Assistance. According to the legal definition contained in the Regulation for Implementation of the Law on Social Assistance (RILSA), a "crisis centre" is a social service package for victims of violence, trafficking or other form of exploitation. The service is provided for a period of six months and focuses on offering individual support, meeting everyday needs and providing legal consultation and socio-psychological help when immediate intervention is required, including mobile expert teams trained in crisis intervention. The relevant RILSA regulations provide for immediate and mandatory support to victims of domestic violence who seek help.

Crisis centres in Bulgaria do not have any specific profiles according to the different types of violence. In practice, these centres are distinguished based on the type of target group they service: Across the country, there are 21 State-funded crisis centres for victims of violence, with a total capacity of 214 slots in 15 regional centres, ${ }^{10}$ and there are nine "Mom \& baby" cells, 15 centres for children and six crisis centres for women who have been victims of DV. The latter also accommodate mothers with children and have a total of 64 places. Crisis centres only provide social services: emergency medical and nursing care, crisis intervention, forensic evidence collection, medical follow-up, medical counselling and referral to community resources. The services that the centres provide to victims are mainly individual in nature and reflect the specific needs of the particular person. The services are provided free of charge. Currently, the number of crisis centres is insufficient, the places are quickly filled, and the victim often has to be moved from one centre to another. In addition, owing to a lack of regulation and resources, the police cannot

\footnotetext{
${ }^{9}$ Interview, prosecutor, Sofia, May 2020

${ }^{10}$ Burgas, Varna, Veliko Tarnovo, Vidin, Montana, Pazardjik, Pernik, Pleven, Plovdiv, Ruse, Silistra, Stara Zagora, Sofia, Sofia proper, Shumen
} 
guarantee their safety nor the permanent protection of victims in crisis centres. When resources are scarce and it becomes problematic to transport the victims, police officers may work with NGOs to transport victims and place them in shelters without this being part of their immediate obligations. Some crisis centres are funded by municipalities as part of government action plans, but it is clear that the scope of such services is not sufficient to provide care at the local and national levels.

While the State does not provide sufficient assistance to victims of domestic violence, non-governmental organisations with a high level of national activity work with women. The participation of the NGO sector in assisting domestic violence victims is substantial. In fact, specialised NGOs offer legal advice and representation - to the extent their resources and funding permit - to victims within proceedings for protection orders against DV.

Since 2009, the Ministry of Justice has financed projects by NGOs that involve specialised programmes for perpetrators and victims and work with the judiciary and police to monitor the implementation of the law, as well as publications. NGOs involved in countering DV take part in developing the National Programmes for Prevention and Protection against DV and are listed as major partners in each of them. They also exchange information and undertake common action with institutions. ${ }^{11}$ The NGOs' main role in assisting domestic violence survivors is to provide social services (crisis centres and other specific services, such as social, legal and psychological aid and support). They are involved in Prevention Centres, which are structures on the local level that are co-organised by the MI, municipalities and civic organisations and tasked with countering a number of unlawful acts, including domestic violence. Civic organisations also participate in ad hoc inter-agency structures at the local level. Examples include the Expert Council against DV in Silistra $^{12}$ and consultative councils with the mayor and regional governor of Pernik. The leading NGOs involved in countering domestic violence have formed an Alliance for Protection against gender-based violence. Since its establishment in

\footnotetext{
${ }^{11}$ For example, one of the most recent (September 2018) common initiatives was the implementation of the online platform EMPROVE to provide information and help to DV victims. Thanks to a personalised link, psychologists can communicate with subscribers while the latter can remain anonymous. The objective is to encourage women victims of DV to file a complaint. However, the results have been inconclusive due to the lack of direct human contact. Interview, Sofia, February 2019.

12 Silistra regional administration (2014). В Силистра властта и институциите с Експертен съвет срещу домашното насилие [Silistra authorities and institutions create Expert Council against Domestic Violence]. Silistra, Silistra Regional Administration.
} 
2009, the members ${ }^{13}$ of the alliance have provided interdisciplinary services to women victims of DV at eight locations in Bulgaria and worked on proposing legislation, monitoring the implementation of the legislation and training professionals. Each year, an average of 3,000 women request psychological support from these organisations.

In 2011, the Bulgarian Centre for Gender Studies Foundation in partnership with Animus Association Foundation implemented a project entitled "Disclosure and provision of a set of innovative services in the community to prevent and tackle social exclusion of adult victims of domestic violence in the cities of Sofia, Plovdiv and Dimitrovgrad!" It was funded through the Human Resources Development Programme 2007-2013 under the Social Services for Social Inclusion framework. Over the course of the project, the Animus Association Foundation developed an innovative programme for prevention and risk management related to the social exclusion of domestic violence victims - specialised work with families and couples.

The Animus Association Foundation offers a 24/24 helpline that is the most popular and accessible programme for survivors of violence. For many clients, the helpline offers the only opportunity they have for emotional support and understanding while retaining their anonymity. This service is for women who live in a situation of violence but are not ready to take the steps required to change it; women who have noticed the first signs of domestic violence and need consultation; women victims of violence who need assistance to make a decision. The helpline has a specialised assistance database that women can take advantage of when facing specific difficulties. In a crisis situation, following a recent occurrence of violence, the helpline consultants develop a security plan and refer the client to the Crisis Unit or to another appropriate programme. Most of the women call the helpline after instances of domestic violence, sexual violence or trafficking. The helpline also provides prevention information to young women planning to travel or work abroad and free legal consultations for women survivors of violence. A volunteer with a law degree gives these specialised consultations. The first contact with the centre is established through the helpline. This line was opened in October 1997, it receives on average more than 1,500 calls per year.

\footnotetext{
${ }^{13}$ Animus Association (Sofia), Demetra Association (Burgas), SOS - Families at risk (Varna), Bulgarian Gender Research Foundation (Sofia, Plovdiv, Haskovo), PULS (Pernik), NAYA Association (Targovishte), Ekaterina Karavelova Association (Silistra), Bulgarian Fund for Women (Sofia), Alliance for Protection against DV.
} 
In cities where there are active NGOs, agreements are signed between these NGOs and the courts to deal with perpetrators of domestic violence through appropriate programmes. These programmes are insufficient - they are only offered by five $\mathrm{NGOs}^{14}$ in the country. In addition, the Open Doors Association in the city of Pleven has ceased activity after 13 years of social work following a conflict with the municipality.

In cooperation with the Gender Alternatives Foundation, the Animus Association Foundation conducts periodic training seminars for social workers from community support centres. These two foundations also develop and publish a training manual for social workers. The website of the Animus Association Foundation provides access to "Sample standards and methodological instructions for working with domestic violence cases within the boundaries of community social services".

Police officers have been trained mainly by NGOs on DV issues and on supporting victims. For example, during 2016, more than 500 social workers, police officers and trainers were trained to handle cases involving DV. In 2016 and 2017, 180 police officers participated in three national training seminars on improving the legislative framework and harmonising with European standards in the field of DV. In addition, two training guides were published with the help of European experts.

The most common format is that of NGOs organising a training course lasting several days that brings together different types of stakeholders in the field of DV. This is particularly the case for the PULSE Foundation in Pernik, which regularly organises training courses with support from the Ministry of Justice. This type of seminar brings together police officers from the General Directorate of the National Police, the Regional Directorate of the Ministry of Interior (Pernik), social workers from the Social Assistance Directorate and the Child Protection Directorate of the small towns of Pernik, Radomir, Breznik and Tran, as well as representatives of the Regional Directorate of Social Assistance and family lawyers from the city of Pernik. Participants work together on DV cases, build role-playing games, share their professional experiences and work on the publication of a pocket guide for police

\footnotetext{
${ }^{14}$ Bulgarian Gender Research Foundation (Sofia), Demetra Association (Burgas), SOS-families at risk Foundation (Varna), Animus Association Foundation (Sofia), PULSE Foundation (Pernik)
} 
officers. The themes discussed are: different types of violence, perpetrator-victim relationships, crisis intervention and the effectiveness of intervention measures.

Generally, the participants are satisfied with this training format, but they highlight weaknesses that compromise the success of the training: Participants are not notified well in advance, and the police respond in a rather urgent manner to find participants. Consequently, the GDNP appoints police officers who oversee DV cases to participate in training organised by NGOs. The participants are often the same, and there are also police officers "subscribers" 15 at the training, which compromises the effectiveness of the knowledge and the know-how transmitted.

Even though professionals from institutions receive annual training in the field of domestic violence, there is no consolidated training programme to build capacity, skills and cooperation between different specialists on the topic of domestic violence. There is also no database of good practices, methodologies and recommendations.

Most of the funding for training programmes comes from European programmes, international projects and the Norwegian Financial Mechanism.

\section{Case study of PULS Foundation: good practices to deal with the State's failures in the fight against DV at local level}

In post-totalitarian Bulgaria, interpersonal links are more effective than interinstitutional relations, communication between public actors suffers from systemic difficulties and the oral tradition has a strong influence over the written culture. In this context, the non-governmental sector plays a pioneering role in the implementation of actions for the public good, in general, and policies for the protection of victims of domestic violence, in particular. Because of their organizational and operational flexibility, as well as their local roots and the support of national and international networks, NGOs have established themselves as actors of democratic change. The case of PULSE Foundation in the city of Pernik is an example of good practices built on individual initiative and personal involvement on international, national and local level. This NGO plays an important role in the

\footnotetext{
${ }^{15}$ Police Officer from General Directorate of National Police interview in Sofia, February 2019.
} 
protection of DV victims and thus helps to overcome the shortcomings of State policies in this area.

PULSE Foundation is registered in 1999 under the name "Animus" - Pernik to underline its relationship with the "Animus" Association in Sofia, which gave rise to the idea of creating a similar NGO outside the capital. Its goal is to promote a society based on non-violence and equality of the genders. Since the beginning of 2002, the organization continues its charitable activity under the name "PULSE" - "Positive Personal Skills in Society". Since its creation until today, PULSE continues to benefit from significant international support. Its most important aid provider was the GIZ (former GTZ) - Deutsche Gesellschaft für Internationale Zusammenarbeit. The Foundation was created by three young women which were working as therapists and all volunteering with a women's rights organization in Sofia, the capital of Bulgaria. They noticed that a large proportion of the telephone calls that they were receiving came from women in Pernik. That's what compelled them to create their own organization in Pernik. Their idea was to promote a society based on non-violence and equality of the genders. Its slogan is "The best way to fight violence is to create conditions where it won't happen".

The key factors for the success of the PULS Foundation's actions are: the commitment of its members - professionals and volunteers - and their support by national and international networks fighting against DV; the implementation of a wide range of actions aimed at priority categories of public; its role in steering the fight against DV at local level; the presence of specific people playing the role of specialized relays in the partner organizations; the sharing and processing of information within the partnership networks, as well as the effort to train stakeholders and produce knowledge.

The priority of PULSE Foundation is to create and affirm effective regional care programs for children, adolescents, adults and their families who have suffered or are at risk of violence. The service offers two types of activities- prevention and rehabilitation. The first one refers to the existing attitudinal and institutional biases in cases of domestic violence and child abuse, and adopts an educational approach and planning for community facilities. The second one refers to identified cases of violence and adopts an individual and family approach (Bassett ETZ AL. 2011). 
Thus, PULS offers its services to a wide range of categories of victims or perpetrators of domestic violence, seeking to specialize its effectiveness so that each case can be treated individually. The Foundation works with the following target groups; people, affected by physical, psychological or sexual abuse; victims or potential victims of violence or trafficking, or other forms of exploitation; children, living in dysfunctional families, with antisocial behaviour, homeless children and adolescents in hazardous environments; Roma community; drug addicts; adolescents and young people at risk; general public. Efforts are concentrated on helping the most physically threatened victims and the most dangerous perpetrators.

In the region of south-west, the PULSE Foundation and « Animus » are the largest organizations that have the capacity to shelter victims. They often work together especially regarding the creation of a Crisis center. A Crisis center was opened in 2008 within the building of the Foundation. It has been specially adapted to the rehabilitation program. The Crisis center is on the first floor near the rooms for psychological and legal consultations. The location is secured as well as it provides a safe environment for people in an acute danger. A group of specialists works with the abused to overcome their psychological traumas, provides them with support for official documents and assists their daily needs. The Crisis center provides a 24hour service.

The most developed partnerships - corresponding to projects in which PULS is a pilot or partner - pursue several targeted programmes simultaneously that address different problems such as, for example, domestic violence among migrants and refugees, protection of children and adolescents who witness violence, forced marriages and honour crimes. Each of these problems is handled by a dedicated team and benefits from the support of the actors involved and specific working groups.

Considering the inefficiency of the National Coordination Mechanism and National Program against DV, PULSE Foundation took the initiative to set-up a Regional Coordination Mechanism to work in cases of domestic violence. The Convention for cooperation between institutions and organizations in Pernik District was signed in December 2016: at the end of 16-day global campaign for action against DV all participants agreed on the idea of timely, adequate and coordinated assistance to victims. The partners in this agreement are: Municipality of Pernik, Child Protection 
Department- Pernik, Social Assistance Directorate- Pernik, Regional Police Directorate- Pernik, District Court- Pernik, Regional Inspectorate in EducationPernik, Regional Inspectorate for Public Health Control- Pernik, KABKIS (Room for Free and Anonymous Consulting and Examination of HIV/AIDS)- Pernik, Hospital "Rahila Angelova", Bulgarian Red Cross. Two and a half years after the implementation of this agreement, the results do not quite match expectations at the time of signing.

Since the establishment of the Regional Coordination Mechanism, PULS tries to organize two meetings per year with the signatories. These consultation meetings are crucial in the fight against DV because the partners have to agree on how to respond effectively to concrete cases of DV. The inter-professional dialogues make it possible to build a common vision of situations and to develop joint operational solutions. During these processes, the participants accept the external viewpoint of the other partners, but the question of control from another institution remains thorny. One of the reasons for this is the weak assessment culture within the institutions. Indeed, the assessment of weaknesses and strengths is not part of the internal paradigm of public actors. As a result, some partnerships - e.g. with hospitals - find it more difficult to adopt a constructive approach to agree on the treatment of DV cases. According to the testimonies of PULS members, progress has nevertheless been made as emergency departments are dealing with DV cases in a more discerning and prompt manner.

Not all partners who support PULS in the collaborative arrangement adhere to the coordination initiatives with the same level of commitment. The attention paid by the police to DV issues increases over time, but local police see the Law for Protection against DV as secondary. In order to better protect victims, police officers consider that actions in case of DV should be included in the police's internal regulations. In fact, the chain of assistance for victims is sometimes broken at the first contact with the police, both for reasons related to the difficulties inherent in the functioning and the recent past of this institution. Due to endemic corruption, the opinion that services for disadvantaged people are deficient compared to those for influential people with relationships predominates. Concerning the interactions with the judicial system the members of PULSE deplore the impossibility of shortening judicial delays, which leads victims renouncing to continue the process. 
PULS is hindered in its actions by the fact that not all the partnership relays have a high status or adequate resources allocated by the respective organizations. For example, within the police, the regional coordinator of actions against DV does not have autonomy of action or particular influence with his management. The reason for this is the absence of an internal police regulation that gives prerogatives to police officers specialized in DV issues. For their part, the police officers in charge of the DVs do not have any specific devices to facilitate their tasks or encourage them in the exercise of their duties. On the other hand, these police officers are disappointed by the long time it takes for investigators to gather all the evidence required by the prosecutor. The prosecutor is not inclined to pay particular attention to DV cases. Its involvement in the Regional Coordination Mechanism does not show any specific engagement. Collaboration with the Police and the Prosecutor's Office is also more difficult because the focal points have no leverage to ensure that their institution complies with the commitments of the Regional Coordination Mechanism.

The PULS Foundation is one of the first regional organizations to be contacted by both victims and institutional partners in cases of DV. It has a database of all persons - victims or perpetrators of domestic violence - who have used its services. The data is collected by means of forms filled in each time a person is received by the Foundation. As the Foundation has been developing its activities for more than twenty years, these data are sufficiently complete to represent an operational tool at regional level. In the best of cases, it allows us to quickly identify people who are at risk and to evaluate the strategies to be adopted in order to shelter them in case of reported violence. If, on the other hand, the person in question is not known to the Foundation, the latter can contact the regional police to broaden its search.

The first contact with DV victims is quick and effective. PULSE Foundation operates his hotline (+359 7660 1010), it can be contacted also via e-mail. Women at risk and social workers from the whole country call the number for legal, psychological and social assistance. PULS remains one of the few possibilities to accommodate DV victims because, overall, Bulgaria does not fulfil the Council of Europe Recommendation of safe accommodation in specialised women's shelters. 
The fight against DV and in particular PULSE's actions are put in difficulty by the insufficient awareness and training of front-line officers in dealing with DV. In particular, this is the case for the local police hotline. A single agent handles all calls and has to deal with six phones on his own. Therefore, he or she cannot handle all calls, especially at peak times during weekends and holidays. Fot this reason, certain emergency cases do not receive an adequate response. The situation at times of many calls can quickly become impossible to control when the duty officer does not have much experience and lacks appropriate training. Our request to observe the work of this call centre over a weekend was not approved by the local police chief.

\section{Conclusions: main challenges and issues}

The most important reforms in post-communist Bulgaria came through the action of foreign actors, especially following pressure from the European Council to meet EU standards. As a matter of principle, the country's problems have been received effective solutions when recommendations from international organizations served as a sounding board for the agenda of national stakeholders.

However, in the field of protection against domestic violence, a majority of the population adhering to "traditionalist values" hardly conceals their feelings of homophobia and intolerance towards "negative practices" from Europe. The decision of the Constitutional Court on July 27, 2018, proclaiming the unconstitutionality of the Istanbul Convention was the paroxysm of this atmosphere marked by the rift between two opposing social visions of family values. Civil society defending women's rights qualified this decision as "the worst decision of the Constitutional Court in its history".

Currently, institutions and people involved in the DV processing chain are in fact working as part of an already well-defined mechanism, but there are significant gaps in its operational functioning. The main cause remains lack of political willpower to build a sustainable framework for the care of victims and perpetrators of violence. This is also one of the main reasons why there is no evaluation of the state of domestic violence or procedures to assess particular situations from the point of view of the risks incurred by the victims. Furthermore, the chain of assistance for victims is often broken at the first contact with the police, both for reasons related 
to the recent communist past and the difficulties inherent in the functioning of this institution.

In such a hostile environment, the work of frontline responders to DV is made difficult by several reasons. The lack of a national data base of registered cases of domestic violence is seen by police authorities as substantially hampering their work in the area. There are local exceptions where the police establish their own database but the benefits remain limited. Another difficulty comes from the lack of structures of safe accommodation in specialized women's shelters. At the national level, only six crisis centers managed by NGOs are operational.

On the national level NGOs working in the area of protecting and assisting victims of domestic violence, make several recommendations:

- Awareness raising and education should be done among all stakeholders, including police and courts, about the specificities of domestic violence and their own powers in protecting its victims;

- Swift communication should be existing among institutions, preceding official correspondence, so that timely co-ordination takes place;

- Directors of local Social Protection Directorates should use their powers to initiate proceedings for issuing protection orders for each case of domestic violence against children, persons under legal guardianship and persons with disabilities;

- When urgent reaction is needed, especially regarding children victimized by domestic violence, the specific law on domestic violence should have priority over other legislation, because it allows for a swift protection procedure, while long-term measures can be devised later;

- It is sufficient that there has been at least one previous case of violence to initiate criminal proceedings. And in serious cases - beating, medium and serious bodily injury, it should not be examined whether there have been previous cases in order to initiate criminal proceedings;

- Risk assessment should be part of a broad training and enforcement effort in the field of DV;

- Systematic monitoring of the implementation of the specific law on domestic violence should be in place. 
The most important recommendation of national police officers concerns the establishment of social workers within the Police to improve the reception of victims of DV and help police officers in the long-term assistance of those cases.

\section{References}

Ivanova, S. (2016). National Study on Domestic and Gender-Based Violence in Bulgaria Analytical. Sofia, Partners Bulgaria Foundation.

Bjørnsen, G., Nesheva, E., \& Ilcheva, M., (2015). National Study on Domestic and Gender-Based Violence and Elaboration of a Victims Support Model: Legal, Institutional and Policy Analysis. Sofia, CSD.

Ilcheva, M. (2018). Mapping the Legislation and assessing the impact of Protection Orders in the European Member States. Sofia. CSD.

Nesheva, E., Kolarova, D., \& Minkovski, R. (2016). Domestic and Gender-Based Violence: Victims Support Model. Sofia, CSD.

Tisheva, G. (2005). The Law on Protection against Domestic Violence - A Breakthrough in the Division between Public and Private Sphere in the Protection of Human Rights in Bulgaria. Legal Thought, 2, 112-122.

Dimova, R., Kmetova, T. \& Alii. (2015). In Response to Violence Against Women: a Guide for Companies against Gender Violence. www.carve-daphne.eu

Avon Womens Foundation. (2019). National bigh school survey on violence against women. https://www.avon.bg 


\title{
FRONTLINE RESPONSE TO HIGH
} IMPACT DOMESTIC VIOLENCE IN

\section{FINLAND}

\author{
MartTa October,,${ }^{1}$ Marianne Mela,, 2 Suvi Nipuli ${ }^{1} \&$ \\ JARMO HOUTSONEN ${ }^{2}$ \\ ${ }^{1}$ Finnish Institute for Health and Welfare Finland, Helsinki, Finland. \\ E-mail: martta.october@thl.fi,suvi.nipuli@thl.fi \\ 2 Police University College of Finland, Tampere, Finland. \\ E-mail: marianne.mela@poliisi.fi, jarmo.houtsonen@polamk.fi
}

Abstract Finland is committed to the Council of Europe Convention on preventing and combatting violence against women and domestic violence (Istanbul Convention). The Convention entered into force in Finland on August 1st 2015. The Current Government Programme of the Prime Minister also includes several initiatives to better combat domestic violence. In 2020, 10,800 incidents of domestic violence and intimate partner violence offences were reported to the authorities. The number of reported offences decreased by 1,2 per cent from 2019. Among all the adult victims of domestic violence and intimate partner violence, 75.2 per cent were women, whereas 78.1 per cent of suspects were men. In 2020, there were in total 29 shelters for victims of domestic violence in Finland. There are several NGOs supporting victims of domestic violence and providing perpetrator programmes in Finland. When discussing the good practices of cooperation, 'Anchor' ('Ankkuri') teams shall be mentioned. 'Anchor' teams are multi-agency teams working in several police departments in Finland. These teams often consist of police officers, social workers, and psychiatric nurses. The Anchor model supports the well-being of children and adolescents and prevents juvenile crime and violent radicalisation.

Keywords: domestic violence, Finland, interagency cooperation, victims, police, NGO 


\section{Description of country}

The Republic of Finland has about 5.5 million inhabitants in an area of $338,455 \mathrm{~km}^{2}$. Although increasing global economic competition, an ageing population and budget deficits have posed serious challenges to the sustainability of public policy, Finland still follows a Nordic welfare state model that endorses citizens' universal social rights to health, education and social care. The Nordic model of risk-sharing involves a relatively large public sector with the welfare benefits and services mainly financed by taxes. The responsibility for organising social and health services lies with local government, the municipalities. Yet, the state is just one provider of social and health services, which are also provided by private businesses and non-governmental organisations (Kettunen, 2014).

Finland has a unified national police force (Devroe \& Ponsaers, 2017). The police are accountable to the central government that sets the general objectives and allocates finances for it. The Ministry of the Interior controls the National Police Board (NPB) directed by the National Police Commissioner. Performance management goes down from the ministry, via the NPB to local police. First, the ministry sets strategic priorities, targets and indicators. Then, the NPB negotiates annual performance contracts with the 11 local police districts. The local police districts maintain strong cooperative relations with other public agencies and with important private and civic society partners at a local and regional level. Various stakeholders are specifically brought together around local and regional safety and security planning (Virta \& Taponen, 2017). In addition, the police, health care, social care, and non-governmental organisations can cooperate around a few selected topical issues such as domestic violence prevention, discrimination, and social marginality.

Finland is committed to the Council of Europe Convention on preventing and combatting violence against women and domestic violence (Istanbul Convention). The Convention entered into force in Finland on 1 August 2015.

The Current Government Programme of Prime Minister Sanna Marin also includes several initiatives to better combat domestic violence. According to the Programme, the Government will safeguard the implementation of fundamental and human rights and tackle violations of people's rights. 


\section{Legislation regarding domestic violence}

\section{Domestic violence in the Criminal Code (1889/39)}

Many forms of actions that are commonly regarded as domestic violence in research literature and international policy documents are not defined as specific criminal offences in the Criminal Code of Finland. Furthermore, some forms of violence such as oppression and psychological violence may be difficult to prove in court, because often it is one person's word against another and the causal link between the actions of the perpetrator and the impairment of mental health of victim requires evidence to stand in court. However, active intervention in and prevention of domestic violence requires the police to be able and motivated to identify all forms of domestic violence in order to manage the types and sources of risks that may lead to or trigger violence. Risk assessment should be done in close cooperation with the social and health care sector agencies and the relevant NGOs.

\section{- Physical violence}

Different forms of physical violence are criminalised in the Criminal Code (e.g. assault, killing, homicide, murder, negligent bodily injury, negligent homicide, imperilment, endangerment of health and abandonment). In 2014, the new offence of 'Preparation of an aggravated offence against life or health' was inserted into the Criminal Code.

All physical violence is subject to public prosecution even if the offender is a family member or ex-family member of the victim. Petty assaults occurring in close relationships and against children have been subject to public prosecution since 2011. This means that the police do not have discretion over filing a criminal offence report when suspecting physical domestic violence.

\section{- Coercive control}

Many forms of domestic violence are covered in the Criminal Code but it is unclear how often the detectives identify these forms in the preliminary investigation. For instance, coercive control, defined as an act or a pattern of acts of physical violence, threats, humiliation and intimidation or other abuse (Kelly \& Johnson, 2008) can be hard to identify and prove. There is not yet academic research in Finland on how 
effectively cases of coercive control occurring in intimate relationships such as 'eavesdropping', 'illicit observation' or 'deprivation of personal liberty' have been identified in police investigations and later dealt with in the courts.

\section{- Psychological violence}

Psychological violence is not a specific offence in the Criminal Code but, if psychological violence has caused the victim physical injuries or mental health issues, psychological violence can be prosecuted as an 'assault' in court. Yet, this is not very common since the intended negative consequences of psychological violence towards one's physical health are difficult to prove. However, some illegal acts that may be used as tools of psychological violence are criminalised, such as disseminating private information, violating personal privacy, menace, stalking, coercion, defamation, and invasion of domestic premises.

\section{- Economic violence}

Additionally, economic violence is not a specific offence. Acts like fraud, criminal damage, extortion, identity theft and human trafficking are criminalised. If economical violence takes the form of restricting access to financial resources, education or the labour market, or not complying with economic responsibilities (EIGE, 2017), the judicial system may have difficulties in responding effectively to this type of abuse.

\section{- Forced marriage}

In 2019, the Finnish Parliament adopted changes to the Marriage Act (234/1929) and repealed the exception that under-aged persons could marry with special approval from the Ministry of Justice. The purposes of the changes are to protect children and limit the risk of forced marriages. Even if forced marriage is not a specific offence, it is illegal in Finland and may be considered as human trafficking or compulsion. 
Article 32 of the Istanbul Convention requires that "marriages concluded under force may be voidable, annulled or dissolved without undue financial or administrative burden placed on the victim". The aim of this provision is to ensure that, where women and girls free themselves from marriages concluded without their free consent, they do not have to bear any consequences regarding their civil status. GREVIO's country report on the implementation of the Istanbul Convention of Finland (2019) noted that Finland should review the criminal offences of rape, sexual violence, stalking, sexual harassment and forced marriage to increase the probability of prosecutions and to align them more closely with the requirements of the Istanbul Convention. Furthermore, GREVIO encouraged the Finnish authorities to incorporate into the relevant legislative act(s) the possibility of voiding, annulling or dissolving marriages concluded under force.

\section{- Female Genital Mutilation (FGM)}

Although there is no specific criminal offence to cover female genital mutilation, there is a general agreement that the act of FGM falls within the scope of (aggravated) assault.

The Istanbul Convention requires the criminalisation of behaviour that involves the intentional exertion of influence on a girl who herself does not have the intention of undergoing FGM. The aim of the article is to ensure that criminal liability ensues, for example where relatives or community members incite, coerce or procure a girl to undergo FGM but do not take an active part in ensuring that the procedure is carried out. In its country report on Finland (2019), GREVIO noted with concern that very few reports of cases of FGM have been made, none of which have led to prosecution.

In 2019, a citizen's initiative was launched to place the question of introducing a specific criminal offence of FGM on the parliamentary agenda. In 2020, the Legal Affairs Committee of the Parliament passed a Committee Report on a citizen's initiative supporting the passing of specific criminalisation of FGM. 


\section{- Sexual offences}

In general, criminal acts regarding sexual offences reflect societal attitudes about sexual norms and limits. In principle, Finland can be identified as one of the Nordic countries where more liberal gender norms give women more freedom to fulfil their sexuality based on their own needs. However, usually it has not been until a few decades later that Finland has followed the amendments that more equal Nordic countries such as Sweden have previously passed. As an example, Finland was one of the last countries in Europe to make rape in marriage a crime.

Sexual violence is criminalised in the Criminal Code covering rape offences, coercion into a sexual act, sexual abuse and sexual abuse of a child. In the act currently in effect, the offence of rape is not based exclusively on the lack of consent, which is the central element in the way the Istanbul Convention frames sexual violence. Rape is currently categorised according to the degree of physical violence used or threatened by the perpetrator. Alternatively, there is a requirement to show that the victim was in a state of fear or helplessness and unable to defend herself or to formulate or express her will. This formulation has been criticised for not capturing the realities of how (mostly) women experience sexual violence and how they respond to threat.

The principle established by the Istanbul Convention is that all sexual acts without the consent of the victim must give rise to reprimanding sanctions. Therefore, GREVIO (2019) strongly encouraged Finland to speedily reform all sexual offences contained in Chapter 20 of the Criminal Code, and to incorporate the notion of freely given consent as required by Article 36 of the Convention. Furthermore, Finland should ensure appropriate sanctions for all sexual acts without the consent of the victim, including where the circumstances of the case preclude valid consent.

Currently, in 2020, Finland is undergoing a complete reform of the whole Chapter 20 of the Criminal Code regarding sexual offences. This is largely being influenced by the public debate(s) and the changing of attitudes towards sexual crimes, but also due to the criticism and pressure received from international legal sources such as GREVIO. The reform will base the new definition of rape on the lack of consent. 


\section{The Social Welfare Act (1301/2014)}

The current Social Welfare Act entered into force in April 2015. It emphasises the timeliness of assistance, improves the basic services and reduces the need for reparative measures. The act strengthens the right of families with children to services that support their ability to cope with daily life. These include services such as home-help services, family work, support persons and families and peer group activities. With regard to domestic violence, the act strengthens the victim's right to all services necessary due to a need created by having experienced domestic violence and its consequences, such as dwelling and livelihood.

\section{The Child Welfare Act (417/2007)}

The Child Welfare Act determines regulations concerning child welfare and applies to all children who live in Finland. The applicability is not dependent on their nationality, religion or culture. According to the law, all children are entitled to a safe and stimulating living environment, balanced and diverse development and special protection. Since 2015, notwithstanding secrecy provisions, the authorities working with children and families have been obliged to submit a child welfare notice if they are concerned about a child's wellbeing.

\section{Reporting rates of domestic violence}

In 2020, there were 10,800 incidents of domestic violence and intimate partner violence offences reported to the authorities. The number of reported offences decreased by 1,2 per cent from 2019. Among all the adult victims of domestic violence and intimate partner violence, 75.2 per cent were women, whereas 78.1 per cent of suspects were men. The suspect was also male in one-third of cases where the victim was a male. These numbers include only incidents that have been reported to the authorities (Statistics Finland, 2021).

In 2018, emergency response centres received about 26,000 emergency calls to homes because of domestic violence. In that year, only about 5,500 domestic violence crimes were filed (PolStat, 2020). Not all the cases referred to the police from the emergency centre as domestic violence cases always relate to actual domestic violence. However, this gap and other evidence such as victim surveys 
suggest that some domestic violence remains unidentified by the authorities. According to the studies, only 10 per cent of the most serious incidents of violence in the intimate relationships is reported to the police in Finland (FRA, 2014).

\section{The role of the police, other front-line and first-responder agencies and pertinent stakeholders in responding to high-impact domestic violence}

\section{Police}

Uniformed police officers are often the first responders encountered by a victim of domestic violence. For the police, domestic violence call-outs are the most common sources of information about violence in close relationships (Fagerlund, 2016). In 2011, the Criminal Code was reformed to give a clear message that even milder forms of violence in close relationships are unacceptable. Through the reform, all forms of assault in close relationships including petty assaults became subject to public prosecution. The aim of the reform was to ensure that domestic violence cases that at first may appear mild are also investigated and not to hold the victim responsible for reporting the offence. The police should record the offence immediately, and collect and document the necessary evidence in every case immediately (Fagerlund et al., 2020).

In a domestic violence case, uniformed police officers intervene and often interrupt the unlawful activity, question the parties, collect the evidence and file a report. The uniformed police officers also inform Child Welfare if there are minors in the family, or report a need for social welfare services if they are concerned about the ability of an adult client to cope. The uniformed police officers also apprehend the suspect based on the Police Act (872/2011) or Coercive Measures Act $(806 / 2011)$ depending on the seriousness of the crime or the risk of continuation or recurrence of violence.

The police have a duty to conduct a preliminary investigation without undue delay when there are grounds to suspect that a crime has been committed. During the preliminary investigation, the police will interrogate the victim, the suspect and any witnesses. The police will also collect evidence (e.g. various statements such as a doctor's statement, photographs and the results of technical investigations). Detective chief inspectors and detective superintendents manage investigation units 
and decide about the use of coercive measures. The Pre-Trial Investigation Act (805/2011) regulates the principles concerning preliminary investigations and the Coercive Measures Act (806/2011) regulates the use of and the prerequisites for the use of coercive measures.

During the preliminary investigation, the police have a duty to assess the victim's special needs for protection and the required protection measures. These protection measures can include that the questioning may be conducted by the same person or by a person of the same gender as the victim. In the trial, the victim may be heard behind a screen, via video link or without the dependant or public being present, or the interrogation of the victim may be video-recorded.

The Criminal Investigations Act (805/2011) requires preliminary investigation authorities to tell the victim about his/her rights in terms of support services, advice, interpretation and translation, compensation, protection, reimbursement of costs and information on the handling of the case in criminal proceedings (Victim Support Finland, 2020). With the victim's consent, the police can provide Victim Support and other support services with the victim's personal data.

Victims have a right to have a lawyer and a support person present at the questioning and at the trial. The presence of a lawyer may help the victim to perform better in the questioning. Victims of domestic violence can often be provided with a lawyer paid for by the state. The support person service of Victim Support Finland is always free for the victims and witnesses.

After the investigation is closed, the detectives prepare the record of the pre-trial investigation. The record includes the official interview records and collected evidence. The record of the pre-trial investigation is submitted to the prosecutor for consideration of charges or for issuing a fine. Alternatively, the police may close a pre-trial investigation without submitting the case to the public prosecutor, if the investigation shows that no offence has been committed. 


\section{Health care}

In Finland, 7 per cent of emergency department patients have reported recent and 20 per cent lifelong domestic violence (Notko et al., 2011). Domestic violence is seriously unrecognised in emergency care, with the result that victims are likely to suffer from a wide range of mental and somatic health issues and to make repeated visits to emergency departments and other medical services (Siltala et al., 2020).

The majority of domestic violence victims are likely to remain unidentified in the day-to-day practices of health care and those who are identified have typically already suffered several assaults (Leppäkoski et al., 2011). Currently, it seems that the identification of domestic violence in emergency care is based on external and visual injuries, and it fails to account for the majority of victims who have other issues like obstetrical and gynaecological complaints, pain and mental health problems. Very few emergency departments have routines to identify victims, so patients experiencing domestic violence are systemically unrecognised in medical settings (Siltala et al., 2020; Tampere University Dissertations, 2020).

In health care, the documentation of domestic violence is also variable. The documentation of injuries, evidence collection and reports are not always consistently high-quality. The documentation of domestic violence in health care is inadequate. The proper ICD10 perpetrator codes are used poorly, and the codes used do not always match to the content of the patients' medical records. The proper use of ICD-10 coding would help victims, health care professionals and researchers in the detection, treatment and prevention of domestic violence (Tampere University Dissertations, 2020).

Assessment by healthcare professionals in forensic documentation and interpretation of injuries can result in a number of benefits for the victims and positive court outcomes, including an increase in the rate of successful prosecutions. Multidisciplinary collaboration between health care, police, legal and social service professionals is needed to provide comprehensive care and support (Tampere University Dissertations, 2020). Universal screening of domestic violence is needed due to the prevalence of the problem. 


\section{Social work and shelters}

According to the Social Welfare Act (1301/2014), a municipality must arrange social services to support those who have experienced domestic violence or other forms of violence or abuse. The shelter is a home-like environment where victims find refuge from violence and where they get help to stop the violence, free of charge. In 2020, there were in total 29 shelters for victims of domestic violence in Finland. The shelters could accommodate 211 families or clients who come alone. Shelter services are state-funded special services defined in legislation for people who have experienced acts or threatened acts of domestic violence. For many clients, the domestic violence started long before coming to the shelter. For 35 per cent of clients in shelters over the age of 15 , the violence had been going on for between one and five years.

The number of clients in shelters during 2020 was 5,244 2,929 of whom were adults and 2,311 children. About 92 per cent of the adult clients were female and 8 per cent male. Victims can go to shelter either on their own initiative or on referral. Of the clients, 42 per cent came to the shelter on their own initiative, 27 per cent were referred by Social Welfare, 6 per cent by the police and 4 per cent by health care.

Victims of violence get support, guidance and counselling from professionals at the shelter as well as assistance and information for dealing with practical arrangements. The staff at the shelter explore together with the client what measures of support he or she will need after their stay in the shelter. Where necessary, the staff will also collaborate with the municipality and other service providers. The municipality is responsible for providing community care for those of its residents who have experienced domestic violence, as well as for arranging support after clients leave the shelter.

Shelters are run by municipalities or NGOs. The staff of the shelters are salaried, trained professionals. The Finnish Institute of Health and Welfare (THL) is responsible for the steering, assessment, development and national co-ordination of the shelters. The number of clients has been growing since 2015 when the shelter services became state funded. Since 2015, the number of clients has grown by 72 per cent. 


\section{NGOs}

There are several NGOs supporting victims of domestic violence and providing perpetrator programmes for perpetrators in Finland. For example, the Helsinki Shelter Association offers shelter services as well supported accommodation for adults and children who have experienced violence. Additionally, the organisation has a Counselling Unit for the victims and perpetrators of domestic violence.

Some of the NGOs are specialised in supporting victims of stalking (Varjo), sexual violence (SERI Support Center, Tukinainen) or religious violence (Uskontojen uhrit ry). Suvanto ry supports elderly people who have experienced domestic abuse. Some NGOs provide assistance for immigrant women and children who have experienced violence (e.g. MONIKA) or prevent honour-related conflicts in families (SOPU work, DIDAR). There are also several NGOs offering treatment programmes for perpetrators (e.g. Jussi-work, Maria Akatemia).

In this chapter, we present the work of three NGOs in order to give a concrete description of the indispensable work being done by NGOs. However, it must be strongly stressed that there are several organisations working successfully in the field of domestic violence and they all merit being presented in this chapter.

RIKU (Rikosuhripäivystys - Victim Support Finland) is a member of the European umbrella organisation, Victim Support Europe (VSE), advocating on behalf of all victims of crime. In 2017, the Ministry of Justice decided to issue a public service obligation to Victim Support Finland for providing general victim services in Finland during 2018-2027. These services are available free of charge and confidentially in accordance with the needs of the victim and the family members of the victim. The services are available before, during and for an appropriate time after criminal proceedings (Victim Support Finland, 2020).

RIKU's main operation is to improve the position of victims of crime by influencing and producing support services. RIKU offers practical advice and psychological support for those who have become a victim of crime or attempted crime, their family members and witnesses of criminal cases. RIKU helps victims of crime operate according to their rights and supports them in coping with the experience of crime. Services are provided as national telephone and online assistance services, 
as well as personal services at 30 service points around Finland. The operations are based on professionally guided voluntary work. Statements given on the position and needs of victims of crime, training, communication and participation in public debate also number among RIKU's main operations (Victim Support Finland, 2020).

MONIKA - Multicultural Women's Association is an umbrella organisation of multicultural women's NGOs developing and offering specialised services for immigrant women and their children who have been subjected to domestic violence, honour-related violence, forced marriage or human trafficking. MONIKA Multicultural Women's Association acts as an expert organisation and advocate in issues related to ethnic non-discrimination and violence. This NGO also promotes integration by supporting civic society activities for immigrants (Monika-Naiset liitto ry 2020).

Loisto Setlementti SOPU work aims to prevent honour-related conflicts and violence in families and communities. SOPU works with youth, families and communities to resolve conflicts that relate to honour. SOPU organises group activities, camps and peer support activities, and provides confidential support to individuals and families in honour conflict situations. As an example of good practice, SOPU arranges low-threshold meetings where the client can talk with an HRV-specialised police officer. SOPU also offers training in honour-related topics for various professionals including police officers.

\section{Good practices of co-operation}

\section{Anchor teams}

'Anchor' teams are multi-agency teams working in several police departments in Finland. These teams consist often of police officers, social workers and psychiatric nurses. The composition and involvement of handling domestic violence cases varies in different locations.

The Anchor ('Ankkuri') model supports the wellbeing of children and adolescents and prevents juvenile crime and violent radicalisation. At some police stations, the Anchor model is also used to prevent domestic violence by intervening in incidents at the earliest possible stage and by referring the parties involved to relevant support services. 
The Anchor model is based on multi-agency cooperation involving different public authorities to work together at police stations. The social sector workers and the nurses are municipal employees. The staff cooperate closely as a team, each bringing to the team their professional competence, support and expertise in their own background organization.

Multidisciplinary cooperation based on an agreement and managed locally, regionally and nationally makes it possible for professionals to serve the customer in a holistic manner based on the 'one-stop shop' principle. The benefits of this holistic approach and multi-agency co-operation are evident in challenging situations where the customer suffers from multiple problems like intimate partner violence, homelessness, substance addiction and mental disorder. If the customer agrees, the Anchor team exchanges information with the police, social work and health care agencies. The exchange of information is simple when the customer has children, because the cooperation can be justified by the child's interests without asking for the customer's assent. On the other hand, childless couples who do not want to receive assistance from the Anchor team tend to fall through the service net.

\section{Specialised domestic violence investigation teams}

Some police departments have individuals and/or teams specialised in investigating domestic violence cases. During the field study of IMPRODOVA, we examined one of these investigative teams. This particular team is presented as an example of good practice in this subsection.

The Domestic Violence investigative team investigates all crimes that have occurred in intimate relationships, such as assaults, (attempted) homicides and kidnapping. Intimate relationships include family relationships, existing intimate relationships, ex-spouses and people who have a personal bond (e.g. a common child).

Investigative teams specialised in domestic violence have contributed significantly to several positive outcomes. Specialising in one particular type of crime has developed highly skilled detectives and provided an opportunity for motivated people to apply for a job in the Domestic Violence investigative team. These detectives are specialists who understand domestic violence as a problem with links to various psychological, social, economic and legal issues. They know, for instance, 
how to approach a victim and a suspect to build trust, how to motivate the person to talk about their situation and to accept assistance.

Specialisation in domestic violence investigation facilitates the work of the detectives in keeping up and maintaining professional networks with, for example, support services. Good networks make effective service counselling possible, when the detectives have good connections to different governmental and non-governmental services.

\section{MARAC - Multi-Agency Risk Assessment Conference}

A Multi-Agency Risk Assessment Conference is a tool to identify and assess the risks of domestic violence and to manage the sources of risks. The MARAC method consists of 1) risk assessment and referral to an MARAC meeting, 2) sharing information between the agencies, 3) drawing up a personal safety plan and 4) monitoring the victim's situation. The MARAC questionnaire can be filled in by any public official to whom the victim turns for help. The MARAC team may consist of professionals from several service organisations such as the police, social services, victim support services, health care professional and child welfare services. The participants discuss and exchange views about each victim's situation and create an action plan to improve their safety. With the victim's consent, the participants can exchange information in order to be able to manage the sources of identified risks systemically. Currently there are more than 30 MARAC teams operating in about 90 Finnish municipalities (Rikoksentorjunta.fi, 2020).

\section{The main challenges}

Domestic violence is a serious public health issue is Finland. From the perspective of the authorities, domestic violence is also a largely hidden crime. Effective intervention and prevention of domestic violence require the authorities to have skills in identifying the different forms of violence, to share a clear understanding of the different roles and duties of the other actors and to have secure resources and structures for inter-professional cooperation. Domestic violence is a serious problem (Rittel \& Webber, 1973) that cannot be solved by the police alone, but attitudes towards the significance of domestic violence as a problem and the means of intervening pose a challenge to inter-professional cooperation (cf. D'Amour \& 
Oandasan, 2005). Additionally, in the changing field of service systems, serious problems such as domestic violence are often overlooked in favour of tasks that are more easily managed (Niklander et al. 2019).

One of the main challenges in the professionals' work related to domestic violence is the lack of training among the police, social work and health care professionals. A recent study (Niklander et al. 2019) shows that 27 per cent of frontline responders had received no training as part of their degree programme and 48 per cent had participated in lectures that had taken more than hour but less than days. Additionally, 35 per cent of the frontline responders had received no training as part of their professional in-service training. The lack of training may be one of the reasons explaining the ineffective intervention and prevention of domestic violence among professionals. The limited understanding of the forms and nature of domestic violence, and of the methods of how to intervene in complex issues (e.g. the lack of risk assessment tool designed for uniformed police officers) may also be connected to the frustration and victim-blaming attitudes observed among some individual professionals. However, blaming the under-resourced frontline responders who work at grass-roots level for being un-trained or working without adequate risk assessment tools is unreasonable. To improve the current situation, the focus should also be on levels of policy and management and the allocation of resources.

\section{References}

Child Welfare Act. (2007). Official Gazette of Finland, 417/2007. https://www.finlex.fi/en/laki/kaannokset/2007/en20070417_20131292.pdf

Council of Europe. (2019). GREVIO's Baseline Evaluation Report. https://rm.coe.int/grevio-report-onfinland/168097129d

Criminal Code of Finland. (1889). Official Gazette of Finland, 39/1889, amendments up to 766/2015 included. https://finlex.fi/fi/laki/kaannokset/1889/en18890039_20150766.pdf

D'amour, D. \& Oandasan, I. (2005). Interprofessionality as the field of interprofessional practice and interprofessional education: An emerging concept. Journal of Interprofessional Care, (19), 8-20.

Devroe, E. and Ponsaers, P. (2017). European national police systems and metropolitan realities. In Devroe, E., Edwards, A. \& Ponsaers, P. (Eds.), Policing European Metropolises (pp. 23-74). Routledge.

European Institute for Gender Equality. (2017).Glossary of definitions of rape, femicide and intimate partner violence. https:// eige.europa.eu/publications/glossary-definitions-rape-femicide-andintimate-partner-violence

European Union: European Agency for Fundamental Rights (FRA). (2014).Violence against women: an EU-wide survey. https://www.refworld.org/docid/5316ef6a4.html 
Kelly, J. B., \& Johnson, M. P. (2008). Differentiation among types of intimate partner violence: Research update and implications for interventions. Family Court Review, (46), 476-499.

Kettunen, P. (2014). Conflicts and compromises in the Nordic pattern of social regulation. In Kettunen, P., Kuhnle, S. \& Ren, Y. (Eds.), Reshaping Welfare Institutions in China and the Nordic Countries (pp. 96-121). NordWel Studies in Historical Welfare State Research 7.

Leppäkoski, T., Paavilainen, E. \& Åstedt-Kurki, P., (2011). Experiences of emergency care by the women exposed to acute physical intimate partner violence from the Finnish perspective. Int. Emerg. Nurs., 19(1), 27-36. https://doi.org/10.1016/j.ienj.2010.02.006.

Monika-Naiset liitto ry. (2020). Homepage. https://monikanaiset.fi/

Niklander, E., Notko, M. \& Husso, M. (Eds.). (2019). Intervening in domestic violence and training of professionals in social services and health care and the police: Evaluation of the EPRAS project. Helsinki: National Institute for Health and Welfare.http://urn.fi/URN:ISBN:978-952-343-413-4

Notko, M., Holma, J., Husso, M., Virkki, T., Laitila, A., Merikanto, J. \& Mäntysaari, M., (2011). Lähisuhdeväkivallan tunnistaminen erikoissairaanhoidossa [Encountering domestic violence in specialist health care]. Lääketieteellinen Aikakauskirja. Duodecim, 127(15), 1599_ 1606.

Poliisin tulostietojärjestelmä PolStat. (2020). Perheväkivaltatehtävät. Personal communication, Vesa Leppänen.

Rikoksentorjunta.fi. (2020). Marac. https://rikoksentorjunta.fi/en/marac

Rittel, H. and Webber, M. (1973). Dilemmas in a general theory of planning. Policy Sciences, 4(2), 155169.

Siltala P., Kuusinen-Laukkala A. \& Holma, JM. (2020). Victims of family violence identified in emergency care: Comparisons of mental health and somatic diagnoses with other victims of interpersonal violence by a retrospective chart review. Preventive Medicine Reports, 19, 1-7. doi: 10.1016/j.pmedr.2020.101136

Statistics Finland. (2021). Recorded cases of domestic violence against minors decreased by 14 per cent. https://www.stat.fi/til/rpk/2020/15/rpk_2020_15_2021-06-01_tie_001_en.html

Tampere University Dissertations. (2020). The Documentation of Family Violence in Healthcare and the Associations of Violence on Well-Being. http://urn.fi/URN:ISBN:978-952-03-1407-1

Victim Support Finland. (2020). Homepage. https://www.riku.fi/en

Virta, S. and Taponen, J. (2017). Policing regime in transition in the Nordic countries: Some critical notes from the Nordic reality. In Devroe E, Edwards, A. and Ponsaers, P. (Eds.), Policing European Metropolises (pp. 121-144). Routledge. 


\title{
FRONTLINE RESPONSE TO HIGH
} IMPACT DOMESTIC VIOLENCE IN

\section{FRANCE}

\author{
MARION Tillous, ${ }^{1}$ ThierRy DelPEUCH ${ }^{2} \&$ \\ FRANCOIS BONNET ${ }^{2}$ \\ ${ }^{1}$ Université Paris, UMR LEGS / UMR PACTE, Paris 8 Vincennes Saint-Denis, France. \\ E-mail: marion.tillous@univ-paris8.fr \\ ${ }^{2}$ Université Grenoble Alpes, Sciences po Grenoble, CNRS - UMR PACTE, \\ Saint-Martin-d'Hères, France. \\ E-mail: thierry.delpeuch@umrpacte.fr; francois.bonnet@umrpacte.fr
}

Abstract Since the 2000s, several laws have been enacted by the French parliament to make domestic violence a crime taken more seriously. Among the most important developments, a 2010 bill introduced the protection order in French law; the inter-ministerial mission for the protection of women against violence and the fight against human trafficking (MIPROF) was created in 2013, and a set of conferences between public stakeholders and NGOs took place in 2019 (the "Grenelle des violences conjugales"). In France, policies to combat domestic violence at the local level essentially rely on the setting and diffusion of two types of organisational arrangements. The first type of arrangement is a specialised domestic violence unit that is set up within a larger organisation with a more general mission, such as law enforcement agencies, hospitals, or social services. The second type of arrangement is an inter-organisational structure intended to provide a framework for partnership cooperation against domestic violence, such as social workers embedded in police stations to provide expert assistance to victims when they report domestic violence.

Keywords:

domestic

violence,

France,

interagency

cooperation, victims, police, NGO 


\section{National framework of public policies to combat domestic violence}

In France, as in many other Western countries, domestic violence has been denounced since the 1970s by feminist movements who identify the central role it plays in the reproduction of patriarchal oppression. The response to violence, as elsewhere, involves the creation of shelters for victims, the development of legislation making such violence illegitimate and the punishment of those who transgress this new legal framework. France stands out as a country where shelters are developing as part of the social work field, in contrast to the United States, where shelters are part of the mental health sector. There, the institutionalisation of the fight against domestic violence has been more rapid than in France, as a result of an early criminalisation and prosecution.

In France indeed, although violence committed within the couple was included in the Penal Code in 1994 (art. 222-13-6) as a specific offence and an aggravating circumstance, it was not until the mid-2000s that a genuine legislation began to emerge. Thus, the 2004 divorce reform included a clause on the eviction of violent spouses (art. 220-1 of the Civil Code) allowing the Judge for Family Affairs (JAF) to impose separation of residence and to attribute the exclusive enjoyment of housing to the victim of violence. Then the law of April 4, 2006 introduced the notion of 'respect' in marriage vows (which makes it possible to obtain a divorce for just fault in the event of violence), recognised theft and rape between spouses, expanded the notion of aggravating circumstances to de facto partners, those in civil unions and expartners (not just currently married people), and facilitated the eviction of the violent spouse from the home.

The law of 9 July 2010 is important because it provides the justice system with a new tool to respond to domestic violence: the protection order (art 515-9 and following of the Civil Code / law reinforced by the one of 4 August 2014). This can be issued by the family affairs judge in an urgent hearing when violence occurs within the relationship. It allows emergency measures - even if a complaint has not been filed - such as: eviction of the violent spouse, prohibiting him or her from coming into contact with the victim or their children, prohibiting the possession of a weapon, and non-disclosure of the victim's domicile or place of residence. On the financial level, the Judge of Family Affairs (JAF) can pronounce measures such as attribution of use of the shared home or temporary access to legal aid for the victim and can set 
the degree of the violent spouse's contribution to the family's costs. The threat that the violent spouse poses to the children is also taken into account, with the possibility for the JAF to reduce his or her exercise of parental authority, to decide on visitation and accommodation rights and to set up measures for a protected visitation i.e. in the presence of a third person - who comes to pick up the child from the victim spouse's home, preventing the latter from being exposed to his or her aggressor. The protection order is pronounced for a period of 6 months, renewable under conditions.

Another central tool for responding to domestic violence and protecting victims from the risk of spousal homicide is the Serious Danger Telephone (TGD) generalised by the law of 4 August 2014 'for real equality between women and men'. The TGD is allocated by the Public Prosecutor's Office to victims of violence who are no longer living with their attacker - who have been notified of a judicial ban on contact with the victim. If the victim identifies that her attacker is nearby, all she has to do is press a button on the TGD to be put in touch with a tele-assistance service which assesses the danger and the victim's location. If necessary, the tele-assistant alerts the police on a dedicated channel so that a patrol can be sent to the victim without delay and, if necessary, the attacker can be arrested. To prevent repeat offending, the law of 4 August 2014 also included awareness-raising courses for authors of domestic violence that can be ordered by the court as additional or alternative sentences. And it introduced an obligation for initial and ongoing training for all professionals concerned; training then became one of the priorities of national public action.

In France, the official body responsible for coordinating the fight against domestic violence is the general directorate of social cohesion (DGCS) which reports to the solidarities and health ministry as well as to the secretary of state for equality between the sexes. The DGCS comprises of three departments, including a women's rights department (SDFE). This department pilots and coordinates policies against violence against women and runs a devolved network on women's rights, which includes a representative in each of France's regions and counties. the interministerial Mission for the protection of women against violence and the fight against human trafficking (MIPROF), created in 2013, has the threefold mission of developing training programmes for professionals who take charge of women who are victims of violence, ensuring the collection and analysis of data relating to such 
violence, and coordinating the actions against trafficking in human beings at a national level. Finally, the Higher Council on Equal opportunities (HCE) is responsible for the assessment of the policy against domestic violence since its creation, also in 2013.

The report published on 9 October 2020 by the HCE points out the limits of French policy in the fight against domestic violence. In particular, it denounces the lack of a real inter-ministerial approach and calls for the rapid development of a framework for a large-scale public policy, namely a global action plan identifying the major challenges in this area, based on training, associated indicators, identified and earmarked funding and, finally, an annual evaluation by an independent body. The "Grenelle against domestic violence" could have given the necessary impetus to this large-scale public policy, but a year later, the HCE and the associations supporting victims of domestic violence regret that only the legislative measures - i.e. the least costly - have been implemented: the lifting of medical confidentiality to allow the reporting of domestic violence (which is highly controversial) and the deployment of the electronic tracking bracelets for the perpetrators. The most costly measures such as social support for victims and emergency accommodation are still awaited.

The specific measures taken during the covid-19 crisis in response to the very rapid rise in domestic violence caused by lockdown follow the same logic. They mainly consisted of the multiplication of measures enabling women victims to report the violence that had been done to them, for example by making it possible to pharmacists, or by organising, with voluntary associations, counselling areas

in shopping centres. However, following the report, there was a lack of solutions proposed: what happens after the women talked? Where is she supposed to go? A certain number of hotel nights, either for victims or for the perpetrator, have been financed. But by redeploying existing funding, and, which is even more problematic, funding dedicated to domestic violence. These are those of programme 137 for "Equality between women and men", which is used to finance associations providing assistance to victims, on the front line in the fight against domestic violence. It would have been logical, as suggested by the members of the senatorial delegation in charge of the assessment of the period, that the financing of hotel nights for the purpose of assigning aggressors to house arrest should have been covered by the justice budget. 
In 2018, the resources mobilised to combat violence against women, whether public or private, were estimated at 79 million euros (HCE, 2018). As the report of the Senate's financial commission (2020) points out, the new credits announced following the Grenelle (the "Catherine" fund against feminicides) or lockdown were only internal redeployments. There is therefore a serious lack of funds to meet the needs, estimated between 506 million and 1.1 billion euros by the HCE (2018).

\section{Data on domestic violence in France}

There are two sources of data on domestic violence, administrative (police) and victimization surveys. Before the 2000s, there was little French data-police and survey — on domestic violence. In surveys, there had been a question about rape and sexual assault in the public studies of sexual behaviour in 1992 (ACSF) and 1994 (ACSJ), but no dedicated survey on DV/IPV. Meanwhile, police/justice data were notoriously poor. In the 1990s, police data did not indicate the gender of the perpetrator, and justice data only focused on the perpetrator. It was thus impossible to assess the extent of domestic violence. In 1997, the French government, pressured by both activists and international norms after the Fourth World Women Conference on Women (Beijing 1995), commissioned a survey, which was finalized in 2000 as Enveff (Enquête nationale sur les violences faites aux femmes en France). In 2003, the murder of a famous actress by her rock star companion created an enormous scandal and put DV/IPV on the agenda.

\section{Victimization Data}

The pioneer study is Enveff (2000). 6,970 women, age 20-59, were interviewed by telephone and asked about psychological, sexual and physical violence. The theoretical underpinnings of Enveff are in the "violence against women" framework. Enveff found that 2,3\% of women were victims of physical violence in the household.

The successor of Enveff is Virage ("Violences et rapports de genre", 2015), with a sample of 27,268, 15,556 women et 11,712 men aged 20-69 (first in France proper, then with a follow-up in the overseas territories in 2016). An important difference between Enveff and Virage is that Virage interviews also men. Virage aims at better 
capturing the combination of gender-based violence with emerging issues of ethnicity and disability. Virage follows a holistic approach to violence victimization, asking questions about violence in the family, by the partner, in public space, in the work space, and at school; and has a greater sensibility to psychological and verbal violence than the main public survey (CVS, see below). Enveff and Virage have a strong visibility in French academia and the nonprofit sector.

Table 1: Domestic violence in the current relationship, in the last 12 months, by sex (\%)

\begin{tabular}{lcccc} 
& \multicolumn{2}{c}{ Women } & \multicolumn{2}{c}{ Men } \\
\hline & $\begin{array}{c}\text { At least } \\
\text { once }\end{array}$ & $\begin{array}{c}\text { More than } \\
\text { five times }\end{array}$ & $\begin{array}{c}\text { At least } \\
\text { once }\end{array}$ & $\begin{array}{c}\text { More than } \\
\text { five times }\end{array}$ \\
\hline $\begin{array}{l}\text { Has insulted you, humiliated you, } \\
\text { criticized your physical appearance, } \\
\text { opinions or skills }\end{array}$ & 2,3 & 2,3 & 0,3 & 0,3 \\
\hline $\begin{array}{l}\text { Has brutally shaken you, hit you, or } \\
\text { committed other act of brutality }\end{array}$ & 2,9 & 1,5 & 0,3 & 0,1 \\
\hline $\begin{array}{l}\text { Forced you to touch genitals, or } \\
\text { forcibly tried to have sex }\end{array}$ & 0,8 & 0,4 & $<0,1$ & n.s. \\
\hline
\end{tabular}

Source: Violences et rapports de genre, 2015

Since 2007, there is another source of victimization data, CVS ("Cadre de vie et sécurité"), which is co-organized by the French statistical authority (INSEE), the ONDRP and the Ministry of Interior's statistics department (SSMSI). Since 2007, CVS annually surveys circa 23,000 respondents. CVS is a general victimization survey which investigates most forms of crime (including for instance burglaries). Its theoretical orientation is traditionally criminological. It uses a narrower definition of domestic violence than Enveff / Virage, with more direct questions, and yields lower estimates of domestic violence, although, since 2014, it asks about the psychological, verbal and administrative aspects of IPV. It surveys respondents age 18-75. It is conducted face-to-face, and some questions are asked through headphones, to make sure that family members cannot overhear the questions. CVS has high response rates and high quality responses because of the attention to details put in the research protocol. It over-samples poor neighbourhoods, and can be administered in other languages than French (e.g., Arabic or Soninké). 
Table 2: Domestic violence: yearly averages for 2011-2018.

\begin{tabular}{lcc}
\hline & Total & Women \\
\hline Domestic violence victims & 295000 & 213000 \\
\hline Among which: victims of physical violence only & 227000 & 152000 \\
\hline Among which: victims of sexual violence only & 34000 & 30000 \\
\hline Among which: victims of both physical and sexual violence & 34000 & 31000 \\
\hline Share of victims among 18-75 year olds & $0,7 \%$ & $0,9 \%$ \\
\hline Share of women among victims & $72 \%$ & $100 \%$ \\
\hline Share of victims pressing charges & $14 \%$ & $18 \%$ \\
\hline
\end{tabular}

Source: “Cadre de vie et sécurité" survey, 2019.

There are other ventures of more limited scope in survey research that touch upon domestic and/or sexual violence. The French Ministry of Health has commissioned a survey on sexual behavior where questions are asked about sexual assault and rape; the department of Seine Saint-Denis (northeastern banlieue of Paris) also commissioned a study of violence against female teenagers and young adults (called CSVF, 2007).

\section{Police data}

Police data in France historically are notoriously poor, in part because police officers have little time to dedicate to inputting quality information, in part because softwares have inherent limitations, and in part because many governments have taken an active step in manipulating data towards political ends. In 2003 the ONDRP was created to analyze police and justice data, and in 2014 the SSMSI was created within the Ministry of Interior to improve the quality of police statistics. The SSMSI is headed by a statistician, not a police officer. Since 2014, it collects data from both the police and the gendarmerie. It is certified as a credible statistics organization by the European Union. 


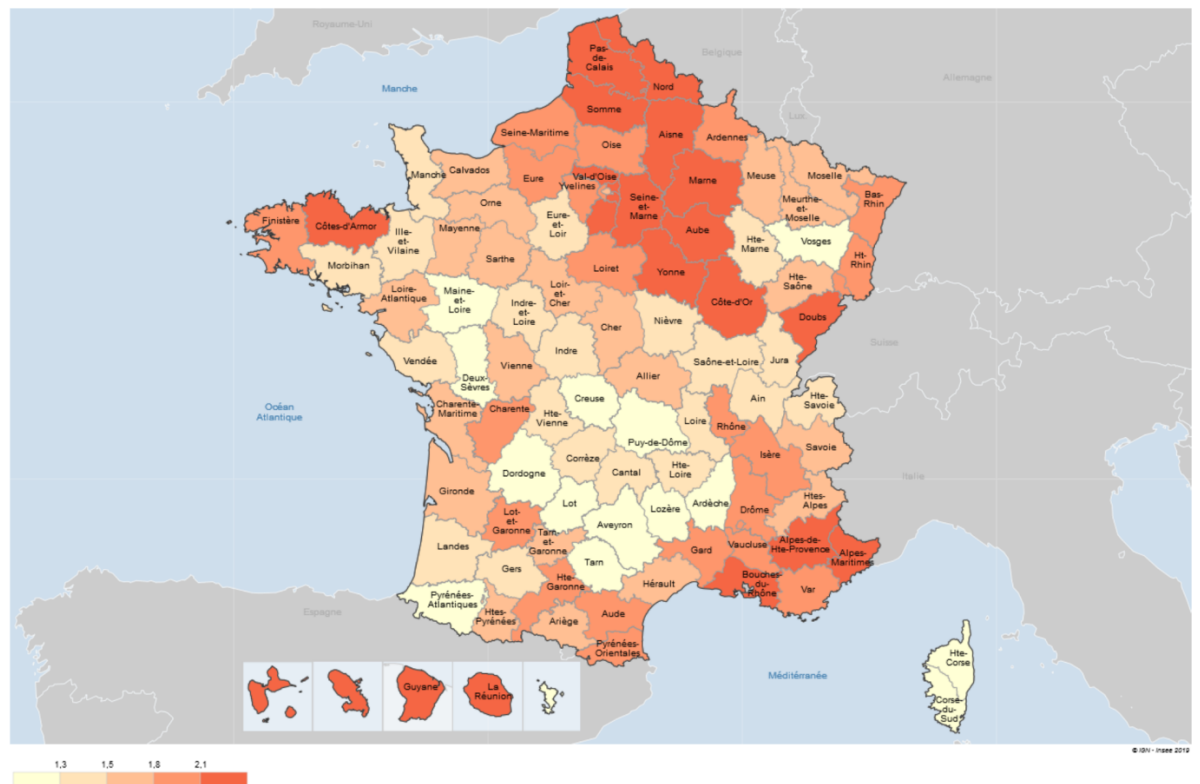

Source : SSMSI, Base des victimes de crimes et délits 2018; traitements SSMSI.

Figure 1: Number of domestic violence victims according to police and gendarmerie data in 2018, per 1000 residents

Today, police data are collected in the following manner. Victims in France may ask to simply register their claim ("main courante", no formal charges and no investigation) or to formally press charges.

The first option, "main courante", is originated either by victims themselves, who wish to let the police register that something happened without formally pressing charges, or by the police officers themselves who report on what they have seen and done on patrol (they fill in a "gestion d'événement"). All this goes into the MCI, a software that looks outdated and difficult to use and less precise than the software that manages formal charges. The Ministry of Interior's SSMSI does not use these data, but the Gendarmerie, at the department-level, may use them to get an idea of territorial trends.

The second option is to press charges, which may happen in any police station (where the victim lives, where the incident happened, or elsewhere), or with the prosecutor's office. Charges are filed by the investigating police officer into a software called the LRPPN (Logiciel de Rédaction des Procédures de la Police 
Nationale) or the LRPGN (for the Gendarmerie). Every time a victim presses charges, the police officer inputs into the LRPP/GN all sorts of information about the assumed nature of the crime, the relationship between perpetrator and victim, questions of gender, age and nationality, which are statistically usable.

A source of bias is that the low quality of the information that is filed into the LRPP/GN. In dense urban regions, police receive too many complaints. Investigators are overburdened and often do not fill in the forms as diligently as they should, because there are too many items. Investigators routinely misrepresent the crime's nature ("nature d'infraction"), or fill in wrong information because it is the first one in the multiple choices that appears in the drop-down menu (this is a common problem to drop-down menus, not specific to the French police). Ministry of Interior statisticians consider that data about domestic violence is usable since 2015.

Another source of bias is the police practice of "codes Q", which consists in using a range of subterfuges to make criminal charges disappear from official statistics, so as to avoid unfavorable-looking crime numbers. According to informal sources within the French police, in the early 2010 s, up to $7-10 \%$ of charges pressed to the police could thus disappear. It is unclear how much the practice persists or whether it is possible for Ministry of Interior statisticians to reconstruct "codes Q".

Another source of bias is the variations in police practices. In some precincts, police officers use a specific questionnaire when a victim press charges for DV which is designed to clarify what is it exactly that the charges are about, because victims often don't know that specific behaviors are penal infractions. But in other precincts, these questionnaires are perceived by officers as inducing responses and spurring inflated complaints, and are therefore not used.

Another concern pertains to the definition of DV. The options to qualify the infractions in the LRPP/GN do not allow for making a distinction between, on the one hand, common disputes in socially disadvantaged households where alcohol is consumed in great quantities, and on the other hand more insidious dynamics of control which may or may not be violent. Police officers often empirically know the difference, but the software does not allow for such specifications. 
Another source of bias derives from the organization of justice in France. In short, small crimes are judged by all-professional courts (tribunal correctionne), while serious crimes are judged by popular juries (cour d'assises). Popular juries are expensive, cumbersome, difficult to organize, and unpredictable in their decisions. Legal professionals are dismayed that wily defense lawyers are able to persuade gullible popular juries in spite of hard evidence. As a consequence, there is an understanding among police and justice professionals that is it best to recast serious crimes into less serious crimes, so as to have them judged by the professional correctionnel, and to have confidence that at least some justice will be served. This means that attempted murders are routinely recast as assault, rapes as sexual aggressions, incurring lesser penalties, but with greater certainty of conviction.

Another (hopefully final) concern is that is difficult to follow charges pressed to the police/gendarmerie to their effective judicial treatment by prosecutors. All cases are relabeled, put into another software, so as to preserve the sanctity of judicial decisions over police records-based on the legal theory that police charges are not enough to make a defendant guilty, that only court proceedings can establish judicial guilt. It is thus difficult to know which crime qualification is eventually used by prosecutors, whether prosecutors tend to requalify DV cases in stronger or milder terms, how frequently prosecutors drop cases, etc.

In addition to regular police data, the Délégation aux Victimes at the Ministry of Interior presents since 2004 a yearly report of all the women killed by their partner in France, which provides an accurate account of the number of women killed and of the circumstances.

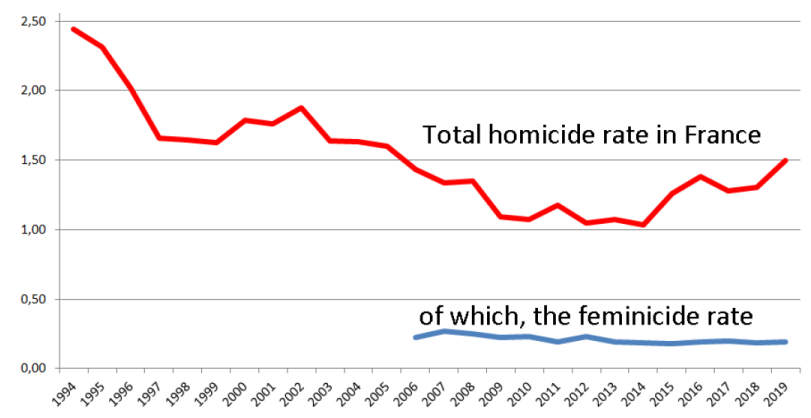

Figure 2: Total homicide and feminicide rate in France, 1994-2019.

(Source: authors' calculation based on DAV and Ministry of interior data.) 


\section{The frontline response}

In France, as in other EU member countries, the development of policies to combat DVs at local level essentially relies on the setting and diffusion of two types of organizational arrangements.

The first type of arrangement is a specialized DV unit that is set up within a larger organization with more a general mission, such as law enforcement agencies, hospitals or social services. The second type of arrangement is an interorganizational structure intended to provide a framework for partnership cooperation against DV.

Most government agencies that play a role in addressing DVs have developed specialized unit and/or staff. This is true in particular for law enforcement agencies. For example, the gendarmerie has set up a network of 1,600 local crime prevention officers (about one per gendarmerie station, there are approximately 120000 gendarmes in France). They are responsible for taking care of victims who come at the gendarmerie station, for interviewing them properly, for directing them towards the right support providers, for assessing the risk to the victim, for investigating DV cases, for facilitating information sharing on women at risk among the various gendarmerie units of the département, for raising awareness among their colleagues on the issue of DV's, and for representing the gendarmerie in grassroots inter-agency cooperation at the municipal level.

In addition, to improve the quality of criminal investigations of intimate partner violence cases, specialized detective units have been set up in gendarmerie stations and headquarters (at the département level), such as the "family protection brigades" which were created in 2009 in each département (the département is a French political and administrative-territorial level, of which there are about a hundred in France, département police and gendarmerie directorates are the main level of command for local police forces).

The French national police followed the same evolution, creating victim assistance desks, victim support officers or managers (about 800 in the whole country, the National Police has about 150000 police officers), and DV investigation groups in a growing number of jurisdictions (there is about 200 family protection brigades in 
the French National Police employing 1300 specially trained detectives). At the same time, victim support associations and legal aid NGOs have set up information desks in many police stations and most courts of justice, which are staffed by volunteers or employees trained to respond to the specific needs of DV victims. These associations, which are themselves subsidized by the public authorities, also provide training to police officers on the prevention and fight against DV, further contributing to the commitment and specialization of dedicated law enforcement professionals. In a similar way, hospitals have established clearly identified and specially trained health professionals to whom other hospital staff members can refer when they are confronted with hard DV cases.

Our field observations show that there is a clear difference in the quality of care provided to victims depending on whether their case is handled by a specialist or by a generalist. By "specialist", we mean police officers (or social workers, or medical professionals) whose job specialty consists in handling domestic violence cases. By "generalist", this deliverable refers to those police officers (or social workers, or medical professionals) who indifferently handle all the cases that they encounter in their work.

Generalists will typically be less knowledgeable about domestic violence, less inclined to take non-physical violence seriously, more inclined to rely on personal discretion, and less likely to make informed and helpful referrals. Conversely, specialists will be better trained, knowledgeable about the different types of violence, abuse and control dynamics - and the risks they entail, more likely to follow protocols and procedures design to safeguard the victim's interests, and more likely to be part of a network of professionals from other sectors who will be themselves more likely to help the victim in their multifaceted needs.

The deficit of inter-agency cooperation has been identified as one of the main limitations of French efforts to combat domestic violence since the mid-2000s. It was at this time that the development of local partnerships between stakeholders involved in supporting victims became one of the main orientations of French policies in that domain. 
During the last decade, local policy arrangements and tools for information sharing, coordination, and day to day collaboration have been set up in a growing number of localities. These cooperation schemes and devices take a variety of forms: social workers or psychologists in police stations specifically tasked with bridging the gap between law enforcement agencies and social services; official or informal multiagency workgroups dedicated to steering and implementing local prevention and law enforcement policies; establishment of state officials in charge of organizing and animating networks of public and non-governmental actors; setting up of interagency protocols and contact persons to ensure continuity of care for victims despite the multiplicity of support providers.

In France, there is a profusion of actors who can claim to coordinate the provision of services to victims of domestic violence at the local level. Local government officials in charge of women's rights, prosecutors, prefects, police chiefs, local victims support committees of the Ministry of Justice, municipal crime prevention and public safety committees, all have been given the mission to coordinate the action of the various stakeholders by different directives taken at different times. Fortunately, not all of them are ready to assume this mission with the same level of commitment. In some places, one of these authorities manages to make its leadership recognized by others, through expertise, commitment and diplomacy. In other places, several authorities are competing for leadership. In some localities, no partnership emerges and the various stakeholders continue to work separately or in a loosely coordinated manner.

One of the most effective arrangements that has been developed in France involves both specialization and inter-agency cooperation. These are social workers operating in police stations and gendarmerie units.

The idea of setting up embedded social workers in police and gendarmerie stations came up in the early 1980s, following a governmental white paper which putted the stress on the social dimension of police work: the Belorgey report on police reforms (1982). This report highlighted that the police did not take action when facing information on the social distress of victims who came to the police station. The potential of police information as a trigger of social intervention and victim support was not exploited. This report recommended to consider a device to fill this gap. 
It appeared quickly that the simple transmission of written information to social services was not enough to trigger proper social services intervention. It became clear that the only effective solution was the complete information of a social worker by the police as well as the presence of this social worker in the police/gendarmerie station, so that this social worker can directly collect the additional elements he or she needs to process the case. Hence the idea of embedding a social worker in the police station to collect in real time all information related to police interventions and to use this information to provide support to victims.

The first thoughts on this subject date back to 1986. The objective was that victims present in the police/gendarmerie station could be seen, on site and without delay, by a social worker, in order to provide immediate responses to his/her need for assistance. The first attempts, in 1988 and 1989, failed mainly because of the resistance of social workers. This resistance decreased when social workers were guaranteed that their professional ethics would be fully respected. It was decided that the embedded social worker would continue to belong to the social services of the département. The police station promised to provide the social worker with an office and to provide him/her with all the necessary equipment and information.

The first successful experiences took place in the years 1991-1993 despite the refusal of some département councils to finance the scheme and despite the unwillingness of some police stations to integrate social worker (considered by some police officers as an ideological enemy) into their midst. The missions of the embedded social workers were defined by a 2006 guidelines establishing a reference framework for the "Intervenant social en commissariats de police et unites de gendarmerie" (ISCG - social worker in police stations and gendarmerie units). According to this guidelines, the main tasks of ISCG are: to assess the nature of the social needs that are detected during police activity; to carry out social intervention, as a matter of urgency if necessary; educational or social mediation activities; technical assistance, support, and information activities; and to facilitate the person's access to social services and to their social rights. The function was enshrined in law in 2007 (Article L 121.1.1 of the Code of social action and families). In 2019, there is 261 ISCG in France and 73 psychologists working in police stations. 
Embedded social workers have leeway to define their missions and not all do exactly the same things. They are often involved with improving the likelihood of reporting. After police interventions for DV, embedded social workers call the victims to motivate her to come to the police station to report the crime (if any). These callbacks are scheduled even if the incident doesn't lead to an arrest or a formal procedure.

An embedded social worker spend a considerable amount of time analysing police reports and victims' statements in search of "red flags", of signals of at-risk situation — for instance death threats, knife attacks, schizophrenia, alcohol and drugs, violence in front of children - any sign of a situation that may potentially escalate in high-impact domestic violence.

The main function of embedded social workers is to assist the police in handling domestic violence victims. This means soothing victims and talking them into filing a report with the police. They provide social assistance to victims-helping them with housing and children, explaining to them what happens next, reassuring them or managing their expectations, putting them in contact with NGOs or psychologists, and so on, so that police officers can focus on the strictly policejudicial aspects of the case. This enables police officers to build more solid cases with more cooperative victims, with greater judicial consequences, while at the same time providing victims with basic psychological assistance and referrals to core services, thus greatly improving victims' experiences with the police.

The policy of hiring embedded social workers in police stations clearly fits international recommendations. As female civilians, embedded social workers help diversifying the workforce. We see embedded social workers as a clear example of best practice in the sense that it is a concrete step in improving the quality of the handling of domestic violence by the police. It is not a cost-neutral-policy: it requires the hiring of a full time employee for one or two police stations, depending on caseload. But it delivers tangible benefits which are easily replicable. The main problem is the issue of making people from the world of social work fit into the world of police officers. 
Social workers and police officers belong to two different professional cultures where tacit assumptions about what constitutes normal collegial behaviour differ. Embedded social workers usually manage, with a steep learning curve during their first year in the police station, to figure out the do's and the don'ts. The main culture shock comes from the issue of information sharing. Embedded social workers need to have access to reports and victims' statements, but in the police world, these documents are not to be shared with outsiders. After a few years, embedded social workers come to know the police organization from the inside, and are able to use the most obscure acronyms to good effect. But mistakes happen, and sometimes these mistakes cause irreparable damage to certain personal relationships, which in turn can severely hinder the social worker' ability to effectively work with her police partners.

The specializations logics within organizations involved in combating DV take various forms in different local jurisdictions, despite the efforts of the national management to impose uniform standards and practices throughout the country.

Each local dynamic generates a specific network of specialized professionals. This network can be developed within one of the many existing official schemes, but it can also be structured in an ad hoc way by adopting an original and unique configuration, functioning and leadership. One of the consequences of this variety of local arrangements is that a part of the know-how of specialized professionals is relevant only in the local context in which they practice, especially the expertise dealing with working together with other local stakeholders. This is why the training initiatives put in place at the local level by local actors play an important role in the specialization process of DV first responders.

\section{References}

Commission sénatoriale des finances. (2020). Rapport d'information sur le financement de la lutte contre les violences faites aux femmes. Rapport $\mathrm{n}^{\circ} 602$.

Delage, P. (2017). Violences conjugales. Du combat féministe à la cause publique. Paris, Presses de Science Po.

HCE. (2018). Où est l'argent contre les violences faites aux femmes? https:/ / www.haut-conseilegalite.gouv.fr/IMG/pdf/rapport-ou_est_argent-vf.pdf

HCE. (2020). Violences conjugales. Garantir la protection des femmes victimes et de leurs enfants tout au long de leur parcours. Rapport n²020-09-22 VIO-43. 
Délégation sénatoriale aux droits des femmes et à l'égalité des chances entre les hommes et les femmes. (2020). Rapport d'information sur le bilan de la lutte contre les violences faites aux femmes et aux enfants au sein de la famille: conséquences du confinement, défis du déconfinement. Rapport n597. 


\title{
FRONTLINE RESPONSE TO HIGH IMPACT DOMESTIC VIOLENCE IN GERMANY
}

\author{
Stefanie Giljohann, ${ }^{1}$ Catharina Vogt ${ }^{2}$ \\ LisA SONDERN, ${ }^{3}$ PAULINA JUSZCZYK, ${ }^{3}$ JOACHIM KERSTEN ${ }^{2}$ \\ $\&$ BETTINA PFLEIDERER ${ }^{3}$ \\ ${ }^{1}$ Police Berlin, Berlin, Germany. \\ E-mail: gil@zedat.fu-berlin.de \\ ${ }^{2}$ German Police University, Criminology and Interdisciplinary Crime Prevention, \\ Münster, Germany. \\ E-mail: c.vogt@respectresearchgroup.org; joachim.kersten@t-online.de \\ ${ }^{3}$ Westfalian Wilhelm-University Münster, Faculty of Medicine, Münster, Germany. \\ E-Mail: lisa.sondern@wwu.de; paulina.juszczyk@wwu.de; pfleide@wwu.de
}

Abstract With a total of 141,792 incidents in 2019, domestic violence is a serious problem throughout Germany. The country chapter provides an overview of crime statistics and results from victim studies and a cost study. Concerning legislation, there have been two major waves improving victim protection in recent times, initiated by implementing the Act on Protection against Violence in 2002 and the ratification of the Istanbul Convention in 2018. An ongoing trend towards interagency cooperation and setting up coordination bodies can be noted in the social sector, also incorporating law enforcement agencies and medical institutions. After delineating the scope of responsibilities of front-line responders in the police, medical, and social sectors, the country chapter describes examples of good practices for interagency cooperation. The country chapter concludes with the main challenges to be anticipated in combatting domestic violence. The three main objectives identified are minimising unreported cases, expanding the scope of interventions, and improving victim protection in the short and medium-term. In the long term, the implementation of policies and standards will be vital to evaluate and improve prevention and protection measures to assure a high and nationwide comparable quality standard.

Keywords: domestic violence, Germany, interagency cooperation, victims, police 


\section{Country and legislation regarding domestic violence}

Germany is a federal parliamentary republic led by a chancellor. It is the European Union's most populous member state: Federal Statistical Office figures (2021) show that more than 83 million inhabitants live in the 16 constituent federal states (Länder). The largest city is Berlin, the German capital. Regrettably, domestic violence (DV) is a serious problem throughout the country.

In 2017, Germany ratified the Council of Europe Convention on Preventing and Combating Violence against Women and Domestic Violence (Council of Europe, 2011). As documented in the first German state report on implementation of the 'Istanbul Convention', considerable nationwide efforts have been made to improve the prevention, documentation and prosecution of crimes as well as to provide relevant professionals with guidelines for action, training and cooperation within the support sector (BMFSFJ, 2020). The Convention has also triggered legislative changes, such as the tightening up of the German criminal law on sexual offences in 2016 and the nationwide expansion of victim protection.

German legislation does not include a general legal definition of domestic violence nor does it provide a specific legislative framework. Instead, the applicable laws refer to criminal offences and are embedded in the national legislation in several fields of law like criminal and civil law, criminal procedure and administrative law as well as the Police Regulations (Polizeidientvorschriften) of the Länder.

Most offences committed in the course of domestic violence are investigated under the Criminal Code (Strafgesetzbuch/StGB) and prosecuted ex officio. These offences range from insult to offences against physical integrity, sexual selfdetermination, personal liberty and life. A significant milestone in women's protection came in 1997 when sexual coercion and rape within marriage became an offence ( $\$ 177$ StGB). In 2016, the legislation on sexual offences was further tightened: according to the principle "No means no", any sexual act against the apparent will of the victim, including touching them in a sexually explicit manner, is considered a criminal offence. Two more recent milestones in victim protection are legislation prohibiting stalking ( $\$ 238 \mathrm{StGB}$ ) in 2007 and its significant strengthening in 2017. With this latest change, stalking is punishable if the act is likely to seriously 
affect the victim's life, even if the victim does not give in to the pressure and/or does not change her/his life.

Apart from the StGB, the Act on Protection against Violence (Gewaltschutzgesetz/GewSchG) in particular plays a major role in victim protection. This act was introduced in 2002 as a national law in order to resolve the legal uncertainties of civil claims related to incidents of violence in the private sphere. GewSchG understands violence as all intentional and unlawful violations of the body, health or freedom of another person, regardless of whether the act takes place within a joint household or outside it. Within this concept of violence, the psychological aspect is also included "explicitly in the case of threats and unreasonable harassment, and indirectly when it has led to psychological or physical impairment to the health of another person" (BMFSFJ \& BMJV, 2019). The issue of a protection order lies within the jurisdiction of the district courts. GewSchG protects domestic violence victims primarily by facilitating the temporary allocation of a shared home to the victim ( $\$ 2$ GewSchG). Under GewSchG, housing allocations may be supplemented by additional protection orders; these are also regulated within GewSchG and include, for example, the prohibition on contacting or approaching the victim or approaching places usually frequented by the victim $(\$ 1$ GewSchG). The perpetrator's breach of such a judicial protection order constitutes a criminal offence.

The introduction of GewSchG expanded the police laws of the Länder by authorising the police to expel the perpetrator from a shared home in cases of the imminent escalation of violence. The expulsion order has a maximum duration of 10-14 days; an extension can be requested in court. Police laws differ slightly between the Länder with regard to this duration, the factual preconditions and further protective measures, such as contact, approaching and proximity bans. Breaching a police ban is not sanctioned under criminal law, but leads to stronger police measures, including taking the perpetrator into custody when the victim is at high risk of endangerment.

In cases of domestic violence involving a minor and/or a pregnant female, the law enforcement authority must inform the youth welfare office immediately, according to the Social Security Statute Book (Sozialgesetzbuch/SGB, §8a SGB VIII). This protection mandate of child and youth welfare must be fulfilled even if a minor may 
initially appear not to be a witness or victim of the violence. In case the minor's physical, mental or psychological best interests are endangered, the protective standards of the Civil Code apply (Bürgerliches Gesetzbuch/BGB, \$1666 BGB).

Finally, two important principles play an important role in victim protection and cooperation within the support network: the principle of legality and the principle of professional secrecy. The principle of legality means that German law enforcement authorities must intervene ex officio pursuant to the Code of Criminal Procedure (Strafprozessordnung/StPO). Police must investigate once sufficient indicators of offences have come to the attention of law enforcement agencies, regardless of the victim's intentions to report a crime $(\$ 152 \mathrm{StPO}$ in conjunction with $₫ 163$ StPO). Second, all professionals working in law enforcement, medical or social sectors are legally bound to exercise professional discretion ( $\$ 203 \mathrm{StGB}$ ), unless the person concerned has released them from this obligation or in cases of “justifiable need" ( $\$ 34 \mathrm{StGB})$. This requires a thorough consideration of whether the breach of confidentiality is a suitable and necessary means of averting an acute danger to life, limb or freedom which clearly goes beyond the patient's interest in confidentiality.

\section{Statistics on domestic violence in Germany}

\section{Police Crime Statistics}

Annually since 2015, the Federal Office of Criminal Investigation (Bundeskriminalamt) has published a special report on Police Crime Statistics (PCS) regarding "partner violence". However, the extent to which the PCS on partner violence relate to the actual crime rate and its development over time is difficult to assess because only a few representative, nationwide victimisation surveys on domestic violence have been conducted.

The most recent report for 2019 lists a total of 141,792 incidents of partner violence ${ }^{1}$ (Bundeskriminalamt, 2020), in line with the upward trend seen in the past few years. Without exception, the proportion of female victims was higher than that of men,

\footnotetext{
${ }^{1}$ The PCS count all registered offences (as opposed to victims) for which a police investigation was completed within the year. That is, if a person is repeatedly reported as a victim in the reporting period, they are several times included in the statistics.
} 
in total (81.0 \% were women) as well as in all offence categories. Most victims were recorded in cases of intentional minor bodily injury $(\mathrm{N}=86,812$ of whom $89 \%$ were women), followed by threats, stalking and coercion ( $N=32,477$, of whom $89 \%$ were women), and dangerous and grievous bodily harm (17,227, of whom $70 \%$ were women). The proportion of women was particularly high in cases of rape, sexual assault and coercion ( $98 \%$ women of $\mathrm{N}=3,086$ in total) and also quite high in cases of the deprivation of liberty ( $89 \%$ women of $\mathrm{N}=1,697$ in total). In total, 117 women and 32 men were victims of partner violence resulting in death in 2019.

In 2019, 118,176 suspects were reported for partner violence offences, including attempts ( $79.4 \%$ of them male). About half (50.5\%) the victims lived in the same household as the suspect. With regard to the relationship of the suspects to the victims $^{2}$, the status "former partnership" dominated with $39.0 \%$, followed by "spouse" and "registered civil partnership" with $35.0 \%$ and "unmarried partnership" with $29.7 \%$.

\section{Victimisation studies}

Schröttle and Müller (2004) conducted the first representative and nationwide victimisation survey on women's experiences of violence in Germany. For this purpose, a total of 10,264 women, aged 16 to 85 years, were interviewed between 2002 and 2004 about their experiences of violence, its consequences and their use of institutional help.

At least every fourth woman in the sample had experienced violence by an (ex)partner one or more times in the course of her life (Schröttle \& Müller, 2004). Two-thirds of these had encountered more than 1 violent situation, $24.3 \%$ more than 10 and $6.5 \%$ more than 40 incidents (Schröttle \& Ansorge, 2008).

Further, $23 \%$ of the women reported physical and $7 \%$ sexual violence by their (ex)partner (Schröttle \& Müller, 2004). The physical violence was classified as "very severe" in $37 \%$ of cases, including sexual violence (Schröttle \& Ansorge, 2008). The severity of psychological violence rose significantly with the severity of physical

\footnotetext{
2 The number in relationship status categories exceeds the actual number of suspects since the relationship status changed in several cases over the course of time and after further offences occurred.
} 
violence. Sexual violence was mainly "very severe" and was completed in $81 \%$ of the attempted cases.

(Ex)partners were by far the most frequent perpetrators (50.2\%) of physical and sexual violence in the overall sample, followed by other family members $(30.1 \%)$ and strangers (19.5\%) (Schröttle \& Müller, 2004). All forms of violence, including psychological violence, were committed to a greater degree by male perpetrators.

The study also addressed mutual physical violence in the last violent relationship, e.g. in the form of fighting back (Schröttle \& Müller, 2004): Two-thirds of the women physically fought back at least once, $36 \%$ "occasionally to frequently". Just under one-fifth of the women (19\%) stated they had initiated violence by physically attacking their partner at least once, for $4 \%$, this was the case "occasionally to frequently".

In order to shed light on the context of migration and violence, interviews with women of Turkish $(\mathrm{N}=368)$ and Eastern European origin $(\mathrm{N}=475)$, the two biggest migrant groups in Germany, were additionally analysed within the framework of this prevalence study (Schröttle \& Khelaifat, 2008). Both groups were identified as particularly vulnerable with regard to violence in partnerships (Table 1).

Table 1: Violence in the partnership. Criteria: All interviewed women up to the age of 75 who have once lived in a couple relationship (all) or, among this sample, those who refer to the recent partnership (recent)

(Schröttle \& Khelaifat, 2008)

\begin{tabular}{lccc}
\hline & Turkish & from CCCP & Germany \\
\hline physical/sexual violence (all) & $37 \%$ & $27 \%$ & $26 \%$ \\
\hline physical/sexual violence (recent) & $29 \%$ & $17 \%$ & $13 \%$ \\
\hline severe, frequent physical violence (recent) & $12 \%$ & $5 \%$ & $4 \%$ \\
\hline sexual violence (recent) & $6 \%$ & $3 \%$ & $1 \%$ \\
\hline psychological violence (all) & $20 \%$ & $14 \%$ & $7 \%$ \\
\hline
\end{tabular}

Besides the study of Schröttle and Müller (2004), no other representative victim survey has been conducted in Germany. Recent data on partner violence in Germany is retrievable from a European study that surveyed women ( $N=1,534$ in Germany) aged 18 to 74 years (FRA, 2014). This study showed a similarly high lifetime prevalence of partner violence in Germany as revealed in the study by Schröttle and Müller (2004): $22 \%$ of the women had experienced physical and/or sexual violence 
by (ex)partners since the age 15. During the 12-month period before the interview, this applied to $3 \%$ of the women. The lifetime prevalence of psychological violence was $50 \%$.

The most recent data on partner violence in Germany provides a snapshot of the exceptional situation during the first lockdown in spring 2020. In a representative online survey by Steinert and Ebert (2020), 3,800 women between 18 and 65 years of age were interviewed one month after the 1st lockdown (from 22 April to 8 May 2020) about the time during the pandemic. The results showed that women were exposed to different forms of emotional violence during the lockdown: $3.8 \%$ of them felt threatened by their partner, $2.2 \%$ were not allowed to leave their house without their partner's permission, and for $4.6 \%$ the partner regulated the woman's contacts with other people (including digital contacts). At least one physical assault at home had been experienced by $3.1 \%$ of the women, while $3.6 \%$ of the women had been forced to have sexual intercourse with their partner. The risk of experiencing physical violence increased with the stress factors involved and proved to be even higher for children than for their mothers.

Jungnitz, Puchert and Walter (2004) conducted a pilot study directed at partner violence involving men as victims. In this study, data concerning almost 200 men were included in the analysis. Almost every fourth man (22.6\%) had experienced violence by his current or last partner in the course of his life, $6.9 \%$ during the preceding 12 months. The men had been exposed to psychological violence, such as verbal attacks, humiliation and especially controlling behaviour much more frequently than physical violence during the course of their lives. Physical violence was generally not severe, but more a mild push (18\%), light slapping (7\%), biting, scratching, kicking as well as hard grabbing and pushing $(7 \%)$. Not a single man reported having been "beaten up". Men were also considerably less likely to have been affected by sexual violence ( $5 \%$ ). In these cases, they were more likely to be exposed to sexual harassment and, unlike women, they experienced coercive sexual encounters only in exceptional cases. About half the men affected by violence stated that they had never physically defended themselves during the violence. Two-thirds stated that they had never initiated physical violence. 


\section{Cost Study}

The first nationwide survey of the costs of domestic violence (Sacco, 2017) shows how far-reaching and large the financial impact of domestic violence is. The study considers "tangible" costs (e.g. for police, justice, counselling centres, shelters, healthcare), "indirectly tangible" costs (e.g. for loss of employment, unemployment, trauma follow-up costs for children) and "intangible costs", to which no direct but only a notional monetary value can be attributed (e.g. for life impairments due to fear, pain, illness or premature death). By adding tangible (EUR 1,043.8 billion) and indirect tangible costs (EUR 2,756.5 billion), the study arrives at total costs of at least EUR 3.8 billion per year. In addition, there is an estimated EUR 18 billion in "lifetime costs" caused by intangible costs.

\section{The response of the police, social and medical sectors to domestic violence}

In Germany, the main stakeholders active in preventing and intervening in cases of domestic violence are the police, the judiciary and institutions in the social and medical sectors. The following flowchart (Figure 1) gives an overview of the stakeholders' interconnected work while dealing with cases of domestic violence. 


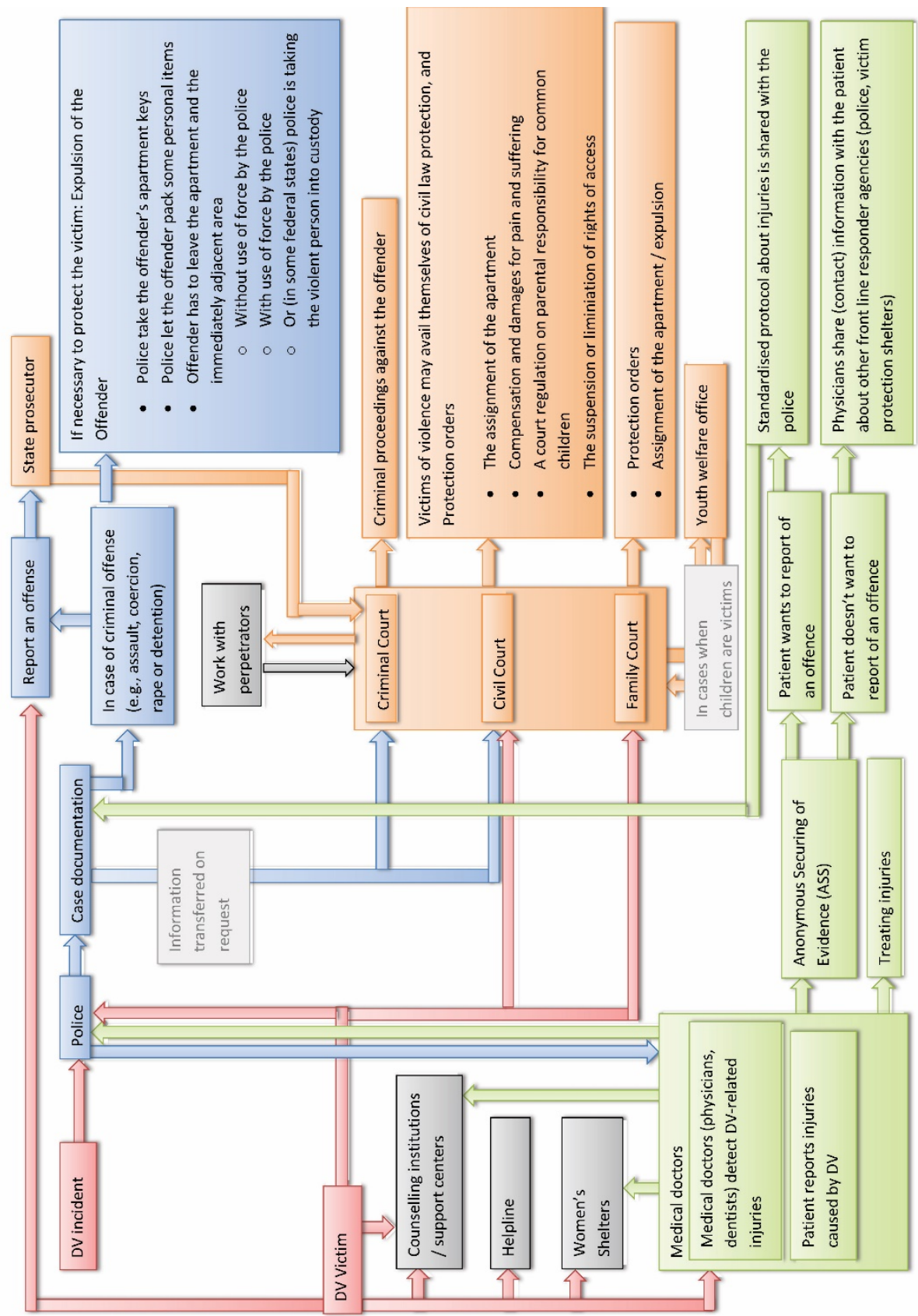

Figure 1: Overview of interventions in DV cases in Germany. The interventions of the main stakeholders active in this field are shown in different colours: the police (blue), judiciary (orange), social sector (grey) and medical sector (green). 
In cases involving a large number of cooperating organisations, there has been an ongoing trend to set up coordination bodies in the social sector, also incorporating law enforcement agencies and medical institutions. Two major waves of cooperation building in Germany can be identified in the past 20 years. The first was the result of the introduction of the Protection against Violence Act in 2001, which initiated or intensified cooperation in many places. Then came the implementation of the Istanbul Convention in 2018 and the explicit demand for inter-agency cooperation, risk assessment and case conferences, which triggered the wave we are currently experiencing. In Lower Saxony, for example, a total of 51 agencies that had already been working together for two decades formalised their cooperation by establishing the "Interdisciplinary Coordination Centre for Domestic Violence" (Interdisziplinäre Koordinierungsstelle Häusliche Gewalt) for the Braunschweig region in 2018. The pilot project "Combating Domestic Violence", which started in the Mannheim Police, Baden-Württemberg, in 2020 and the pilot project "Service Centre "pro-active" (Servicestelle «pro-aktiv»), which is being rolled out this year in Berlin, are good examples of forces joining together to implement scientificallybased high-risk assessment and interdisciplinary case conferences.

\section{The police sector}

The police are mainly reached in three ways: via police intervention after an emergency call and when victims voluntarily contact the police to file a complaint or seek a consultation. A risk assessment is to be carried out as soon as law enforcement agencies become involved. The degree of structure in the approach and the scientific soundness of the risk factors considered vary among the different agencies. Along with the case documentation, the risk assessment forms the basis for police interventions, which primarily aim to prevent (further) offences, reduce the risk of escalation and ensure prosecution. On this basis, the judiciary also grants necessary protective measures and sanctions offences.

With regard to the victim, the police take measures to avert danger, for instance by informing them about protective behaviours or bringing them to a safe place. Some police forces have committed themselves to the 'proactive' approach. This means they link victims and, in some places, also offenders with cooperating institutions in the support and counselling network in a timely manner. In high-risk cases, there are different approaches in the Länder for remaining in close contact with the victims. 
It is the declared aim that in the future interdisciplinary case conferences will be arranged nationwide in high-risk cases in order to be able to more effectively identify and exploit protection measures. In general, the principle applied is that restrictive measures, insofar as they are necessary, appropriate and proportionate, shall be directed primarily against the perpetrator. The main measures to be considered are an official warning, expulsion from the shared home, prohibition on approaching and contacting and, finally, detention (Giljohann \& Bendix-Kaden, 2020a, b). In some Länder, one can find additional measures like ankle bracelets in high-risk cases in Bavaria and North Rhine-Westphalia.

\section{The social sector}

Organisations of the social sector like NGOs, counselling services and support hotlines are a common entry point for victims of domestic violence. The overriding objective of the social sector is to reduce and prevent domestic violence, assist victims in establishing a life free of violence by addressing the structural causes of it, and support them in facing the consequences of their experiences. These organisations generally offer support by providing information, practical support and counselling. In addition, they are an important crossroads of the services of other agencies and sectors, including help in the labour and work market, legal and financial aid or medical care. The support is usually free of charge, being financed by the federal government, the Länder, associations and foundations, and it is often possible to access it anonymously.

This field also offers support for perpetrators, for instance via counselling hotlines or within domestic violence perpetrator programmes. The aim is to end violent behaviour. The courts can compel perpetrators to participate in such programmes. In this case, the counselling institution is obliged to provide feedback to the issuing authority on the progress and outcome of the measure (BMSFSJ, 2016). Standards for working with perpetrators are defined by the Federal Working Group on Perpetrators of Domestic Violence (Bundesarbeitsgemeinschaft Täterarbeit Häusliche Gewalt e.V.; BMSFSJ, 2008). 


\section{The medical sector}

The health effects of domestic violence are multifaceted (FRA, 2014; Schröttle, 2004) and of such a wide scope that medical professionals from all disciplines come into contact with its victims. The German Medical Association (Bundesärztekammer, 2015) emphasises that medical professionals are typically victims' first professional contact and thus hold outstanding responsibility in the recognition, intervention and prevention of domestic and sexual violence. Another task carried out by physicians is the confidential and court-proof securing of evidence.

\section{Good practice of co-operation between police, other frontline responder agencies, and relevant stakeholders in Germany}

To analyse good practice for multi-professional and inter-organisational cooperation networks within the IMPRODOVA framework, case studies were conducted on two well-established cooperation networks in the social sector in Germany (Bradley et al., 2020): the "Berlin Initiative against Violence towards Women" (Berliner Initiative gegen Gewalt an Frauen/BIG) and the "Hanover Intervention Programme against Domestic Violence" (Hannoversches Interventionsprogramm gegen Häusliche Gewalt/HAIP). BIG and HAIP share many similarities, which is not surprising since they were both developed in line with the Domestic Abuse Intervention Project (DAIP) from Minnesota, USA (Novak \& Galaway, 1983). In both cases, they aim to facilitate networked interventions, to (conceptually) improve victim protection, provide appropriate support and training to supporters as well as to influence the social and professional conditions to reduce incidences of domestic violence. These two cooperation bodies are the coordinating heart of their respective large multi-professional and inter-organisational networks, which consist of all professional stakeholders and societal forces relevant to their goals, such as the senate, police, justice system, counselling centres, women's shelters, child protection institutions and many more. BIG and HAIP both thrive on the fact that all actors are closely networked and precisely informed about their respective work, framework conditions and requirements. Thus, working in the permanent coordination units and temporary task groups is highly efficient. The start of HAIP was linked to a police order, which determined the basic process of the network: when the police receive information about a case of domestic violence, this is 
forwarded to the BISS centre, which then offers free counselling in a timely manner. HAIP offers this 'proactive approach' to victims as well as to offenders, while BIG and the Berlin Police have long had such a cooperation agreement for victims. When high-risk cases are identified within the HAIP network, case conferences are convened with the victim's consent to analyse the particular risk situation in depth and to jointly find effective protection strategies. Such a concept is also currently being developed in the BIG network. A far more detailed description of these two cooperation models can be found in the IMPRODOVA report on case studies (Bradley et al., 2020).

Many examples of successful inter-agency cooperation, ranging in size and orientation, can be found in Germany. A very small selection of these is mentioned below to illustrate the diversity of their content and structure. In the field of stalking prevention, the NGO "Stalking-KIT" (Crisis-Intervention-Team Stalking and Domestic Violence) in the city of Bremen is unique and well acknowledged. Operating since 2006, this cross-agency cooperation was developed by the police and the public prosecutor's office to provide stalking victims as well as perpetrators with professional help. Within this network, the timely interventions and their effects are reported back to the police, the public prosecutor's office, partners from victim support and offender control as well as other institutions or authorities relevant to the individual case.

Special mention should also be made in the medical field of S.I.G.N.A.L. e.V. in Berlin. For 20 years, this coordination and intervention programme has been committed to establishing sensitive and competent healthcare for victims of domestic and/or sexualised violence. It collaborates with all actors involved in the intervention chain against domestic and sexualised violence, with particularly close contacts with addiction counselling and care facilities, medical and nursing facilities, research institutions, forensic medicine institutes and child protection facilities. The most important goals include the systematic anchoring of intervention and prevention concepts in healthcare, the integration of the topic of domestic and sexualised violence into the education and training of healthcare professions along with the continuous refinement of intervention and prevention approaches. Other central concerns are the development of materials, public relations, knowledge transfer, the evaluation of intervention measures as well as the promotion of 
networking and professional exchange between the health sector and other actors involved in the intervention.

In this sense, S.I.G.N.A.L. e.V. has been the responsible agency for the "Round Table Berlin - Health Care for Domestic and Sexualised Violence", launched in 2018 by the Berlin government. The round table brings together 29 partners, particularly organisations from the health sector, but also from the psychosocial support system, child and youth welfare, violence prevention, law enforcement agencies, gender equality policy and science. In a joint cooperation declaration, the members agreed to embed the WHO guidelines for dealing with violence in relationships and sexual violence (WHO, 2013) in Berlin's healthcare system and thus to implement the essential health-related requirements of the 'Istanbul Convention'.

As part of the federal government's "Action Programme against Violence against Women", another influential round table was launched in the same year. It draws together representatives of the federal government, of all 16 Länder and the most important municipalities to expand and financially secure the work of women's shelters, outpatient help and care facilities. Legal solutions for a nationwide uniform procedure in emergencies are being sought, e.g. in the form of paying the costs for accommodation in a women's shelter or a legal right to protection and counselling.

\section{Main challenges and issues to be anticipated while managing domestic violence in Germany}

The extensive research and the interviews with first responders in domestic violence cases conducted as part of IMPRODOVA revealed short-, medium- and long-term challenges, some of which we address in this concluding section.

\section{Short- and medium-term challenges: Prevention and protection matter}

Three important objectives are identified among the main challenges in domestic violence management: minimising unreported cases; expanding the scope of interventions; and improving victim protection. 


\section{- Minimising unreported cases}

The sustainable prevention of (further) violence and victim protection depend on victims being able to access the support system. Thus, whatever barriers exist that prevent victims, bystanders and/or perpetrators from reporting domestic violence to first responders or making contact with support networks must be lowered.

To lower this threshold, it is essential that those involved have a comprehensive view of the phenomenon in all of its various manifestations, together with an attitude of gender equality and intolerance of any form of violence. For all parties, be they victims, bystanders or perpetrators, this means they must have developed a sense of when a red line has been crossed in order that they seek help before a domestic violence incident occurs or escalates. In Germany, far more education, sensitisation and empowerment is needed to increase the number of calls made for help.

At the same time, requesting help and reporting a case requires that services be available and accessible. While both criteria are often met in metropolitan areas, rural areas often lack such infrastructure. Although there is a 24/7 nationwide hotline in Germany, face-to-face contact and a somewhat longer period of support than can be provided by a hotline are often indispensable for victims. As a result of the Covid 19 pandemic, many support services now offer digital counselling and it is desirable that this extended accessibility be maintained in the future. There are also various examples of an overall lack of services and/or funding for certain support forms in Germany, such as psychotherapy, trauma- and violence-informed medical care, counselling for perpetrators, services for male victims and women's shelters.

Beyond this, the support network needs to be trusted to provide help when needed, and unfortunately this trust is currently not yet strong in Germany. According to an EU-wide survey on intimate partner violence (FRA, 2014), $14 \%$ of respondents stated they did not believe the social support system could offer them support. Respondents also stated that they believed the police would not act $(14 \%)$ or could not act $(14 \%)$, that they would not be believed $(9 \%)$, and that the fear of the perpetrator was too great $(14 \%)$. Accordingly, it remains an important task to communicate more clearly the seriousness with which the support network takes the injustice experienced by victims and that domestic violence will not be tolerated, in addition to the forms of support offered. 


\section{- Expanding the scope of interventions}

In order to support more victims of domestic violence, they must be recognised even if they do not reveal themselves as such. Correctly identifying cases of domestic violence requires frontline responders to be aware that they are seeing victims each and every day. This holds true for the police and frontline responders in the social sector, but also for medical professionals, who ought to be more aware that even among their patients there are victims of domestic violence. After all, the medical sector is the sector most frequently approached by domestic violence victims (FRA, 2014): $20 \%$ of the victims stated they had visited a doctor, health centre or other healthcare facilities, while $9 \%$ stated they had visited a hospital (vs. $11 \%$ approaching the police and $5 \%$ social services/victim protection institutions). However, victims rarely talk to doctors about their experiences of violence (Grass, Mützel \& Preuss, 2014) and thus doctors need to become better at detecting victims. Even though doctors generally do not ask patients about possible experiences of violence when they have been injured, it may be assumed that there is a high level of social acceptance in Germany in this regard: $83 \%$ of respondents in the FRA study stated that such a routine question was acceptable to them (FRA, 2014).

Within the framework of a federal pilot project with medical professionals, the majority of participants stated at the project's beginning that they had no routine for dealing with potential victims of domestic violence (Steffens, Janz \& Stolte, 2015). Two-thirds of them admitted that they did not feel sufficiently informed to be able to appropriately deal with potential victims. Beyond the insecurity in dealing with victims, a lack of knowledge about available support services was also revealed. More than $70 \%$ of the respondents had not yet participated in any training on the topic. Given that this topic is not part of the curriculum in medical schools either, there is an urgent need for action to integrate it into their curriculums and to create sufficient certified training opportunities to ensure that domestic violence cases are identified and referred to the support system. 


\section{- Improving victim protection}

In the field of victim protection, challenges and opportunities for improvement were identified with respect to the process of securing evidence, case documentation, risk assessment, protection measures and interagency cooperation, as explained in the following paragraphs.

\section{Securing evidence}

The more the influencing factors are assessed by the frontline responders, the more effective the victim protection becomes. The initial step in this direction is to secure evidence. Here, the police and the medical sector play an important role. However, physicians and hospitals do not inform victims sufficiently about the possibility of securing evidence (S.I.G.N.A.L., 2018). While German police officers are well trained in the securing of evidence, most professionals in the medical sector are not. To establish a high standard of documentation in the medical sector, it is important to raise awareness of training and of the well-developed materials available to many medical disciplines (e.g. the materials provided by S.I.G.N.A.L. (2020), based on the WHO's guidelines). Further, greater transparency is needed about how different hospitals, organisations and medical practices deal with securing evidence and the anonymous securing of evidence in particular.

\section{Documenting cases}

The second step in victim protection involves case documentation. Documentation and case processing in the police is IT-based and thus strongly standardised. After the first police contact, in some police organisations the case processing is taken over by officers specialised in domestic violence. Case completion is then checked by a supervisor, ensuring regular quality control of both the documentation and the case processing. In contrast, and although some positive exceptions exist, systematic case documentation seems rare in the social sector and too little is known about how it is done in the medical sector to generalise. Opportunities to support victims in possible court proceedings may be missed here since it is possible that victims release frontline responders from their duty of confidentiality. In these cases, good documentation for a witness statement is inevitable. 


\section{Assessing the risk}

Well-secured evidence and documented cases provide a solid basis for an accurate risk assessment. German police forces are at very different stages of risk assessment development, ranging from experts using a standardised approach or even a validated risk assessment tool (e.g. Danger Assessment, Campbell, Webster \& Glass, 2009) to officers trained in using generally structured approaches or checklists, to risk assessment mainly based on expertise, common sense and intuition. It is to be hoped that a more comparable approach with minimum standards will be established nationwide. In the social sector, risk assessment seems to be predominantly woven into the analysis of the individual problem and the search for solutions during counselling. Too little is known about risk assessment in the German medical sector to allow generalisation (Hera \& Szego, 2020).

\section{Initiating protective measures}

The outcome of the risk assessment determines the choice of protective measures. Enforcing repressive measures is the sole responsibility of the German police. In addition, consulting victims on security measures is a standard procedure. It is desirable that the pro-active approach applied by many police forces would likewise become a common practice across the country, especially if it links not only victims but also perpetrators to the support network. However, the latter are still underrepresented in the support network in many regions in Germany and their resources are generally quite limited. With regard to the social sector, it seems well established that consultations on self-security are carried out very thoroughly but, once again, too little is known about the medical sector to generalise.

\section{Cooperating to better support victims}

To comprehensively support and protect victims of domestic violence, frontline responders and other professionals working with victims must cooperate. Although the ratification of the Istanbul Convention entails the obligation to promote and strengthen inter-agency cooperation and while some best practice examples exist that show how all sides benefit from the interaction of various stakeholders (Bradley et al., 2020), the situation in Germany calls for improvement. In some cases, the stipulated exchange of information between institutions is still not efficient enough. 
For example, the late transmission of violence protection decrees to the police could endanger not only the victim but also the officers on duty as they are then unaware of possibly relevant information about the threat posed by the perpetrator. In particular, the medical sector, as an important reference for domestic violence victims, should be better integrated into the support network. Moreover, the lack of cooperation leaves especially high-risk cases far too isolated in potentially lifethreatening situations. Case conferences, which are already in place in some Länder, urgently need to be rolled out nationwide when victims are at high risk.

\section{Long-term challenges: Policies matter}

Organisationally and educationally speaking, the police have quite homogeneous structures that for other groups of frontline responders in Germany do not (yet) exist. The underlying national legal framework and the police regulations provided by the Länder define how domestic violence is to be dealt with. This transparent approach permits the strengths and weaknesses to be clearly delineated.

In contrast, the medical and social sectors consist of very diverse organisations with very different ideologies, principles and organisational cultures. Training still holds a subordinate role, at least in the medical field, and this should change to make violence-informed treatment the standard of medical care. Regulations with regard to dealing with domestic violence victims are non-existent or merely recommendations, and an evaluation of the situation is not taking place. This particularly includes the challenge of identifying cases of domestic violence among patients and the question of how to best deal with them in the context of the healthcare system.

In the long term, the implementation of policies and standards will be vital for evaluating and improving prevention and protection measures in domestic violence cases to assure the quality standard this important work needs to have throughout the country. Starting from the Istanbul Convention, policies for both the medical and social sectors could be developed with respect to dealing with victims of domestic violence and, in the second step, be aligned with police regulations in order to build a cooperative approach (Vogt, 2020). Further, the WHO's guidelines offer important reference points for establishing minimum standards, such as that professionals working with victims of domestic violence should be trained on this 
topic, that standard procedures are established in which confidentiality is guaranteed, privacy is maintained, and that referrals to further services and court-proof documentation of injuries and traces are ensured.

\section{References}

BMSFSJ. (2008). Standards und Empfeblungen für die Arbeit mit männlichen Tätern im Rabmen von interinstitutionellen Kooperationsbündnissen gegen bäusliche Gewalt der Bundesarbeitsgemeinschaft Täterarbeit Häusliche Gewalt e.V. https://www.bagtaeterarbeit.de/images/pdf/Standards_THG_Langfassung.pdf

BMFSFJ. (2016). Gewalt gegen Frauen: Täterarbeit. https://www.bmfsfj.de/bmfsfj/themen/gleichstellung/frauen-vor-gewaltschuetzen/haeusliche-gewalt/gewalt-gegen-frauen-taeterarbeit/gewalt-gegen-frauen-taeterarbeit/80700

BMFSFJ. (2020). Report submitted by Germany pursuant to Article 68, paragraph 1 of the Council of Europe Convention on preventing and combating violence against women and domestic violence (Baseline Report). https://rm.coe.int/state-report-from-germany/pdfa/16809f59c6

BMFSFJ \& BMJV. (2019). Greater Protection in Cases of Domestic Violence. Information on the Act on Protection Against Violence.

https://www.bmjv.de/SharedDocs/Downloads/DE/Service/Formulare/Mehr_Schutz_bei _haeuslicher_Gewalt_ENG.pdf?_blob=publicationFile\&v $=7$

Bundesärztekammer. (2015). Beschlussprotokoll. Frankfurt am Main, 12. bis 15. Mai 2015. https://www.bundesaerztekammer.de/fileadmin/user_upload/downloads/pdfOrdner/118._DAET/118DAETBeschlussprotokoll20150515.pdf

Bundeskriminalamt. (2020). Partnerschaftsgewalt Kriminalstatistische Auswertung - Berichtsjahr 2019. https://www.bka.de/DE/AktuelleInformationen/StatistikenLagebilder/Lagebilder/Partners chaftsgewalt/partnerschaftsgewalt_node.html

Bundesministerium für Familie, Senioren, Frauen und Jugend. (2005). Lebenssituation, Sicherheit und Gesundheit von Frauen in Deutschland. Eine repräsentative Untersuchung zur Gewalt gegen Frauen in Deutschland. https://www.bmfsfj.de/bmfsfj/studie--lebenssituation--sicherheit-undgesundheit-von-frauen-in-deutschland/80694.

Bundesministerium für Familie, Senioren, Frauen und Jugend. (2008). Gesundheit-Gewalt-Migration: Eine vergleichende Sekundäranalyse zur gesundheitlichen und sozialen Situation und Gewaltbetroffenheit von Frauen mit und ohne Migrationshintergrund in Deutschland.

https://www.bmfsfj.de/resource/blob/93964/588d6d5da075d2803f8696dfbbe3d35c/gesun dheit-gewalt-migration-langfassung-studie-data.pdf

Bundesministerium für Familie, Senioren, Frauen und Jugend. (2008a). Gewalt gegen Frauen in Paarbeziehungen - Eine sekundäranalytische Auswertung zur Differenzierung von Schweregraden, Mustern, Risikofaktoren und Unterstützung nach erlebter Gewalt. https://www.bmfsfj.de/blob/93968/f832e76ee67a623b4d0cdfd3ea952897/gewaltpaarbeziehung-langfassung-data.pdf

Campbell, J. C., Webster, D.W. \& Glass, N. (2009). The danger assessment: validation of a lethality risk assessment instrument for intimate partner femicide. Journal of Interpersonal Violence, 24(4), 653 - 674. doi: 10.1177/0886260508317180

Council of Europe. (2014). Council of Europe Convention on preventing and combating violence against women and domestic violence. https://wcd.coe.int/ ViewDoc.jsp?id=1772191\&Site $=$ CM\&BackColorInternet $=$ C3C3C3\&BackColorIntranet $=$ EDB021 \&BackColorLogged $=$ F5D 383 
FRA. (2014). Violence Against Women: An EU-wide Survey: Main Results (Dignity). https://fra.europa.eu/sites/default/files/fra_uploads/fra-2014-vaw-survey-main-resultsapr14_en.pdf

Giljohann, S. \& Bendix-Kaden, M. (2020). Polizeilicher Opferschutz bei Fällen bäuslicher Gewalt. Klinik für Kinder- und Jugendpsychiatrie/Psychotherapie, Universitätsklinikum Ulm. https:// haeuslichegewalt.elearning-gewaltschutz.de

Giljohann, S. \& Bendix-Kaden, M. (2020a). Polizeilicher Opferschutz bei Hocbrisikofällen bäuslicher Gewalt. Klinik für Kinder- und Jugendpsychiatrie/Psychotherapie, Universitätsklinikum Ulm. https:// haeuslichegewalt.elearning-gewaltschutz.de/

Grass, L. H., Mützel, E. \& Preuss, R. (2012). Medizinische Interventionen gegen Gewalt an Frauen II. Die Versorgung kann verbessert werden. Deutsches Äryteblatt, 109, 16.

Grass, H., Steffens, M. \& Hefer, B. (2014). Gewaltprävention - Schwierige Gratwanderung in der ärztlichen Praxis. Deutsches Ärzteblatt, 13, 450.

Hera, G. \& Szegő, D. (2020). Country Reports and Cross-National Comparison on the Risk Assessment Tools and Case Documentation used by Frontline Responders. https://improdova.eu/pdf/IMPRODOVA_D2.3_Risk_Assessment_Tools_and_Case_Doc umentation_of_Frontline_Responders.pdf?m $=1585673380 \&$

Hochschule für Politik München. (2020). Gewalt an Frauen und Kindern in Deutschland wäbrend COVID19-bedingten Ausgangsbeschränkungen: Zusammenfassung der Ergebnisse. https://www.kriminalpraevention.de/files/DFK/Praevention\%20haeuslicher\%20Gewalt/20 20_Studienergebnisse $\% 20$ Covid $\% 2019 \% 20$ HGEW.pdf

IMPRODOVA. (2020). Identifying gaps and bridges of intra- and inter-agency cooperation. https://improdova.eu/pdf/IMPRODOVA_D2.4_Gaps_and_Bridges_of_Intra_and_Interagency_Cooperation.pdf?m $=1585673383 \&$

Jungnitz, L., Lenz, H., Puchert, R., Puhe, H., \& Walter, W. (Eds.). (2007). Gewalt gegen Männer: Personale Gewaltwiderfahrnisse von Männern in Deutscbland. Opladen; Farmington Hills: Verlag Barbara Budrich. doi:10.2307/j.ctvdf049f

Novak, S. \& Galaway, B. (1983). Domestic Abuse Intervention Project Final Report. Duluth MN: Domestic Abuse Intervention Project.

Sacco, S. (2017). Häusliche Gewalt - Kostenstudie für Deutschland - Gewalt gegen Frauen in (ehemaligen) Partnerschaften. Trediton Verlag.

S.I.G.N.A.L. e.V. (2018). Umgang mit Gewalt in Paarberiehungen und mit sexueller Gewalt gegen Frauen. Leitlinien der WHO für Gesundheitsversorgung und Gesundheitspolitik. https:/ / www.signalintervention.de/sites/default/files/2020-04/WHO_Broschuere_4_9_18_web.pdf

S.I.G.N.A.L. e.V. (2020). Leitfäden für die Intervention in der Gesundheitsversorgung bei bäuslicher und sexualisierter Gewalt. https://signal-intervention.de/sites/default/files/202006/2020_06_10\%20Uebersicht_Leitfaeden_Gesundheit_final_0.pdf

Steffens, M. \& Janz, U. (2013). Arbeitshilfe für die ärztliche Praxis zum Vorgeben bei bäuslicher Gewalt. In: DGGG/Hess. Sozialministerium (HRSG). Ärztliches Praxishandbuch GEWALT (pp. 89_ 114). Verlag S. Kramarz.

Vogt, C. (2020). Interagency Cooperation. European Law Enforcement Research Bulletin, (19), 153-163. http://bulletin.cepol.europa.eu/index.php/bulletin/article/view/412

World Health Organization (WHO). (2013). Responding to intimate partner violence and sexual violence against women. WHO clinical and policy guidelines.

https://www.who.int/reproductivehealth/publications/violence/9789241548595/en/

\section{Legislative framework}

Council of Europe. (n.d.). Vollständige Liste der Verträge des Europarates. https://www.coe.int/de/web/conventions/full-list/-/conventions/rms/090000168008482e 
German Act on Protection against Violence (Gesetz zum zivilrechtlichen Schutz vor Gewalttaten und Nachstellungen/GewSchG). (2001). BGBl. I S. 3513. https://www.gesetze-iminternet.de/gewschg/BJNR351310001.html

German Civil Code (Bürgerliches Gesetzbuch/BGB). (2013). Federal Law Gazette I p. 3719. https://www.gesetze-im-internet.de/englisch_bgb/index.html

German Code of Criminal Procedure (Strafprozeßordnung/StPO). (2019). Federal Law Gazette I, p. 1066. https://www.gesetze-im-internet.de/englisch_stpo/index.html

German Criminal Code (Strafgesetztbuch/StGB). (1998). Federal Law Gazette I, p. 3322. https://www.gesetze-im-internet.de/englisch_stgb/index.html\#gl_p0776

German Social Code (Sozialgesetzbuch/SGB). (1990). BGBl. I S. 1163. https://www.gesetze-iminternet.de/sgb_8/

\section{Websites}

Baden-Württemberg.de. (n.d.). Pilotprojekt „Bekämpfung Häuslicher Gewalt" startet. https://www.badenwuerttemberg.de/de/service/presse/pressemitteilung/pid/pilotprojekt-bekaempfunghaeuslicher-gewalt-startet/

BIG. (n.d.). Webpage of the Berlin Initiative against Violence towards Women. https://www.bigberlin.info/node/270

BKA. (n.d.). Webpage of the Federal Criminal Police Office with the annual reports of the German Police Crime Statistics in English. [The specific reports on partner violence, however, only exist in German.] https://www.bka.de/EN/CurrentInformation/PoliceCrimeStatistics/policecrimestatistics_n ode.html

Charité. (n.d.). Physical violence. https://gewaltschutzambulanz.charite.de/en/affected/physical_violence/

DAIP. (n.d.). Webpage of the Domestic Abuse Intervention Programs. https://www.theduluthmodel.org/what-is-the-duluth-model/

Destatis. (n.d.). Webpage of the Federal Statistical Office with official data on the society, the economy, the environment and the state. https://www.destatis.de/EN/Themes/SocietyEnvironment/Population/Current-Population/_node.html

HAIP. (19.3.2021). Webpage of the Hanover Intervention Program against Domestic Violence. https://www.hannover.de/Leben-in-der-Region-Hannover/Verwaltungen-Kommunen/DieVerwaltung-der-Landeshauptstadt-Hannover/Gleichstellungsbeauf $\% \mathrm{C} 2 \%$ ADtragte-derLandeshauptstadt-Hannover/Wir-f $\%$ C3\%BCr-die-B $\% \mathrm{C} 3 \% \mathrm{BCrgerinnen-und-}$ B $\%$ C3\%BCrger/Hannoversches-Interventionsprogramm/\%C3\%9Cber-HAIP

Interdisciplinary Coordination Centre for Domestic Violence. (n.d.). Webpage of the "Interdisziplinäre Koordinierungsstelle Häusliche Gewalt für die Region Braunschweig". https://www.lab.niedersachsen.de/startseite/standorte/standort_braunschweig/interdiszipli nare_koordinierungsstelle_hausliche_gewalt/

S.I.G.N.A.L. (n.d.). Intervention im Gesundheitsbereich gegen bäusliche und sexualisierte Gewalt. https://www.signal-intervention.de/

Stalking KIT. (n.d.). Webpage of the Crisis-Intervention-Team Stalking and Domestic Violence in Bremen. http://www.stalking-kit.de/ 


\title{
FrontLine RESPONSE TO High IMPACT DOMESTIC VIOLENCE IN HUNGARY
}

\author{
GÁBOr HÉRA \& DÓRA SZEGŐ
}

Foresee Research Group, Budapest, Hungary.

E-mail: gabor.hera@foresee.hu; szegodori@gmail.com

Abstract The first part of the chapter describes the legalisation of domestic violence. The Criminal Code criminalises domestic violence, including several areas of domestic violence such as emotional, physical, economic, and sexual violence. Two main limitations are that the Criminal Code does not sanction verbal abuse, and the police are obliged to file a criminal complaint ex officio only if domestic violence involves serious physical injuries. In all other cases, it is upon the request of the victim to file a criminal complaint against the offender. The second part of the chapter describes the roles of the different front-line agencies in responding to domestic violence; the police, the Child Protection Perceiving and Reporting System, the Guardianship office, the family support and child welfare services and the different NGO's that operate crisis management and different helplines. The next part of the chapter introduces the work of the National Crisis Telephone Helpline as a good practice of cooperation between stakeholders that helps victims of domestic violence and human trafficking through a free of charge telephone line. The last part shows the main challenges and shortcomings characterising the handling of domestic violence in Hungary.

Keywords:

domestic violence, Hungary, interagency cooperation, victims, police, NGO 


\section{Short description of Hungary's history and legislation regarding domestic violence}

In Hungary, several legislative and policy-related steps took place before domestic violence as a crime became part of the Criminal Code (Act C of 2012 on the Criminal Code), passed only in 2012. Among its antecedents, the most important ones were the following: the first law, which directly regulated issues related to domestic violence, was Act XXXI of 1997 on the protection of children and administration of guardianship. That law aimed at ratifying the children's fundamental rights as defined by the United Nations Convention on the Rights of the Child. The law described violent acts within families that are directed against children. It should also be mentioned that, since the amendment of the Criminal Code in 1997, forced intercourse and acts of indecency between spouses were subject to punishment.

The government has established the National Strategy for Social Crime Prevention in 2003 (Parliamentary Decree No: 115/2003 (X.28.) on the National Strategy for Social Crime Prevention), which covered the issue of domestic violence as a priority area. In line with the National Strategy, an instruction of the Hungarian National Police Headquarters was passed in 2003 that addressed domestic violence (hereinafter: DV) and victims thereof more precisely (Hungarian National Police Instruction (III. 27) No: 13/2003 on the tasks of the police force related to domestic violence and the defence of minors). A new police instruction was passed in 2007 (Hungarian National Police Instruction (OT 26.) No: 32/2007 on the execution of police tasks related to handling violence between family members and the protection of minors), which replaced the previous one and regulated tasks of the police handling violence between family members and the protection of minors. The instruction referred to various criminal acts of the Criminal Code that in special instances are considered violent domestic crimes. Victims of DV are "all those who are the direct victims of the DV offences, as well as those, who suffered physical, mental, emotional or moral harm in relation to the offences, including those relatives, who were not directly targeted by the violence" - as defined by the above mentioned document (OT 26.; No: 32/2007). 
The next, significant legislative step was the establishment of the legal framework of restraining orders (Act LXXII of 2009 on restraining orders applicable due to violence between family members). A temporary preventive restraining order is ordered by the police, prohibiting any contact by the offender towards the victim for 72 hours, in order to prevent further, serious harm. Preventive restraining orders can be requested by the police, by the victim, or by the victim's representative before the court and ordered by the court for a maximum of 60 days. (ibid, Article 14 (1)).

In addition to this, the court of justice is obliged to report any threat of violence between family members and endangerment of children (ibid, Article 2 (1)). Such reports shall be made to the guardianship office, to the child welfare services, and if there are circumstances detected that make temporary preventive restraining reasonable in a civil lawsuit, the court of justice shall also report this to the police (ibid, Article 17 (1)).

There is a further form of a restraining order, not exclusively targeting domestic violence cases. Contrary to the temporary preventive restraining orders, it is always ordered as part of a criminal procedure, initiated against the defendant by the investigative authority, ordered by the judge in case of a significant risk of committing violent crimes. Based on a personal hearing, the necessary measures shall be taken to prevent and stop violence between family members.

The Criminal Code (Act C of 2012 on the Criminal Code) includes provisions regarding domestic violence. It criminalizes several activities under the scope of DV that were not covered by the previous Code, including those that do not include physical violence but are nonetheless serious violations of the victim's human dignity. The present regulation sanctions four areas of domestic violence: emotional, physical, economic and sexual. The Criminal Code does not sanction verbal abuse. The major limitation of the present legal framework of DV as a crime is that the police are obliged to file a criminal complaint ex officio only if the offender committed an aggravated battery (Article 164 (3)), and DV involves serious physical injuries. In all other cases - if the DV involves less serious physical injuries or no physical injuries at all - it is upon the request of the victim to file a criminal complaint against the offender. 
The latest instruction of the Hungarian National Police Headquarters in relation to DV was passed in 2018 (Hungarian National Police Instruction (I. 25) No: 2/2018 on the implementation of police tasks relating to the handling of violence between relatives). It provides a very detailed protocol for the police on the necessary legal and administrative steps when taking measures and investigating in domestic violence cases. The most important tasks of the police defined in the instruction are the following: 1.) the instruction defines the necessary conditions and procedural steps of the different types of restraining orders; 2.) it regulates the ways of cooperation among the different FLR's, including the police, the court, the social services and other members of the Child Protection Perceiving and Reporting System and the role of the police in initiating cooperation; 3 .) it prescribes to provide sufficient information for the victims about their rights concerning filing a criminal complaint and about available victim-protection services; and 4.) it orders and specifies the regular education of the police staff who takes part in DV cases, including a mentoring system, conflict-management training and specific training about the legal and psychological aspects of domestic violence.

\section{Reporting rates about domestic violence}

We requested country-wide statistics about the number of the registered victims of violence against partners and family members (including the following crimes: domestic violence, sexual abuse, sexual violence, sexual exploitation, sexual coercion, coercion, deprivation of sys personal freedom, private justice, physical battery, homicide, aggravated cases of homicide). Altogether, there were 2334 victims registered in the above mentioned crimes where the offender was a partner or family member in 2017, and 1225 in the first half of the year 2018 (Coordination and Statistical Unit of the Ministry of Interior, 2019).

However, it is important to underline that solely domestic violence appears in the official DV statistics from the crime categories mentioned above. For comparison, there were only 339 cases of domestic violence as a crime registered in 2018, and 392 in 2019 (Coordination and Statistical Unit of the Ministry of Interior, 2020, as cited in Munk, (2020). These statistics show that the crime category of domestic violence makes up a small amount of all violent crimes committed against partners and family members. 
As a consequence of the COVID-19, we have seen a remarkable increase in the number of domestic violence crimes. According to the statistics, there were altogether 103 domestic violence crimes registered only in April and May of 2020, and the number of all registered domestic violence cases between 1 March and 31 August was 330 - which equals the number of cases in the whole year if compared to previous years (Coordination and Statistical Unit of the Ministry of Interior, 2020).

\section{The role of police, other front-line and first-responder agencies, and pertinent stakeholders in responding to high impact domestic violence}

Organizations in contact with victims of domestic violence and their most important tasks will be described in this chapter.

The police have a major role among the frontline responder organizations helping victims of domestic violence. Officers have to follow very detailed regulations regarding the handling of domestic violence as well as crime prevention duties that have been defined in different instructions and laws, already discussed in chapter 1. Among other tasks, they are authorized to issue temporary preventive (72 hours) restraining orders and to initiate preventive (long-term) restraining orders at the court. Reports can be made to the police through a telephone helpline or through the also free witness hotline, ensuring anonymity. If any violent action between family members is reported, police officers are sent to the venue without delay (as is required by the Hungarian National Police Instruction (I. 25) No: 2/2018 (ibid, Section 4). As mentioned earlier, the police are obliged to file a criminal complaint ex officio only if the DV involves serious physical injuries. In all other cases, the police only take measures and investigate if the victim files a criminal complaint.

The Child Protection Perceiving and Reporting System is an institutional network and protocol established to handle family situations of harm and neglect that concern children. It is divided into institutions providing services or performing authority tasks by the Act XXXI of 1997 on the protection of children and administration of guardianship. 
Authority tasks concerning children shall be performed by the guardianship office. Under the relevant legislation (Government Decree No: 149/1997. (IX. 10.) on guardianship offices and child protection and guardianship) the abuse or severe negligence of children or in case of any other severe cause of endangerment the guardianship office shall immediately take measures required for the protection of the child. The guardianship office may take the following measures to protect children: taking them into protective custody, providing temporary accommodations, temporary foster care, and permanent foster care.

Upon the victim's request, the guardianship office shall provide legal, medical, psychological and mental health assistance. In the scope, the victim and the offender shall be informed about potential therapy and other available help and conflict management opportunities. The guardianship office may order mediation proceedings ex officio or upon the request of the involved persons. The mediator shall notify the guardianship office without delay if urgent measures are required in a child's interest, particularly if the child's abuse or gross negligence is suspected by any parent (Government Decree No: 149/1997., ibid, Article 30/C).

The act on restraining order prescribes that if children are endangered by violence, the police and other frontline organisations have to report the threat to the Guardianship Office.

It is worth noting here that the children's rights representative shall (inter alia) advocate for and protect children's rights in child protection care (Act XXXI of 1997 on the protection of children and administration of guardianship, Article 11/A).

Service tasks are fulfilled by family support and child welfare services. According to the definition of the Act III of 1993 on social administration and social supports, the family support services provide support for persons and families needing help in crisis situations - including violence - to maintain their ability to manage their lives (ibid, Article 64 (1)). Child welfare services are special personal social services protecting children's interests using the methods and means of social work (ibid, Article 39 (1)). The primary task of child welfare services is to prevent and stop the endangerment of children. For this objective, the child welfare services operate, organize, and harmonize the Child Protection Perceiving and Reporting System regulated by Act XXXI of 1997 on the protection of children and administration of guardianship. The organizations named in the Act shall report - among other information - any incident or suspicion of domestic violence to the child welfare services in order to 
prevent and stop the endangerment of the child. Recording reports, exploring the problems of endangered children and searching for solutions are obligations of the child welfare services.

The operation of temporary homes for children, crisis centres, secret shelter homes and halfway houses is regulated by the Act XXXI of 1997 on the protection of children and administration of guardianship. Those children can be placed in a temporary home for children living in their family but were temporarily left without care and supervision or would be left without these in the event of a lack of intervention and whose care is endangered due to family difficulties. People in crises due to domestic violence can be accommodated in crisis centres and secret shelter homes. Secret shelter homes also help manage psychological injuries of abuse and give legal advice to protect the interests of the victim. The crisis centre may provide halfway-house services for the abused family leaving the shelter home as a supplementary service to help the victims' social reintegration.

Under Act CXXXV of 2005 on helping the victims of criminal offences and mitigation of damages by the government, victims can turn to any victim support service as well. The service can provide support by facilitating the enforcement of interests, protection of witnesses, financial support and mitigation of damages, as well as providing protected accommodations.

Victims of domestic violence often contact the health care services first, typically for the treatment of their injuries or in order to provide medical reports. If children are concerned with domestic violence, health care workers are obliged to report to child protection services, the guardianship office, and the police (based on whose report temporary preventive restraining may be ordered). Public education institutions also have a similar reporting obligation.

There are several NGO's that operate crisis management and psychological telephone helplines. Among them, the Blue Line (Kékvonal), operated by the Child Crisis Foundation (Gyermekkrízis Alapítvány), must be mentioned. Child abuse and lost children can be reported on a free telephone number. National Crisis Telephone Information Service (OKIT) aims to help victims of domestic violence and human trafficking on a phone number available free of charge, year-round throughout the country. According to Government Decree No: 1351/2013. on the national strategy between 2013 and 2016 on the fight against human trafficking and Government 
Decree No: 354/2012. (XII. 13.) on the identification order of victims of trafficking in human beings, placement to protected accommodation and cooperation among the institutional network of protected accommodations and other FLR's shall be coordinated by OKIT.

Although specific organizations are not named in the legal regulations, several NGOs work in protecting and supporting the victims of domestic violence.

\section{Good practice of co-operation between police, other front-line responder agencies, and pertinent stakeholders}

This chapter presents the work of the National Crisis Telephone Information Service (Országos Kríziskezelő és Információs Telefonszolgálat, hereinafter: OKIT). The organisation helps victims of domestic violence and human trafficking through a telephone line available free of charge, year-round throughout the country. Trained domestic violence counsellors (working in pairs) provide primarily counselling and information about available victim support services. In addition, they refer victims leaving their homes and escaping their abusers to one of the shelters or crisis centres operated by the state and by NGO's. A risk assessment tool supports the counsellors in assessing crisis situations and making decisions about the adequate response. However, the professional staff at OKIT reacts even if the evidence is not available; victims do not have to prove (by a medical report, testimony of witnesses or video footage) that abuse has occurred. All in all, the organisation can offer a low-threshold service targeted to the complex needs of DV victims and thereby decrease latency.

OKIT was launched in 2005, based on the findings and experiences of a pilot program related to a hotline focusing on domestic violence. Since 2005 the network of the institutions providing safe accommodation for victims and working in close cooperation with OKIT has been continuously developing (16 crisis centres, 2 secret shelters, 2 temporary homes were established just between 2007 and 2016). As a result, OKIT was able receive altogether 77,213 calls (not including an extra 67,212 fake calls) between 2008 and 2016 (Arnold, Hera, Meszaros \& Szabo, 2017, p. 6273). 
Among the strengths of the organisation, effective victim protection should be highlighted. There is a strict regulation about the confidentiality of shelter locations; OKIT also keeps their addresses confidential. Therefore, even victims escaping abusive relationships are not informed about their destination and, as a result, victims living in shelters feel safe. There are other policies that also increase trust: referrals are made to shelters, for instance, even if victims do not report DV incidents to the police and the organisation does not record calls. Victim protection is an important requirement even if the police contact OKIT because of a woman/family reported to be missing. The organization informs the police if the missing person was relocated by OKIT; however, the exact address of the victim's new location is considered as confidential information and is not sent to the police.

OKIT works in close cooperation with several organisations and institutions. In the event of an emergency call, counsellors at OKIT are responsible for primary crisis assessment and intervention. As information about the free capacity of shelters all around Hungary is available for the staff, they know at which institution the victims can be accommodated. In addition, OKIT works with the police; in the event of an emergency call, staff can report the incident to the police in order to ensure effective protection for the victims of violence between family members against threats and revenge. There is also close cooperation between OKIT and the Family Support and Child Welfare Services 1) before and during victims' flight from their abusers (in order to prepare and successfully implement the escape), 2) during victims' stay at shelters (in order to inform the Services about the developments that are achieved), and 3) before the victims leave the safe accommodations (in order to support their social reintegration). In addition, OKIT serves as a link between schools that are attended by child victims before and during their accommodation in shelters.

The organisation successfully facilitates the cooperation between governmental and non-governmental organizations. The website of the National Crisis Telephone Information Service states: "OKIT considers it important to cooperate with all of the actors that can and would like to take part in solving diverse problems, preventing crisis situations and conflicts" (bantalmazas.hu, 2020) to give collective, complex and operative responses to DV cases. 
A further way in which OKIT strengthens cooperation among professionals is that it regularly provides professional exchanges among the shelters - which take place either in forms of institution visits or workshops for experience exchange. Those are considered to be the most useful opportunities by the shelter workers to learn from field experiences and acquire good practices.

All in all, we consider the work of OKIT as an example of best practice, as the organisation is able to offer a low-threshold service that is available even for those victims who do not report DV incidents to the police, as they are afraid of the consequences and/or if the evidence does not confirm their testimony. The organisation can implement real victim protection by keeping information about the shelters and victims confidential and successfully coordinate the relocation of victims to institutions providing safe accommodation. Protecting victims is a core value, which is successfully achieved even by the network that is coordinated by OKIT. Mutual trust among the members of the network has successfully developed; the professional work of OKIT is known and respected by its partner organizations, primarily due to the high professional standards that are created by OKIT to guide professional practices, to be included in the training programs and methodological handbooks created by OKIT. Cooperation is supported even by effective information sharing. As a result, victims reaching out for help and calling the OKIT receive an adequate, professional and immediate response in the form of information, counselling and/or referral to institutions providing safe accommodation.

\section{Main challenges and issues to be anticipated}

A number of our interviewees pointed out shortcomings with respect to the training of professionals facing HIDV. Leaders of the social services and heads of police departments are usually well trained in recognizing and handling DV. However, police officers patrolling the streets (especially young officers without relevant experience) may not be prepared well enough to identify and address DV. Although, law enforcement education both at the secondary and tertiary level provides some training on DV, it is dominated by theoretical knowledge, which does not cover sensitization and is difficult to use in daily practice. The training of healthcare professionals hardly touches upon the subject of domestic violence. Compared to police and health care, professionals working in the social sector gain more 
knowledge about domestic violence as part of their college education, but they also lack specialised training that would offer practical knowledge. As a consequence of the absence of appropriate training, those professionals who directly or indirectly come into contact with violence often fail to recognise signs of DV. In addition, some of them easily get to the mistake of blaming the victims of DV. They are not aware of the mechanism and effects of DV and do not understand why victims do not call for help and leave their abusive relationships.

Those who work with affected families have identified severe structural and organizational problems in the social and healthcare sectors. The most striking ones were the intense fluctuation, burnout, the absence of young professionals, as well as the inefficient and overwhelming administrative and documentation tasks that hinder professional work. As a result, there is less time and energy for professional work, which negatively affects the support provided for the victims and professional development in the workplace.

As part of the study we interviewed crisis centres and secret shelters that offer temporary housing and social and psychological care for victims escaping relationship violence. A number of our interviewees stated that the physical protection provided for victims and staff members at the above institutions is insufficient, and complained that the legal instruments of the temporary preventive restraining order and preventive restraining order are not used effectively by the police and by the court, and do not provide adequate protection for the victim.

Experts of the social sector identified "migrating families" as the most serious midterm problem, which means that many families have moved among the system's various institutions for years. One reason for that is institutional dependency and the lack of support for victims after leaving the institutional net. Housing and integration to the labour market is especially difficult for former victims of domestic violence, especially if they raise their children alone. It is almost impossible to start an independent life after leaving crisis care. Supported housing works as a pilot and provided in small scale only.

One of the study's main conclusions is that prevention and rapid response require cooperation and information sharing between various actors - the police, family services, crisis care institutions and other institutions that come in contact with families, such as nursing services, kindergartens and schools. In our experience, 
personal and direct communication can greatly contribute to the effectiveness of collaboration, thus counteracting the impersonality and sometimes slowness of (mostly paper-based) bureaucratic processes.

Although cooperation is prescribed in protocols, it is rather rare in practice. Experts in most locations reported negative experiences concerning the absence of crosssectorial cooperation, its ad hoc character and the absence of information flow. There is no cross-sectorial or national informational database that would document and preserve information about DV incidents. Each frontline responder (police department, social service, guardianship office, shelter, etc.) from each sector has its own records that is typically not transparent to other frontline responders at different locations or different sectors. FLRs from various sectors cannot see the DV history of their clients. A national database and system of information that records relevant data about victims, offenders and DV incidents (e.g. testimonies from the parties, injuries, observations of the scene, measures, criminal procedures, etc.) would greatly support cooperation, prevention and risk assessment.

It is also important to note that we had the chance to interview many dedicated, highly qualified professionals during the study. These people often complement institutional solutions, seek their own paths, innovate, collaborate, and actively seek out training opportunities. According to the information we gained through our fieldwork, non-profit organizations bring innovative approaches, knowledge, experiences and trainings to the field, which are not sufficiently acknowledged and embedded into the system in general.

A key element of effective action against domestic violence is risk assessment. A further structural problem characterizing the police and the social and health care sectors in Hungary is the lack of sufficient, unified risk assessment tools and policies and measures as reactions to certain risks. Practices vary on a large scale throughout the country depending on the individual competencies and attitudes of the responding services, which intensify the latency of cases and hinder effective frontline response.

Due to the insufficient legislative frameworks, actual criminal charges in domestic violence cases take place very rarely. The reason for that is that according to the present legislation the victim has to file a complaint, provide and maintain a testimony throughout the criminal procedure, as well as provide several evidence 
regarding the regularity of violence as well as of the physical injuries supported by a medical report and by witness testimonies. The collection of sufficient evidence is very difficult. Due to fear, dependency, and the dynamics of violence, victims are usually reluctant to file a complaint against the offender or are likely to withdraw their complaints in the investigation phase. For the same reason, it is also problematic to provide witness testimonies. The long and bureaucratic nature of the investigation process discourages the victims further. A typical scenario is that the police initiate and conduct an investigation, and the prosecutor does not file charges. This practice is confirmed by the statistics from the police department in one of our case locations: there were altogether four DV crime cases investigated in 2018, three of them were based on a police report, and one of them was based on a citizen's report. None of them resulted in a criminal charge by the prosecution. Evidence in DV cases is evaluated freely by the prosecution. There are no unified, country-wide rules for the evaluation of evidence. That which would be enough for a charge in one county would not be enough in another. Stricter legislation and unified practices concerning reporting, risk assessment and management as well as the evaluation of criminal evidence would be the main conditions to support effective institutional responses to HIDV.

\section{References}

Act III of 1993 on social administration and social supports. (1993). https://net.jogtar.hu/jogszabaly?docid=99300003.tv

Act XXXI of 1997 on the protection of children and administration of guardianship. (1997). https:// net.jogtar.hu/jogszabaly?docid=99700031.tv

Act CXXXV of 2005 on helping the victims of criminal offences and mitigation of damages by the government. (2005). https://net.jogtar.hu/jogszabaly?docid=a0500135.tv

Act LXXII of 2009 on restraining orders. (2009). https:// net.jogtar.hu/jogszabaly?docid=a0900072.tv

Act $\mathrm{C}$ of 2012 on the Criminal Code. (2012). https:// net.jogtar.hu/jogszabaly?docid=a1200100.tv Arnold, P. and Hera, G. and Meszaros, Z. and Szabo, A. (2017). A „Kriziskeezelo" szolgálatok fejlesztése” elnevezésü, EFOP1.2.4-VEKOP-16-2016-00001 azonositó sqámú projekt keretében megvalósuló kutatás eredményeiroll (Findings of the research program that is implemented within the framework. of the "Development of crisis management services" program. https://www.kapcsoljegybol.hu/files/shares/PDF\%20dokumentumok/EFOP124_ZAROT ANULMANY_20180119.pdf\#page=72\&zoom $=100,0,134$

Coordination and Statistical Unit of the Ministry of Interior. (2019). Egyes személy elleni eröszakos büncselekemények ismerté vált természetes személyü sértettek száma az elkövetó sértetett kapcsolata szerinti bontásban. Budapest: Coordination and Statistical Unit of the Ministry of Interior.

Coordination and Statistical Unit of the Ministry of Interior. (2020). Büncselekmények. Budapest: Coordination and Statistical Unit of the Ministry of Interior.

Government Decree No: 149/1997. (IX. 10.) on guardianship offices and child protection and guardianship. (1997). https:// net.jogtar.hu/jogszabaly?docid=99700149.kor 
Government Decree No: 354/2012. (XII. 13.) on the order of identifying victims of human trafficking. (2012). https:// net.jogtar.hu/jogszabaly?docid=a1200354.kor

Government Decree No: 1351/2013. on the national strategy between 2013 and 2016 on the fight against human trafficking. (2013). http://www.kozlonyok.hu/nkonline/MKPDF/hiteles/MK13100.pdf

Hungarian National Police Instruction (III. 27) No: 13/2003 on the tasks of the police force related to domestic violence and the defence of minors. (2003).

Hungarian National Police Instruction (OT 26.) No: 32/2007 on the execution of police tasks related to handling violence between family members and the protection of minors. (2007). http://www.police.hu/sites/default/files/32_2007.pdf

Hungarian National Police Instruction (I. 25) No. 2/2018 on the implementation of police tasks relating to the handling of violence between relatives. (2018). https:// net.jogtar.hu/jogszabaly?docid=A18U0002.ORF\&txtreferer=00000001.txt

Munk, V. (2020). Mit ér a törvény, ha sokadszorra ver meg a párod? https://index.hu/belfold/2020/02/13/hiaba_van_ra_torveny_alig_ismerik_fel_a_hatosagok _a_csaladon_beluli_eroszakot/

Parliamentary Decree No: 115/2003 (X.28.) on the National Strategy for Social Crime Prevention. (2003). https://mkogy.jogtar.hu/jogszabaly?docid=a03h0115.OGY 


\title{
FRONTLINE RESPONSE TO HIGH IMPACT DOMESTIC VIOLENCE IN Portugal
}

\author{
Paulo Machado, Lúcia G. Pais, Sérgio Felgueiras \& \\ CARINA QUARESMA \\ ICPOL - Research Centre of the Higher Institute of Police Sciences and Internal \\ Security, Lisbon, Portugal. \\ E-mail: pfsmachado@psp.pt; lmpais@psp.pt; srfelgueiras@psp.pt; \\ carina.quaresma@gmail.com
}

Abstract There have been profound social transformations in Portugal in the last 50 years. Portugal currently adheres to the international and European agenda to prevent domestic violence. In the chapter the Portuguese legislation and the reporting figures regarding domestic violence, the role of the Law Enforcement Agencies, other first responder agencies, and pertinent stakeholders in responding to high impact domestic violence, as well as the National Network for the Support of Victims of Domestic Violence, are addressed. The authors also discuss good practices and significant challenges. Two of these are intertwined - none of them is quickly addressed, nor can they be addressed by themselves. One is developing a collective attitude that considers domestic violence as unacceptable behaviour, besides being punished by the criminal law. The other is directly posed to the law enforcement agencies and has to do with the increasing complexity of the operational procedures (derived from the new tools presented by the government recently). The problem of elites provoking social change on a superlative level is to forget that adopting new social models is not achieved by decree but through social influence processes, which takes time.

Keywords:

domestic

violence,

Portugal,

interagency

cooperation, victims, police, $\mathrm{NGO}$ 


\section{Introduction $^{1}$}

There have been profound social transformations in Portugal, namely its urbanisation rate, industrialisation and tertiarization processes in the last 50 years. However, Portuguese society is still rooted in old customs and social practices that are not gender-friendly, nor very progressive towards the eradication of interpersonal violence as an instrument of coercion over others, namely within the family. In this respect, Portugal is very diverse, but this diversity is not essentially geographical (rural vs urban), political (left vs right), socio-economic (rich vs poor), educational (low vs high educational degrees) or generational (youngers vs elders). It is above all sociological, in the sense that absolute adherence to the international and European agenda in terms of the prevention of violence, namely domestic violence, is assumed by certain political and cultural elites, namely by the Parliament and Government. However, there is still much mistrust and resistance in large crosssectional groups within society.

The question should be understood under the opposition between cultural roots and the change of social values (Inglehart, 2018). There are some areas and some discourses that still embody a social and cultural belief regarding the patriarchal power that ruled social and intimate relationships in Portugal for a long time. We keep hearing a discourse that is tolerant of this issue. Some violent behaviour remains admissible, even taken as naturalised behaviours, at least in some social environments.

Does statistical data on DV reflects those characteristics of the Portuguese social structure?

\footnotetext{
${ }^{1}$ At a court session (in the mid-2000s), a judge addresses an aggressor who had just been convicted of domestic violence and asked him:

"Do you understand why this Court has sentenced you?"

The defendant answers:

"I do not, Your Honour. I beat my wife, not yours".
} 


\section{Portuguese legislation regarding domestic violence}

The current legislation is a consequence of two significant steps:

a. The advent of democracy (after the Carnation Revolution in 1974) and the demands it has brought to tackle the issue of the women's condition and rights (Equality of all citizens towards the Law is one of the Portuguese constitutional principles); and

b. The political overture to the international scenario and its influence towards the growing respect to those rights. The influence of the external environment on national reform dynamics has been evident due to the role of cultural and political elites.

Internally, the main legislative features were:

- 1982 - Penal Code revision, including the crime of mistreatment (partner/children).

- 1999 - Since 1999, Portugal has been implementing a structured public policy on DV. Currently, within the National Strategy for Equality and NonDiscrimination 2018-2030 "Portugal + Equal" (ENIND), Portugal has been implementing the $6^{\text {th }}$ National Plan on DV.

- 2000 - The recognition of DV as a public crime (victim's complaint is not needed for registration, and the subsequent investigation and eventual prosecution) occurred.

- 2007 - DV as a specific type of crime against people in the Penal Code.

- Since 2007 - DV defined as a priority crime in terms of prevention and investigation under the Criminal Policy Law.

- 2009 - The Domestic Violence Act approval. Among other relevant features, it has:

- Brought the victim status;

- Provided the technical means to improve the safety of victims (Tele assistance);

- Displayed protection and coercion measures within 72 hours after the denounce;

- Created urgent measures to be applied within 48 hours (after the indictment of perpetrator); 
- Recognised the urgent nature of the DV process, the detention (arrest) out of flagrant and the risk assessment and safety plans;

- Reinforced the necessity for more attending rooms;

- Demanded the mandatory communication of data (victim status and final decisions in criminal cases);

- Integrated knowledge and intervention on the phenomenon [Source: Law 112/2009, $16^{\text {th }}$ September - updated version].

- 2013 - Amendment in the Penal Code (explicitly inclusion of dating situations in DV).

- 2015 - Amendments in DV Act (DV database; homicide reviews, risk assessment, safety plans...).

- 2018 - Amendment in the Penal Code (Law no. 59/2007, 4th September) DV aggravating circumstances - the inclusion of dissemination (through social networks or other means) of data related to the privacy of the victims. Currently, the definition of the DV crime under Criminal Code is:

- 2021- Amendments in the Penal Code and in the DV Act (Law no. 57/2021, 16th August)- Penal Code: introducing the economic/patrimonial violence in legal typification of DV and defining that children dependent of the perpetrator or dependent of other victim of DV (provided for in the paragraphs a, b or c) are also considered victim of DV even if doesn't coabit with the perpetrator. DV Act: Article no. 37.-A- enlargement of the previous database, which is renamed into database on violence against women and domestic violence (enlarging its scope in terms of data, crimes included and data sources).

\section{Article 152}

Whoever, in a repetitive manner or not, imposes physical or mental abuses, including bodily punishments, deprivations of liberty, sexual offences or prevent access or enjoyment of own or common economic and patrimonial resources to the:

a) spouse or ex-spouse;

b) to a person of another or of the same sex with whom the agent maintains or has maintained a relationship of dating or equal to a relationship of spouses, even if without cohabitation;

c) to the progenitor of a common descendant in the first degree;

d) to a person particularly undefended, namely due to age, deficiency, disease, pregnancy, or economic dependency, who cohabitates with him; 
e) to a child dependent of the perpetrator or dependent of a person mentioned in the paragraphs a), b) or c) even if doesn't coabit with him,

- is punished with a sentence of imprisonment from 1 to 5 years. (...)

At the international level, Portugal has ratified all existing legal instruments, namely the UN Convention on the Elimination of All Forms of Discrimination against Women (1980), which entered into force in Portugal on 03rd September 1981. In 2000 Portuguese authorities adopted the EU Convention on Compensation to Victims of Violent Crimes. Portugal has also ratified in 2013 the Council of Europe Convention on Preventing and Combating Violence against Women and Domestic Violence (Istanbul Convention, 2011), and is, since August 2014, legally binding.

It has been evident the capacity to monitor and transpose into Portuguese legislation the civilisational advances in terms of preventing and combating DV. To this achievement, the political will and participation in the most essential and decisive international fora took a decisive role, both in Europe and worldwide. Indeed, the advances made in terms of legislation and public policies regarding DV are less due to the existence of gender-egalitarian or pro-feminist social pressure from the bottom, which is not remarkable. The emancipatory social movement has been weak and almost partisan. Much more important has been the role played by nongovernmental organisations and, above all, by the public body named Commission for Citizenship and Gender Equality (CIG), whose origin dates back to the early 1970s (although with a capacity quite distinct from today's). CIG's mission is to ensure the implementation of public policies in the field of citizenship, the promotion and defense of gender equality and the fight against domestic and gender violence and trafficking in human beings. CIG is responsible for the coordination of the ENIND (se, above, page 217).

\section{Reporting rates about domestic violence}

A snapshot about DV reported crimes shows its high relevance within the Portuguese criminal panorama: in 2019, as in previous years, this continued to be the second crime most reported at the national level, representing $9 \%$ of all the crime recorded by the LEA. Considering all the different sub-types within DV crime (domestic violence spouse/marital partner; against minors; mistreatment spouse/analogue and other maltreatment), the number of cases in 2019 reached 30 
thousand (for a population of 10,2 million inhabitants, which corresponds to a rate of 2,9 cases per 1000 inhabitants). It means almost 2500 cases per month, 81 per day and 3 per hour.

The current DV situation throughout the country is characterised by marked diversity (see Figure 1) and does not show a clear pattern in regional terms. The incidence rate is very high in the autonomous island regions (Azores and Madeira), in some heavily urbanised coastal regions (Lisbon, Setúbal, Aveiro, Algarve) but also in inland regions that are heavily aged and predominantly rural (Castelo Branco, Portalegre). There are no social indicators that correlate positively and powerfully with DV, and that can be unequivocally considered as good predictors of this type of violence. However, there are not also social conditions immune to these practices. The complexity in designing public policies to prevent DV lies precisely in the uncertainty and variability of this social phenomenon.

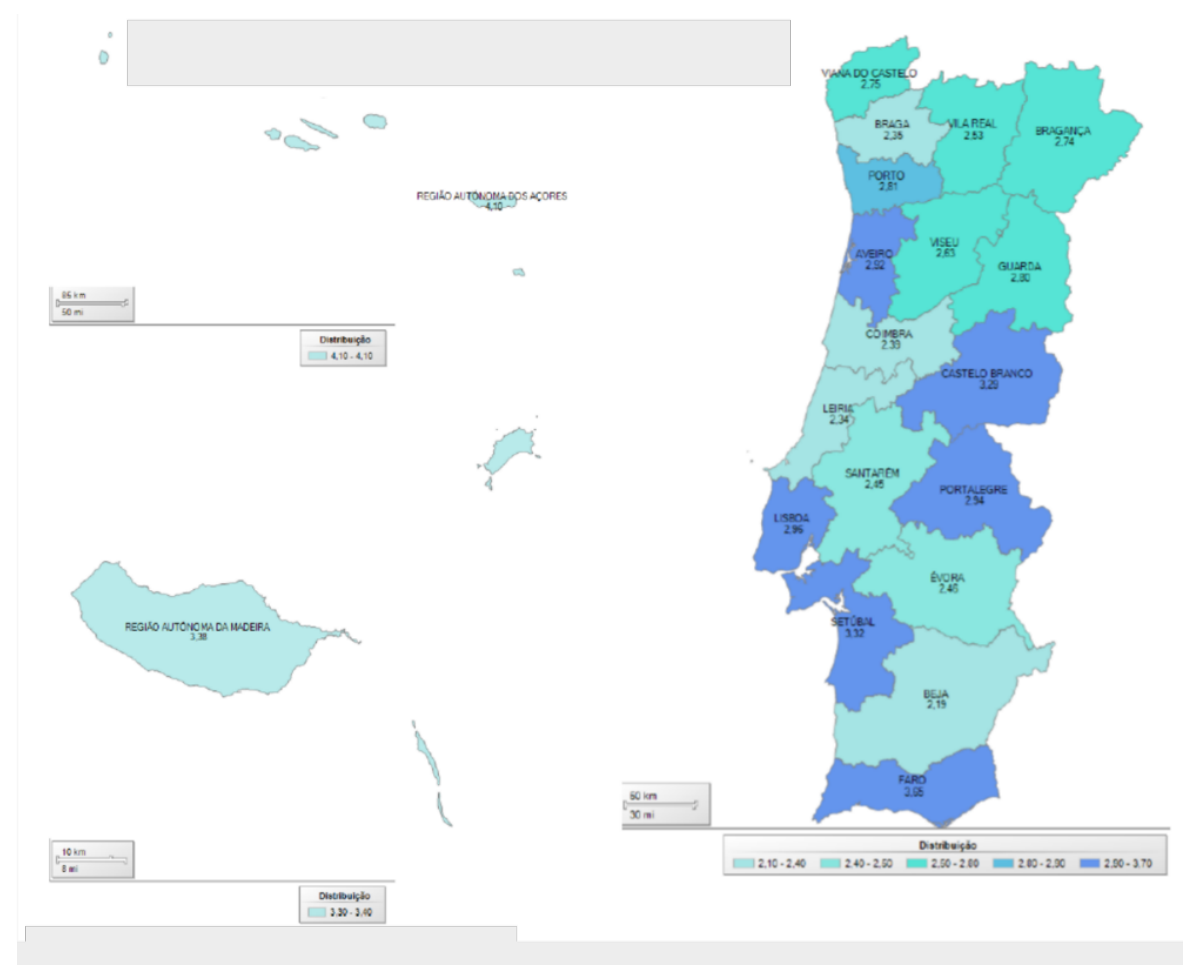

Figure 1: Domestic Violence Incidence Rate in 2019 (per Thousand Inhabitants), by Region (Source: DV Annual Report, Ministry of Interior, 2020) 
According to existing official data (see Figure 2), the evolution of DV crime over the last two decades expresses an evident linear growth $\left(R^{2}=0.7819\right)$, in contrast to both the evolution of offences against person and, above all, to total reported crime figures. It should be noted that the DV crime classification is comprehensive and is not limited to marital crimes, but to crimes committed within the domestic unit or arising from an intimate relationship (e.g. dating) - see article 152 citation from the Penal Code, above).

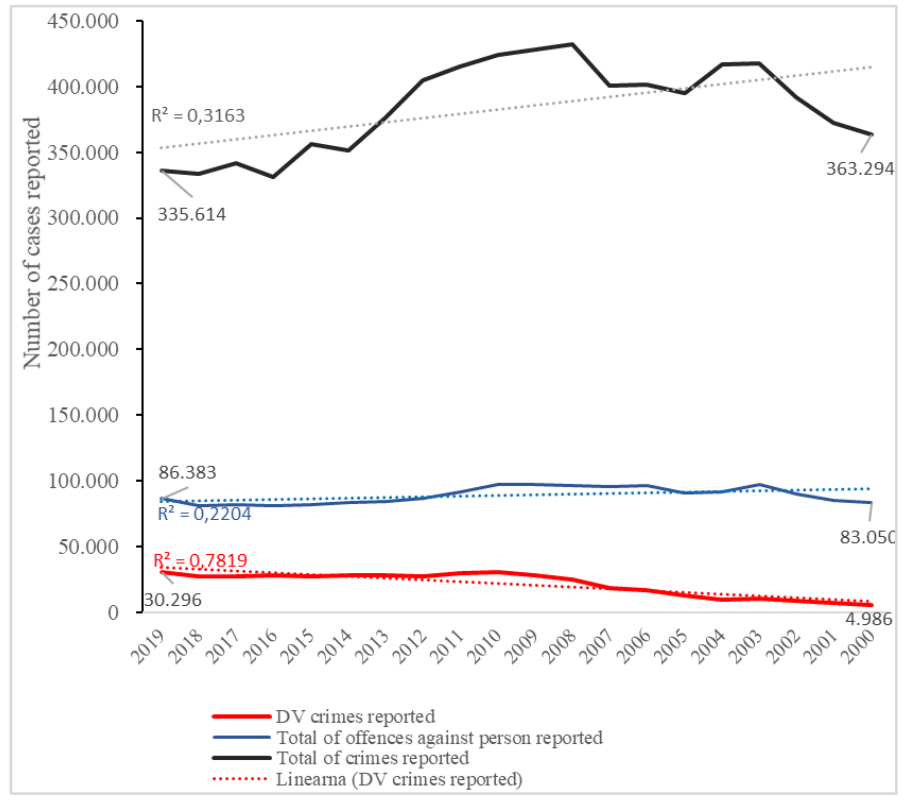

Figure 2: Trends in DV Crime, Offences Against Person and Total Crime in Portugal Since 2000

(Source: Ministry of Justice - Statistics data base (SIEJ))

These two decades are, however, completely different (see Figure 3). The data show that between 2000 and 2009 there was a real explosion in the number of DV cases, which cannot be explained by the sudden radical change in the individual behaviour of offenders, but by the creation of the legal and logistical conditions (strengthening the capacity of the first responders) so that DV victims could complain, reducing the dark figures (unknown numbers) of the phenomena. Thus, it was not the interpersonal social dynamic that brusquely changed, but the creation of a new formal social rule system that brought out the intensity of the social phenomenon of domestic violence. 


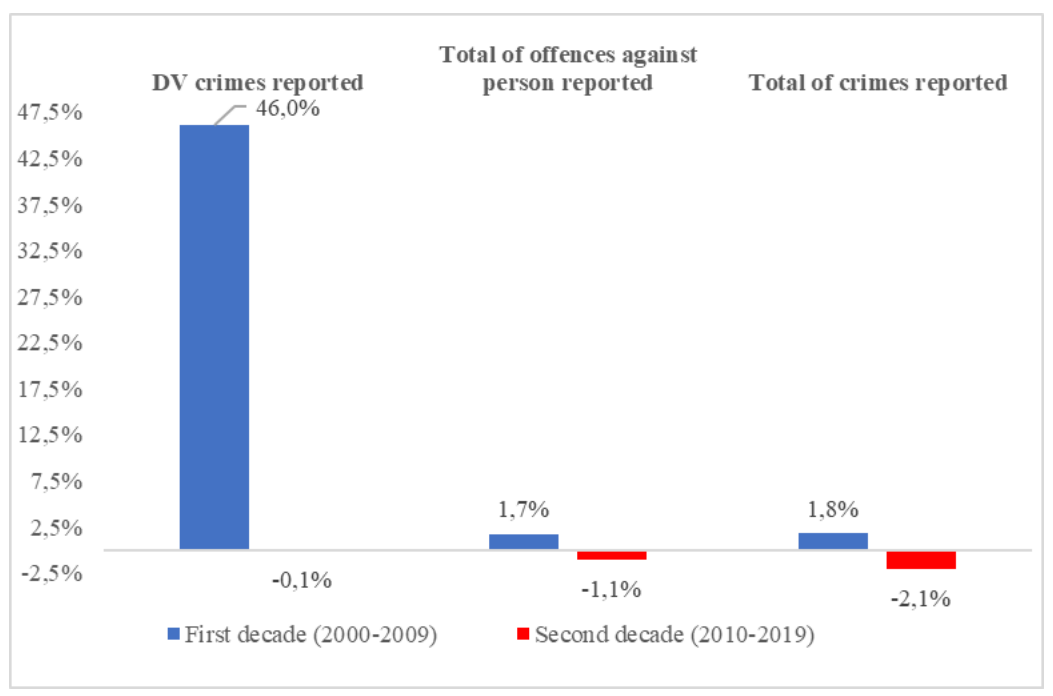

Figure 3: Trends In DV Crime, Offences Against Person And Total Crime In Portugal. Comparison Between Two Decades

(Source: Ministry of Justice - Statistics data base (SIEJ); calculations by the authors)

There are two undeniable indicators of the occurred social change, even considering such a conservative system like Justice. First, the number of people accused of DV crime in Portugal has increased since 2000 (see Figure 4), even before.

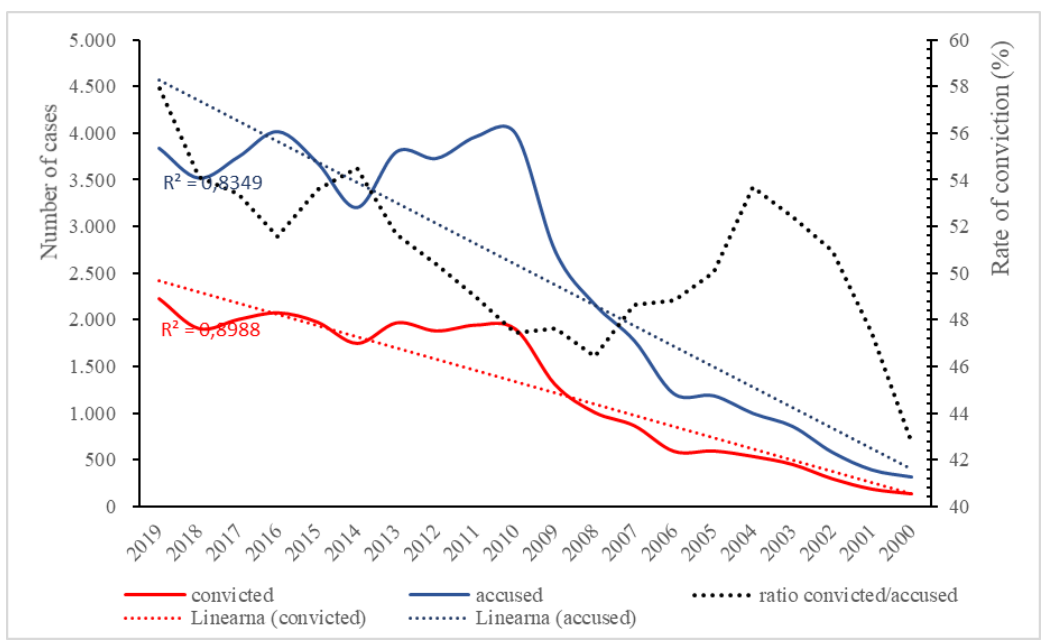

Figure 4: Trends in the Number of DV Crime Convicted, Accused and Ratio of Conviction in Portugal Since 2000

(Source: Ministry of Justice - Statistics data base (SIEJ); calculations by the authors.) 
The growth in accusations has been linear, with an $\mathrm{R}^{2}=0,8349$, reaching over 3.800 cases in 2019. Second, the evolution of the number of convicted was also accentuated, with a linear trend $\left(\mathrm{R}^{2}=0,8988\right)$, with 2.223 convictions in 2019 , the highest number ever (see also Figure 4). The ratio convicted/accused expresses the increased capacity of the prosecution system (accusation) in recent decades, and even more so the Courts to convict. In 2019 this ratio reached $58 \%$, meaning, however, that much still seems to be done in terms of the efficacy and efficiency of the criminal investigation system (Police and Prosecution Office) and sentencing system (Court).

From the data collected by the LEAs, it is possible to draw a profile of victims, perpetrators and occurrences of DV, all of it updated to the year 2019 (see Figure 5), but which has not undergone significant changes in the last two decades.

\section{Characterization of victims}

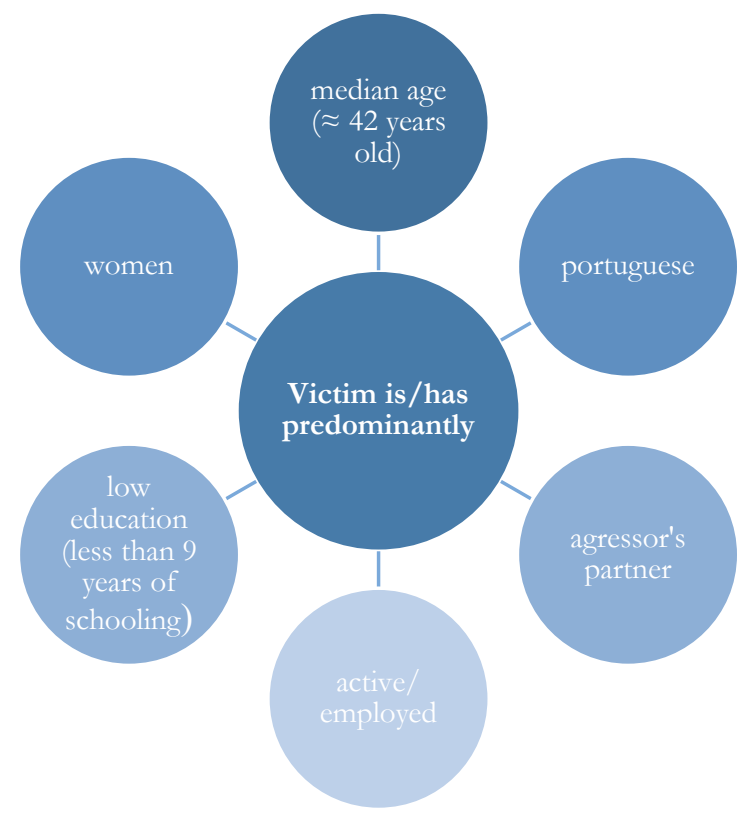




\section{Characterization of perpetrators}

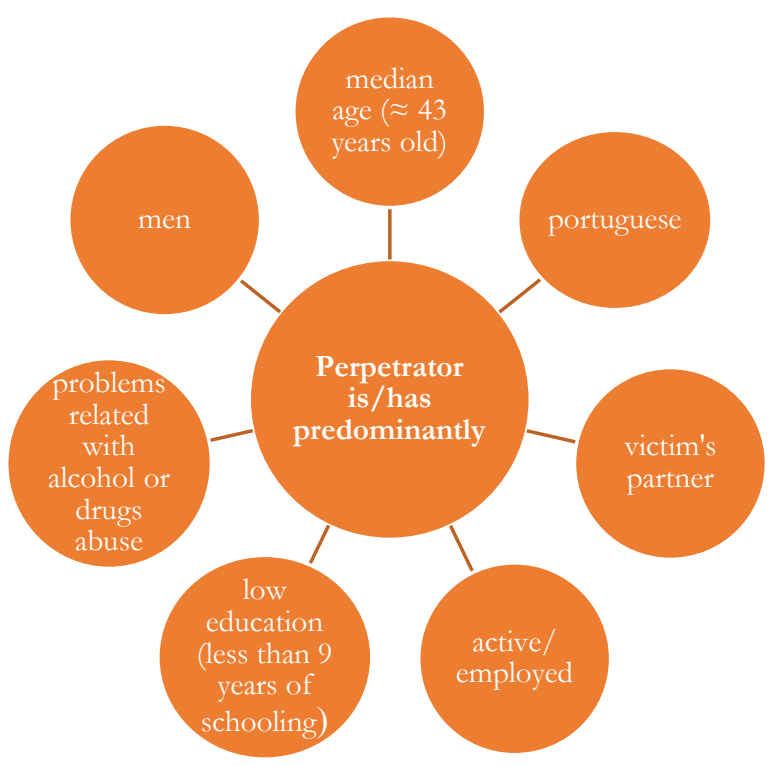

\section{Characterization of occurrences}

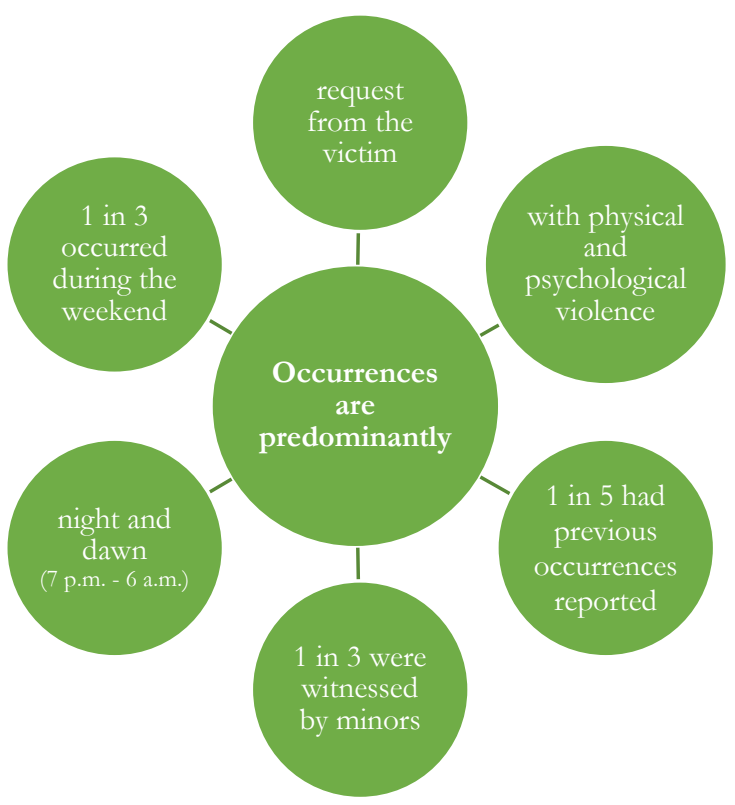

Figure 5: A Fresh Approach to DV Victims, Perpetrators, and Occurrence's Profiles (Source: DV Annual Report, Ministry of Interior, 2020) 
These data from the DV profile in Portugal allow to reinforce that co-presence at home is an increased risk factor (at night, during weekends), and that low schooling and alcohol and drug addiction can be assumed as individual characteristics for an increased vulnerability to DV. Nevertheless, in-depth studies (possible with the vast information available) are needed for a comprehensive understanding of this phenomenon.

\section{The role of Police, other frontline and first-responder agencies, and pertinent stakeholders in responding to high impact domestic violence}

\section{The role of the Law Enforcement Agencies (LEAs)}

In 2019, 30.030 risk assessments and 23.376 reassessments were carried out by the Portuguese LEAs. These figures would not be possible without the reforms mentioned above (see Introduction). According to data from the Annual Internal Security Report 2019 (RASI 2020), there were in Portugal more than 1.300 police officers with specific responsibilities within the scope of the DV.

Around $69 \%$ of the police stations (GNR - Portuguese National Guard, and PSP - Portuguese Public Security Police) with on-site presence had a room for victim's attendance (RVA), totalising 472 RVAs. Two decades before, probably there was not more than a dozen. The Government recently (November 2020) has adopted a new regulation on the material conditions of the RVAs, defining common criteria for such RVA (in terms of physical conditions, but also in terms of its usage and information materials to be available there) according to Order no. 11718-A/2020 of 25 November.

In the early 2000s, some specialised police structures and programmes were created to deal with DV. Since then, the procedures changed quite a lot. Nowadays, the complaints of DV presented to the Police (GNR or PSP) originate two documents: A Complaint Report and a Risk Assessment form (RVD-1L). Both documents are sent jointly to the Public Prosecution Service (PPS). A risk assessment revaluation should occur (RVD-2L). The time frame between RVD-1L and RVD-2L depends on the level of risk determined and the decision of the supervisor responsible for 
that documentation. The following evaluations are also sent to the PPS and usually it is also the police that makes such reassessments.

After the assessment is made, the Police may adopt immediate measures at their disposal; others may be proposed to the PPS. So, the evaluation procedure also contains a set of strategies to adopt to promote the victim's safety and security. The design of the Individual Security Plan begins here. In the risky situations, the adoption of protective measures will depend on the coordination between the Police, the PPS, and the Investigating Magistrate, and must be implemented as fast as possible. Also, in these cases, the victim can be enrolled in the Tele assistance programme. There is no deadline for the revaluation to cease, which will naturally stop if the judicial process ends.

For understandable reasons, perhaps because of the traditional willingness of the police $24 / 7$, for 365 days a year, there is a strong propensity of citizens to lodge complaints about DV, and others, with the Police (GNR and PSP), more than in the Courts, near the Public Prosecutor's Office, and even near the Judiciary Police's facilities (criminal investigation police). In Portugal, polices are the frontline responders (FLR) at the central stage of the DV public approach. All the following considerations must be understood under this assumption.

However, Police as all does not have a unique capacity of response, and the differences we can point out are relevant for the understanding of the frontline institutional response to DV problems in Portugal. There are different generations of professionals with different skills to address DV situations, also geographical capacities, and so the different kinds of outputs in terms of the information collected and registered. Contrary to the vox populi that sees bureaucracy as an obstacle, it seems evident that institutions that deal directly with the phenomenon of violence need greater bureaucratisation (in the Weberian sense) of diminishing the preponderance of individual and traditional action and strengthening rational action (free of prejudice and self-determination).

On the other hand, it seems clear that first responders are not exploring all the potentialities of the data gathered, transforming such massive stock of information into knowledge. From the police service point of view, the experience seems to be limited to the strategy of data gathering. In the absence of this knowledge, the 
capacity to identify predictors (e.g. mainly by path analysis using previous risk assessments) decreases significantly. Moreover, if it decreases, prevention is almost impossible, and the add-value chain weakens.

The new database that will be implemented is a special opportunity to develop a true integrated knowledge in this area to serve public policies but also to serve better and more informed interventions namely by LEAs and the PPS.

\section{The role of the National Network for the Support of Victims of Domestic Violence (RNAVVD) and NGOs}

Support services for victims of domestic violence are organized in the National Network for the Support of Victims of Domestic Violence ("the national network") created under Law no. 112/2009. The national network comprises namely the CIG, the ISS (Institute of Social Security), shelters, emergency accommodation structures and centres providing counselling, psychosocial and/or legal support. This network is coordinated by the CIG and ISS, according to respective competences. Most of the support services under the RNAVVD is managed by NGOs.

In a country without a great tradition of organised civic participation, the exception to initiatives coming from the Catholic Church, the so-called civil society and its non-governmental organisations play, however, a crucial role in terms of direct and indirect support to DV victims, but this role could grow significantly. There are just a few specific NGOs dedicated, cross-nationally, to DV. Most of them only have a regional, or even local spectrum.

Two other sensitive problems in the activity of NGOs concerning DV have to do with a) the difficulties in working together with the Police for reasons of prejudice (that is still visible, although much less than in the past); b) the significant dependence they have, in terms of logistical and financial support, on the State, creating instability regarding the sustainability of responses. In other words, the very centralist model adopted by the State in terms of the strategy to prevent and combat DV ends up limiting the role of civil society and its organisations. 
Again, a highly professionalised model that limits discretionary action, personal knowledge rather than the existence of suitable criteria, is something that seems to be lacking in the NGO sphere, about which there is, on the State side, an attitude of some distrust. However, it does not seem possible that support for the victims of DV can be achieved today without these organisations. For instance, they have quite the monopoly of the shelters for victims. They also constitute what we can understand as the $2^{\text {nd }}$ level responders (see Section 3.4., below), which means many responsibilities towards victims. Finally, they have trustworthiness with the victims and their families. The problems we mentioned earlier concern more the relationship between the State and these institutions, and less so between them and the people they serve.

\section{The role of the Health Services}

The health services provided to victims are overwhelmingly in the State sphere, and the few that are carried out by private companies are generally agreed with the State. There are two different open doors to the National Health System (SNS): hospitals, and health centres. The first ones deal predominantly with emergencies, often quite close after a DV occurrence; the second ones regard situations known within regular medical appointments (indoor approach) and during community medical work (outdoor approach). Both indoors and outdoors approaches benefit from an interdisciplinary team (where medical doctors (MDs), nurses, psychologists, social workers, and when necessary police officers contribute to a final and common outcome).

However, the current conditions of medical attendance in health services, namely hospitals, do not allow us to assure that health professionals have the proper conditions to make an in-depth assessment of a DV victim. This situation was real before the SARS-CoV-2 pandemic but was very much damaged by it. The SNS is under intense pressure, and this situation is very unfriendly to proceed according to the existing recommendations.

According to the document named "Interpersonal violence: Approach, diagnosis, and intervention in the bealth services" (2016), the MDs follow a set of steps during medical appointments. There are six steps to consider: (1) screening, (2) detecting/assessing, (3) diagnostic evaluation (hypothesis), (4) registering, (5) acting, and (6) signalling. 
When handling cases where the victim needs urgent primary medical care, it is usual to present the victim for forensic medical expertise by the National Institute of Legal Medicine and Forensic Sciences. The risk indicators are usually assessed by the MD, together with the victim. The diagnose of imminent danger occurs when there is the possibility of suffering an imminent episode of violence, life-threatening for the victim (or her/his significant persons), based on the interview, the victim's perception, biopsychosocial assessment, and physical exam.

However, the Ministry of Health in 2019 established the National Program for the Prevention of Violence in the Life Cycle. This Program aims the reinforcement, in the scope of health services, the mechanisms of prevention, diagnosis and intervention concerning interpersonal violence against social groups of increased vulnerability.

The general and specific medical training is scarce, and the level or degree of dissemination is probably not sufficient to allow us stating that it occurs transversally in the whole SNS. Central hospitals need to have closer cooperation with the Police. For instance, we know that they complain about not having women police officers at the Emergency Services and the necessary commitment regarding DV cases when they arrive at the Hospital (specifically to those Emergency Services). It should be remembered that in Portugal only central hospitals have a police officer within the premises.

Given a more comprehensive vision of the national organisational model of response to DV, the following scheme (see Figure 6) sums up all the relevant tasks performed by the different stakeholders. The arrows show the interactions amongst the services (each service as a specific colour) to attend the DV incident. 


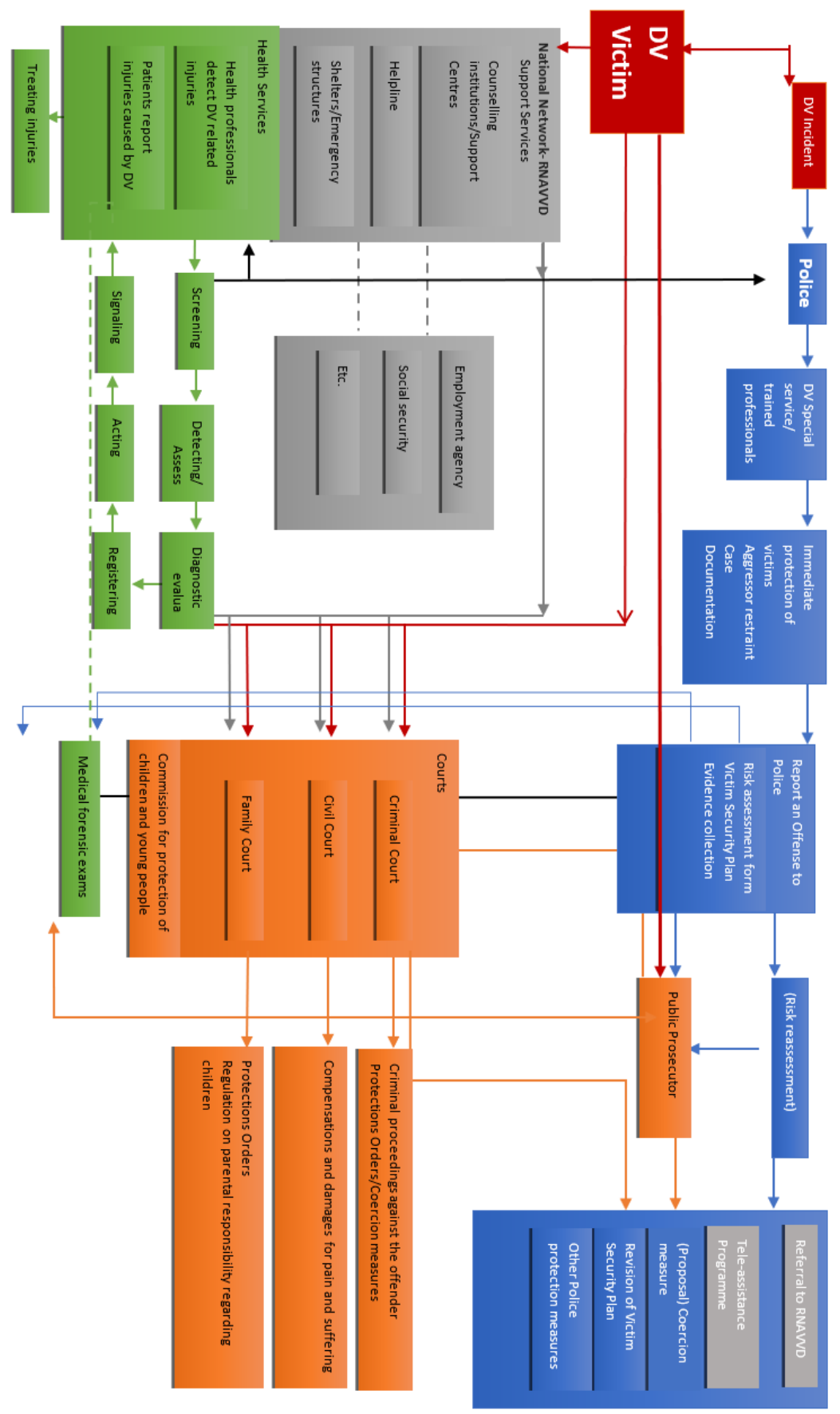

Figure 6: Flowchart of the Attendance Process to a DV Victim (Updated 2020) 


\section{Good practices of cooperation between Police, other frontline responder agencies, and pertinent stakeholders}

There are three different levels of responders. All of them may be asked for help and advice in specific circumstances by the victims, their relatives, neighbours, work colleagues, or any citizen who may know about a DV occurrence. The first level responders are responsible for the direct and immediate response to DV occurrences:

- The Portuguese National Guard (GNR);

- The Portuguese Public Security Police (PSP);

- The Judiciary Police (PJ; only in cases of homicide), and

- The Public Prosecution Service (PPS).

The second level responders usually are not mobilised and do not intervene in the DV situation itself. They are services to which the victims appeal for help or assistance (strictly social service). They are also services where DV occurrences become disclosed in front of different situations (e.g. divorce, or child neglect). For instance:

- Police local service desks by the central hospitals;

- Hospitals (they communicate with the Police whenever they find some specific evidence or strange situations - signalling to police authorities and providing medical treatment);

- Health Centres - around 400 (for sure at the municipal level, though in many cases at parish level);

- National Network of Support to Victims of Domestic Violence (RNAVVD);

- CPCJ local bureaus (State local Commissions for the Protection of Children and Young Persons);

- Directorate-General of Reintegration and Prison Services. 
The third level responders provide specialised responses to help DV victims resolving situations following specific needs (e.g. regular medical assistance, job search, insolvency procedure). For instance:

- Social Security - approximately 442 local offices for public attendance;

- Employment Agency - 106 offices, region-based;

- DECO (consumer protection) - 6 regional delegations;

- Education (13850 public schools, from pre-primary to secondary education).

In March 2019, following a succession of alleged cases of homicides in the context of DV (occurred at the beginning of that year) and the publication of GREVIO's Report on the implementation of Istanbul Convention in Portugal, the Portuguese Government created the Multidisciplinary Technical Commission for the Improvement of the Prevention and Combat of Domestic Violence (CTM). This Commission produced a report with several recommendations on data and statistical indicators. Following this report, a Governmental Order was approved (Council of Ministers Resolution no. 139/2019, 19th August), defining the priority actions to be developed, as well as other measures to be taken in areas such as health, education and social security. Among measures determined, it should be underlined: a) the implementation of the database on violence against women and domestic violence (to improve official data in this domain); b) the elaboration of a joint training plan of professionals regarding Violence against Women and DV; and c) a guide of functional procedures to be followed within the 72 hours after the report by LEAs.

In accordance, at the end of June 2020, the Portuguese Government presented four new instruments to prevent and fight DV:

- Handbook on Functional Performance within 72 hours following the reporting of domestic violence (Portuguese version available from https://bit.ly/38453Iz);

- Integrated Intervention Guide for Children or Young People Victims of Domestic Violence (Portuguese version available from https://bit.ly/2CCOQOE);

- Annual Joint Training Plan on Violence Against Women and Domestic Violence (Portuguese version available from https://bit.ly/2YzaYBY); 
- Handbook on the Minimum Requirements for Primary Prevention Programmes and Projects of Violence Against Women and Domestic Violence (Portuguese version available from https://bit.ly/3eC3AeW).

- New models for attributing the status of victim were developed and entered into force in September 2021. It includes a model for DV casesthe especially vulnerable victim status (DV).

- Aligned with the handbook on functional performance within 72 hours the Standard form for registering DV cases reported to LAE was also revised and will enter into force in January 2022. This model will be used not only by the GNR and the PSP, but also by the the PPS and the PJ.

\section{LEA - GNR (The Portuguese National Guard)}

In the context of the GNR, it is essential to mention a program that consists, roughly, in the specialisation of human resources for prevention, investigation and monitoring of situations of violence against women, children and other specific groups of victims (IAVE Project). There are 24 IAVE's Nuclei, seated at the territorial commands or deployments of the GNR (with 3-4 researchers) or the level of the territorial squads, closer to the population, including 350 Teams (with 1-2 elements). These teams have a strong relationship with local entities and operate in a proximity policing logic.

\section{LEA - PSP (The Portuguese Public Security Police)}

In terms of models for organising policing at DV, there are several initiatives, in addition to the traditional service at the Police Station and the Integrated Model of Proximity Policing: the Victim Information and Assistance Office (GAIV) in Porto, found in 2013, the "Espaço Júlia" in Lisbon and the "Casa da Maria" in Oeiras, among others. These models have been implemented in the last years, reinforcing the availability of police elements with specialised training in DV, service spaces with greater comfort and privacy for the victim, a more direct articulation between the Police and the PPS and the victim service structures. 
GAIV manages all the DV related calls in the city of Porto (Machado et al., in press). GAIV has become the DV pivotal frontline responder in the city. In the backstage, PSP created the Crime Investigation Special Teams for DV (EEIV) which are specialised in the criminal investigation of these crimes. This new arrangement allowed the PSP to obtain a high level of public awareness regarding DV.

The "Espaço Júlia", opening date in 2015, was designed to provide an integrated response to DV victims. A response that is lacking in many police stations in the country is here: to support and accompany the victims of domestic violence, 365 days a year, 24 hours a day, with specialised technicians. Ten agents from the PSP officers work within "Espaço Júlia" - male and female agents with training in DV and Victim Care; along with two technicians of Victim Support from the Santo António Parish Council, coordinated by the Technical Director of this facility. All cases signalled by Dona Estefânia Hospital's Paediatric Emergency Department and São José Hospital's Emergency Department are conducted to this facility. However, any person who goes to this space will be attended.

\section{Public Prosecution Service (PPS)}

Also, it should be mentioned the Victims of Gender Violence Assistance Offices (GAV) that were created through a protocol between the Ministry of Justice (MJ) and the Attorney General's Office (PGR) and integrate victim support technicians from NGOs. Since 2019 six GAV were created.

The PPS adopted the Directive no. 5/20192 aimed at providing public prosecutors with guidelines for homogeneous action in the segments identified as especially missing in standardised intervention.

This Directive also intended to promote the articulation within the recent created Specialized Integrated Domestic Violence Sections (SEIVD), which comprise Criminal Action Nucleus (NAP) and Family and Children Nucleus (NFC). These SEIVD were created, at an experimental level, in several Criminal Investigation and Action Departments. These Sections contribute to the increasing movement of

\footnotetext{
${ }^{2}$ Available at: http://www.ministeriopublico.pt/sites/default/files/documentos/pdf/diretiva_num_5_2019.pdf
} 
specialization of the intervention of the PPS in domestic violence and facilitate specific attention and articulation in the cases where children are involved.

As far as the Third Sector is concerned, some local support networks in the DV field have been set up over the last few years, and it is relevant to mention them here. These networks are local in scope, and their main objective is to increase the coverage of the territory concerning the provision, namely, of victim care facilities. These initiatives are the result of a policy of establishing territorial protocols of the National Network of Support to Victims of Domestic Violence (RNAVVD) with several municipalities. A NGO carries out the coordination of each protocol with local/regional implementation.

Many other initiatives could be flagged about good practices of cooperation between Police and other stakeholders, crossing the different levels of responding and types of partnerships, and that can be understood as experiences of social response to admittedly wicked social problems. There is, in fact, an area for intervention that is not defined by experimentalism but by innovation. Synthetically, some experiences have already been partially evaluated and others that should be evaluated with the greatest possible urgency. This urgency arises from the need to understand what should be stimulated and replicated by the country. Moreover, what does not work well and should be closed and forgotten.

\section{Main challenges and issues to be anticipated}

No society can collectively eradicate interpersonal violence, and most especially not the violence that is hidden in intimate relationships. The tremendous social challenge, however, concerns the development of a collective attitude that considers such violence as unacceptable behaviour and a crime punishable by Law. The modern societies' recent fight against DV is the story of how this path has been taken. Thus, the enlarged social visibility of violence and its moral condemnation is a cross-cutting challenge that cannot be interrupted and is projected as vital in the very long term.

Another challenge is the reinforcement of the fight against a relativistic attitude towards violence in a context of intimacy, embedded in retrograde ideologies that see gender equality as a danger for civilisation and defend the past as an idyllic 
historical reality. There are clear signs that this risk is not only theoretical, nor does it belong to a distant future. On the contrary, it is a risk still of the present.

The slow and gradual transformations, sometimes speeded up by significant legal reforms and driven by international conventions, have simultaneously brought new challenges. One of these challenges, directly posed to the LEAs, has to do with the increasing complexity of operational procedures (more sophisticated administrative proceedings, victim status attribution, risk assessments, individual security plans, and recently adopting the reinforcement of all procedures within 72 hours). However, in the sense of the complexity of procedures and the need for training that responds to new challenges, this tendency is not exclusively of the police institution. This complexity has not ended and has dragged on other changes in intern police organisation and other public systems as well. Often, the problem of elites provoking social change on a superlative level, almost an ultimate social goal, is to forget that the adoption of new social models is not achieved by decree, but through processes of social influence, and this takes time. The key variable seems to be more and more training. Only training and supervision can counteract individual facilitation and routine on activity, responsible for errors and omissions that do not help condemn the aggressors and fuel an idea of impunity in the community.

On the other hand, civil society responded to the new challenges by multiplying the available resources, which forced it to redesign the map of institutional actors that moves around DV. This change is still under consolidation, and mutual distrust is still widespread and seems to be an immediate challenge to overcome.

The total confinement resulting from the COVID-19 pandemic (from March to May 2020) added a new challenge, increasing the complexity of the public response to violence in intimate relationships. More than never, institutional support became very difficult, and DV became even more hidden. The number of cases reported remains lower and very unstable. What will the «new normal» look like in terms of DV? Has the pandemic partially reduced interpersonal violence, just as it has reduced other types of crime? When the great focus of public policies concerning the fight against DV was the greater visibility of this phenomenon, the combination of fears can trigger a silent crisis that will affect the victims of this other pandemic which is the violation of citizens' rights to their peace and tranquillity in the family context. 


\section{Note}

At a court session (in the mid-2000s), a judge addresses an aggressor who had just been convicted of domestic violence and asked him:

"Do you understand why this Court has sentenced you?"

The defendant answers:

"I do not, Your Honour. I beat my wife, not yours".

\section{References}

Constitution of the Portuguese Republic.

https://www.parlamento.pt/sites/EN/Parliament/Documents/Constitution7th.pdf

GREVIO. (2019). GREVTO baseline evaluation report: Portugal. Strasbourg: Secretariat of the monitoring mechanism of the Council of Europe Convention on Preventing and Combating Violence against Women and Domestic Violence, Council of Europe.

Inglehart, G. (2018). Cultural evolution: People's motivations are changing and reshaping the world. Cambridge University Press.

Machado, P., Pais, L. G., Morgado, S., \& Felgueiras, S. (2021). An inter-organisational response to domestic violence: The pivotal role of police in Porto, Portugal. European Law Enforcement Research Bulletin, 21. https://bulletin.cepol.europa.eu/index.php/bulletin/article/view/418

Ministry of Interior. (2020). Annual Internal Security Report 2019. https://www.portugal.gov.pt/pt/gc22/comunicacao/documento?i=relatorio-anual-deseguranca-interna-2019-

Portuguese Penal Code. (2007). Law no. 59/2007. https://dre.pt/pesquisa//search/640142/details/maximized

SGMAI - General Secretary of the Ministry of Internal Affairs. (2020). Annual monitoring report on domestic violence - 2019. https://www.sg.mai.gov.pt/Documents/vd/RelVD_2019.pdf 


\title{
FRONTLINE RESPONSES TO
}

\section{DOMESTIC ABUSE IN SCOTLAND}

\author{
RUTH FRISKNEY, OONA BROOKS-HAY \& \\ MiCHELE BURMAN \\ University of Glasgow, Scottish Centre for Crime and Justice Research, Glasglow, \\ Scotland, UK. \\ E-mail: ruth.friskney@glasgow.ac.uk; oona.brooks@glasgow.ac.uk; \\ michele.burman@glasgow.ac.uk
}

Abstract Scotland's progress in tackling domestic abuse is recognised for the gendered analysis which underpins it. This gendered analysis recognises structural gender inequalities as the context in which domestic abuse occurs, enabling more effective targeting of resources for prevention and response. The Domestic Abuse (Scotland) Act 2018, described as a 'gold standard' in legislation to tackle domestic abuse, draws on the gendered concept of coercive control. The Act seeks to recognise in law the nature of domestic abuse not as isolated incidents but rather as an ongoing exercise of power and control by the perpetrator, using various tactics. In this chapter, we describe what is known about domestic abuse in Scotland, the strengths and weaknesses of different data sources in capturing the gendered nature of domestic abuse and the reality of how victimsurvivors experience it. We consider the multi-agency structures, in particular Multi-Agency Risk Assessment Conferences and Multi-Agency Tasking and Coordinating groups, which support Scotland's partnership approach in the front-line response to domestic abuse, recognising the crucial role of feminist third sector agencies alongside statutory agencies such as police, health, social work, and housing.

Keywords:

domestic

violence,

Scotland, interagency cooperation, MARAC, MATAC, police, NGO 


\section{Introduction}

Scotland has been recognised for its approach to tackling domestic abuse in particular and violence against women (VAW) as a whole (Brooks-Hay et al, 2019; Brooks-Hay et al, 2018, Coy et al., 2007; Lombard and Whiting, 2015; Stark, 2007); Stark has called the recent Domestic Abuse (Scotland) Act 2018 (DA(S)A) "a new gold standard" in domestic abuse legislation (Brooks, 2018). Scotland's progress around domestic abuse is underpinned by its commitment to a gendered analysis, originating in grass-roots organisations and reflecting the crucial work of feminist activists within Scotland. Feminist non-governmental organisations continue to be respected as key partners in effective multi-agency working and policy development. Nevertheless, domestic abuse persists and Scotland faces considerable challenges in realising the promise of developments such as $\mathrm{DA}(\mathrm{S}) \mathrm{A}$ to tackle the ongoing harms to women and children.

\section{The Scottish approach to understanding domestic abuse (as a gendered phenomenon)}

Scotland is part of the United Kingdom with a different legal system and separate legislative powers, and its own national police force, known as Police Scotland. In 2000 the Scottish Government adopted a gendered definition of domestic abuse, maintained through to the most recent national strategy Equally Safe: Scotland's strategy for preventing and eradicating violence against women and girls (Scottish Executive, 2000; Scottish Government, 2018). The gendered analysis is based on the United Nations (UN) Declaration on the Elimination of Violence Against Women (1993) and understands domestic abuse as both cause and consequence of gender inequality (Centre for Families and Relationships et al., 2013). Further key features of the Scottish policy definition are the focus on abuse between partners and ex-partners, rather than between family members; and the adoption of the term 'domestic abuse', in preference to 'domestic violence', to better represent the range of abusive behaviours (including psychological, financial, sexual and physical) that perpetrators may carry out as part of their overall course of controlling behaviours. Scotland's strategic approach of situating domestic abuse as both a cause and consequence of gender inequality is considered good practice, and a "benchmark" for the other nations of the UK (Coy et al., 2007, p. 7). 
A gendered analysis recognises the context of structural gender inequalities in which domestic abuse occurs, enabling more accurate targeting of social change efforts and resources to prevent, respond to and eradicate it (Brooks-Hay and Burman, 2019; Nichols, 2013; Dobash and Dobash, 2004). Lacking a gendered analysis, assuming that there are no differences between men's and women's experiences of abuse, fails men and women (McFeely et al, 2013). Research that seeks an understanding of precisely "who does what to whom" identifies domestic abuse as a problem of men's violence against women, with men more likely to perpetrate abuse more frequently, and more severely, with the purpose of creating fear in the victim and control over them (Hester, 2013, p.623; Dobash \& Dobash, 2004). Domestic abuse is therefore gender asymmetric; a gendered analysis requires an understanding of the context of this abuse, in society's constructions of men and women and expectations of how they should behave (Brooks-Hay \& Burman, 2019). A gendered analysis is relevant to different relationships, including the experiences of lesbian, gay, bisexual, transgendered, intersex and queer individuals (Whiting, 2007).

\section{Legislation}

The Domestic Abuse (Scotland) Act 2018 (DA(S)A) came into force in April 2019. This Act created for the first time in Scotland a specific criminal offence of domestic abuse (previously domestic abuse had been prosecuted under a range of existing offences (e.g. assault, vandalism) with a possible domestic abuse aggravator). The offence draws upon the (gendered) concept of 'coercive control' (Stark, 2007), recognising that domestic abuse is characterised by an ongoing course of conduct rather than an incident, or even a series of incidents. The offence incorporates a range of abusive behaviours (covering emotional, financial, psychological and sexual abuse) where 'abusive behaviour' is understood to be that with the likely effect of: making a partner or ex-partner dependent on or subordinate to the perpetrator; isolating them from friends, relatives or other sources of support; controlling, regulating or monitoring their day-to-day activities; depriving or restricting their freedom of action; or frightening, humiliating, degrading or punishing them. The new offence also creates a child aggravator, to be applied where a child is likely to be 'adversely affected' by the behaviours of the perpetrator, recognising growing understanding of the harm caused to children by domestic abuse. The original purpose of creating the offence was to more properly reflect the ongoing experience by victims of multiple forms of behaviours by the perpetrator's exercise of power 
and control, to make prosecution more effective (Thomson, 2014). While the Act was positively received, both within Scotland and internationally, considerable challenges remain for its implementation. Effective implementation is dependent on police officers, but also other frontline responders, recognising the subtle and insidious controlling behaviours that make up domestic abuse and on a significant shift in understanding from responding to incidents to recognising a series of interrelated events (Burman \& Brooks-Hay, 2018).

\section{Scottish data on domestic abuse: seeking to capture the scale and experience of coercive control}

While there are key data sources about domestic abuse in Scotland, all have limitations. In particular, most data collected in Scotland retains incident based measures of counting domestic abuse, which fail to capture the cumulative and persistent restrictions on women's (and children's) liberty which constitute coercive control (Brooks-Hay and Burman, 2019). The Domestic Abuse (Scotland) Act 2018 offers some opportunities for improving data collection to better reflect women's and children's experience of coercive control.

\section{Scottish police data}

Scottish Government produces an annual bulletin of domestic abuse incidents and crimes recorded by the police in Scotland. In 2019/20 the police in Scotland recorded 62,907 incidents of domestic abuse, 115 recorded incidents per 10,000 population (Scottish Government, 2021). Less than half of incidents, $40 \%$, included the recording of at least one crime or offence. Although there was only a $4 \%$ increase in the number of incidents recorded compared to the previous year, there has been a marked rise in the number of domestic abuse incidents recorded by the police over the last fifteen years (from 45,331 in 2005/6).

While police data provide some useful information about the police response to domestic abuse, these are only a partial picture. Despite the rise in incidents recorded, most likely due to increased reporting, domestic abuse is still one of the most under-reported crimes (MacQueen \& Norris, 2014). 


\section{The Scottish Crime and Justice Survey}

The Scottish Crime and Justice Survey (SCJS), a large-scale national victimisation survey of individuals within households, provides a picture of the extent of domestic abuse that does not come to the attention of the police. Despite key gaps in the survey reach (e.g. the use of residential address to identify survey respondents excludes women in refugees, a group who are likely to be among those most seriously affected by domestic abuse), SCJS findings consistently indicate that only around one in five incidents of domestic abuse are reported to the police.

The SCJS 2018/201 (Scottish Government, 2021a) reported that $3.7 \%$ of women and $2.6 \%$ of men experienced partner abuse in year prior to being interviewed for the survey. Young women (aged 16-24) were the most likely age group of women to report partner abuse in the past year (10.2\%). $21.2 \%$ of women and $11.2 \%$ of men had experienced partner abuse since the age of 16 .

\section{Children affected by domestic abuse}

Many children are affected by domestic abuse; a 2011 UK wide prevalence study found that $12 \%$ of under $11 \mathrm{~s}, 17.5 \%$ of $11-17 \mathrm{~s}$ and $23.7 \%$ of $18-24 \mathrm{~s}$ had experienced domestic violence between adults in their homes during childhood Hester et al., 2011, p. 47). Children describe living with domestic abuse as living in a climate of fear (e.g. Katz, 2015); the impacts on children are wide-ranging, including ill-health, behavioural problems, under-performance at school (Mitchell \& Morrison, 2019; Devaney, 2015).

Current Scottish police statistics do not include information about children affected by domestic abuse; the SCJS is also limited as it relies on adults' reporting of children's experiences rather than asking children directly (see Devaney, 2015). The 2018/20 SCJS reports some information about children: $32 \%$ of those who experienced partner abuse in the twelve months prior to the survey said there were children living in the household when the most recent incident took place and over two-thirds of these, $71 \%$, said that children were present during that incident.

\footnotetext{
${ }^{1}$ The SCJS includes a self-completion module on partner abuse. These modules, completed by the respondent in private, are reporting biennially, combining two sweeps of the annual survey, in order to provide appropriate sample sizes. The partner abuse figures 2018/20 combine the 2018/19 and 2019/20 SCJS surveys.
} 


\section{Data available from support services}

Established in 1976, Scottish Women's Aid (SWA) is the national lead organisation addressing domestic abuse in Scotland. SWA has a network of 34 specialist local Women's Aid groups providing support to women and children in the community and in refuge and runs a 24-hour national helpline offering information and support to anyone affected by domestic abuse. SWA conduct an annual census of women and children accessing these services on a single day. In 2020 SWA reported contacts on census day from 1,130 women and 261 children and young people; for 111 women and 16 children this was their first contact with Women's Aid (Scottish Women's Aid, 2020). The main reasons for accessing support were emotional support, practical support and legal issues. 341 women and 357 children and young people were living in refuge on census day, including those admitted that day. Refuge was requested for a further 31 women and 43 children on census day; the majority of these women and children were unable to be admitted due to a lack of safe and suitable space. These data are crucial to include in the picture of domestic abuse, remembering that only one in five incidents are likely to come to the attention of the police, giving a sense of the demand on (and the resource limitations of) frontline responders.

\section{Moving data beyond the incident to capture the reality of coercive control}

One concern about both police statistics and crime surveys is the focus on discrete incidents or acts of abuse, while domestic abuse is characterised by ongoing coercive and controlling behaviours as a cumulative form of subjugation (Stark, 2007). Kelly and Westmarland (2016, p.125) argue that the criminal law and crime survey approach of identifying and counting domestic abuse in individual 'incidents' reflects the way that perpetrators downplay their behaviours (as isolated, out of character, not serious) and fails to capture the "heart and reality" of domestic abuse as a course of conduct experienced by survivors in the everyday. This failing contributes to what Myhill $(2017,42)$ describes as a "hugely misleading" apparent similarity in prevalence rates for domestic abuse among men and women in some data sets. 
Johnson $(1995$; 2008) developed a key typology of intimate partner violence (IPV), which defines three forms of IPV: intimate terrorism (IT), situational couple violence (SCV) and violent resistance (VR). IT is differentiated by the attempt to exert general control over one's partner, using a range of power and control tactics, including violence. A single assault may enable the perpetrator to exercise ongoing control by non-violent acts, through creating a context of terror. IT is normally what is meant by 'domestic violence', 'spousal abuse' or similar terms. VR is used to describe someone affected by IT fighting back; it is distinct because the person resisting is not attempting to control. SCV describes conflict situations in relationships which escalate to violence; it is distinguished because it is not embedded in a pattern of controlling behaviour. Johnson uses his typology to consider gender in existing survey data, finding that (in heterosexual couples) SCV is close to gender-symmetric whereas IT is perpetrated almost entirely by men. Developing data collection to more effectively capture the reality of domestic abuse as a course of conduct is likely to contribute to a more accurate picture of prevalence by gender.

\section{Opportunities of the Domestic Abuse (Scotland) Act (DA(S)A) 2018}

The creation of a new offence of domestic abuse (in force from April 2019), aiming to more effectively capture the experience of domestic abuse as an ongoing course of conduct, may provide opportunities for data collection to improve beyond the incident focus. The new offence may also provide data on the prevalence of harm to children through domestic abuse, through the aggravator to be applied where a child is likely to be 'adversely affected' by the behaviours of the perpetrator. Work is also ongoing to consider how the SCJS could be updated to reflect the new criminal offence. Initial Crown Office (2020) figures report that 1,065 charges were recorded under the new offence in its first year of operation. For $96 \%$ of the charges the accused was male; the child aggravator was recorded against $24 \%$ of the charges. However, the effectiveness of statistics on the new offence to more accurately capture the experience of coercive control depends on the ability of the police and other frontline responders to recognise the pattern and range of behaviours carried out by perpetrators to subjugate and coercively control a(n) (ex-)partner. 


\section{The role of Scotland's frontline services as part of a multi-agency response to domestic abuse}

Scotland has a longstanding commitment to partnership working as a platform for tackling domestic abuse, reiterated in Equally Safe (Scottish Government, 2018). Led by the national commitment, all local authority areas in Scotland have domestic abuse partnerships and/or training consortia, generally composed of statutory (police; housing; social work; community services; local NHS Boards) and thirdsector organisations. The role of the third sector, with its roots in feminist activism, is crucial; a strong feminist voice persists in current Scottish third-sector organisations, and echoes in statutory decision makers.

Individual agencies have put in place national and local structures to respond to domestic abuse as a priority issue. For Police Scotland, a particular focus has been to improve victim care in partnership with specialist agencies (Brooks-Hay, 2019). Domestic abuse liaison officers (DALOs) are specially trained individuals with responsibilities to offer a personal contact point for victims, explain police and legal procedures and liaise with other agencies. Scotland's health services are seeking to redefine Gender-Based Violence as core business, recognising that health workers are in a unique position to identify and respond to domestic abuse (Scottish Government, 2008). The national health service in Scotland (NHS Scotland) have introduced a programme of routine enquiry in key areas including maternity services and health visiting.

\section{Multi-Agency Risk Assessment Conferences (MARACs) and Multi-Agency Tasking and Coordinating groups (MATACs)}

A key development in partnership approaches is Multi-Agency Risk Assessment Conferences (MARACs). MARACs are regular, local and confidential meetings where statutory and voluntary agencies (e.g. police, health, housing, children and young people's services) share information in order to develop action plans to improve the safety of high-risk domestic abuse victims (Cordis Bright Consulting, 2011). A key professional feeding into the MARAC and ensuring that the victimsurvivor's safety is central to proceedings, is the Independent Domestic Abuse Advocate (IDAA), a single specialist professional who works with victim-survivors 
to develop a trusting relationship and who can help with everything they need to become safe (Robinson \& Hudson, 2011).

Multi-Agency Tasking and Coordinating groups (MATACs) are a Police Scotland initiative aiming to identify and proactively target those domestic abuse perpetrators who pose the greatest risk of harm to victims and their families; fourteen police-led multi-agency groups have been rolled out across Scotland. Crucially, this reflects a victim-centred and perpetrator-focused approach to policing.

Neither MARACs nor MATACs have been formally evaluated in Scotland. Initial observations of MATACs suggest some promising results in relation to reduced levels of reoffending for perpetrators targeted by MATAC. Evaluation of MARACs is hindered by a lack of robust data (Steel et al, 2011) though the data available suggests MARACs may reduce re-victimisation and that women identify benefits to their experiences from agencies working together (Robinson \& Tregidga, 2007). Additionally, Payton \& Robinson (2016, p.256) suggest that MARACS contribute to a change in partnership practice, "from being ad hoc and discretionary to becoming routine and coordinated".

MARACs focus on the most high-risk victims, that is, the top $10 \%$ of those most likely to suffer serious harm or domestic homicide, as identified by the DASH-RIC (domestic abuse, stalking and 'honour' based violence risk indicator checklist). This risk assessment tool has been adopted by frontline responders in Scotland including police, health and voluntary services (e.g. the IDAAs). Limitations of risk assessment tools generally have been flagged (see Robinson and Rowlands, 2009); in particular in terms of MARACs the DASH has been criticised as privileging actuarially based decision-making at the expense of professional judgement, neglecting the complexity of cases. Use of the DASH in Scotland has not been evaluated. It is important therefore to be cautious about the current use of risk assessment in Scotland; irrespective of how good a risk assessment tool may be, its effectiveness will depend on how it is used.

Another multi-agency development is the Disclosure Scheme for Domestic Abuse Scotland (DSDAS), rolled out across Scotland in 2015. The scheme enables both the police to initiate or partners/friends/other agencies to request disclosure of a person's history of domestic abuse. Where there is evidence of a concern a multi- 
agency decision-making forum is convened to determine if a disclosure is to be made (and in what form). The purpose of the scheme is to enable a potential victim to make informed choices about the relationship and provide help and support around such decision-making. Such schemes are however controversial with concerns that they place the onus for stopping abuse on the victim-survivor and do not provide for victim safety (Duggan, 2012).

\section{Challenges for maintaining Scotland's progress in tackling domestic abuse}

The response to domestic abuse in Scotland is located within a broader policy framework to address violence against women/gender-based violence, situating gender-based violence as both cause and consequence of women's inequality. The application of a clear gendered lens to domestic abuse, developed through the work of feminist NGOs and a long history of partnership working between statutory and voluntary agencies, has enabled Scotland's progress, and global reputation, on tackling domestic abuse. It is crucial that this gendered understanding remains at the front and centre of Scotland's response to domestic abuse, to address the current challenges.

\section{Challenges for multi-agency working: operating on different planets}

One barrier to engagement across agencies is the difference in perspectives, agendas and practice models of different professionals working within different agencies, developed over time by organisations working in separate spheres, developing their own analyses and responses that may not always include a clear gendered perspective. Hester (2011) describes the domestic abuse, child protection and child contact spheres to be as far apart as different planets, with the gaps between them causing failures to inhibit harm to women and children.

Understanding and responding to domestic abuse within child protection poses significant challenges, notwithstanding the greater recognition in Scotland of the impact of domestic abuse on children (Morrison \& Mitchell, 2019). Child protection often operates with unrealistic expectations on mothers to protect the children from the perpetrator of the abuse, while the perpetrator himself, the source of risk and harm, remains invisible to child protection services. Social work may attribute this 
'failure to protect' narrative to women affected by domestic abuse where they are unable to separate from the abusive partner. This comes from the misconception, held in Scotland and elsewhere, that separation means safety, where research shows that domestic abuse often continues and escalates after separation (Radford \& Hester, 2006).

Scotland's work using Safe and Together has the potential to link the child protection and domestic abuse planets. Safe and Together is an approach to domestic abuseinformed child welfare. Three key principles underpin the model: (i) keeping the child Safe and Together with the non-abusing parent; (ii) partnering in a strengthsbased way with non-abusing parents; and (iii) intervening with the perpetrator to reduce risk and harm to the child (Mandel, 2014). The City of Edinburgh Council was one of the first areas outside the US to adopt Safe and Together, and work is ongoing across other local authority areas and certain national structures (e.g. health visiting) to embed the model (Morrison \& Mitchell, 2019).

Despite developments on the child protection planet, child contact remains an area of particular risk and harm. Contact between children and fathers post-separation provides particular opportunities for domestic abuse to continue, affecting both mothers and children (e.g. Holt, 2015; Thiara \& Gill, 2012). Nevertheless, child contact systems and professionals may appear to ignore domestic abuse and the harm caused to children (and women) by ongoing contact, resting on automatic assumptions that contact between a child and a non-resident parent must be preferred (Hester, 2011). The failings of civil courts to consider domestic abuse persist despite statutory obligations in Scotland (Morrison et al., 2013). As with $\mathrm{DA}(\mathrm{S}) \mathrm{A}$, whether legislative aims to protect women and children from domestic abuse are achieved depends on effective implementation, including a clear understanding among family court professionals of the gendered nature of domestic abuse and its impact on children.

A particular challenge for police: pro-arrest policies and dual reports or counterallegations Scotland, in common with many other jurisdictions worldwide, has adopted pro-arrest policies; the joint protocol between Police Scotland and the Crown Office \& Procurator Fiscal service (2019) sets out a pro-arrest policy where there is sufficient evidence (whether or not the victim is making a complaint). While such policies have the potential for more perpetrators to be held accountable for 
their actions, an unintended consequence in Scotland as in other jurisdictions may be that more women risk arrest as perpetrators (DeLeon-Granados et al., 2006; Brooks and Kyle, 2015). The proportion of domestic abuse incidents in Scotland where women were recorded by the police as perpetrators and men as victims has increased from $9 \%$ in 2002/03 to $15 \%$ in 2019/20. Brooks and Kyle (2015) note that a possible cause for this rise is counter-allegations (where perpetrators falsely claim they are victims of domestic abuse, in order to deflect legal proceedings against themselves or extend their control) and dual-reports (where both parties in a relationship are reported to the police as perpetrators, and may include counterallegations, violent resistance to coercive control or situational couple violence, as described by Johnson, 2008).

As part of work to implement $\mathrm{DA}(\mathrm{S}) \mathrm{A}$, training aimed at achieving behavioural change across Police Scotland was commissioned by Scottish Government, from Safe Lives: Domestic Abuse Matters Scotland. This training included material around Johnson's typology and also around the tactics perpetrators may use to manipulate police officers/staff. As at May 2020, 18,496 officers and staff have completed the initial e-learning package of this training and 13,510 a one-day core training, delivered in partnership by a domestic abuse and a police expert; a further 700 have completed a second day of training to be 'champions' (Safe Lives, 2020a). Feedback forms from the training generally reported that participants felt their knowledge had increased in all areas of the training; future data on implementation of $\mathrm{DA}(\mathrm{S}) \mathrm{A}$ may help consider whether this training has in practice enabled police officers to meet the challenge of effectively identifying the subtle and insidious behaviours of coercive control and applying a gendered lens in their everyday practice.

\section{Challenges for all: the persistence and scale of domestic abuse}

Domestic abuse has devastating consequences for those experiencing it, their children and families and their wider communities. It also has significant social and economic impacts. Despite the considerable progress made in Scotland to develop more effective legislation and policies, in practice domestic abuse persists, and the scale of domestic abuse is presenting challenges across the multi-agency structures as well as within individual agencies, statutory and third-sector organisations. Police Scotland estimate receiving a domestic abuse report once every nine minutes, 
making it the single biggest demand on their time (Police Scotland, 2017). Safe Lives $(2017,2020)$ estimate that 39 MARACS are needed to meet adequate levels of provision in Scotland; 32 are currently operating, including three in development. Despite a positive evaluation of Scotland's first specialist domestic abuse court (Connelly, 2008), such provision is not available universally across Scotland.

Research in England suggests that improved recognition of the impact of domestic violence on children may mean that children are known to statutory services, but not necessarily that this means they have access to support or intervention (Stanley et al, 2011). As described above SWA, the main specialist provider of support and refuge for those experiencing domestic abuse, was unable to provide refuge space to most of the women and children requesting this on their census day 2020 due to the lack of safe and suitable space. In 2017/18 89 \% of Women's Aid groups in Scotland reported a real term cut in their funding from local and central government, and an increased need to apply for short-term and ad-hoc funding to cover core work (SWA, 2019).

Significant resources and investment are required to ensure the capacity of statutory and third sector organisations to respond to the volume of domestic abuse. The longer term implications of the COVID-19 pandemic, with lockdown often facilitating intensification of abuse by perpetrators as well as requiring services and those affected by abuse to adapt how to access and what is provided in terms of support, compounds these pressures (Brooks-Hay et al., 2020).

While Scotland's legislative developments are promising, tackling domestic abuse depends on how these are implemented and further Scotland's gendered lens tells us that women's structural inequality in society, as both cause and consequence of domestic abuse, must be addressed.

\section{References}

Brooks, L. (1.2.2018). Scotland set to pass "gold standard" domestic abuse law. The Guardian. www.theguardian.com/society/2018/feb/01/scotland-set-to-pass-gold-standard-domesticabuse-law

Brooks, O. \& Kyle, D. (2015). Dual reports of domestic abuse made to the police in Scotland: A summary of findings from a pilot research study. The Scottish Institute for Policing Research, (23). 
www.sccjr.ac.uk/publications/dual-reports-of-domestic-abuse-made-to-the-police-inscotland-a-summary-of-findings-from-a-pilot-research-study/

Brooks-Hay, O. \& Burman, M. (2019) Understanding, Defining and Measuring Domestic Abuse. In Brooks-Hay, O., Burman, M. and McFeely, C. (eds), Domestic Abuse: Contemporary Perspectives and Innovative Practices, (pp. 10-24). Dunedin Academic Press.

Brooks-Hay, O., Burman, M. \& McFeely, C. (2018). Introducing Scotland's Approach to Domestic Abuse. In Brooks-Hay, O., Burman, M. and McFeely, C. (eds), Domestic Abuse: Contemporary Perspectives and Innovative Practices, (pp. 1-9). Dunedin Academic Press.

Brooks-Hay, O., Burman, M., Mirza, N., Reed, D., Saunders, K., Shaw, A. \& Wiseman, P. (2020). Domestic Abuse \& Sexual Violence. In Armstrong et al, Left Out and Locked Down. Impacts of COVID-19 lockdown for marginalised groups in Scotland. University of Glasgow/Chief Scientist Office.

https://scotlandinlockdown.files.wordpress.com/2020/12/scotlock_project_report_full_dec 2020-2.pdf

Brooks-Hay, O. \& Burman, M. (2018). Aligning policy and law? The creation of a domestic abuse offence incorporating coercive control. Criminology and Criminal Justice, 18(1), 67-83. https://doi.org/10.1177/1748895817752223

Binsbacher, R., DeLeon-Granados, W., \& Wells, W. (2006). Arresting developments: Trends in female arrests for domestic violence and proposed explanations. Violence Against Women, 12(4), 355-371. https://doi.org/10.1177/1077801206287315

Centre for Families and Relationships. (2013). Domestic Abuse and Gender Inequality: An Overview of the Current Debate. https://era.ed.ac.uk/handle/1842/8769

Connelly C. (2008). Handling Domestic Abuse Cases: A Toolkit to Aid the Development of Specialist Approaches to Domestic Abuse. The Scottish Government.

Cordis Bright Consulting. (2011). Research into Multi-Agency Assessment Conferences (MARACs). Home Office. https://assets.publishing.service.gov.uk/government/uploads/system/uploads/attachment_ data/file/116538/horr55-technical-annex.pdf

Crown Office \& Procurator Fiscal Service. (2020). Domestic abuse and stalking charges in Scotland 2019 2020.

https://www.copfs.gov.uk/images/Documents/Statistics/Domestic\%20Abuse/Domestic\% 20Abuse $\% 20$ and $\% 20$ stalking $\% 202019-20$.pdf

Coy, M., Foord, J. \& Kelly, L. (2007). Map of Gaps: The Postcode Lottery of Violence Against Women Support Services in the UK. End Violence Against Women Coalition.

https://www.endviolenceagainstwomen.org.uk/wp-content/uploads/map_of_gaps1.pdf

Devaney, J. (2015). Research review: The impact of domestic violence on children. Irish Probation Journal, (12), 79-94.

https://pureadmin.qub.ac.uk/ws/files/17369087/Research_review_impact_of_domestic_vi olence_on_children.pdf

Dobash, R. P. and Dobash, R. E. (2004). Women's violence to men in intimate relationships: Working on a puzzle. British Journal of Criminology, 44(3), 324-49.

https://doi.org/10.1093/bjc/azh026

Duggan, M. (2012). Using victims' voices to prevent violence against women: A critique. British Journal of Community Justice, 10(2), 25-37. https://www.mmuperu.co.uk/assets/uploads/bjcj_files/BJCJ-10-2_-_Duggan-FULL.pdf

Hester, M. (2011). The Three Planet Model: Towards an Understanding of Contradictions in Approaches to Women and Children's Safety in Contexts of Domestic Violence. The British Journal of Social Work, 41(5), 837-853. https://doi.org/10.1093/bjsw/bcr095

Hester, M. \& Radford, L. (2006). Mothering Through Domestic Violence. Jessica Kingsley.

Hester, M. (2013). Who does what to whom? Gender and domestic violence perpetrators in English police records. European Journal of Criminology, 10(5), 623-37. https://doi.org/10.1177/1477370813479078 
Holt, S. (2015). Post-separation fathering and domestic abuse: Challenges and contradictions: Postseparation fathering and domestic violence. Child Abuse Review, 24(3), 210-22. https://doi.org/10.1002/car.2264

Johnson, M. (2008). A Typology of Domestic Violence: Intimate Terrorism, Violent Resistances, and Situational Couple Violence. University Press of New England.

Johnson, M. P. (1995). Patriarchal terrorism and common couple violence: Two forms of violence against women. Journal of Marriage and the Family, 57(2), 283-94. https://doi.org/10.2307/353683

Katz, E. (2015). Recovery-promoters: Ways in which children and mothers support one another's recoveries from domestic violence. British Journal of Social Work, 45(1), 153-169. https://doi.org/10.1093/bjsw/bcv091

Kelly, L. \& Westmarland, N. (2016). Naming and defining "Domestic violence": Lessons from research with violent men. Feminist review, 112(1), 113-27. https://doi.org/10.1057/fr.2015.52

Lombard, N. \& Whiting, N. (2015). Domestic abuse: Feminism, the government and the unique case of Scotland. In R. Goel and L. Goodmark (Eds.), Comparative Perspectives on Domestic Violence: Lessons from Efforts Worldwide (pp.155-68). Oxford University Press.

MacQueen, S. \& Norris, P. A. (2014). Police awareness and involvement in cases of domestic and partner abuse. Policing in Society: An international Journal of Research and Policy, 26(1), 55-76. https://doi.org/10.1080/10439463.2014.922084

Mandel, D. (2014). Safe and Together Model: Overview and evaluation data briefing. www.endingviolence.com/wp-content/uploads/2013/01/2015Overview-and-EvidenceBriefing-October-2014.pdf

Mitchell, A. \& Morrison, F. (2019). Domestic Abuse and the Role of Children and Families' Social Work. In Brooks-Hay, O., Burman, M. and McFeely, C. (eds), Domestic Abuse: Contemporary Perspectives and Innovative Practices (pp.80-92). Dunedin Academic Press.

Myhill, A. (2017). Measuring domestic violence: Context is everything. Journal of Gender-Based Violence, 1(1), 33-44. https://doi.org/10.1332/239868017X14896674831496

Nichols, A. (2013). Meaning-making and domestic violence victim advocacy: An examination of feminist identities, ideologies, and practices. Feminist Criminology, 8(3), 177-201. https://doi.org/10.1177/1557085113482727

Payton, J. \& Robinson, A. (2016). Independent Advocacy and Multi-Agency Responses to Domestic Violence. In Hilder, S. and Bettinson, V. (Eds.), Domestic Violence: Interdisciplinary Perspectives and Intervention (pp. 249-271). Palgrave Macmillan.

Police Scotland (2017). Second anniversary of Disclosure Scheme for domestic abuse. 1st October 2017. www.scotland.police.uk/whats-happening/news/2017/september/second-anniversarydisclosure-scheme-domestic-abuse-scotland

Police Scotland and Crown Office \& Procurator Fiscal Service (2019). Joint protocol between Police Scotland and the Crown Office \& Procurator Fiscal Service: In partnership challenging domestic abuse (5th edn.). https://www.scotland.police.uk/spa-media/ymzlwhwj/joint-protocol-between-policescotland-and-copfs-in-partnership-challenging-domestic-abuse.pdf?view $=$ Standard

Bassett, C., Bradley, C., Collishaw, S., Corral, S., Fisher, H., Howat, N. \& Radford, L. (2011). Child Abuse and Neglect in the UK Today. National Society for the Prevention of Cruelty to Children. https://learning.nspcc.org.uk/media/1042/child-abuse-neglect-uk-today-research-report.pdf

Robinson, A. and Hudson, K. (2011). Different yet complementary: Two approaches to supporting victims of sexual violence in the UK. Criminology \& Criminal Justice, 11(5), 515-533. https://doi.org/10.1177/1748895811419972

Robinson, A. and Rowlands, J. (2009). Assessing and managing risk among different victims of domestic abuse: Limits of a generic model of risk assessment. Security Journal, 22(3), 190-204. https://doi.org/10.1057/sj.2009.2

Robinson, A. L. and Tregidga, J. (2007). The perceptions of high-risk victims of domestic violence to a coordinated community response in Cardiff, Wales. Violence Against Women, 13(11), 11301148. https://doi.org/10.1177/1077801207307797 
SafeLives. (2017). Whole lives: Improving the response to domestic abuse in Scotland. www.safelives.org.uk/sites/default/files/resources/Whole $\% 20$ Lives_Improving $\% 20$ the $\% 20 \mathrm{r}$ esponse $\% 20$ to $\% 20$ domestic $\% 20$ abuse $\% 20$ in $\% 20$ Scotland.pdf

SafeLives. (2020). Domestic Abuse Matters Scotland Evaluation Report. https://safelives.org.uk/sites/default/files/resources/Domestic $\% 20$ Abuse $\% 20$ Matters $\% 20 \mathrm{~S}$ cotland $\% 20-\% 20$ Evaluation $\% 20$ Report.pdf

SafeLives (2020a). Marac in Scotland National Update Report 2020. https://safelives.org.uk/sites/default/files/resources/SafeLives $\% 20$ Scotland $\% 20$ Maracs $\% 20$ National $\% 20$ Overview.pdf

Scotland's Commissioner for Children and Young People. (2013). Child Contact Proceedings for Children Affected by Domestic Abuse. https://cypcs.org.uk/wpcypcs/wpcontent/uploads/2020/03/Child_contact_proceedings_March_2013.pdf

Scottish Executive. (2000). Scottish Partnership on Domestic Abuse: National Strategy to Address Domestic Abuse in Scotland. https://www.southayrshire.gov.uk $/$ documents $/$ file $=$ The $\% 20$ National $\% 20$ Domestic $\% 20$ Abuse $\% 20$ Strategy.pdf

Scottish Government. (2008). Gender-Based Violence Action Plans. https://www.sehd.scot.nhs.uk/mels/cel2008_41.pdf

Scottish Government. (2018). Equally Safe: Scotland's Strategy for Preventing and Eradicating Violence Against Women and Girls.

https://www.gov.scot/binaries/content/documents/govscot/publications/strategyplan/2018/04/equally-safe-scotlands-strategy-prevent-eradicate-violence-against-womengirls/documents/00534791-pdf/00534791-pdf/govscot\%3Adocument/00534791.pdf

Scottish Government. (2021). Domestic Abuse Recorded by the Police in Scotland, 2019-20. https://www.gov.scot/publications/domestic-abuse-statistics-recorded-police-scotland2019-20/

Scottish Government. (2021a). Scottish Crime and Justice Survey 2019/20: Main Findings. https://www.gov.scot/publications/scottish-crime-justice-survey-2019-20-main-findings/

Scottish Women's Aid. (2019). Equality and Human Rights Committee inquiry draft budget scrutiny 2020-21 Scottish Women's Aid submission. https://womensaid.scot/wpcontent/uploads/2019/08/SWA-submission-to-EHRiC-inquiry-into-draft-budget-scrutiny2020-21.pdf

Scottish Women's Aid. (2020). Census Day 2020 Key findings. https://womensaid.scot/wpcontent/uploads/2020/12/Census-Day-2020-Key-Findings.pdf

Stanley, N., Miller, P., Foster, H. R. \& Thomson, G. (2011). A stop-start response: Social services' interventions with children and families notified following domestic violence incidents. The British Journal of Social Work, 41(2), 296-313. https://doi.org/10.1093/bjsw/bcq071

Stark, E. (2007). Coercive Control: How Men Entrap Women in Personal Life. Oxford University Press.

Steel, N., Blakeborough, L. \& Nicholas, S. (2011). Supporting High-Risk Victims of Domestic Violence: A Review of Multi-Agency Risk Assessment Conferences (MARACs), Research Report 55. Home Office.

https://assets.publishing.service.gov.uk/government/uploads/system/uploads/attachment_ data/file/116537/horr55-report.pdf

Thiara, R. K. and Gill, A. K. (2012). Domestic Violence, Child Contact and Post-Separation Violence: Issues for South Asian and African-Caribbean Women and Cbildren: A Report of Findings. National Society for the Prevention of Cruelty to Children. https://letterfromsanta.nspcc.org.uk/globalassets/documents/research-reports/domesticviolence-child-contact-post-separation-violence-report-summary.pdf

Thomson, L. (8.5.2014). Ministerial address by Lesley Thomson QC, Solicitor General for Scotland. COPFS Conference on Domestic Abuse.

https://www.copfs.gov.uk/images/Documents/Our\%20Priorities/Domestic\%20abuse/Sol $\% 20$ Gen $\% 20$ Speech $\% 20$ -

$\%$ 20COPFS $\% 20$ Domestic $\% 20$ Abuse $\% 20$ Conference $\% 208 \% 20$ May $\% 202014$.pdf 
Whiting, N. (2007). A Contradiction in Terms? A Gendered Analysis \& Same Sex Domestic Abuse. Scottish Women's Aid. 


\title{
FRONTLINE RESPONSE TO
}

\section{DOMESTIC ViOLENCE IN SLOVENIA}

\author{
Karmen Jereb, ${ }^{1}$ Aleksander Koporec OberČKal, ${ }^{2}$ \\ Kaja Prislan, ${ }^{1}$ Boštjan SLAK ${ }^{1} \&$ Branko LOBNikaR ${ }^{1}$ \\ ${ }^{1}$ University of Maribor, Faculty of Criminal Justice and Security, Ljubljana, Slovenia. \\ E-mail: carmen.jereb@gmail.com; kaja.prislan@um.si; bostjan.slak@um.si; \\ branko.lobnikar@um.si \\ ${ }^{2}$ Slovenian Police, Research and Social Skills Centre, Ljubljana, Slovenia. \\ E-mail: aleksander.koporec.oberckal@policija.si
}

Abstract In Slovenia, domestic violence is a common social problem that infringes upon fundamental human rights. Results of a European Union Agency for Fundamental Rights survey from 2014 showed that, after the age of 15, $22 \%$ of Slovenian women had experienced physical and/or sexual violence, which is $11 \%$ lower than for the EU overall. The European Institute for Gender Equality, in their report from 2017, estimated that the cost of intimate partner violence against women in Slovenia could amount to EUR 440 million annually. Violence against women continues to be underreported and stigmatised. The Slovenian police are one of the main front-line responders that react to domestic violence incidents. A comprehensive protocol is set in place that enables the police to react as effectively as possible. Interinstitutional cooperation is also available to deal with a case of violence in a multidisciplinary team treating domestic violence. Despite the national policy on preventing and eliminating domestic violence, raising public awareness about it, allocating resources to education and training initiatives, an intervention programme for perpetrators, as well as a coordinated system for providing victim assistance - some deficiencies remain in the implementation of these policies.

Keywords: domestic violence, Slovenia, interagency cooperation, victims, police, NGO 


\section{Description of the country}

The Republic of Slovenia is a country in Central Europe that covers 20,271 square kilometres and has a population of 2.1 million. Ljubljana is the nation's capital and its largest city. Historically, Slovenia was a member of former Yugoslavia. In 1991, Slovenia gained independence and in 2004 it joined the European Union. It is also a member of other international organisations/arrangements like NATO, OSCE, $\mathrm{UN}$, the Schengen Area, etc. Slovenia is a relatively economically developed country.

The Constitution of the Republic of Slovenia (1991) states that Slovenia is a democratic republic governed by the rule of law and a social state that guarantees the human rights and fundamental freedoms of all, irrespective of their ethnicity, race, gender, faith, political or other conviction, material standing, birth, education, social status, or any other personal circumstance. Under the Constitution, everyone has the right to personal dignity and safety, the inviolability of their physical and mental integrity, while their privacy and personality rights are also guaranteed. The state is responsible for safeguarding family, motherhood, fatherhood, children and youth and creating the required conditions.

Domestic violence is a common social problem that infringes upon basic human rights. It has a considerable impact on victims' physical and mental health, brings immediate and long-term consequences, and imposes a significant cost burden on society. Despite the nationwide policy on preventing and eliminating domestic violence, raising public awareness about it, allocating resources to education and training initiatives, an intervention programme for perpetrators, as well as a coordinated system for providing victim assistance - some deficiencies remain in the implementation of these policies. Such limits were also recognised in the Resolution on the 2009-2014 National Programme on Prevention of Family Violence (Slo: Resolucija o nacionalnem programu preprečevanja nasilja v družini 2009-2014 [ReNPPND0914]) (2009).

Prior to the Resolution expiring, the Ministry of Labour, Family, Social Affairs and Equal Opportunities began work on a new strategic document in the form of a national programme for preventing domestic violence and violence against women, which is to set out in greater detail the strategic directions in the area of preventing domestic violence for the coming period (e.g. key areas where deficiencies or poor 
performance in this field have been detected, and objectives and measures for their improvement) (Association for nonviolent communication, 2019).

\section{Legislation on domestic violence}

Slovenia incorporates several international documents and standards concerning domestic violence in its legislation. Mainly, on the EU and national levels, the area of domestic violence is regulated by 'Directive 2012/29/EU of the European Parliament and of the Council of 25 October 2012 Establishing Minimum Standards on the Rights, Support and Protection of Victims of Crime, and Replacing Council Framework Decision 2001/220/JHA' (European Parliament \& Council of the European Union, 2012) and the Council of Europe Convention on Preventing and Combating Violence against Women and Domestic Violence - the Istanbul Convention (Council of Europe, 2014). Slovenia signed this Convention on 8 September 2011 and ratified it on 19 December 2014.

The primary national legislation for regulating domestic violence in Slovenia is the Domestic Violence Prevention Act (2008) and the Act Amending the Domestic Violence Prevention Act (2016). The amending act added stalking as one of the forms of domestic violence, prohibited corporal punishment of children, and extended the list of those obliged to report violence against children. Domestic violence is defined in the Domestic Violence Prevention Act, ${ }^{1}$ with the Act also defining the role and tasks of state authorities, holders of public authority, public service providers and other service providers in the areas of social security, healthcare and education, the competencies of self-governing local communities and non-governmental organisations for dealing with domestic violence and lays down measures for protecting victims of domestic violence.

\footnotetext{
1 (Domestic) violence denotes any form of physical, sexual, psychological, or economic violence inflicted by one family member on another, or the neglect or stalking of the victim regardless of age, gender or any other personal circumstance of the victim or the perpetrator of the violence. It also prohibits corporal punishment of children article ('Act Amending the Domestic Violence Prevention Act (Slo. Zakon o Spremembah in Dopolnitvah Zakona o Preprečevanju Nasilja v Družini [ZPND-A])', 2016; 'Domestic Violence Prevention Act (Slo. Zakon o preprě̌evanju nasilja v drǔ̌ini [ZPND])', 2008).
} 
According to Article 11 of the Domestic Violence Prevention Act (2008), the National Assembly of the Republic of Slovenia in 2009 adopted the Resolution on the 2009-2014 National Programme on Prevention of Family Violence. This strategic document stipulated the objectives, measures and key policymakers for preventing and reducing domestic violence in the Republic of Slovenia for the 20092014 period, prepared by the Ministry of Labour, Family, Social Affairs and Equal Opportunities in cooperation with other ministries. The document's fundamental objectives were to connect the measures of various sectors and ensure that activities to reduce domestic violence are efficient on the levels of identification and prevention.

In its first report on the implementation of the Istanbul Convention, the Ministry of Labour, Family, Social Affairs and Equal Opportunities reported that a working group established by the Ministry for Labour, Family and Social Affairs was then preparing a new Resolution on the National Programme on Preventing Domestic Violence and Violence against Women 2020-2025 (Group of Experts on Action against Violence against Women and Domestic Violence [GREVIO], 2019).

The fact domestic violence is a common social problem that infringes basic human rights has seen it being criminalised in Slovenian legislation. The first Criminal Code of the Republic of Slovenia (1994) did not include domestic violence as a standalone criminal offence, although violent conduct in the family setting was penalised. In the substantially amended Criminal Code of 2008, domestic violence is stipulated as an independent criminal offence in the chapter on criminal offences against marriage, family, and children. ${ }^{2}$

\footnotetext{
${ }^{2}$ More precisely, Article 191 of the Criminal Code - Official Consolidated Text (2012) states:

1. Whoever within a family treats another person badly, beats them, or in any other way treats them painfully or degradingly, threatens with a direct attack on their life or limbs to throw them out of the joint residence or in any other way limits their freedom of movement, stalks them, forces them to work or give up their work, or in any other way puts them in a subordinate position by aggressively limiting their equal rights shall be sentenced to imprisonment of no more than 5 years.

2. The same punishment shall be imposed on whoever commits the acts under the preceding paragraph in any other permanent living community.

3. If the act referred to in paragraph 1 is committed against a person with whom the perpetrator lived in a family or other permanent community, which fell apart, however this act is connected to the community, the perpetrator shall be sentenced to imprisonment for no more than 3 years.
} 
Under the Protection of Public Order Act (2006), domestic violence can also be considered a misdemeanour against public order and peace and be classified as violent and offensive behaviour (Article 6). If the violence bears signs of both a criminal offence and a misdemeanour, according to the Minor Offences Act (2011), the criminal prosecution holds priority. This means that a perpetrator convicted of a criminal offence with signs of a misdemeanour cannot be subjected to proceedings/sanctions related to the minor offence. Domestic violence is usually treated as a criminal offence when it comes to repeated violent acts by which the perpetrator puts the victim in a subordinate position. If the violent behaviour is a one-off act (and does not meet the legal requirements of any other criminal offence), it is typically treated as a minor offence (Filipčič et al. 2021).

The Slovenian Criminal Procedure Act was also adjusted to correspond to the growing awareness of the damaging consequences of domestic violence and its complexity while tackling it, especially when it comes to protecting the victims. The biggest improvements were seen in the Act Amending the Criminal Procedure Act (2019), which gives the police powers as well as an obligation to conduct a risk assessment of the victim(s') safety. ${ }^{3}$

The Slovenian police do pay special attention to domestic violence problems, reflected in its core legislation - the Police Tasks And Powers Act (2013). Under the Act, police officers must be especially considerate while interacting with victims of domestic violence. The Act also gives police officers the ability to issue a restraining order against the perpetrator. In general, the police is seen as giving special emphasis to vulnerable groups, and displays zero tolerance for all forms of violence, as demonstrated in goals contained in the Resolution on the National Programme for the Prevention and Suppression of Crime 2019-2023 (2019). This resolution also lists key risk factors and other factors important for improving the detection of

${ }^{3}$ Article 143 č introduced into the Act Amending the Criminal Procedure Act (2019) states:

1. The competent authority in the pre-trial or criminal proceedings in order to establish the existence of special protection needs already at the first contact with the victim, if possible, to assess the level of exposure of the victim's secondary and repeat victimisation, intimidation and retaliation (individual score).

2. Where an individual evaluation to examine in particular the personal characteristics of the victim, the nature, severity and circumstances of the offence, the conduct of the accused and the victim in police or criminal proceedings and outside, take into account the opinion of the victim, especially if the victim expressly rejects in advance the possibility of special protection. The police especially takes account of the age and any disability of the victim and all other circumstances of the offence, executed due to prejudice, discrimination, exploitation or hate crimes with elements of violence or of a sexual nature and crimes with elements of terrorism, human trafficking and crimes committed in a criminal organisation. 
domestic violence, peer violence and online violence against children (Police, n.d.a).

\section{Reporting levels of domestic violence}

Two types of data sets are available for monitoring domestic violence: official statistics and victimisation studies. However, the full extent of violence against women is hard to estimate. Violence against women continues to be underreported and stigmatised, meaning that what is actually reported is only a fraction of the reality (European Institute for Gender Equality, 2013).

The Slovenian Police in its annual work report for 2020 shows the number of criminal acts of domestic violence was comparable with previous years (Police, 2021). Criminal offences of domestic violence are among the 10 most frequent offences in the category of general crimes.

Table 1: Criminal offences in the category of general crimes [10 most frequent offences]

\begin{tabular}{|c|c|c|c|c|c|c|c|c|c|c|}
\hline \multirow[t]{2}{*}{$\begin{array}{l}\text { Type of } \\
\text { criminal offence }\end{array}$} & \multicolumn{5}{|c|}{ Number of criminal offences } & \multicolumn{5}{|c|}{$\begin{array}{c}\text { Share of criminal offences } \\
\text { investigated } \\
{[\text { in } \%]}\end{array}$} \\
\hline & 2016 & 2017 & 2018 & 2019 & 2020 & 2016 & 2017 & 2018 & 2019 & 2020 \\
\hline Larceny & 20,397 & 19,045 & 18,496 & 16,688 & 15,170 & 25.8 & 25.2 & 26.5 & 30.0 & 30.9 \\
\hline Grand larceny & 11,508 & 10,010 & 9,350 & 9,362 & 9,039 & 16.1 & 20.0 & 20.4 & 19.6 & 20.2 \\
\hline $\begin{array}{l}\text { Damage to third- } \\
\text { person property }\end{array}$ & 3,011 & 3,197 & 3,377 & 3,330 & 3,705 & 23.4 & 23.2 & 21.1 & 23.6 & 25.5 \\
\hline Fraud & 2,629 & 2,407 & 2,706 & 3,134 & 2,662 & 82.4 & 78.5 & 78.1 & 77.2 & 69.5 \\
\hline Threat & 1,399 & 1,455 & 1,543 & 1,610 & 1,917 & 90.5 & 91.6 & 89.6 & 88.8 & 87.6 \\
\hline $\begin{array}{l}\text { Domestic } \\
\text { violence }\end{array}$ & 1,347 & 1,274 & 1,371 & 1,336 & 1,477 & 95.0 & 96.5 & 97.6 & 97.1 & 98.7 \\
\hline $\begin{array}{l}\text { Unlawful } \\
\text { manufacture of } \\
\text { and trade in } \\
\text { narcotic drugs, } \\
\text { illicit substances } \\
\text { in sport and } \\
\text { precursors for } \\
\text { manufacturing } \\
\text { narcotic drugs }\end{array}$ & 1,470 & 1,650 & 1,517 & 1,252 & 1,366 & 93.5 & 94.0 & 92.4 & 92.7 & 93.0 \\
\hline $\begin{array}{l}\text { Light bodily } \\
\text { harm }\end{array}$ & 1,346 & 1,256 & 1,399 & 1,425 & 1,312 & 88.9 & 89.2 & 90.4 & 88.6 & 90.8 \\
\hline Misappropriation & 1,371 & 1,440 & 1,502 & 1,478 & 1,307 & 39.3 & 37.5 & 35.8 & 36.1 & 39.1 \\
\hline $\begin{array}{l}\text { Counterfeiting } \\
\text { documents }\end{array}$ & 1,300 & 1,573 & 986 & 1,301 & 855 & 95.2 & 94.0 & 93.5 & 93.4 & 91.9 \\
\hline $\begin{array}{l}\text { Other criminal } \\
\text { offences }\end{array}$ & 5,907 & 6,104 & 6,054 & 6,119 & 6,757 & 82.5 & 80.9 & 78.2 & 80.2 & 76.7 \\
\hline Total & 51,685 & 49,411 & 48,301 & 47,035 & 45,567 & 42.1 & 43.7 & 43.9 & 46.4 & 47.0 \\
\hline
\end{tabular}


More data concerning subtypes of offences related to domestic violence and against marriage, family and children are presented below. Over 2,000 cases of such offences are recorded per year, and domestic violence is the most prevalent type of offence, representing more than half of all criminal offences against marriage, family and children.

Table 2: Criminal offences against marriage, family and children

\begin{tabular}{|c|c|c|c|c|c|c|c|c|c|c|}
\hline \multirow[t]{2}{*}{$\begin{array}{l}\text { Type of } \\
\text { criminal } \\
\text { offence }\end{array}$} & \multicolumn{5}{|c|}{ Number of criminal offences } & \multicolumn{5}{|c|}{$\begin{array}{c}\text { Share of criminal offences } \\
\text { investigated } \\
{[\text { in } \%]}\end{array}$} \\
\hline & 2016 & 2017 & 2018 & 2019 & 2020 & 2016 & 2017 & 2018 & 2019 & 2020 \\
\hline $\begin{array}{l}\text { Abduction of } \\
\text { minors }\end{array}$ & 279 & 330 & 653 & 375 & 604 & 85.3 & 72.1 & 60.0 & 85.1 & 81.1 \\
\hline $\begin{array}{l}\text { Domestic } \\
\text { violence }\end{array}$ & ,347 & 1,274 & 1,371 & 1,336 & 1,477 & 95.0 & 96.5 & 97.6 & 97.1 & 98.7 \\
\hline $\begin{array}{l}\text { Neglect and } \\
\text { maltreatment } \\
\text { of a minor }\end{array}$ & 507 & 71 & (3) & ו נד & 42 & 94.5 & 93.4 & 95.9 & 94.2 & 95.8 \\
\hline $\begin{array}{l}\text { Non-payment } \\
\text { of child } \\
\text { support }\end{array}$ & 337 & 238 & 216 & 176 & 205 & 94.1 & 97.1 & 96.8 & 98.9 & 98.0 \\
\hline $\begin{array}{l}\text { Other criminal } \\
\text { offences }\end{array}$ & 8 & 5 & 8 & 7 & 4 & 87.5 & 100.0 & 100.0 & 85.7 & 100.0 \\
\hline Total & 2,478 & 2,318 & 2,791 & 2,551 & 2,932 & 93.6 & 92.5 & 88.4 & 94.7 & 94.4 \\
\hline
\end{tabular}

Source: Police (2021, p. 103)

The geographical spread of offences against marriage, family and children per police directorate $[\mathrm{PD}]$ is shown in Figure 2. A total of eight police directorates covers Slovenia. The highest levels of domestic violence (per 100,000 inhabitants) are observed in the Savinjska and Dolenjska regions, and overall more domestic violence is reported in the eastern part of Slovenia, also characterised by poorer social circumstances. 


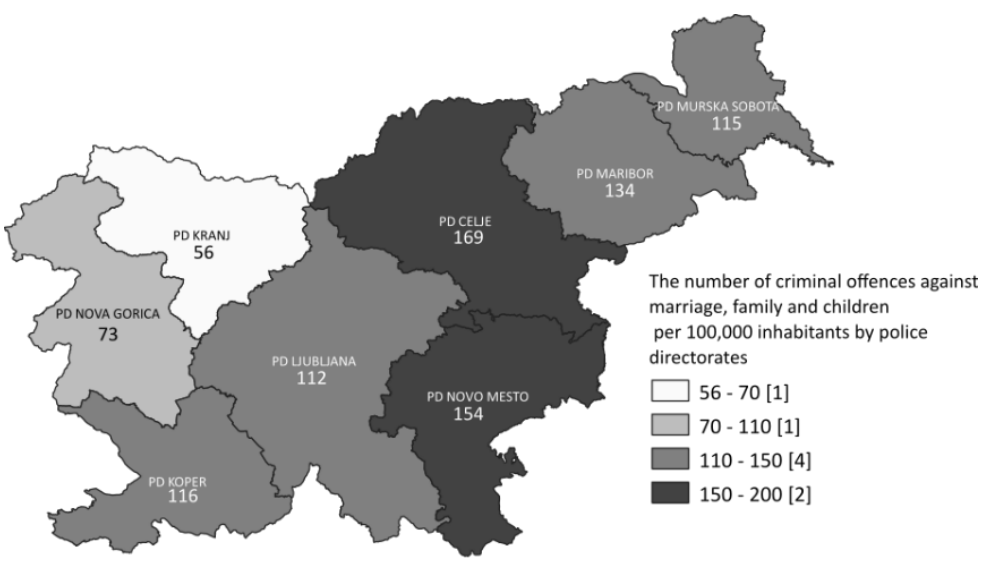

Figure 1: The number of criminal offences against marriage, family and children per 100,000 inhabitants by police directorates [PD]

(Police, 2021, p. 103)

Statistics also show that domestic violence is one of the top ten categories of criminal offences where injured people withdraw from the prosecution.

Table 3: Criminal offences, prosecuted upon the proposal, where injured people withdrew from the prosecution* [10 most frequent offences]

\begin{tabular}{|c|c|c|c|c|c|c|c|c|}
\hline \multirow{2}{*}{$\begin{array}{l}\text { Type of criminal } \\
\text { offence }\end{array}$} & \multicolumn{8}{|c|}{ Number of criminal offences } \\
\hline & 2013 & 2014 & 2015 & 2016 & 2017 & 2018 & 2019 & 2020 \\
\hline $\begin{array}{l}\text { Damage to third- } \\
\text { person property }\end{array}$ & 3,379 & 4,090 & 4,302 & 4,312 & 3,656 & 3,695 & 3,886 & 3,419 \\
\hline Larceny & 5,678 & 5,954 & 5,662 & 5,110 & 4,067 & 4,184 & 3,924 & 3,025 \\
\hline Fraud & 319 & 476 & 435 & 365 & 371 & 461 & 457 & 423 \\
\hline Threat & 53 & 68 & 104 & 244 & 260 & 303 & 309 & 312 \\
\hline Misappropriation & 302 & 376 & 342 & 312 & 355 & 433 & 456 & 309 \\
\hline Light bodily harm & 275 & 260 & 274 & 234 & 193 & 268 & 322 & 193 \\
\hline $\begin{array}{ll}\text { Violation } & \text { of } \\
\text { inviolability } & \text { of } \\
\text { dwelling } & \\
\end{array}$ & 117 & 132 & 96 & 114 & 117 & 103 & 196 & 115 \\
\hline $\begin{array}{l}\text { Abuse of personal } \\
\text { data }\end{array}$ & 6 & 11 & 13 & 10 & 5 & 20 & 29 & 33 \\
\hline Stalking & 0 & 0 & 4 & 6 & 18 & 22 & 27 & 23 \\
\hline Domestic violence & 14 & 14 & 6 & 11 & 8 & 10 & 20 & 18 \\
\hline $\begin{array}{ll}\text { Other } & \text { criminal } \\
\text { offences } & \end{array}$ & 90 & 103 & 90 & 78 & 94 & 140 & 131 & 99 \\
\hline Total & 10,233 & 11,484 & 11,328 & 10,796 & 9,144 & 9,639 & 9,757 & 7,969 \\
\hline
\end{tabular}


Official police statistics on the state of recorded misdemeanours show domestic violence is the second-most prevalent type of minor offence, representing around 10 per cent of all misdemeanours recorded (Table 4). 


\begin{tabular}{|c|c|c|c|c|c|c|c|c|c|c|c|c|c|c|c|c|}
\hline $\begin{array}{l}-1 \\
0 \\
0 \\
\tilde{D}\end{array} \mid$ & 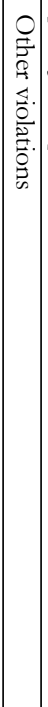 & 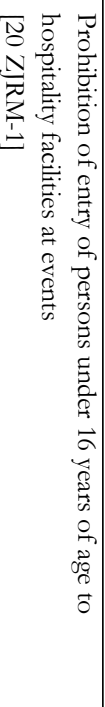 & 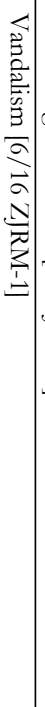 & 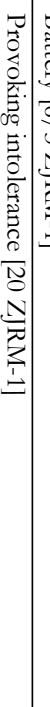 & 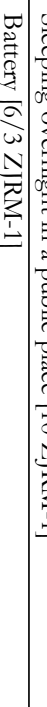 & 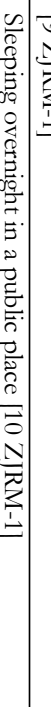 & 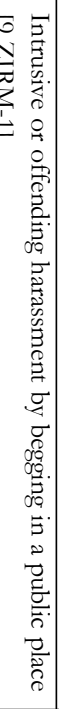 & 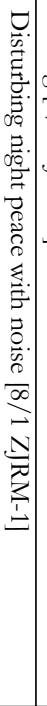 & 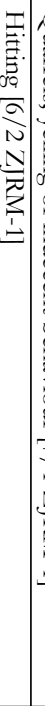 & 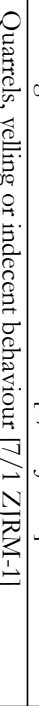 & 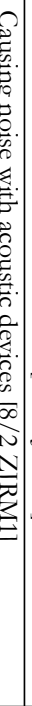 & 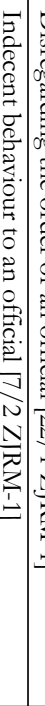 & 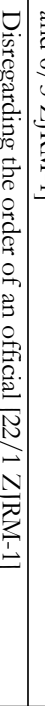 & 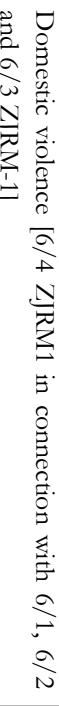 & 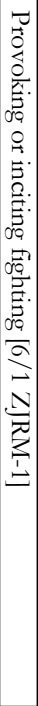 & \\
\hline $\begin{array}{l}N \\
\infty \\
\text { 心్山ు }\end{array}$ & $\begin{array}{l}5 \\
\swarrow \\
\swarrow\end{array}$ & $\Xi$ & $\underset{\Xi}{\vec{\omega}}$ & के & こ & జ్ర & $\underset{\infty}{ు}$ & $\stackrel{\circ}{\vee}$ & $\begin{array}{l}N \\
\tilde{O} \\
0\end{array}$ & 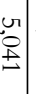 & : & $\begin{array}{c}w \\
\stackrel{w}{t} \\
\stackrel{N}{N}\end{array}$ & $\begin{array}{l}N \\
\infty \\
\infty \\
0 \\
d\end{array}$ & 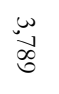 & $\mid \begin{array}{l}\vec{t} \\
\vec{b} \\
a\end{array}$ & \\
\hline $\begin{array}{l}\stackrel{N}{N} \\
\stackrel{\sim}{\omega} \\
\end{array}$ & 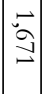 & $\vec{\sigma}$ & $\underset{\bullet}{\vec{\omega}}$ & এૂ & 索 & $\stackrel{\vec{\infty}}{\bullet}$ & $\stackrel{\text { II }}{\rho}$ & $\begin{array}{l}u \\
\oplus\end{array}$ & 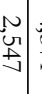 & 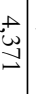 & 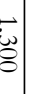 & $\begin{array}{l}N \\
\mathscr{D} \\
\infty \\
\infty\end{array}$ & 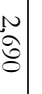 & 岕 & $\begin{array}{l}u \\
0 \\
0 \\
0\end{array}$ & 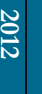 \\
\hline 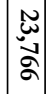 & $\begin{array}{c}5 \\
\vec{w} \\
0\end{array}$ & $\vec{\omega}$ & 尺 & ज] & $\Xi$ & $\overrightarrow{\mathrm{v}}$ & $\vec{J}$ & $\stackrel{1}{\circ}$ & $\begin{array}{l}\text { N } \\
\text { 志 }\end{array}$ & w & 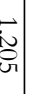 & $\begin{array}{c}N \\
\tilde{v} \\
\tilde{v}\end{array}$ & $\begin{array}{l}n \\
0 \\
0 \\
0 \\
0\end{array}$ & 岕 & 点 & 兯 \\
\hline 荵 & $\stackrel{\breve{\sim}}{\stackrel{\Xi}{\Xi}}$ & $\omega$ & సี & 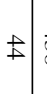 & $\stackrel{.}{\Delta}$ & స్త & 点 & 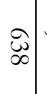 & $\begin{array}{l}\stackrel{N}{N} \\
\mathscr{O}\end{array}$ & 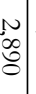 & $\overrightarrow{\mathrm{z}}$ & 孞 & $\begin{array}{l}\vec{\infty} \\
\infty \\
\infty \\
\infty \\
\infty\end{array}$ & $\stackrel{\omega}{\sim \sim N}$ & 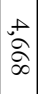 & 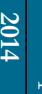 \\
\hline $\mid \begin{array}{l}\infty \\
\infty \\
\infty \\
\infty \\
+ \\
+\end{array}$ & 怘 & $\omega$ & of & $\vec{G}$ & \begin{tabular}{c}
$\mathscr{\infty}$ \\
\hdashline
\end{tabular} & 이 & $\stackrel{\omega}{ \pm}$ & जু & $\stackrel{\circ}{\circ}$ & 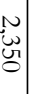 & $\begin{array}{l}0 \\
w \\
\text { s. }\end{array}$ & 品 & 厽 & $\begin{array}{l}N \\
\infty \\
0 \\
\text { N }\end{array}$ & $\begin{array}{l}\stackrel{+}{+} \\
+ \\
+ \\
+\end{array}$ & 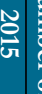 \\
\hline$\left|\begin{array}{l}\infty \\
\stackrel{\infty}{\Im} \\
\text { va }\end{array}\right|$ & 芯 & $\omega$ & ง & 志 & $\stackrel{\substack{\infty \\
\hdashline}}{2}$ & $\vec{\sigma}$ & $\stackrel{\mathscr{\infty}}{\oplus}$ & ㄱ & 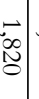 & 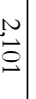 & $\begin{array}{l}\infty \\
+\infty \\
\infty\end{array}$ & a & $\stackrel{\vec{\alpha}}{\circ}$ & $\begin{array}{l}N \\
N \\
D \\
\mathcal{N}\end{array}$ & $\begin{array}{l}\vec{t} \\
\stackrel{a}{a} \\
\vec{\sigma}\end{array}$ & 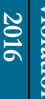 \\
\hline $\mid \begin{array}{c}\infty \\
\infty \\
w \\
+ \\
+\end{array}$ & $\begin{array}{c}\overrightarrow{\vec{A}} \\
\overrightarrow{\mathrm{A}} \\
\end{array}$ & $\omega$ & $\curvearrowright$ & $\infty$ & $\underset{b}{3}$ & $\vec{\omega}$ & 它 & $\begin{array}{l}\vec{H} \\
+\end{array}$ & $\underset{+}{N}$ & 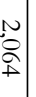 & 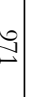 & $\begin{array}{l}\vec{\infty}+ \\
+\end{array}$ & $\breve{a}$ & $\begin{array}{l}N \\
\text { N } \\
\text { N }\end{array}$ & 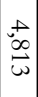 & 苍 \\
\hline 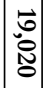 & 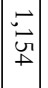 & $\checkmark$ & $\stackrel{\omega}{\omega}$ & রু & $\overrightarrow{ \pm}$ & ్్ㅁ & $\stackrel{\tilde{y}}{\mathrm{~N}}$ & $\mathcal{G}$ & : & $\stackrel{\leftarrow}{\circ}$ & $\stackrel{\vec{\omega}}{\tilde{N}}$ & $\stackrel{-\sigma}{+\infty}$ & tu & \begin{tabular}{l}
$N$ \\
$\infty$ \\
$\infty$ \\
$\infty$ \\
\hdashline
\end{tabular} & 兄 & ్ㅡㄹ \\
\hline $\mid \begin{array}{l}\infty \\
\stackrel{\infty}{0} \\
\stackrel{\sim}{\omega}\end{array}$ & 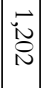 & - & $\vec{A}$ & s̆ & 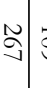 & $\vec{B}$ & $\stackrel{\text { N̦}}{+}$ & $\begin{array}{l}\infty \\
t \\
t\end{array}$ & $\begin{array}{l}\overrightarrow{+} \\
\text { N } \\
N\end{array}$ & $\begin{array}{l}\text { N } \\
\text { N }\end{array}$ & $\begin{array}{l}\overrightarrow{\tilde{N}} \\
\overline{\mathrm{v}}\end{array}$ & 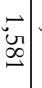 & 芯 & $\stackrel{N}{\stackrel{N}{\alpha}}$ & 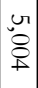 & $\frac{0}{6}$ \\
\hline$\left|\begin{array}{l}0 \\
0 \\
0 \\
6 \\
6\end{array}\right|$ & & $\omega$ & 'ू & 8 & + & $\stackrel{\infty}{\circ}$ & $\stackrel{\sim}{\sim}$ & $\begin{array}{l}\vec{b} \\
0 \\
- \\
\omega\end{array}$ & 㲾 & $\begin{array}{l}\text { ज़ } \\
+ \\
+\end{array}$ & 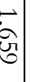 & : & 点 & $\stackrel{N}{N}$ & $\begin{array}{l}\vec{t} \\
\overrightarrow{0} \\
b\end{array}$ & 氕 \\
\hline
\end{tabular}


In addition to official statistics, victimisation studies are available and provide some insights into domestic violence. However, in the past, very few such studies were carried out in Slovenia.

Results of a survey from 2014 (European Union Agency for Fundamental Rights [FRA], 2014) showed that, after the age of $15,22 \%$ of Slovenian women had experienced physical and/or sexual violence; which is $11 \%$ lower than for the EU overall (European Institute for Gender Equality, 2017). Further, $14 \%$ of women in Slovenia have been stalked; $44 \%$ of women in Slovenia have experienced sexual harassment. The European Institute for Gender Equality (2017) estimated that the cost of intimate partner violence against women in Slovenia could amount to EUR 440 million annually.

A nationwide survey carried out in Slovenia in 2010 (Leskošek et al., 2010) on the incidence of violence in the private sphere and in relationships included 3,000 women aged 18 to 80 years. Based on 750 returned questionnaires, the analysis showed that after the age of 15 over one-half $(56.6 \%)$ of women had experienced one form of violence, with $49.3 \%$ experiencing psychological violence, $23 \%$ physical, $14.1 \%$ economic and $6.5 \%$ sexual violence. In most $(90.8 \%)$ cases, the perpetrators were men, showing violent behaviour at a very early age (from the age of 14). The research showed that violence can begin at any time - in early childhood to a late age, and in some cases, it lasts a lifetime. Victims are afraid of speaking out due to traditional reasons; namely, this is still a taboo subject because victims hope the perpetrator will stop with their violent behaviour and will change and not repeat their violent behaviour. Other victims remain silent because they are afraid the perpetrator will take their children away due to the perpetrator's influence in society (Leskošek et al., 2010). One disadvantage of this research is that it focused solely on violence against women and thus neglected men and boys as victims of domestic violence.

In Slovenia, research was also conducted on domestic violence cases resulting in the murder of a partner. The study analysed the profiles of perpetrators and victims between 2000 and 2007. During this time, a total of 48 murders occurred. The results showed that in 37 cases the victims were female, while the perpetrators were men in equal numbers. In 23 cases, alcohol or drugs were detected, 22 cases occurred inside the house, and 16 were inside apartment buildings. Most homicide victims were in 
the age group 35-45. In 23 cases, the motive was jealousy, and in 7 cases revenge. In 34 cases, the police had already intervened before the murder (Mušič, 2010).

Recently, Filipčič et al. (2021) investigated how the COVID-19 pandemic has affected domestic violence report rates by investigating and comparing pre-and postpandemic police statistics. They found that the police recorded slightly higher levels of domestic violence as a criminal offence compared to the pre-pandemic period, while reported cases of domestic violence as a misdemeanour as well as police restraining orders declined during the pandemic. They conclude that these results call for further investigation into the actual reasons for such observed declining reporting levels since experience from other countries has shown reverse trends during the COVID-19 pandemic.

\section{The frontline response}

The Slovenian police are one of the main frontline responders that react to domestic violence incidents. A comprehensive protocol is set in place (Police, n.d.) that enables the police to react as effectively as possible. A domestic violence incident can be reported by anyone - a victim, child, minor, NGO, private entity or state agency. Some occupations and actors (preschools, schools and healthcare agencies, e.g. doctors, therapists, psychiatrists, etc. or where persons are acting in an official capacity) are obliged to report such an incident when children are the victims. This can be done in several ways, including calling the police lines, online forms, or visiting police precincts, social work centres, or prosecutors' offices.

Since both the Criminal Procedure Act (2012) and the Police Tasks and Powers Act (2013) demand that a form of risk assessment be made and, if needed and/or possible, the perpetrator is removed from the residence and a restraining order is issued. First orally, then within 6 hours in written form. The order is valid for 48 hours and its legitimacy is automatically checked by an investigating judge (court), who issues a special decision thereon and can also extend the restraining order's validity to 15 days. The order can on the victim's request be extended to 60 days. In the restraining order, the allowed distance from the victim's place is specified (places where the victim lives, works, studies or moves about on a daily basis are so protected), while the perpetrator is also prohibited from intimidating the victims through means of communication (Police, n.d. - b). 
Under the Domestic Violence Prevention Act (2008), victims of violence can ask for a restraining order or ask the court to prohibits perpetrator to enter victim's residence, keep a certain distance away from her/his home, or stay a certain distance away from places where the victim regularly visits. Courts can also order the perpetrator to leave the residence in which the victim lives (or lived) with the perpetrator. These measures include prohibitions on the perpetrator from encountering, intimidating or interfering in any way with their or solely the victim's children, with this including all means of communication. Overall, the restraining order can be imposed for up to 12 months. The courts treat these requests for protective measures as a matter of priority (Police, n.d.b). Based on the specifics of an individual case, the police will perform several tasks ranging from purely safety and administrative (documenting the incidents, issuing the restraining order) to investigative ones (searches of premises, documenting injuries etc.). They will do so in cooperation with other bodies (e.g. non-governmental organisations and healthcare service providers), among which the main partners are the Social Work centres (Police, n.d.c).

\section{Social Work centres}

Rules on the organisation and work of multidisciplinary teams and regional services as well as the activities of social work centres for dealing with domestic violence were adopted within the scope of the Domestic Violence Prevention Act and the Act Amending the Domestic Violence Prevention Act. The coordination of interinstitutional cooperation is managed by a Social Work Centre (SWC), which is the local authority for handling a case of domestic violence. Interinstitutional cooperation is also available to deal with a case of violence in a multidisciplinary team treating domestic violence.

When domestic violence is detected, all authorities in Slovenia are obliged to notify the SWC of such incidents and, especially when the circumstances allow the conclusion that a child is a victim of violence, the authorities must inform the nearest SWC, the police or the state prosecutor's office (Domestic Violence Prevention Act, 2008). The SWC and the police immediately exchange information about the notification according to the competencies and rules of the profession, coordinate the initial activities (Domestic Violence Prevention Act, 2008). 
Within 24 hours of receiving the notification or the perception of domestic violence, the police notify the SWC. The police, and particularly the SWC, may convene a multidisciplinary team to address the domestic violence. A representative of the police is involved in the team's work, especially to:

- exchange the information needed to clarify the circumstances of providing victim protection and assistance;

- obtain information relevant to the professional actions of the police;

- provide information relevant to the actions of other bodies and organisations, particularly about who is suspected of having committed a crime;

- in accordance with the terms of reference and rules of the profession coordinate police activities with those of other bodies and organisations;

- provide assistance to the SWC in the implementation of emergency measures under the law; and

- participate in the formulation and implementation of the plan to give assistance.

In order to assist victims of violence, intervention services, to help coordinate the activities of authorities and organisations, and to monitor and analyse the occurrence of violence in the area of the SWC, within each SWC a service for coordination and victim assistance is formed. This service acts pursuant to the law on social security, and enforces urgent measures for protecting the child's interest under the law on family relationships. Each service includes an intervention service and a crisis centre.

Regional department for coordination and victim assistance provides services under the law governing social protection and emergency measures to protect the child's interests under the law regulating family relations. The regional service includes service intervention, crisis centres and a regional coordinator for the prevention of violence. In Slovenia, shelters are developing as part of the social work and NGO fields. According to the Women against Violence Europe [WAVE] (2016, 2018, 2019) reports, Slovenia has made a big improvement in expanding the provision of shelters for domestic violence victims and is now one of only 5 countries in the EU (out of 26 that WAVE has data for) which meet the minimum standards of shelter-provision as specified in the Istanbul Convention. These countries are Liechtenstein, Luxembourg, Malta, Norway and Slovenia. According to the Association for 
nonviolent communication (2019), in 2018 a total of 15 maternity homes for mothers and children's units, and 28 units of safe houses, women's shelters and crisis centres were available in Slovenia, all co-financed by the Ministry of Labour, Family, Social Affairs and Equal Opportunities.

Non-governmental organisations (NGOs) dealing with and protecting against violence in the framework of their programmes provide protection and psycho-social assistance to victims, organise programmes for the perpetrators of violence to teach them nonviolent behaviour in interpersonal relationships to prevent further violence and change violent behavioural patterns, and cooperate with authorities and organisations in various fields like the police, the State Prosecutor's Office, courts, social work centres, health organisations and educational institutions.

One prominent NGO in this domain is the Association for Nonviolent Communication (Slo: Društvo za nenasilno komunikacijo) (2021). The Association for Nonviolent Communication is a nongovernmental, non-profit and humanitarian organisation dedicated to the prevention and reduction of violence and its consequences. It was founded in 1996 when it was the first NGO in Slovenia with programmes for both victims and perpetrators of violence. In addition, some other NGOs are available to help victims of domestic violence. Women experiencing rape and sexual assault and/or domestic violence can access a specialist service for women.

The Društvo SOS (n.d.) (which may be translated as SOS Helpline for women and children - victims of violence) runs a national helpline, and female victims of domestic violence can also obtain help by email and online. It is anonymous and free of charge, but not 24/7. Run by an NGO, it has been operating since 1989 . Overall, Slovenia does not meet the Istanbul Convention standards for national women's helplines but, as noted, it does meet the standards for women's shelters provisions and exceeds the recommended number of shelters per head of population and beds needed according to the WAVE (2019) report.

Slovenia also has specialised services for the victims of human trafficking, the Društvo Ključ (n.d.), which is a centre in the fight against human trafficking. Društvo Kljuc and Karitas (n.d.) can provide crisis accommodation with intensive support, as well as traditional accommodation. 


\section{Healthcare sector}

An important frontline responder to domestic violence is the healthcare sector. Health professionals play an important role in intersectoral cooperation and teams. They are compelled to become involved with combating domestic violence for both ethical and legal considerations, given that the Domestic Violence Prevention Act (2008) requires them to take action and report domestic violence. The CSWs, police and health professionals are bound by the Act to appropriately respond to victims of domestic violence, prevent domestic violence and cooperate with other sectors. While the police and the CSW have adequately implemented the provisions of the law, this has not been the case with healthcare services (Bradley et al., 2021).

Although the Rules on the Regulations and Procedures for Responding to Domestic Violence in Healthcare Services entered into force in March 2011, it is still rare for health professionals to report domestic violence incidences in practice. Intersectoral cooperation with NGO representatives, the SWC and the police remain highly inadequate (POND, n.d.). The absence of a systematic response to domestic violence in healthcare services remains a grave problem in Slovenia, explaining why the project "POND" (which stands for 'Recognising and treating domestic violence victims in healthcare settings: guidelines and training for health professionals') was developed. It was supported by Norway Grants under the Public Health Initiatives programme in Slovenia. The project's main objective was implementation of the Family Violence Prevention Act in the health sector in order to make health workers more competent to recognise domestic violence. Unfortunately, this problem still exists. According to the IMPRODOVA field interviews in Slovenia (Bradley et al., 2021), healthcare professionals do not routinely screen for health risks such as domestic violence or abused or neglected children. They usually do not ask about or identify domestic violence, even in instances when it is obvious. They are more focused on treating the injuries and often disregard the violence that caused those injuries (Bradley et al., 2021).

The Professional Guidelines for Responding to Domestic Violence in Healthcare Services were developed in 2014. These guidelines entail a collection of recommended conduct while responding to child victims of abuse and violence and adult victims of violence. They seek to equip health professionals coming into contact with domestic violence victims with basic skills and know-how for identifying and responding to 
such victims (POND, n.d.). Since around 2009, domestic violence content has also been included in curriculums at the Faculty of Medicine in the specialisation for family doctors. The inclusion of domestic violence content was also an outcome of the POND project and certain highly motivated persons/researchers who recognised the need for such content at the medical faculties. These guidelines were approved by the Slovenian Medical Council and are publicly available (POND, n.d.).

\section{Good co-operation practices between police and other first-line responders}

The Shadow Report by Slovenian NGOs indicates the cooperation of the authorities and organisations in multidisciplinary teams to deal with domestic violence cases is generally evaluated as satisfactory. NGOs noted that mutual cooperation in Slovenia not only means the better identification of cases and more efficient help for victims, but also the possibility of speeding up the processes, obtaining additional relevant information, preventing the negative effects of the procedures introduced and, in particular, protecting the most vulnerable victims (Association for nonviolent communication, 2019).

The IMPRODOVA field study (Bradley et al., 2021) also shows that police and social work professionals found the cooperation to be very good, although these good practices vary across the country depending on the individuals involved rather than institutions. This is especially the case in the northeast of the country (e.g. Murska Sobota), where the police and the SWCs have established good informal relationships, the meetings are regular, and protocols are in place. Good practices of cooperation can be found in all sectors, but they are not unified. There seem to be some gaps in local capacities/attitudes or approaches. Domestic violence should be reported by preschools, schools and healthcare institutions (doctors, therapists, psychiatrists etc.), whereas persons acting in an official capacity must report it ex officio, although this is often not the case. Taking the victim's interests into account requires a high degree of professionalism from all relevant professional groups and in all areas of action (such as schools, nursery schools, general practitioners in medical professions, and courts). 


\section{Main challenges}

Even though the Republic of Slovenia has, especially in the last decade, already adopted important legislation, conducted numerous awareness campaigns and placed greater emphasis on the training of professionals, the situation concerning domestic violence in the country remains unsatisfactory. Ratification of the Istanbul Convention does not necessarily result in actual realisation of its standards. This makes it necessary to ensure understanding of the key causes of violence against women and to continuously implement activities to eliminate them.

One of the concerning gaps between ratification and effective implementation of the Istanbul Convention remains the requirements to provide a national women's helpline (e.g. for several years already, Slovenia has not met the standards of operating a helpline both free of charge and 24/7). In addition, some NGOs report they are still unable to rely on the state for sufficient support (WAVE, 2019). On the other hand, Slovenia is one of only four countries (Slovenia, Malta, Latvia, Luxembourg) of the $28 \mathrm{EU}$ countries currently meeting the minimum requirement in the Istanbul Convention to provide shelter and bed spaces for victims (WAVE, 2019). The IMPRODOVA field study (Bradley et al., 2021) noted that the medical profession and the judiciary must still strengthen their efforts. Especially the judiciary does not consider the characteristics and dynamics of domestic violence and its consequences for the victims of violence. Therefore, it is important to create greater opportunities for education and training.

Like other countries, Slovenia is committed to reviewing and, where necessary, adjusting its national legal and policy frameworks to ensure that actual implementation of the Istanbul Convention's provisions has been appropriately translated into the national legislation. Despite the aforementioned limitations, having kept this issue high on the political agenda, the country has made significant progress in prevention and response.

Slovenia committed itself to the overall goal of eliminating domestic violence when it adopted several strategic documents which define programmes for the prevention of violence and the measures for the protection of victims. Comprehensive normative measures have contributed to the improvement of the systemic regulation of preventing and combating domestic violence (Grevio, 2019). (Association for 
nonviolent communication, 2019). Building high-quality, diverse and widely available programmes of assistance and protection for domestic violence victims; improving the protection, treatment and position of victims of this type of violence; providing highly competent professionals and experts; and building greater awareness among society of these problems are just a few of the future ways of reducing domestic violence in the country.

\section{References}

Act Amending the Criminal Procedure Act. (2019). Official Gazette of the Republic of Slovenia, (22/19).

Act Amending the Domestic Violence Prevention Act. (2016). Official Gazette of the Republic of Slovenia, $(68 / 16)$.

Association for Nonviolent Communication. (2021). https://www.drustvo-dnk.si/en/

Bradley, L., Brooks-Hayes, O., Burman, M., Bonnet, F., Cuillerdier, F., Delpeuch, T. ... Vassileva, M. (2021). Country Reports and Cross-National Comparison on the Implementation of International Norms and National Best Practices of Frontline Responders.

https://www.improdova.eu/pdf/IMPRODOVA_D2.2_Norms_and_Best_Practices_of_Fro ntline_Responders.pdf?m $=1585673378 \&$

Constitution of the Republic Slovenia. (1991). Official Garette of the Republic of Slovenia, (33/91-I).

Council of Europe. (2014). Council of Europe Convention on preventing and combating violence against women and domestic violence.

https://rm.coe.int/CoERMPublicCommonSearchServices/DisplayDCTMContent?documen tId $=090000168008482 \mathrm{e}$

Criminal Code of the Republic of Slovenia. (1994). Official Gazette of the Republic of Slovenia (63/94).

Criminal Code of the Republic of Slovenia. (2008). Official Gazette of the Republic of Slovenia, (55/08, $66 / 08)$.

Criminal Code of the Republic of Slovenia. (2012). Official Gazette of the Republic of Slovenia, (50/12).

Criminal Procedure Act. (2012). Official Gazette of the Republic of Slovenia, (32/12 with amendments 47/13, 87/14, 8/16, 64/16, 65/16, 66/17, 22/19, 55/20).

Domestic Violence Prevention Act. (2008). Official Gazette of the Republic of Slovenia, (16/08).

Drustvo Ključ. (n.d.). https://drustvo-kljuc.si/

Društvo SOS. (n.d.). https://drustvo-sos.si/

European Institute for Gender Equality. (2017). Combating violence against women: Slovenia. Publications Office.

https://eige.europa.eu/sites/default/files/documents/2016.5492_mh0416666enn_pdfweb_2 0170215100610.pdf

European Parliament \& Council of the European Union. (2012). Directive 2012/29/EU of the European Parliament and of the Council of 25 October 2012 establishing minimum standards on the rights, support and protection of victims of crime, and replacing Council Framework Decision 2001/220/JHA. Official Journal of the European Union, (315), 57-73. https://eur-lex.europa.eu/eli/dir/2012/29/oj

European Union Agency for Fundamental Rights [FRA]. (2014). Violence against women: An EU-wide survey. https://fra.europa.eu/sites/default/files/fra_uploads/fra-2014-vaw-survey-mainresults-apr14_en.pdf

Filipčič, K., Drobnjak, M., Plesničar M.M.,\& Bertok, E. (2021). Intimnopartnersko nasilje v času pandemije covida-19 [Intimate Partner Violence During the Covid-19 Pandemic]. Revija za kriminalistiko in kriminologijo, 72(1), 65-78. 
GREVIO's (Baseline) Evaluation Report on legislative and other measures giving effect to the provisions of the Council of Europe Convention on Preventing and Combating Violence against Women and Domestic Violence (Istanbul Convention) SLOVENIA GREVIO/Inf(2019)

Group of Experts on Action against Violence against Women and Domestic Violence [GREVIO]. (2019). Report submitted by Slovenia pursuant to Article 68, paragraph 1 of the Council of Europe Convention on preventing and combating violence against women and domestic violence (Baseline Report). https://rm.coe.int/grevio-inf-2019-15-eng/pdfa/1680989a54

Karitas. (n.d.). https://www.karitas.si/

Leskošek, V., Urek, M., \& Zaviršek, D. (2010). Nacionalna raziskava o nasiju v zasebni sferi in partnerskih odnosih. Inštitut za kriminologijo pri Pravni fakulteti.

Mušič, T. (2010). Kratek prikaz stanja in aktivnosti policije pri preprečevanju in preiskovanju kaznivih dejanj na področju nasilja v družini. V A. Dvoršek in L. Selinšek (ur.), Nasilje v drǔ̌ini: kazensko pravni, kriminalistični in kriminološki problemi (str. 45-70). Ljubljana: Fakulteta za varnostne vede.

Police. (n.d.). Domestic violence—Police procedure. https://www.policija.si/eng/prevention/personalsafety/domestic-violence/domestic-violence-police-procedure

Police. (n.d.a). Annual Report of the Work of the Police 2019. https://www.policija.si/images/stories/Statistics/Annual\%20Reports/AnnualReport2019.p df

Police. (n.d.b). Police restraining order. https://www.policija.si/eng/prevention/personalsafety/domestic-violence/police-restraining-order

Police. (n.d.c). What the police will do after domestic violence has been reported. https://www.policija.si/eng/prevention/personal-safety/domestic-violence/what-the-policewill-do-after-domestic-violence-has-been-reported

Police. (2021). Annual Report of the Work of the Police 2020. https://www.policija.si/images/stories/Statistics/Annual\%20Reports/AnnualReport2020.p df

Police Tasks And Powers Act. (2013). Official Gazette of the Republic of Slovenia, (15/13).

POND. (n.d.). Domestic violence. http://www.prepoznajnasilje.si/en/domestic-violence

Protection of Public Order Act. (2006). Official Gazette of the Republic of Slovenia, (70/06).

Resolution of National Programme of Family Violence Prevention 2009-2014. (2009). Official Gazette of the Republic of Slovenia, (41/09).

Resolution on the national programme for the prevention and suppression of crime 2019-2023. (2019). Official Gazette of the Republic of Slovenia, (43/19).

Women against Violence Europe [WAVE]. (2016). WAVE Report 2015 on the role of specialist women's support services in Europe. Women against Violence Europe [WAVE]. http:// fileserver.wavenetwork.org/researchreports/WAVE_Report_2015.pdf

Women against Violence Europe [WAVE]. (2018). WAVE Country Report on the role of specialist women's support services in Europe 2017. Women against Violence Europe [WAVE]. http://fileserver.wave-network.org/researchreports/WAVE_CR_2017.pdf

Women against Violence Europe [WAVE]. (2019). WAVE Country Report on the role of specialist women's support services in Europe 2019. Women against Violence Europe [WAVE]. https://www.wavenetwork.org/wp-content/uploads/WAVE_CR_200123_web.pdf

\section{List of legislation}

Provisions of the key acts were presented in the text, while full texts of legislative documents are available at https://www. pisrs.si 


\section{EUROPEAN PLATFORM - DEVELOPING IMPROVED DOMESTIC VIOLENCE RESPONSE PROTOCOLS AND OPTIMISED DOMESTIC VIOLENCE INTERVENTION AND PREVENTION}


4 ist

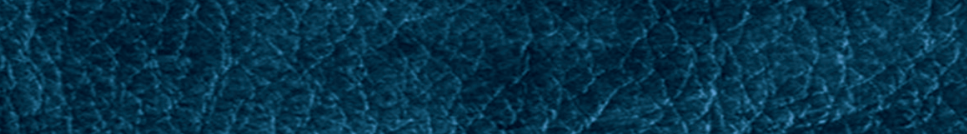

3.1.2.

(1)

W.7.

$$
\text { (1) }
$$

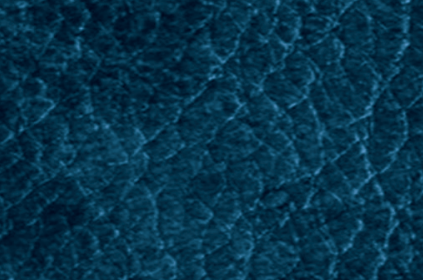

aris

$\cos 2$

1. 3 ?

13:

28.

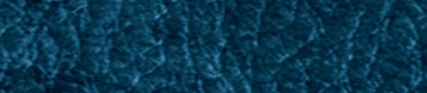

(1)

1)

3

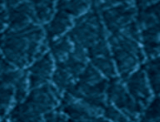

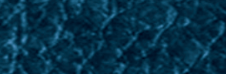

to

(⿻)

xtrat

3.

(1) 


\section{A Digital Communication}

\section{PLATFORM FOR INTER-AGENCY}

Collaboration to MANAGE

HigH-IMPACT DOMESTIC ABUSE:

\section{STRUCTURE AND ESSENTIALS}

\section{CATHARINA VOGT}

German Police University, Criminology and Interdisciplinary Crime Prevention, Münster, Germany.

E-mail: c.vogt@respectresearchgroup.org
Abstract Interagency cooperation is a necessary response to domestic abuse to care best for victim-survivors. However, for many reasons especially pertaining data security, digital solutions to support such action remain scarce. This chapter explains what needs to be considered when installing such a tool into a network of front-line responders' activity by pointing to the advantages of digital communication platforms to manage high impact domestic abuse and summarising what IMPRODOVA researchers' expertise presented regarding the status quo of exchange of information in domestic abuse cases. Afterwards, criteria are defined that need to be fulfilled by an ICT tool set up for the management of domestic abuse by professional front-line responders. Moreover, criteria to be fulfilled by the users of the ICT tool set up for the management of domestic abuse by professional front-line responders are discussed. Finally, the

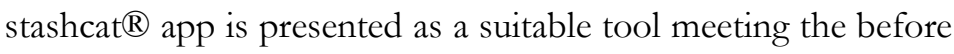 defined criteria to a great extent. This is also attested by the evaluation of the stashcat $\AA$ app during its piloting by a Slovenian network of front-line responders. In sum, this chapter shows that digital solutions can assist professionals to communicate quick and effectively when supporting victim-survivors of domestic abuse.

Keywords:
IMPRODOVA,
domestic
violence,
digital
support,
ICT,
police,
social
work,
health
sector,
training

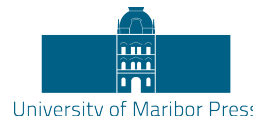




\section{Introduction}

Interagency cooperation is a necessary response to domestic abuse to promote victim-survivors' safety, satisfaction, and well-being. This insight is highlighted in many of the chapters of this book based on field studies with frontline responders and has also been echoed wider in scientific literature (e.g., Malos, 1997; Robinson, 2006; Vogt, 2020). While in some places in Europe such existing face-to-face cooperation networks are already considered as a best practice ${ }^{1}$ to manage domestic abuse, digital solutions to support such action remain scarce. This is partly due to the required high level of security standards that such a tool must meet. This chapter explains the prerequisites that must be considered when installing such a tool in a network of frontline responders' activity. Especially during phases of lockdown or shutdown, such tools empower frontline responders to work in an agile and flexible mode, despite restrictions on contacts and thus to care for domestic abuse cases in a comprehensive way.

Cooperation networks aimed at managing domestic violence are understood as inter-institutional structures designed to provide a framework for working in partnership. These partnerships usually involve the police (often units specialised in domestic violence), victims' aid organisations, social services, courts and city administrations (Bradley et al., 2020) - in many cases, the police are the central figure as they deal with both victims and perpetrators, and because they have the legal mandate to intervene in matters of domestic violence and abuse. On one hand, partners of such networks bring their knowledge and expertise regarding domestic abuse cases and the respective interventions.

"This is to achieve a beneficial change for victims or a more appropriate treatment for perpetrators. The collaboration between agencies serves a greater purpose than any of the individual organisations can achieve by their specific tasks alone. Finding a common purpose, for instance, protecting and helping the victim, provides a shared mission and identity bonding various partners together" (Bradley et al., 2020, p. 6).

\footnotetext{
${ }^{1}$ Multi-agency risk assessment conferences (MARAC) and the Hanover Intervention Programme (HAIP), for example, are considered to be best practices (see the IMPRODOVA report by Bradley et al., 2020).
} 
On the other hand, they also bring their organisational culture, which shapes their understanding of the domestic abuse phenomenon, the necessary action, their perception of other stakeholders involved in the management of domestic abuse, and their style of communication. In fact, whether cooperation networks can work depends on their communication. Members of such networks need to find a common ground in their communication, which includes respectful, trustful and open communication guided by strong leadership and accompanied by successful information management (Bradley et al., 2020). Thus, cooperation networks rely on complete and functional management systems including strong mechanisms for conflict prevention and resolution, as well as dedicated and competent network managers and boundary spanners. In order to facilitate inter-agency collaboration, improved rules and procedures must stimulate resource and information sharing among the participants.

\section{Advantages of digital communication platforms to manage high-impact domestic abuse}

While the need to ensure a solid information management system seems plausible in every form of collaboration, this is very important while handling domestic abuse cases (Bradley et al., 2020). In particular, the prevention of cases entailing a high risk of high-impact domestic abuse - i.e. the perpetrator's actions that that can be reasonably expected to lead to dangerous bodily injury, homicide or suicide for the victim - requires the close and fast collaboration of all frontline responders involved (Vogt, 2020). If all collaborators have carried out the necessary steps to work with one information and communication system or arranged for their own systems to properly communicate with this communication platform (e.g. feed the system with information), information on cases can be collected, shared and analysed by the collaborators. The combined exchange of information would enable collaborators to recognise victims and perpetrators faster and earlier and to monitor their trajectories more closely, for example. Sharing of information via a digital solution (taking professional confidentiality into account) would be easier and save resources for frontline responders collaborating in a network as this would give them the best way of knowing how to only share the information via the response platform instead of looking for telephone numbers, checking who is responsible etc. 
Moreover, the likelihood of informed and good decisions in favour of victimsurvivors thereby increases (Feld \& Straus, 1989). When domestic violence cases, including background information, are quickly shared among network partners, the partners can also quickly take steps toward prevention, intervention or follow-up in line with their individual area of expertise. At best, this "avoids victims having to repeat their story several times to the succession of workers they meet: sharing a file containing what each partner needs to know - and has the right to know - about the situation being treated reduces this form of 'secondary victimization' due to being constantly re-interviewed" (Bradley et al., 2020, p. 10). Irrespective of times of pandemic or other situations where frontline responders are required to stay at home, such an information and communication technology (ICT) tool will enable the management of domestic abuse.

Besides, such a platform would also allow for the storing of content that defines the 'How' of the cooperation like policies, administrative rules, leadership, or training activities. Further, this platform could enable various groups of everyday management of first-responder personnel (e.g. police group leaders, 'silver' managers, school principals, senior physicians, departmental heads, heads of hospitals, head at other social agencies) to collaborate, and a first-responder frontline practice (e.g. patrol officers, general practitioners, paediatricians, gynaecologists, nurses, physicians at hospitals, emergency room staff, school and kindergarten teachers). If managed well, and within its regional boundaries, such a platform holds the potential to display a strong offensive against domestic abuse and strong protection for victim-survivors and their loved ones.

\section{Exchange of information in domestic abuse cases: Status quo}

According to the IMPRODOVA partners' collected insights, the status quo is that no such platform ${ }^{2}$ is in use anywhere in their countries. Nonetheless, one can find websites $^{3}$ to obtain training tools, downloads of reports and other products.

\footnotetext{
${ }^{2}$ In Austria, it is planned that uniformed officers use an app integrated into the police issue smart phones that would guide through interventions in cases of domestic violence on site. This should include a short risk assessment and transfer the information directly into the case-documentation to save officers time during reporting.

${ }^{3}$ https://stop-violences-femmes.gouv.fr/outils-de-formation-violences-au; http://gewaltfreileben.at/de/material/infopackage
} 
The most elaborated system might be KANTA ${ }^{4}$, an app used in Finland, where data recorded about all patients in healthcare services and pharmacies (and in social welfare services in the future) are saved. Information may only be shared among professionals with the consent of the (adult) patient. All data communicated between healthcare providers, pharmacies, contact points and the KANTA services are encrypted between authenticated users. Professionals use a personal smart card to sign into the information systems using strong authentication. User permissions required for different professional roles are defined by organisations. Log data are one way to monitor system usage. Besides, Finnish frontline responders use encrypted emails to share information. Only in cases of an emergency may information be shared by phone.

In other European countries, enthusiastic professionals share information with each other using services that are not developed for frontline responders, e.g. Google (Gmail for mailing, Drive for storage), Facebook Messenger (for communication), Dropbox (for storage), or WhatsApp. However, these tools are solely used for structuring the collaboration since no personal information regarding a case is allowed to be shared in this way. Some organisations have internal shared drives used to store and share resources (e.g. ROBOCOP); only in a few cases do they exist to enhance intra-agency cooperation.

Of course, the usual form of collaboration is the face-to-face gathering of professionals/frontline responders involved in the management of a particular case of domestic abuse. Examples of such meetings are MARACs and MATACs (e.g. Brooks-Hay et al., in this book ${ }^{5}$; Jaffré, 2019; Robinson, 2006). Depending on the way such a gathering is established, clients can also be present. In most of these meetings, all professionals present record the decisions and details of the meetings in their own respective databases, not a shared one. This is perceived as effective by most of the professionals because professional cultures are real hurdles, as one quote from a German interviewee shows:

"We do not have something like an online platform for our network. It would be difficult, when it comes to the transmission of data. They

\footnotetext{
${ }^{4}$ https://www.kanta.fi/en/wellbeing-data

${ }^{5}$ The chapter on Frontline response to high-impact domestic violence in Scotland
} 
are only allowed to be sent encrypted. We have many 'online topics'. But HAIP is about regular meetings and exchange - I think that is the best. It would be nice to be connected online additionally. Nevertheless, that does not substitute one-on-one conversations that we have before or after HAIP meetings. [...] The shelter has to stay anonymous. It would be good to have something as an add-on.”

Thus, it currently seems more efficient to share operational information in face-toface meetings. However, innovation in information and communications technologies (ICT) has progressed so far that it is implausible to spare the management of domestic abuse from such arrangements (Rodríguez-Rodríguez et al., 2020). Naturally, the security architecture of the platform needs to be well considered, but this has already been ensured for other communication platforms that are designed for other purposes. Thus, the IMPRODOVA project ${ }^{6}$ aimed to $^{-}$ set up and pilot a national response platform.

\section{Criteria to be met by an ICT tool intended to manage domestic abuse by professional frontline responders}

Generally speaking, the envisioned ICT platform should be a digital solution that is well displayed on PCs, tablets and smartphones, and grants access to different stakeholder groups of frontline responders. On this platform, individual networks should have a closed space. The platform should allow for information to be shared in various ways like uploading, storing, changing, and downloading resources (e.g. external memory of the network, wiki, address book). At the same time, this platform should provide access to the training materials collected during the IMPRODOVA project 7 . Most importantly, the platform would need to have a solid security architecture. Legal issues would also have to be considered because such a platform would need a high level of moderation to comply with General Data

\footnotetext{
${ }^{6}$ All articles in this edited book are written in the context of the project Improving Frontline Responses to High Impact Domestic Violence (IMPRODOV A). This EU-project is designed to provide solutions for an integrated response to high-impact domestic violence, based on comprehensive empirical research of how police and other frontline responders (e.g. medical and social work professionals) respond to domestic violence in European countries. Project website: www.improdova.eu.

${ }^{7}$ https://training.improdova.eu/en/. See also chapter on Development of a training platform on domestic violence by Bettina Pfleiderer and Paulina Juszczyk in this book.
} 
Protection Regulations (GDPR) ${ }^{8}$ and privacy rights as well as laws governing e.g. medical practices.

Given that usability and use-value depend on the platform's simplicity and its immediacy, with which it responds to practitioner needs, the guiding question for the set-up is: How should the communication or 'response' platform be constructed so that FLR are likely to actually use and benefit from it? To answer this question, the IMPRODOVA team conducted an internal workshop and an internal survey drawing from the rich background of the experienced practitioners and academic experts involved in the project (mostly law enforcement authorities). Six themes emerged: objective of usage, functions, usability, IT system, safety measures, and further demands to be met by the ICT tool for it to become usable by police.

\section{Objective of usage}

Altogether, there was considerable agreement on the demand to share information and documentation concerning domestic abuse cases. The platform should aim to support the communication in various communities of professionals. In Austria, with regard to victims' support groups in hospitals, the demand for a platform to communicate with other victim support groups was mentioned.

\section{Functions}

Multiple functions the platform should offer were named: The platform should allow the users to upload and share photos, documents, images. It should enable them to invite other professionals. It should offer modalities for open and hidden forums. It should be designed to avoid duplicated efforts to avoid the need to enter information in one system and then copy the same content into another ${ }^{9}$. Date and time, changes to documentation etc. would also need to be visible to everyone so that everybody is constantly up to date and can see who has made changes to a specific case.

\footnotetext{
${ }^{8}$ https://gdpr-info.eu/

${ }^{9}$ However, this is more a question of how the platform is integrated into the work of frontline responders' networks and (if the platform covers typical functions of messaging and data storage) less a question of the platform's functions.
} 


\section{Usability}

Usability and use-value depend on the platform's simplicity and the immediacy with which it responds to practitioner needs. The platform should thus be intuitive, easy to use, visually clear, and logically organised. In addition, entering the data should be simple, straightforward and trustworthy (e.g. no need to enter the same data several times due to problems with Internet access).

\section{IT system}

The IT system behind the platform must ensure that all connected processes run smoothly; the platform should run fast on a computer or mobile device. It must be able to run in operating systems, be optimised for most ICT tools (especially smart phones), and be downloadable from the App Store and Google Play. Naturally, it should ensure real-time communication among users - who can then ask questions from other users in the case of an emergency or professional uncertainty. Thus, it must be accessible from everywhere and might also create a mirror of the site as an app. In this way, the contents could be accessed offline.

\section{Safety measures}

In terms of domestic abuse management and capacity-building, it is inevitable that all ICT solutions maintain the highest digital security simplicity in order to protect the victim-survivors whose data are being processed (Rodríguez-Rodríguez et al., 2020). Safety measures must ensure the data is protected from destruction or corruption due to an attack or other threats. Confidential data in particular must be protected from disclosure due to intrusion or phishing. With regard to the platform, one measure towards meeting this goal is that the platform must encrypt the data stored on it.

Equally, to protect the data stored on the platform, the server must be located in the European Union. Since the data generated or shared via this platform are European and subject to European law, and as the project using the platform is a European one, European security measures have to be applied. 
The architecture with respect to who grants the right(s) of use or access to the platform to the different professionals is a primary concern: The platform must be secure in a general sense, such that it cannot be accessed in an unauthorised way. This means authentication is required. Users can run the platform only if it is password-protected. The uploading and sharing of information should also require registered user accounts. Namely, every frontline responder needs their own account to see who has made changes in the system (adding new information etc.). This will allow for better moderation and should require registered users to sign terms of use. The architecture should include a legal disclaimer providing clear guidance on which information to (not) share. At the same time, different safety measures might be related to different functions of the platform and thus the architecture should define who is moderating comments or who is allowed to post information. Related to this, access rights must be defined clearly, including a precise description of the different roles like moderator, user or guest. Still, it should be considered, if it is possible, to also anonymise certain users because anonymity might encourage shelters to become involved in inter-agency cooperation.

\section{Further demands to be met by the ICT tool for it to be usable by the police}

When it comes to including the police as frontline responders in the use of such an ICT tool, still more barriers must be overcome. From the view of European police organisations ${ }^{10}$, such a platform must be organised to guarantee digital safety and security: One stakeholder has to host the data, ensure its safety etc. and must organise the way stakeholders can access folders and alter different files. The ICT tool must also be used outside of the secure police information system (e.g. access could be arranged through a secured Internet browser). If the system is securityaudited by the Police ICT unit, then it is possible to use it inside the secure police information system.

Internal IT-security measures for law enforcement may prove to be significant barriers to accessing the mentioned ICT platform. Such an ICT platform would be far easier to access if it is accessible as a website rather than being a dedicated app. Even if access to this website may be restricted through police computers, officers may choose to use their personal smartphones.

\footnotetext{
${ }^{10}$ Information retrieved by the IMPRODOVA partners.
} 
However, the content and information exchanged on such a platform is the most critical barrier to law enforcement practitioners becoming involved in such a networked ICT tool. It is hardly realistic to expect the police to share information on cases on a platform with other frontline responders. Instead, they could use it to obtain information, such as practical advice, protocols and usual case scenarios.

\section{Criteria to be met by users of the ICT tool established for the management of domestic abuse by professional frontline responders}

First of all, the ICT tool has to be used within a framework of professional frontline responders cooperating on the management of domestic abuse. It is preferable that most of them have already cooperated as a network and then shifted parts of their communication from face-to-face to virtual. On the strategical level, these already established boards or networks or platforms for managing professionals of different FLR fields should have together planned the mechanisms, care paths and resources before the digital cooperation commences. Participants of these boards should know each other from regular (e.g. quarterly) meetings. Still, sharing information on a platform or during a meeting is not the same and the processes are quite different. Thus, the question concerns need, confidence and trust in the way information is shared. Law, rules or a memorandum of understanding can support different types of processes. They are easier to determine and design for meetings.

Moreover, cooperation networks must possess a complete and functional management system that includes strong mechanisms for conflict prevention and resolution, as well as dedicated and competent network managers and boundary spanners. Hence, when it comes to the different roles users can have, the most essential one is that of the moderator. One might propose that the management level must include one person from every profession and the person who is guiding the process should be someone from a women's office etc. not involved in the everyday practice of handling a case of domestic abuse ${ }^{11}$. Since cooperation on the daily practical level needs a managerial level that is supported by an agreement and managerial functions (strategy setting, supervision, quality assurance, assessment), the requirement of dedicated and competent network managers of the response

\footnotetext{
${ }^{11}$ For example, this is the case of the Hannover Intervention Programme (HAIP) as described by Bradley and colleagues (2020).
} 
platform may mean that its manager(s) should have training and experience in multiagency cooperation, management, domestic violence as well as maintenance of a platform. Moderators of groups therefore must have the rights and opportunities and also the will to prevent and resolute, for example by setting up rules, giving access to the communication and addressing inappropriate user behaviour.

Likewise, conflict prevention and resolution should primarily be achieved by proper moderation and review of the contents provided on the ICT-enabled platform as well as the moderation of all forums and communication taking place on the platform. The central approach to achieve this should entail a combination of open access to viewing all information, combined with registration and moderation for all uploads or shared contents.

Second, cooperation networks in the realm of domestic abuse management need to involve the three areas of frontline response, i.e. the regulatory level, the everyday management of first responder personnel, and the frontline practitioners. This should also be reflected in the ICT platform. To represent the regulatory level, written directions and care paths can be made available on the platform. Parallel to this, the regulatory level (e.g. ministries) could be informed about the platform with a user's guide to the platform. Still, it must be considered that NGOs often do not have regulatory levels while the police and the medical profession are organised rather hierarchal and have to stick to their legal codes. Further, their everyday practice is structured by federal working instructions. Accordingly, the everyday management of first responderpersonnel might have a user account on the platform to be able to oversee the work of their staff using the platform. Nonetheless, it is the group of frontline practitioners who would and should be the end-users of such a platform in the sense described above. In order to serve their needs best, they should be involved in designing the platform. For example, all participating practitioners' contact information should be available on the platform along with resources like training materials or minutes of strategy meetings.

The third important point concerns the legal framework conditions: Within the context of domestic abuse, the platform clearly requires a high level of moderation to comply with privacy rights as well as laws governing medical practices. The platform therefore must cover data safety and GDPR issues to ensure the restricted sharing of protected (or confidential) data between professionals. Safety measures 
could be defined by clarifying the role of each stakeholder group, for example by determining what each sector is able to actively share or passively retrieve from the system.

\section{The stashcat ${ }^{\circledR}$ App}

During the course of the IMPRODOVA research, the stashcat ${ }^{\circledR}$ app emerged as a useful tool to present the technical background of the digital communication platform for inter-agency collaboration to manage high-impact domestic abuse. stashcat ${ }^{\circledR}$ is a GDPR-compliant highly secure messenger with an integrated file storage, videoconferences, calendar and survey tool ${ }^{12}$. In order to test whether the stashcat ${ }^{\circledR}$ app would meet the requirements to serve as a communication platform for frontline responders active in the field of high-impact domestic abuse, the six themes of necessary requirements we defined above (objective of usage, functions, usability, IT system, safety measures, and further demands to be met by the ICT tool for it to be usable by the police) formed the standard against which the stashcat ${ }^{\circledR}$ app was compared. The following information was retrieved from the stashcat ${ }^{\circledR}$ flyer (stashcat ${ }^{\circledR}$ GmbH, n.d. b), the stashcat ${ }^{\circledR}$ handbook (stashcat ${ }^{\circledR}$ $\mathrm{GmbH}$, n.d. a), the stashcat ${ }^{\circledR}$ website ${ }^{13}$ and the stashcat ${ }^{\circledR}$ app.

\section{Objective of usage}

stashcat ${ }^{\circledR}$ is a messenger designed to serve organisations in their communication by combining typical functions of messengers (single chats and channels/groups) and personal file storage. File storage is also possible in channels and conversations.

\section{Functions}

Accordingly, the uploading and sharing of documents is possible in stashcat ${ }^{\circledR}$. External links to documents can be shared with non-members as well. A synchronising function automatically synchronises local folders with the respective stashcat ${ }^{\circledR}$ folders.

\footnotetext{
12 https://stashcat.com/en/

13 Ibid.
} 
Administrators are able to invite other external persons to stashcat ${ }^{\circledR}$. Granting access to guest users is possible, too. Within stashcat ${ }^{\circledR}$, users can invite each other to channels. Modalities for open and hidden forums exist in the form of public channels (accessible to every user), password-protected channels (for invited users or users who enter the correct password) and encrypted channels (hidden channels that cannot be found by search). The date and time of activities are always visible. Other functions include a contact book, calendar, survey function, voice and video calls as well as video conferencing.

\section{Usability}

Usability and use-value must be estimated by the frontline responders who use the platform (results are published by Juszczyk and Pfleiderer, 2021, and summarised below). From a general point of view, it can be stated that stashcat ${ }^{\circledR}$ is easy and intuitive to use. If questions arise, they can be answered by using the clearly structured stashcat ${ }^{\circledR}$ handbook (stashcat ${ }^{\circledR} \mathrm{GmbH}$, n.d. a).

\section{IT system}

The IT system and its processing in everyday practice need to be estimated by the frontline responders who use the platform (results are published by Juszczyk and Pfleiderer, 2021 and summarised below). stashcat ${ }^{\circledR}$ runs on Android and iOS, and can be downloaded on the App Store or Google Play.

\section{Safety measures}

The stashcat ${ }^{\circledR}$ app meets the highest standards of digital security in order to protect the data being processed (stashcat GmbH, n.d. ${ }^{14}$ ):

The deployment of stashcat ${ }^{\circledR}$ takes place centrally on encrypted, redundant servers, which are operated by the MIVITEC GmbH in a high security centre in Munich, Germany. Frequent, automatic online backups avoid the loss of data through hardware failure, virus attacks or act of nature. [....] All relevant data is secured through the latest

\footnotetext{
14 https://stashcat.com/en/technology
} 
SLL encryption methods in a second step. The protection takes place based on a 256-bit AES SSL/TLS encryption on the way to our servers and encrypts the data exchange between the server and terminal device. In a third step, an encryption on the user's terminal device takes place where the data is encrypted through a combination of AES and RSE algorithms. For the encryption with AES a key length of 256 bit is used while for the RSA encryption a key length of 4096 bit is employed. In this way we can ensure that neither unauthorized third parties nor the stashcat ${ }^{\circledR}$ team itself can decrypt or access any data. All relevant data is thus transmitted encrypted on the way to and from the server and stored there also encrypted. Encryption applies to all types of data, i.e. it includes all messages, comments and other text fields.

Further, chats can be masked before the user has left the application.

The app can only be accessed in an authorised way via invitation and authentication and the app can only be opened using a pin-code. Likewise, the uploading and sharing of information requires registered user accounts. User roles with individual authorisations are defined by the administrator of an organisation using stashcat ${ }^{\circledR}$ by creating individually defined permissions.

\section{Further demands to be met by the ICT tool for it to be usable by the police}

Among others, the stashcat ${ }^{\circledR}$ app was designed especially for government agencies ${ }^{15}$. Although stashcat ${ }^{\circledR}$ is hosted in Germany, it is also possible for organisations to host it on the premises of their own datacentre. Finally, the stashcat ${ }^{\circledR}$ environment is accessible as a website and also as a dedicated app and can thus be used outside of the secure police information system.

\footnotetext{
15 https://stashcat.com/en/sectors/government-agencies, https://stashcat.com/en/references/nimes-policedepartment-lower-saxony
} 


\section{Evaluation of the stashcat ${ }^{\circledR}$ App}

Regarding the technical point of view, overall the stashcat ${ }^{\circledR}$ app in theory satisfies all the criteria defined above as necessary to serve as a solid tool to manage domestic abuse by a network of professional frontline responders. With respect to the practical application of stashcat ${ }^{\circledR}$, the tool was piloted by a Slovenian inter-agency network of professional frontline responders managing domestic abuse. The piloting team contained ten members of the local police, three members of the national-level police, six social workers and two additional coordinators from social work in the Murska Sobota area. The piloting team intended to use stashcat ${ }^{\circledR}$ to exchange critical information on actual cases and thus operated in a stashcat ${ }^{\circledR}$ environment separate from the IMPRODOVA researchers. For the evaluation, the piloting team completed an online survey provided by IMPRODOVA researchers (Juszczyk \& Pfleiderer, 2021). The survey focussed on the usability and quality of stashcat $\AA$ and led to a set of recommendations. Along with the stashcat ${ }^{\circledR}$ app, an accompanying webpage ${ }^{16}$ providing training materials with regard to domestic abuse management in the Slovenian language was evaluated (for more details, see Jyszczyk \& Pfleiderer, 2021).

In general, stashcat ${ }^{\circledR}$ received a positive rating from the respondents. Respondents reported that stashcat ${ }^{\circledR}$ was on average straightforward to use, information was easy to locate and that its functions were working as expected and easy to understand. In this respect, however, police officers rated the survey items more positively than social workers. It seemed that stashcat ${ }^{\circledR}$ was running less smoothly on the social workers' devices or at least that they had other reasons for their difficulties in using it. Nonetheless, both groups of professionals on average provided positive feedback on the usability of stashcat ${ }^{\circledR}$ for domestic violence risk assessment, support delivery, victim protection and collaboration. Police officers and social workers stated that they perceived stashcat ${ }^{\circledR}$ as secure, innovative and appealing to work with. Their communication as a piloting team was also perceived as trusting, respectful and constructive.

16 https://www.fvv.um.si/improdova/ 
Recommendations pertaining the use of stashcat ${ }^{\circledR}$ were that all institutions involved should (beforehand) meet at joint events to agree on objectives and exchanged content. Jusczcyk and Pfleiderer (2021, p. 12f) note that “... a focus should be put on the points where individual services connect in order to help victims of domestic violence. Especially frontline responders from the social sector would benefit from such a preparatory meeting. In addition, it should be checked whether it is technically possible to have more options to adapt the app to the frontline responders' personal needs and requirements".

To sum up, the technical criteria of stashcat ${ }^{\circledR}$ support its use as a tool for interagency collaboration in cases of domestic abuse. Still, its implementation must always consider the human factors and especially users' needs, and integrate them accordingly.

\section{Conclusion}

Digital solutions feature among the top achievements of the twenty-first century, as do apps and technology designed to support victim-survivors of domestic abuse (e.g. Finn \& Atkinson, 2009; Hassija \& Gray, 2011). Software and apps to support the coordinated action of frontline responders have, however, been missing. The stashcat ${ }^{\circledR}$ app is a first step towards rectifying this gap and comprehensively working to support victim-survivors' safety and well-being.

\section{References}

Bradley, L., Brooks-Hay, O., Burman, M., ..., \& Vogt, C. (2020). Identifying gaps and bridges of intra- and inter-agency https://improdova.eu/pdf/IMPRODOVA_D2.4_Gaps_and_Bridges_of_Intra_and_Interagency_Cooperation.pdf?m $=1585673383 \&$

Feld, S. L. \& Straus, M. A. (1989) Escalation and desistance of wife assault in marriage. Criminology. 27 (1), 141-162. DOI: 10.1111/j.1745-9125.1989.tb00866.x.

Finn, J., \& Atkinson, T. (2009). Promoting the safe and strategic use of technology for victims of intimate partner violence: Evaluation of the technology safety project. Journal of Family Violence, 24(1), 53-59.

Hassija, C., \& Gray, M. J. (2011). The effectiveness and feasibility of videoconferencing technology to provide evidence-based treatment to rural domestic violence and sexual assault populations. Telemedicine and e-Health, 17(4), 309-315.

Juszczyk, P., \& Pfleiderer, B. (2021). Assessment of the National Response Platform Pilot. https://improdova.eu/results/reports/index.php 
Malos, G. H. E. (1997). Inter-agency initiatives as a response to domestic violence. The Police Journal, 70(1), 37-45.

Robinson, A. L. (2006). Reducing repeat victimization among high-risk victims of domestic violence: The benefits of a coordinated community response in Cardiff, Wales. Violence Against Women, 12(8), 761-788.

Rodríguez-Rodríguez, I., Rodríguez, J. V., Elizondo-Moreno, A., Heras-González, P., \& Gentili, M. (2020). Towards a holistic ICT platform for protecting intimate partner violence survivors based on the IoT paradigm. Symmetry, 12(1), 37. https://doi.org/10.3390/sym12010037

stashcat ${ }^{\circledR} \mathrm{GmbH}$ (n.d. a). Manual for using stashcat ${ }^{\circledR}{ }^{\circledR}$. Version 3.27.

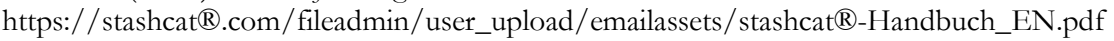

stashcat ${ }^{\circledR} \mathrm{GmbH}$ (n.d. b). The secure messenger with file storage for mission critical authorities. Information flyer.

Vogt, C. (2020). Interagency Cooperation. European Law Enforcement Research Bulletin, 19, 153-163. https://bulletin.cepol.europa.eu/index.php/bulletin/article/view/412 


\title{
DEVELOPMENT OF A TRAINING Platform on Domestic VIOLENCE
}

\author{
BetTina Pfleiderer \& Paulina Juszczyk \\ Westfalian Wilhelm-University Münster, Faculty of Medicine, Münster, Germany. \\ E-mail: pfleide@wwu.de; paulina.juszczyk@wwu.de
}

Abstract As part of the IMPRODOVA project, a training platform with training formats and materials was designed to optimise front-line response strategies and enhance interorganisational cooperation to prevent, investigate and mitigate domestic violence. The teaching concept involved two pillars: training platform can either be used as an online self-learning tool to train oneself individually combined with knowledge assessment, case studies and training videos or as a source for training materials on domestic violence for trainers who want to conduct a training on domestic violence on their own. The chapter explains the needs identified through the IMPRODOVA research and requests from front-line responders, focusing on the most relevant topics for the police, the health and the social sector. The training materials specially designed for this training platform and tailored to each domestic violence responder group are presented. The chapter addresses the challenge that even though the English international platform provides a good overview on the EU level and corresponding policies, it does not necessarily reflect national/local context and reference frameworks. The chapter concludes with a description of the evaluation results of the IMPRODOVA training platforms and highlights gaps to improve the platform's usability.

Keywords: training platform, domestic violence, Europe, police, social work, health sector, IMPRODOVA 


\section{Training platform on domestic violence}

As part of the IMPRODOVA project, a training platform with training formats and materials was designed to optimise frontline response strategies and enhance interorganisational cooperation to prevent, investigate and mitigate domestic violence.

A freely accessible online training platform is a low-threshold measure to reach frontline responders. Scenario-based learning and case studies, workshop concepts and presentations, educational videos tailored to the various frontline responders, as well as guidelines to enhance frontline responders' cooperation across different professions were integrated as basic material to elaborate and illustrate training modules. To sensitise the various frontline responders from the police, the health sector and the social sector, a special focus was put on how to detect signs of domestic violence.

Table 1 provides the main links to all modules/sections of the platform. Training materials related to various topics of interest can be easily found by using the "Search" function on the platform.

Table 1: Link list for the webpages on the international training platform

\begin{tabular}{ll}
$\begin{array}{l}\text { IMPRODOVA training } \\
\text { platform }\end{array}$ & Link \\
\hline $\begin{array}{l}\text { International training } \\
\text { platform }\end{array}$ & https://training.improdova.eu/ \\
\hline German training platform & https://training.improdova.eu/de/ \\
\hline $\begin{array}{l}\text { Introduction - Police as } \\
\text { frontline responder to } \\
\text { domestic violence }\end{array}$ & $\begin{array}{l}\text { https://training.improdova.eu/en/introduction-police-as- } \\
\text { frontline-responder-to-domestic-violence/ }\end{array}$ \\
\hline $\begin{array}{l}\text { Introduction - Domestic } \\
\text { violence in the Health } \\
\text { Sector }\end{array}$ & $\begin{array}{l}\text { https://training.improdova.eu/en/introduction-domestic- } \\
\text { violence-in-the-health-sector/ }\end{array}$ \\
\hline $\begin{array}{l}\text { Introduction - Domestic } \\
\text { violence in the Social }\end{array}$ & $\begin{array}{l}\text { https://training.improdova.eu/en/introduction-domestic- } \\
\text { violence-in-the-social-sector/ }\end{array}$ \\
Sector & $\begin{array}{l}\text { https://training.improdova.eu/en/training-modules-for- } \\
\text { the-police/ }\end{array}$ \\
Police & $\begin{array}{l}\text { https://training.improdova.eu/en/training-modules-for- } \\
\text { the-health-sector/ }\end{array}$ \\
\hline $\begin{array}{l}\text { Training modules for the } \\
\text { Health Sector }\end{array}$ & $\begin{array}{l}\text { https://training.improdova.eu/en/training-modules-for- } \\
\text { the-social-sector/ }\end{array}$ \\
\hline $\begin{array}{l}\text { Training modules for the } \\
\text { Social Sector }\end{array}$ & \\
\hline
\end{tabular}




\begin{tabular}{ll}
$\begin{array}{l}\text { IMPRODOVA training } \\
\text { platform }\end{array}$ & Link \\
\hline Data and statistics & https://training.improdova.eu/en/data-and-statistics/ \\
\hline $\begin{array}{l}\text { Training materials for the } \\
\text { Police }\end{array}$ & $\begin{array}{l}\text { https://training.improdova.eu/en/training-materials-for- } \\
\text { the-police/ }\end{array}$ \\
\hline $\begin{array}{l}\text { Training materials for the } \\
\text { https://training.improdova.eu/en/training-materials-for- } \\
\text { Health Sector }\end{array}$ & $\begin{array}{l}\text { the-health-sector/ } \\
\text { https://training.improdova.eu/en/training-materials-for- } \\
\text { Training materials for the } \\
\text { Social Sector }\end{array}$ \\
\hline
\end{tabular}

\section{Preparation phase}

The development of the platform involved three phases with some of the phases overlapping (Figure 1). In Phase 1, research was done in the EU project IMPRODOVA by analysing policy implementation, legislation, data, risk assessment, case documentation, cooperation, and trainings.

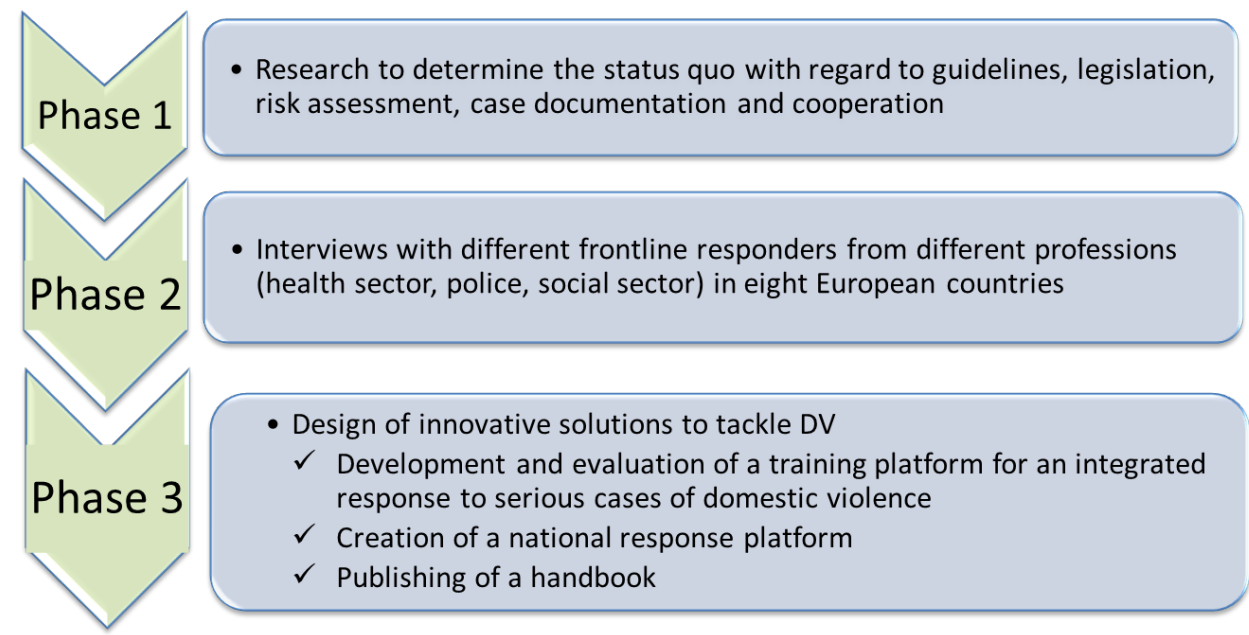

Figure 1: Phases of the IMPRODOVA project

This was complemented in phase 2 by the analysis of 296 interviews with different frontline responders from police, the health sector, and the social sector in eight European countries to investigate frontline responder practices with a special emphasis on inter-agency cooperation. It was also assessed to the extent to which standards are converted into practice (Herbinger et al., 2020) and actors are involved in multi-professional approaches to tackle domestic violence (Vogt, 2020). 
After analysing the interviews, it became clear that the main challenge is to meet the needs of different frontline responder groups in different countries, as well as to tackle gaps in their understanding of their roles in fighting domestic violence (DV), and finally, to improve inter-agency cooperation. The interviews also provided important country-specific information about frontline responders' training provisions which already exist and could be further optimised. The objective was to gain more insight into the country-specific domestic violence training and education for frontline responders to see gaps, good practices, or possibilities for improvement. A great availability of various education and training formats could be identified (Houtsonen, 2020). For example, health professionals are often the first point of contact for victims of domestic violence and thus, play a major role in the detection and intervention of domestic violence. Interviews with professionals from the medical sector within the IMPRODOVA project indicated that they are not sufficiently trained in handling domestic violence cases and are not aware of their role as frontline responders in domestic violence cases. It also became clear that interagency collaboration was lacking (Pfleiderer \& Sondern, 2021). Yet, one of the most important goals in the fight against domestic violence is to have all frontline responder groups (e.g., the police, the medical profession, social work, victim protection shelters, law enforcement, and counselling centres) actively involved at all levels to draw more victims into existing help networks and to deal with a case comprehensively.

In phase 3, it was decided to design a freely available online training platform on domestic violence in addition to a national response platform (chapter 4.1.) and writing a book on DV. A main challenge emerged: even though the international English platform provides a good overview of the EU level and corresponding policies, it does not necessarily reflect national/local context and reference frameworks. As a best practice model for a local/national version of the training platform a German IMPRODOVA training platform was developed, which, even though the main content was based on the English international platform, was tailored and adapted to the local German context and needs. 


\section{Concept of the training platform on DV}

We decided to present our teaching material in the form of building blocks with various modules being made available to the different stakeholder groups - police, health sector, social sector - and materials tailored to the situation in different countries. The teaching concept involved two pillars: the training platform could either be used as an online self-learning tool to train oneself individually combined with knowledge assessment, case studies and training videos or as a source for training materials on DV for trainers/teachers who want to conduct a training on domestic violence on their own.
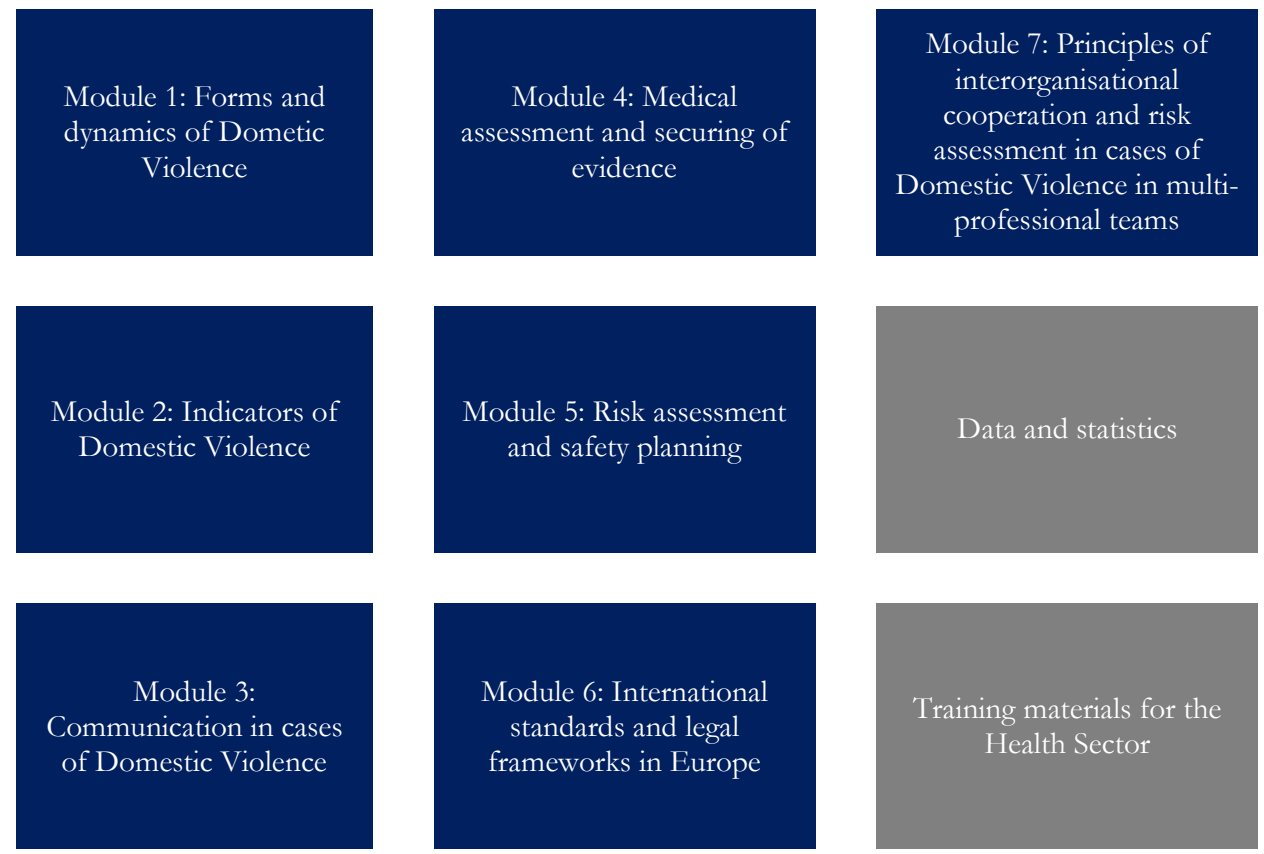

Figure 2: Modular concept of the training platform - exemplary screenshot for the medical sector

For the building blocks, partners of the IMPRODOVA consortium were asked to provide country-specific information and case scenarios and knowledge assessment questions by completing a template with several feedback cycles to further optimise the provided information. Information was organised in seven modules and three additional sections - data and statistics, teaching materials and introductions were added as well (Figure 2). The introductions for the police, the health sector, and the 
social sector summarise the most important information for the three frontline responders being no experts in DV, hereby considering the limited time resources of practitioners. The seven modules are thematically the same, but the content is tailored to the needs of each sector.

\section{Specific training needs of the various frontline responders}

\section{Specifics for the police}

Interviews in the IMPRODOVA project indicate that not all police officers may have adequate competencies to deal with domestic violence. Therefore, when cases of domestic violence arise, police officers often feel frustrated and discontent. As a result, victims may feel not being sufficiently supported or protected, so that they neither report the violence they have experienced nor seek help. Police officers who handle such cases would benefit from a gender-sensitive training on DV and risk assessment.

Based on our findings, risk is assessed by non-standardised procedures and frequently based on a "gut feeling". Often gender aspects are not integrated sufficiently in existing risk assessment tools and procedures. This leads to an increased likelihood that police officers will overlook male victims of domestic violence in intimate relationships. Gendered perceptions bear the risk of revictimising the victim or to not take the victims' complaints seriously. This might be responsible for victims not sharing all information that are relevant for the risk assessment. Police officers must therefore be trained to reflect their own behaviour and judgement, because sex and gender aspects may not only affect the questions being asked but also how the questions are being asked and how the answers will be interpreted by those asking (Pfleiderer \& Sondern, 2020). Furthermore, training should enable police officers to be more open to inter-organisational cooperation in order to meet the various needs of the victims (Houtsonen, 2020).

Accordingly, IMPRODOVA training materials tailored to the police include gendersensitive communication and risk assessment. Recommendations for innovative gender-sensitive trainings and education for various frontline responder groups follow in the next chapter 4.3. 


\section{Specifics for the health sector}

Short and long-term health consequences of domestic violence prompt victims to seek help from the medical profession. Interviews with health professionals in the IMPRODOVA countries revealed that not all of them have been sufficiently trained in the area of domestic violence. In most European countries, knowledge about domestic violence, symptoms and red flags are not regularly part of the mandatory curriculum, neither for physicians nor for medical students. Therefore, many health professionals may not be aware of the important role they play in the network. Instead, they see their role primarily in taking care of the medical needs of their patients and rarely consider themselves as frontline responders to domestic violence. A better understanding of their own role, but also of the roles of other frontline responders is a prerequisite in order to work together against domestic violence and to help and assist victims (Pfleiderer \& Sondern, 2021).

Usually, physicians due to their tight schedules, consider extended communication with victims about their experiences of domestic violence as almost impossible. The aim of the section on our training platform for the medical sector "Introduction Domestic violence in the Health Sector" aims to support practitioners in identifying patients and their children who have been victims of domestic violence and to respond to them appropriately in as little time as possible.

\section{Specifics for the social sector including the school system}

Frontline responders' feedback revealed that professionals from the social sector usually play the role of training providers rather than as beneficiaries of a training. Participation in training is cost-intensive and consequently, the costs cannot be covered by employers. Social sector professionals are comparatively well trained in the area of domestic violence. What they lack are practical examples and precise instructions for their activities, e.g., to assess the risk of domestic violence. Practical examples specially tailored to the social sector have been added to the training platform. We also included concise recommendations for teachers on how to deal with (suspected) cases of domestic violence at school (Figure 3). 


\section{Recommendations on how to proceed in cases of suspected domestic violence}
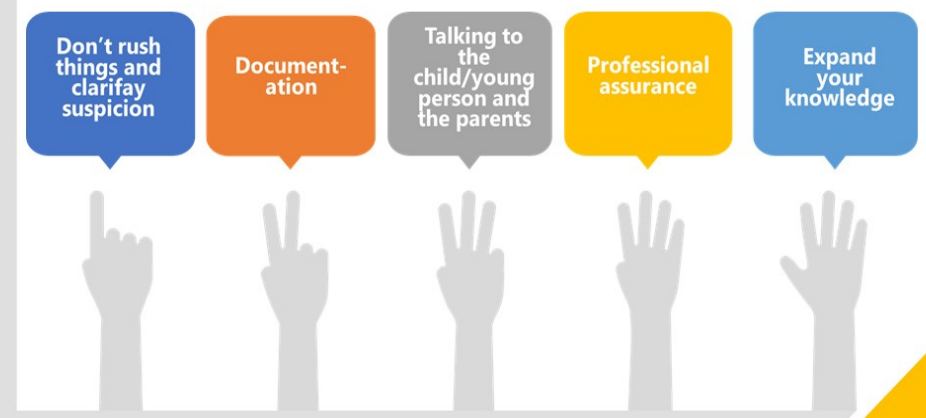

Figure 3: Recommendations on how to proceed in cases of suspected domestic violence for school teachers to be found in module 2 for the social sector

As visible injuries, behavioural problems, or changes in behaviour of a child or adolescent may raise the suspicion that domestic violence could be present in a family, educators, school social workers and teachers need to be sensitised to this. In any case, the primary goal should be to end the violence against a child, an adolescent, or a parent. In most domestic violence cases, the best way to help the child or the adolescent is for the parent itself to change the situation. Encouraging parents to do so and giving them access to help is important in the school sector.

\section{Training modules of the platform}

Based on the needs identified through the IMPRODOVA research and requests from frontline responders, the platform includes a section on DV data and statistics, as well as seven modules focused on the topics most relevant for frontline responders. (cf. Figure 2): 
Table 2: Overview of the modules included on the IMPRODOVA training platform

\begin{tabular}{|c|c|}
\hline $\begin{array}{l}\text { Module 1: Forms and } \\
\text { dynamics of domestic violence }\end{array}$ & $\begin{array}{l}\text { Module } 1 \text { aims at a better understanding of } \\
\text { Domestic Violence, its forms, and consequences. } \\
\text { Knowledge is transmitted about the specific context } \\
\text { and the impact of domestic violence that can be a } \\
\text { helpful step in understanding the individual needs of } \\
\text { victims. }\end{array}$ \\
\hline $\begin{array}{l}\text { Module 2: Indicators of } \\
\text { domestic violence }\end{array}$ & $\begin{array}{l}\text { The objective of Module } 2 \text { is to become familiar with } \\
\text { the various indicators of domestic violence, their } \\
\text { related risks and to get sensitised to them. At this } \\
\text { point, a special focus is put on how to detect signs } \\
\text { of high impact domestic violence. The content is } \\
\text { tailored for police officers, the health sector, and the } \\
\text { social sector. }\end{array}$ \\
\hline $\begin{array}{l}\text { Module 3: Communication in } \\
\text { cases of domestic violence }\end{array}$ & $\begin{array}{l}\text { Module } 3 \text { presents the different ways of asking about } \\
\text { domestic violence in situations where a frontline } \\
\text { responder suspects the incidence of domestic } \\
\text { violence. Furthermore, first steps after the disclosure } \\
\text { of domestic violence are presented. There is a } \\
\text { version for police officers, the health sector, and the } \\
\text { social sector of Module } 3 \text {. }\end{array}$ \\
\hline $\begin{array}{l}\text { Module 4: Police investigation } \\
\text { and legal proceedings }\end{array}$ & $\begin{array}{l}\text { Module } 4 \text { for police officers presents the most } \\
\text { important aspects to be considered in police } \\
\text { investigations and subsequent legal proceedings after } \\
\text { the disclosure of domestic violence. }\end{array}$ \\
\hline $\begin{array}{l}\text { Module 4: Medical assessment } \\
\text { and securing of evidence }\end{array}$ & $\begin{array}{l}\text { Module } 4 \text { for the health sector presents the most } \\
\text { important aspects to be considered after the } \\
\text { disclosure of domestic violence and how to } \\
\text { document domestic violence injuries for court } \\
\text { proceedings. }\end{array}$ \\
\hline $\begin{array}{l}\text { Module 4: Support services of } \\
\text { the social sector }\end{array}$ & $\begin{array}{l}\text { Module } 4 \text { for the social sector presents the support } \\
\text { offered by social services after the disclosure of } \\
\text { domestic violence. Different contact points are } \\
\text { introduced to the reader. }\end{array}$ \\
\hline $\begin{array}{l}\text { Module } 5 \text { : Risk assessment } \\
\text { and safety planning }\end{array}$ & $\begin{array}{l}\text { Module } 5 \text { presents why risk assessment is such an } \\
\text { important step when tackling domestic violence and } \\
\text { what needs to be considered when assessing the risk } \\
\text { of victims of domestic violence, and what steps are } \\
\text { necessary to improve the safety of victims. Risk } \\
\text { assessment and safety planning is introduced to the } \\
\text { police, the health sector and the social sector adapted } \\
\text { to their working environment. }\end{array}$ \\
\hline $\begin{array}{l}\text { Module 6: International } \\
\text { standards and legal } \\
\text { frameworks in Europe }\end{array}$ & $\begin{array}{l}\text { Module } 6 \text { introduces the international framework in } \\
\text { which the work of frontline responders takes place. } \\
\text { It also presents country-specific regulations in order } \\
\text { to gain an impression of how other European } \\
\text { countries tackle domestic violence. }\end{array}$ \\
\hline
\end{tabular}




\begin{tabular}{|c|c|}
\hline $\begin{array}{l}\text { Module } 7: \text { Principles of } \\
\text { interorganisational } \\
\text { cooperation and risk } \\
\text { assessment in cases of } \\
\text { domestic violence in multi- } \\
\text { professional teams }\end{array}$ & $\begin{array}{l}\text { The aim of module } 7 \text { is to understand how frontline } \\
\text { responders work and why cooperation in multi- } \\
\text { professional teams is most successful in tackling } \\
\text { domestic violence. This information is introduced } \\
\text { with slightly different content for the police, the } \\
\text { health sector, and the social sector. }\end{array}$ \\
\hline $\begin{array}{l}\text { The section on data and } \\
\text { statistics }\end{array}$ & $\begin{array}{l}\text { This section includes information about } \\
\text { victimisation surveys and police data in the EU as } \\
\text { those sources have made available the most reliable } \\
\text { and extensive domestic violence data. Additionally, } \\
\text { recommendations on good data harmonisation and } \\
\text { consolidation are summarised that should be } \\
\text { regarded in these cases. In order to be able to use the } \\
\text { platform, as planned, a training material kit for } \\
\text { trainers, a section for teaching materials for police } \\
\text { officers, the health sector and the social sector } \\
\text { completed the platform. }\end{array}$ \\
\hline
\end{tabular}

\section{Design of innovative training materials}

In addition to the modules, the platform was complemented by training material specially designed for this training platform and tailored to each DV responder group. Based on the information of the training platform, downloadable fact sheets were designed for every module for police, the health sector, and the social sector. These can serve as handouts in a course or workshop and can be adapted to individual needs. Scenario-based learning, case studies and knowledge assessments for police, the health sector, and the social sector as well as an exemplary workshop concept for the various sectors can be adapted by trainers. As examples, we highlight our training videos, the risk assessment tool as scenario-based learning method, and an exemplary workshop concept for a 90 minute-medical student course with downloadable presentations that trainers can adapt.

\section{Training videos}

The training videos are about 1-2 minutes in length and summarise the most important aspects of each module. The used drawn figures were diversified by a graphic designer to include further gender and diversity aspects (Figure 4). 

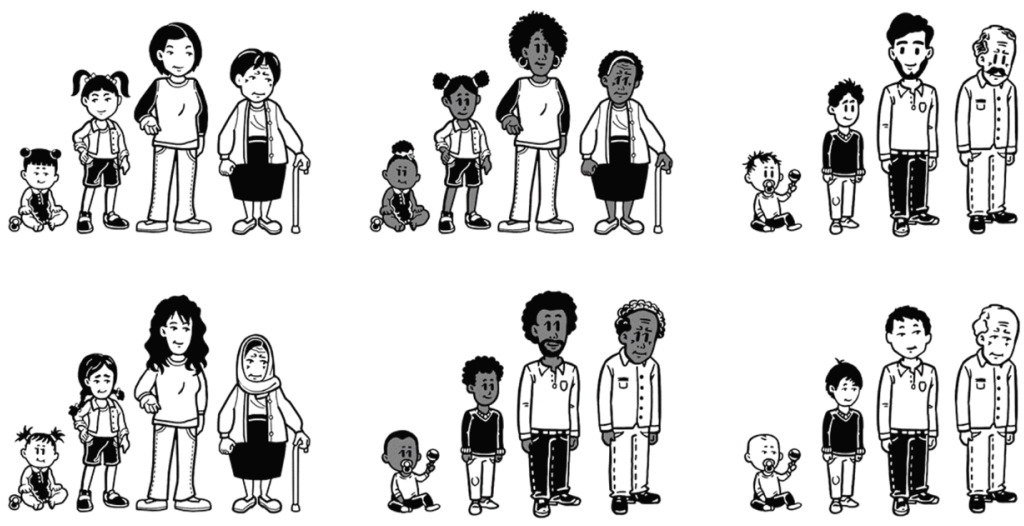

Figure 4: Examples of diversified drawings of victim groups

The videos are shared on IMPRODOVA's YouTube channel ${ }^{1}$ and cover the following topics:

\section{- Domestic violence in Health Services}

"Domestic violence in Health Services" is about the role of frontline responders in the medical sector. For many victims of domestic violence, health professionals are the first point of contact. This video explains what constitutes domestic violence, who can be a victim of domestic violence, and what may be the next steps if you suspect a patient has experienced domestic violence.

\section{- How to respond to a disclosure}

"How to respond to a disclosure" deals with the response and attitude when a victim discloses domestic violence. The key steps of a response to a disclosure, which include listening, communicating belief, validating the decision to disclose, emphasizing the unacceptability of violence, and offering support are explained in more detail.

\footnotetext{
${ }^{1}$ https://www.youtube.com/channel/UC998cREyGoT--daViEII2fQ
} 


\section{- What happens when you call the police?}

"What happens when you call the police?" looks at the role of police as frontline responder. For those affected by domestic violence, police officers are a key service in an emergency. The video reflects the responsibilities of police to investigate, to ensure the safety of those affected by domestic violence, and to offer help and reassurance.

\section{- What happens when you contact a women's shelter?}

"What happens when you contact a women's shelter?" is about women affected by domestic violence who are forced to leave their homes to be safe. In this video, the shelters' key elements of providing information, support and counselling are described.

\section{- Who is affected by domestic violence?}

"Who is affected by domestic violence?" questions the factors that lead to becoming a victim of domestic violence and explains the different forms of experience. The videos underline that there are many factors causing people to stay in abusive relationships although they are affected by domestic violence.

\section{- Who are the perpetrators of domestic violence?}

"Who are the perpetrators of domestic violence?" explains the factors that can play a role in persons when they are becoming abusive, and how perpetrator programmes can assist to stop abusive behaviours. In this video, it is highlighted that perpetrators are responsible for their actions and that an understanding of gendered inequalities in society is a key component in ending domestic violence.

\section{- Why is cooperation in cases of domestic violence important?}

In "Why is cooperation in cases of domestic violence important?", the emphasis is on frontline responders from health services, police and non-governmental organisations sharing the common goal of preventing further harm to those affected by domestic violence. The video points out why working together is the most effective way to tackle domestic violence for agencies. This includes a better 
provision of information and cooperation between professionals on individual cases and a supportive and empowering environment, so people affected by domestic violence feel confident to contact the police and other professionals.

\section{- The UN and its role in combating violence against women}

"The UN ant its role in combating violence against women" gives an overview of the UN resolutions dealing with combating violence against women. The video underlines that countries should take measures to prevent and prosecute acts of violence against women by intensifying efforts to raise awareness about domestic violence and violence against women, by providing training for all professionals and by offering specialised support for women and children affected by gender-based violence.

\section{- Domestic violence in times of disasters}

"Domestic violence in times of disasters" is based on the current situation with COVID-19. There are indications that domestic violence may have increased during the COVID-19 pandemic. In this video, it is explained how frontline responders can help those experiencing domestic violence during the COVID-19 pandemic and the quarantine ordinances. For example, services such as making text or online chat services available 24-7 may help those affected by domestic violence to access support more safely.

\section{Risk assessment tool}

The IMPRODOVA risk assessment integration module (RAIMO; see chapter 2), as an example for scenario-based learning, explains the entire risk assessment procedure for the specific case "Nora", a woman with an immigrant background suffering from intimate partner violence. RAIMO renders a comprehensive approach to risk assessment by demonstrating different risk factors and different approaches to identifying and responding to risk and gives a clear understanding of the specific roles and responsibilities of different agencies (e.g., police officers, social work and healthcare professionals, NGO workers, educators) who come into contact with victim-survivors and perpetrators. 


\section{Workshop and student course concepts}

The student course for medical students is designed as an interactive seminar with presentations for up to 16-20 students in 4 groups. Including preparation and concepts for group work it corresponds to a total of $28 \mathrm{~h} /$ à 45 min each in total. The preparation-phase for the students will start 14 days prior to the course and includes the completion of a home assignment discussing three quotes about domestic violence. The quotes help students to reflect about their current knowledge on DV and attitudes towards domestic violence. The responses given in the home assignments will be discussed at the beginning of the course. Themes discussed in the course are forms and dynamics of domestic violence, indicators for domestic violence, Istanbul convention/legal framework, interagency cooperation, communication, and risk assessment in cases of DV in multi-professional teams. The content of the course is based on the IMPRODOVA training platform and the corresponding modules for the health sector.

\section{Evaluation}

After the international platform as well as the German national platform with all related trainings materials was finalised, the IMPRODOVA training platforms were evaluated by various frontline responder groups to further optimise the training materials. Due to the COVID-19 pandemic, most training sessions needed to be organised online.

In the IMPRODOVA partner countries, students, course participants, teachers, and experts from the three sectors of police, health sector and social sector assessed the content by using a questionnaire tailored to the various frontline responder groups or by participating in structured (focus groups) interviews. A pre- and post-survey was conducted in Germany and in Finland, respectively. Socio-demographic characteristics, the assessment of the training platform and of individual modules as well as self-assessment with regard to the learning objectives and thematically relevant attitudes were investigated. 
Generally, the didactic concept of the training involved a general transfer of knowledge, and more specifically, an increase in competences on domestic violence including providing practical advice, and solutions to problems e.g., how to improve interagency collaboration. The overarching goal is that frontline responders will use the material for their (future) work and to optimise their response to domestic violence.

\section{Evaluation of the German training platform}

The whole English IMPRODOVA training platform and related materials were translated into German and adapted for the German context to have this as demonstrator of how a national version of the training platform can look like (https://training.improdova.eu/de/). This included an adaptation of the contents of the individual modules to the legal framework in Germany, but also a translation and adaptation of the individual training materials such as videos and case studies to the German context. The German IMPRODOVA training platform was evaluated in Germany and by Austrian students.

In Germany, medical students of the Westfalian-Wilhelms-University of Muenster attended the two-day clinical compulsory elective course "Domestic Violence in an International Context", based on the materials of the German training platform. The detailed agenda of the elective course is part of the IMPRODOVA training materials and is explained in more detail in chapter 4.2.4. The pre-survey in Muenster was conducted prior to the elective course, the post-survey after the completion of the elective course.

28 students completed both questionnaires. Students considered the intervention of domestic violence cases as an important part of the work of physicians, and they are motivated to work with victims of domestic violence in the future, but it is difficult for them to ask patients about domestic violence. This is not surprising, as most students have not received any curricular education or training on domestic violence prior to this newly established elective course in Muenster. Overall, students have a strong interest in the various issues related to domestic violence, but most students do not consider themselves competent regarding DV. Finally, against the background of these results, previous research was corroborated that there is a great need for training on domestic violence among medical students and that there is also interest on the part of the students. The comparison of the pre- and post-assessment 
indicated that the training platform, including its teaching materials, has contributed to a significant learning and competence progress of the students in all subject areas (Figure 6). Students felt much more competent after completion of the course.

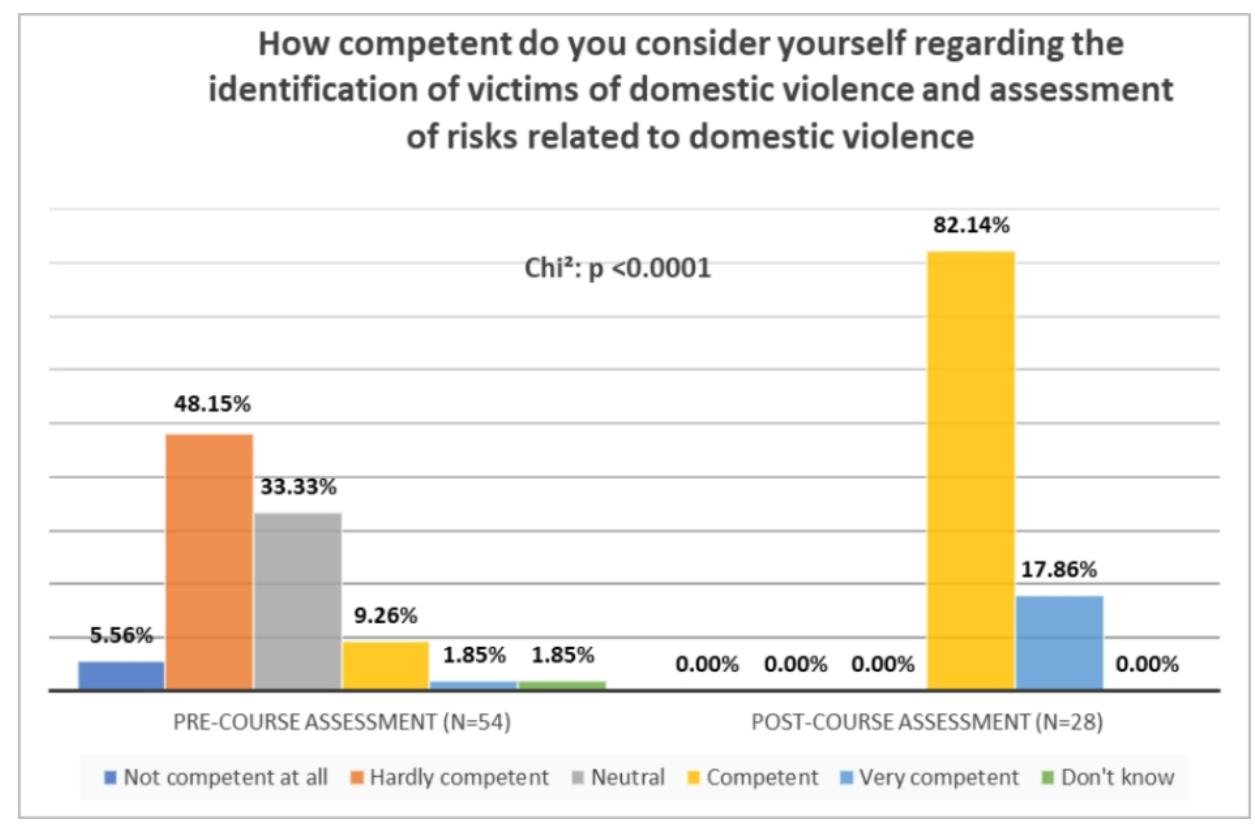

Figure 6: Reported competence of medical students $(n=28)$ in identifying victims of domestic violence and assessing risks related to domestic violence pre and after a student course on domestic violence.

The training platform was rated as very good overall by the medical students. They would recommend it to their fellow students and could imagine using it in the future. They also made some suggestions for improvement to make the training platform more attractive for students, which were implemented accordingly.

\section{Social sector students}

Data from two social sector students was collected in Austria. In general, the training materials were rated as good. Due to the small number of respondents, the evaluation of this sector is limited. 


\section{School teachers}

Three school teachers from different school forms in Germany, each, were invited to look at the materials on domestic violence in the school sector and provide feedback. The training materials were rated as very good. They were judged as being very important materials for the school sector, and being presented in a coherent, clear, and factual way. In particular, the concrete advice, such as the action steps (Figure 3), were found to be very helpful and concise. Based on the teachers' feedback, concrete examples of how to address children on the issue of domestic violence and how to strengthen the child's self-esteem were added after their feedback. The material was re-evaluated after the optimisation cycle and amendments were very well received.

\section{Police officers}

The section "Introduction - Police as frontline responder to domestic violence" on the German IMPRODOVA training platform was assessed by three police officers from Police Berlin; from their feedback it was learned that the introductory section would benefit from including more detailed information regarding police response to emergency calls and how to support officers in knowing hotspots and specifics of their work areas. Nevertheless, it was agreed that the platform has a great potential to deliver useful information for interested police officers and could possibly be used as an additional source in trainings after further optimising it in the future.

In Austria, 29 police officers were recruited with the support of the project partner BMI (Austrian Federal Ministry of the Interior) to participate in two-day training covering specific sections of the IMPRODOVA platform and material for the police. Although the individual modules and training materials were rated as good, the evaluation made clear police officers felt the Austrian national context of the provided information was lacking. In addition, the police officers wanted to have more pictures, quizzes and ficts and facts on the training platform. 


\section{Evaluation of the International IMPRODOVA training platform}

\section{Police students}

In Finland, an online training course with eleven police students at the Police University College of Finland was organised. The course was based on the IMPRODOVA training materials in English. Two online surveys, before and after training, were conducted with the police students to evaluate their change in attitudes and competencies. Ten students completed both questionnaires. The results of the pre- and post-survey indicated that the training platform and its material had a positive impact on students' competencies in relation to the prevention and detection of domestic violence. However, it was notified that some scenarios describe situations that are not necessarily very common in Finland. It was recommended to adapt the materials to the Finnish context.

\section{Medical sector}

Three educators in DV from Peru, Nigeria, and Australia, being members of Medical Women's International Association (MWIA), evaluated the section "Introduction - Domestic violence in the Health Sector". This section of the platform and the training platform as a whole were rated as done very well. It was highlighted that its length, structure, and clarity are very good.

\section{Police sector}

Two Hungarian police experts of the National University of Public Service assessed the section "Introduction - Police as frontline responder to domestic violence" and rated the training material as very good. These experts recommended to use the material not only as self-learning tool but in combination with a trainer supporting the learning process to enhance the impact of the material. They also suggested some slight improvements, e.g., making the section more user friendly by adding more pictures, which was implemented after the evaluation. 
In Finland, four police experts from the Police University College assessed the IMPRODOVA training platform as well. The evaluators also suggested to add some content for the police sector e.g., in the communication between police officers and victims and the treatment of perpetrators. For this reason, the police partners in the IMPRODOVA project were asked to add missing content.

\section{Social sector}

Six experts from the social sector in Finland assessed the IMPRODOVA training platform. In general, most of the suggestions given related to checking spelling mistakes and replacing unclear expressions with more accurate ones. Furthermore, the experts wanted additional content on the training platform, e.g., more content on children as victims of domestic violence. Following the evaluation, the entire training platform will be professionally checked with regard to the linguistic presentation of the content. Nevertheless, additional content will also be included.

\section{Summary}

To summarise, the training platform was positively rated by all evaluators. A prepost comparison of students showed a clear learning gain with regard to competence-based learning goals. Moreover, the training platform contributes to an increase in competence and to learning progress. Still, the evaluation also highlighted some gaps that were subsequently addressed to improve the usability of the platform even further.

The recommendations could be clustered into three areas: (a) Structure and usability; (b) Adaptation to the national and local context, (c) Suggestions for additional content.

\section{Structure and usability}

The majority of the respondents considered the IMPRODOVA training platform and its material as clearly structured. However, some recommended shortening certain modules. In addition, it was proposed to have more shorter sections instead of a long paragraph; it was also stressed that visualisations and summations of the main points may help the users to find respective content, e.g., including more 
images into the training platform could highlight important issues. This was addressed as much as possible. To facilitate finding contents, a table of contents with headings was integrated at the beginning of each module which is linked to the corresponding headings in the module. Also, a new search function was implemented to find content by keyword search.

\section{Adaptation to the national and local context}

The evaluation indicated that there is a strong need for national versions of the IMPRODOVA training platform. Many suggestions for improvement touched the lack of national context of the provided information. Firstly, due the differences in legislation and practises in Europe, some guidelines in the training material cannot be used across Europe without an adaptation to national conditions. Secondly, since some procedures vary from country to country, too universal descriptions may be misleading. This is certainly a disadvantage of presenting a European platform. Since it is not possible to adapt the material, especially the guidelines and procedures that are prescribed by legislation, regulations, and instructions, to national and local contexts within one platform, it was recommended to draft national versions of the training platform. The German version of the training platform was drafted as pilot demonstrator to show how a local adaption could be put into reality.

Originally, the introductions were labelled as " 15 minutes" sections. But we learned from the evaluation that most respondents misunderstood the concept of the " 15 minutes" sections. They expected to learn everything important to know in 15 minutes and therefore criticised missing points or simplifications, when in fact all content can be found in the corresponding modules. Unfortunately, most respondents never consulted the corresponding modules. Thus, the didactic concept for the "15 minutes" sections was adapted accordingly to made it clearer that it is only a short overview for those without any experience in DV, but one still needs to read the corresponding modules. For this reason, and to avoid misunderstandings in the future, we renamed the "15 minutes" sections into introductions. 


\section{Suggestions for additional content}

Supplementary content, in particular, the position of immigrant women and LGBTQ persons as victims of domestic violence were recommended to add by some evaluators. In addition, more detailed information about coercive control, internet abuse and cyber stalking as forms of violence were requested. There were also several suggestions for adding some more content that would describe the positions of children as victims and witnesses of domestic violence. Some also suggested that adding links to facilities and organisations supporting perpetrators would be useful for frontline responders as well as information about perpetrator programmes. Based on these recommendations given in the evaluations we added new content to such training materials, for instance, a section about domestic violence in the media, since media play an important role how DV and how victims are perceived in public. The impact of the COVID-19 pandemic on DV was also added, as well as training materials tailored to school teachers. We added also interviews on our platforms as suggested by the evaluators. For example, one participant of the German medical student course who often works as translator in cases of DV, conducted an interview with a member of a working group specialised on refugees and migrants as victims of domestic violence. The interview being published on the German IMPRODOVA training platform describes how they come into contact with victims, what kind of support is offered, what challenges are present, and the aims of the support given by them. The English translation of the interview was published as a blog on the IMPRODOVA website. ${ }^{2}$ Furthermore, the training platform was improved by including more self-learning assessments and teaching tools (e.g., more quizzes, case studies on specific topics, etc.). Since the IMPRODOVA training platform is a living document, new content will be continuously added.

While all the recommendations have their own merits, one should not forget that the IMPRODOVA training platform is a demonstrator only and it is not possible to address all suggestions in the time given and the available resources.

\footnotetext{
2 https://improdova.eu/blog/detail.php?we_objectID $=214$
} 
All in all, the evaluation results indicated that the IMPRODOVA training platform can be successfully used for self-learning. Likewise, materials are also suitable for integrating in an existing course or can be used for a workshop and provide a deeper understanding of domestic violence and improve frontline response.

\section{References}

Herbinger, P. L., Leonhardmair, N. \& Neunkirchner, M. (2020). European legislation to fight domestic violence. European Law Enforcement Research Bulletin, (20), 141-154. http://bulletin.cepol.europa.eu/index.php/bulletin/article/view/415/339

Houtsonen, J. (2020). Policing Domestic Violence: Strategy, Competence, Training. European Law Enforcement Research Bulletin, (19), 135-151.

https://bulletin.cepol.europa.eu/index.php/bulletin/article/view/417/318

Pfleiderer, B. \& Sondern, L. (2020). Why the integration of sex and gender aspects will improve Domestic Violence Risk Assessment. European Law Enforcement Research Bulletin, (20), 155-165. http://bulletin.cepol.europa.eu/index.php/bulletin/article/view/413

Pfleiderer, B. \& Sondern, L. (2021). The Challenge of Involving Medical Doctors as Important Frontline Responders in Fighting Domestic Violence. European Law Enforcement Research Bulletin, (21), 141-150. https://bulletin.cepol.europa.eu/index.php/bulletin/article/view/414

Vogt, C. (2020). Interagency Cooperation. European Law Enforcement Research Bulletin, (19), 153-163. http://bulletin.cepol.europa.eu/index.php/bulletin/article/view/412 


\section{RECOMMENDATIONS FOR AN}

INNOVATIVE GENDER-SENSITIVE

Training AND EDUCATION FOR

VARIOUS FRONTLINE RESPONDER

\section{GROUPS}

\section{BetTina Pfleiderer \& PAUlina JuszCZyK}

Westfalian Wilhelm-University Münster, Faculty of Medicine, Münster, Germany. E-mail: pfleide@wwu.de; paulina.juszczyk@wwu.de

Abstract Rigid gender roles and gender stereotypes can limit both women's and men's choices, opportunities and access to power and resources. While both sexes suffer from domestic violence, women are more likely to experience repeated and severe forms of abuse, including sexual violence. However, the concept of gender goes beyond numbers, and it is an important human factor that is not integrated sufficiently in existing training, risk assessment tools and procedures. Understanding the gendered nature of domestic violence, but nevertheless taking into account that both men and women can suffer from violence, or be perpetrators, enables front-line responders to develop services that are sensitive to the different needs of individuals affected by domestic violence (DV). This chapter introduces the principles of innovative gender-sensitive training and education for various front-line responder groups. This chapter explains the reasons for it and how the gender norms and perceptions identified in the IMPRODOVA research, which may have a negative impact on front-line responders' responses to DV, were addressed in all IMPRODOVA instruments and guidelines in teaching formats.

Keywords:

domestic violence, gender roles, gender, police, social work, health sector, training 


\section{Introduction}

This chapter addresses whether domestic violence is gender neutral as it affects people of all genders and sexualities, and whether gender is therefore irrelevant to frontline responders' prevention of and response to domestic violence. From the perspective of the IMPRODOVA project, we consider gender to be an important aspect of domestic violence that should not be ignored and should be part of trainings and education of various frontline responder groups.

\section{Background}

The perception and understanding of "sex" and "gender" in general, and their meaning in the context of domestic violence should be an integral component of trainings for frontline responders. In general, "sex" refers to the sum of biological factors that determine whether an individual is female, male and/or intersex, while "gender" refers to the sociocultural factors like social norms and expectations of behaviour and appearance of individuals in social contexts. For example, one "typical" assumption is that men are "naturally" more violent or driven by uncontrollable sexual urges (Jewkes, 2002; Barker \& Pulerwitz, 2008). "Sex" and "gender" aspects differ in relation to men and women and are influenced by intersecting factors like race, social class, and culture. Therefore, gender is socially constructed.

Rigid gender roles and stereotypes can limit both women's and men's choices, opportunities and access to power and resources. The unequal distribution of power and resources of men and women can result in gender inequality and gender-based violence (EIGE, 2018). Gender equality means in turn that women and men have equal conditions, treatment, and opportunities for realizing their full potential, human rights and dignity, and for contributing to (and benefiting from), economic, social, cultural, and political development. Gender equity ensures this process. Transforming gender roles through women's empowerment by raising awareness and increasing access to resources and promoting new models of masculinities which break the connection between masculinity and violence are ways to build more equal gender relations (UNWOMEN, 2015). 


\section{Sex and gender aspects regarding victims of domestic violence}

There is a difference in sexes regarding the prevalence of domestic violence with females clearly outnumbering males (UNODC, 2019; UNODC, 2019a). While both sexes suffer from domestic violence, women are more likely to experience repeated and severe forms of abuse, including sexual violence. In the European Union, $22 \%$ of women have experienced physical or sexual violence in an intimate relationship since the age of 15 (FRA, 2014) and about $43 \%$ of women have experienced psychological violence in an intimate partnership (FRA, 2014). Moreover, almost 50 $\%$ of all homicides against women take place in the domestic sphere (Corradi et al., 2018).

Domestic violence can lead to psychosocial and mental health problems with increased burden on women (Dekker et al., 2017). Since women often feel ashamed by victimisation and want to protect the family reputation or honour, female victims of domestic violence are more likely to stay in abusive relationships than men or do not report domestic violence to the police (Howarth \& Robinson, 2016).

There is a lack of representative data regarding the prevalence of domestic violence against men. Consequently, the number of men as victims of domestic violence is underestimated and support services for them are lacking (Barber, 2008; Ceelen, et al., 2013). Since domestic violence seems to be mostly associated with the female sex, there is an increased likelihood that frontline responders will overlook men as victims of domestic violence in intimate relationships. Due to the strong social stigma associated with being a male victim of domestic violence (DV), male victims seem to report incidents less often than female victims do (Pfleiderer \& Sondern, 2020). The most important reason for men affected by domestic violence not to report incidents is the belief that the police would not take any action (Ceelen, et al., 2013). In addition, it is less likely that it is reported by friends and family, because their perceptions are also gender-biased (Data Europa, 2016). In countries with more traditional gender norms and roles, such as Estonia, Latvia, Lithuania, Poland, Czech Republic, Hungary, Slovakia, Romania, Bulgaria etc. with a low Gender Equality Index score (EIGE, 2017), the perception of a man being the victim of domestic violence seems hardly imaginable. 


\section{Impact of sex and gender aspects regarding the perpetrators of domestic violence}

Gender aspects in domestic violence are often misunderstood as differences in prevalence of DV between sexes. However, the concept of gender goes beyond numbers, and it is an important human factor when focussing on perpetrators. In addition to gender roles accepted in a certain cultural environment (e.g., traditional beliefs that men have the given natural right to control women) gender inequality and gender inequity ${ }^{1}$ play an important role (Salter, 2014). In a patriarchal society where men have more power, more sense of entitlement, and (on average) more income than women, it is known that overwhelmingly more men are the perpetrators of domestic and intimate partner violence (92\%; Hester, 2013). Men see their partners' professional success as a reason for their violent behaviour. However, women can be perpetrators as well, they usually use verbal violence more often. In contrast, male perpetrators use more often physical violence - involving serious injury, rape and even death. Very often - through excuses and justifications based on social and cultural practices, male perpetrators deny their responsibility for violent acts (Anderson \& Umberson, 2001).

It is often assumed that women charged with domestic violence have a history of victimisation by their partner and much of their violence is understood as retaliatory and/or defensive (Downs et al., 2007). In addition, some professionals even believe that women are not capable of being the original perpetrator (Fitzroy, 2001). In contrast, male offenders are primarily seen as perpetrators because they are perceived as more aggressive due to their gender roles (e.g., Eagly \& Steffen, 1986). In fact, studies suggest that women are as violent as men are. In some conditions, women could be the aggressors even more frequently than their violent or nonviolent male partners (Archer, 2000; Johnson \& Kelly, 2008). It should be acknowledged that women, like men, are socialised within a hierarchical social order where they can learn that violence can be an appropriate individualised response to difficult or problematic situations (Fitzroy, 2001).

\footnotetext{
${ }^{1}$ Gender equality and gender equity are related terms but have different meanings. As gender equity refers to the "fairness of treatment for both women and men according to their respective needs" (UNESDOC, 2000), it serves as a means to reach gender equality.
} 


\section{Perpetrator programmes}

Most programmes for perpetrators of domestic violence are tailored to males, there are only a few aiming at female perpetrators (e.g., the Duluth model ${ }^{2}$ ). These programmes include in general cognitive-behavioural approaches to address the perpetrator's use of abuse in their relationships and education about the gendered inequalities in society. Prosecutors and courts can request perpetrators to take part in perpetrator programmes, as for instance is the case in Germany or the UK (Akoensi et al., 2013; Hamilton et al., 2013), but since those programmes exist primarily for men, female offenders are too often left behind. To represent the diversity of perpetrators, programmes should become more inclusive in their service provision in the future.

\section{Impact of sex and gender aspects in frontline response}

Every social interaction is influenced by gendered perceptions (Ridgeway \& SmithLovin, 1999), including the response to domestic violence (Anderson \& Umberson, 2001). Most frontline responders are aware that it makes a difference whether the victim is male or female and whether the frontline responder is male or female. The perception and assumptions about one's own and the other sex and gender are thus important. Sex, gender, own mindsets, and expectations may have an impact on how one speaks with women and with men (e.g., strong voice, holding eye contact). This can also influence how one assesses the risk, the aspects recognised as significant (e.g., who started the incident), and how one perceives the victim. Moreover, it also affects how one is perceived by the victim (male or female) and other frontline partners. For instance, a female police officer could be seen as less threatening by a female victim who may then more willingly share information (Pfleiderer \& Sondern, 2020).

Gendered perceptions run the risk of re-victimising victims in communication through the interrogation style using derogative words and not considering the victim as an autonomous individual. This might be causing victims not to share all relevant information because they do not feel as being taken seriously. Gendered perceptions also carry the risk that frontline responders may not take victims'

2 https://www.theduluthmodel.org/ 
complaints seriously and may downplay the incident, which might end in an escalation of violence because the frontline responders do not intervene to end the violence. Finally, gendered perceptions can eventually lead to not asking about certain forms of domestic violence because it is not assumed that anyone can experience them (Pfleiderer \& Sondern, 2020).

Although gender is an obvious factor of frontline response, it is not integrated sufficiently in existing trainings, risk assessment tools and procedures.

\section{Integration of sex and gender aspects in trainings}

The awareness of sex and gender aspects, particularly gendered perceptions, and biases, in domestic violence is of major importance to frontline responders. Therefore, sex and gender aspects should be integrated in all risk assessment instruments and training materials. A deeper understanding of sex and gender aspects will help frontline responders differentiate between various types of DV more appropriately and become fully aware of the effects gendered perceptions and biases may have on their professional judgements. Frontline responders should be trained to reflect their own behaviour and judgement (Houtsonen, 2020).

Gender-sensitive communication between frontline responders and victims ensures that women and men are treated as persons of equal importance and dignity. Using gender-sensitive language can make it easier to see important differences between male and female victims' needs, challenge unconscious assumptions about gender roles in society, and make victims more comfortable with a disclosure (EIGE, 2019). Therefore, aspects of gender-sensitive communication should be included in all training on DV.

Pfleiderer \& Sondern (2020) recommend based on the IMPRODOVA research results that the following sex and gender aspects should be included in risk assessment tools, procedures, and trainings:

- As victims could be financially dependent on their partners and therefore do not present all information about violent incidents, the victim's financial situation and current work situation should be assessed independent on the sex of the victim. 
- The past sexual history of the victim (e.g., frequent change of sexual partners, the way a victim is dressed) should not influence the risk assessment of the frontline responders and therefore not be part in risk assessment tools.

- Frontline responders should be aware that victims have gendered perceptions and conceptions that may lead biased interpretations and might influence the information that are released by the victim.

- As victims have their own assumptions about frontline responders' genderbased attitudes, frontline responders have to reassure victims to share all information without a fear of being judged or moralised.

Based on these recommendations, gender norms and perceptions that were identified in the IMPRODOVA research were integrated in all IMPRODOVA instruments and guidelines. In particular, Module 1 on the IMPRODOVA training platform (www.training.improdova.eu/en) integrated gender aspects into the training for all three sectors. Besides the definitions of gender and gender-based violence, facts about gender-based violence in Europe are presented. The Istanbul Convention also plays an important role here and is discussed in more detail in Module 6 of the training platform. Various tasks were designed to motivate users to reflect on their own gender perceptions. With the help of these tasks, the gender expectations in society and the respective culture are to be questioned (e.g., how men and women are expected to behave, how they may express their emotions).

Finally, in gender-sensitive DV trainings, stereotypes should also be addressed, since too many still assume that the perpetrators of domestic violence are exclusively men, and the victims are women. It needs to be recognised that most perpetrators are men, yet male victims of domestic violence have been largely ignored. An understanding of the gendered nature of domestic violence, but nevertheless considering that both, men and women can suffer from violence, or be perpetrators, enables frontline responders to develop services which are sensitive to the different needs of individuals affected by domestic violence. Male and female victims have different needs, they require different services and service approaches. To ensure that everyone affected by domestic violence gets the help and support they need, intra- and interorganisational cooperation in cases of domestic violence is needed. 


\section{References}

Akoensi, T. D., Humphreys, D. K., Koehler, J. A., \& Lösel, F. (2013). Domestic violence perpetrator programs in Europe, Part II: A systematic review of the state of evidence. International Journal of Offender Therapy and Comparative Criminology, 57(10), 1206-1225. https://doi.org/10.1177/0306624X12468110

Anderson, K. L. \& Umberson, D. (2001). Gendering violence: Masculinity and power in men's accounts of domestic violence. Gender \& Society, 15(3), 358-380. https://doi.org/10.1177/089124301015003003

Archer, J. (2000). Sex differences in aggression between heterosexual partners: A meta-analytic review. Psychological Bulletin, 126(5), 651-680. https://doi.org/10.1037/0033-2909.126.5.651

Atkinson, C., Downs, W. R., \& Rindels, B. (2007). Women's use of physical and nonphysical selfdefense strategies during incidents of partner violence. Violence Against Women, 13(1), 28-45. https://doi.org/10.1177/1077801206294807

Barber, C. F. (2008). Domestic violence against men. Nursing Standard, 22(51), 35-39. https://journals.rcni.com/doi/abs/10.7748/ns2008.08.22.51.35.c6644

Barker, G. \& Pulerwitz, J. (2008). Measuring attitudes towards gender norms among young men in Brazil: development and psychometric evaluation of the GEM Scale. Men and Masculinities, 10(3), 322-338. https://doi.org/10.1177/1097184X06298778

Ceelen, M., Drijber, B. C., \& Reijnders, U. J. L. (2013). Male victims of domestic violence. Journal of Family Violence, (28), 173-178. https://doi.org/10.1007/s10896-012-9482-9

Corradi, C., Naudi, M. \& Weil, S. (2018). Femicide across Europe. Theory, research and prevention. (1st ed.). Policy Press.

https://library.oapen.org/bitstream/handle/20.500.12657/28243/9781447347163.pdf?seque nce $=1$ \&isAllowed $=y$

Dekker, J. J., Goudriaan, A. E., Kikker, M. J., Kleinhesselink, M. D. \& Waal, M. (2017). Gender differences in characteristics of physical and sexual victimization in patients with dual diagnosis: A cross-sectional study. BMC Psychiatry, 17(270), 1-9. https://doi.org/10.1186/s12888-017-1413-0

Eagly, A. H. \& Steffen, V. J. (1986). Gender and aggressive behavior: A meta-analytic review of the social psychological literature. Psychological Bulletin, 100(3), 309-330. https://doi.org/10.1037/0033-2909.100.3.309

EIGE (2017). Gender Equality Index. https://eige.europa.eu/gender-equality-index/2015/comparecountries/index/map

EIGE (2018). Let's put an end to gender based violence. https:/ / eige.europa.eu/publications/lets-put-endgender-based-violence

EIGE (2019). Toolkit on Gender-sensitive Communication. A resource for policymakers, legislators, media and anyone else with an interest in making their communication more inclusive. https:// eige.europa.eu/publications/toolkit-gender-sensitive-communication

Fitzroy, L. (2001). Violent women: questions for feminist theory, practice and policy. Critical Social Policy, 21 (1), 7-34. https://doi.org/10.1177/026101830102100101

FRA. (2014). Violence against women: an EU-wide survey. Main results. https://fra.europa.eu/sites/default/files/fra_uploads/fra-2014-vaw-survey-main-resultsapr14_en.pdf

Hamilton, L., Koehler, J. A., \& Lösel, F. A. (2013). Domestic violence perpetrator programs in Europe, Part I: A survey of current practice. International Journal of Offender Therapy and Comparative Criminology, 57(10), 1189-1205. https://doi.org/10.1177/0306624X12469506

Hester, M. (2013). Who does what to whom? Gender and domestic violence perpetrators in English police records. European Journal of Criminology, 10(5), 623-637.

https://doi.org/10.1177/1477370813479078 
Houtsonen, J. (2020). Policing Domestic Violence: Strategy, Competence, Training. European Law Enforcement Research Bulletin, (19), 135-151.

https://bulletin.cepol.europa.eu/index.php/bulletin/article/view/417/318

Howarth, E. \& Robinson, A. (2016). Responding effectively to women experiencing severe abuse: Identifying key components of a British advocacy intervention. Violence Against Women, 22(1), 41-63. https://doi.org/10.1177/1077801215597789

Jewkes, R. (2002). Intimate partner violence: Causes and prevention. Lancet, 359(9315), 1423-1429. https://doi.org/10.1016/S0140-6736(02)08357-5

Johnson, M. P. \& Kelly, J. B. (2008). Differentiation among types of intimate partner violence: Research update and implications for interventions. Family Court Review, 46(3), 476-499. https://doi.org/10.1111/j.1744-1617.2008.00215.x

Pfleiderer, B. \& Sondern, L. (2020). Why the integration of sex and gender aspects will improve Domestic Violence Risk Assessment. European Law Enforcement Research Bulletin, (20), 155-165. http://bulletin.cepol.europa.eu/index.php/bulletin/article/view/413

Ridgeway, C. L. \& Smith-Lovin, L. (1999). The gender system and interaction. Annual Review of Sociology, 25(1), 191-216. https://doi.org/10.1146/annurev.soc.25.1.191

Salter, M. (2014). Multi-perpetrator domestic violence. Trauma, Violence, \& Abuse, 15(2), 102-112. https://www.jstor.org/stable/26638339

Data Europa (2016). Special Eurobarometer 449 : Gender-based violence http://data.europa.eu/euodp/en/data/dataset/S2115_85_3_449_ENG

UNESDOC. (2000). Gender equality and equity: a summary review of UNESCO's accomplishments since the Fourth World Conference on Women, Beijing 1995. https://unesdoc.unesco.org/ark:/48223/pf0000121145

United Nations. (2021). Goal 5: Achieve gender equality and empower all women and girls. https://www.un.org/sustainabledevelopment/gender-equality/

UNODC: United Nations Office on Drugs and Crime. (2019). Global study on homicide. Gender-related killing of women and girls. https://www.unodc.org/documents/data-andanalysis/gsh/Booklet_5.pdf

UNODC: United Nations Office on Drugs and Crime. (2019a). Homicide kills far more people than armed conflict, says new UNODC study. https://www.unodc.org/unodc/en/frontpage/2019/July/homicide-kills-far-more-peoplethan-armed-conflict--says-new-unodc-study.html

UNWOMEN. (2015). A framework to underpin action to prevent violence against women. https://www.unwomen.org//media/headquarters/attachments/sections/library/publications/2015/prevention_framewo rk_unwomen_nov2015.pdf?la $=$ en\&vs $=5223$ 


\title{
ROADMAP TOWARDS AN
}

\section{INTEGRATED EUROPEAN}

\section{RESPONSE TO DOMESTIC}

VIOLENCE

\author{
BRANKO LOBNIKAR, ${ }^{1}$ CATHARINA VOGT $^{2} \&$ \\ JOACHIM KERSTEN ${ }^{2}$ \\ ${ }^{1}$ University of Maribor, Faculty of Criminal Justice and Security, Ljubljana, Slovenia. \\ E-mail: branko.lobnikar@um.si \\ ${ }^{2}$ German Police University, Criminology and Interdisciplinary Crime Prevention, \\ Münster, Germany. \\ E-mail: c.vogt@respectresearchgroup.org; joachim.kersten@t-online.de
}

Abstract The main goal of the IMPRODOVA project was to find ways to optimise domestic violence intervention and prevention. We found that effective cooperation of front-line responders comes from a common understanding of the problem. When trying to understand the phenomenon thoroughly, we realised that cross-national comparison of domestic violence definitions is a complex undertaking, as different countries use varied definitions. Intimate partner violence, domestic violence and family violence are used across all countries to describe the phenomenon. However, we can observe primarily gender-based definitions in all three front-line responders sectors. One of the promising findings of our analyses is that international standards are relatively well implemented in all the partner countries. For better cooperation of all stakeholders, we developed a training platform on domestic violence and supported it by analysing the possibilities of using the digital communication platform for inter-agency collaboration to address domestic violence adequately. Multidisciplinary cooperation across the sectors in risk assessment and case documentation was mentioned by many countries as a favourable objective, resulting in more dynamic and comprehensive risk assessment processes. That leads to developing a risk assessment tool - the Domestic Violence Risk Assessment Integration Module to achieve a more integrated European response to domestic violence.

Keywords: IMPRODOVA, domestic violence, Europe, police, social work, health sector, cooperation, risk assessment, training 


\section{Introduction}

The IMPRODOVA project undertook the mapping a path towards implementing the action points of the domestic violence (DV) policy framework. Analyses of various policies presently existent in project partner countries among the three frontline-responders (FLRs). In general, the IMPRODOVA project has set its research focus on the police, social services, and the health/medical sector. In the third part of this book, the authors presented research findings by individual countries involved in the project, including a description of good practices and challenges for action in future responses to domestic violence. In different ways, the country-specific differences between legal structures, policies, and national strategies against domestic violence lead to frontline responders' cooperation. These differences enable specific definitions of domestic violence and result in using a variety of risk assessment tools. In most partner countries, however, the Istanbul Convention is central to the implementation of national policies. The definition of domestic violence in the Istanbul Convention is often used as the leading definition in the country's National Action Plans, and it is based on a gender-related violence concept, mainly understood as violence against women and children. Norbert Leonhardmair, Paul Herbinger, and Marion Neunkirchner discussed this content in more detail in the first chapter of this book (see also Herbinger et al. 2020). We found that, generally, cross-national comparisons of domestic violence definitions are complex, as different countries use specific and varied definitions of domestic violence.

\section{The integrated European response to domestic violence}

Intimate partner violence, domestic violence, and family violence are the main terms used across all countries to describe the phenomena. It appears to be quite well established that violence consists of various forms and types of acts and is not restricted exclusively to physical violence. Violence includes mental, sexual, or economic aspects. Such general terms can cover multiple types of specific acts. A further gap can be demonstrated by the definition of "high-impact" domestic violence, a term not clarified by specific sub-definitions of domestic violence within national policies (Herbinger et al., 2020). 
International organisations (e.g. UN, Council of Europe) have defined a set of minimum standards that governments and service providers (SP) should achieve and implement to meet their international obligation to exercise due diligence to investigate and punish acts of violence, provide protection to victims, and prevent domestic violence. There are international standards for service providers in general and law enforcement in particular (but not specifically for NGOs or medical doctors). The foundations of the basic standards encompass confidentiality, safety, security, and respect for service users, accessibility, and availability. Support should be available free of charge, and actions taken should employ the principles of empowerment and self-determination. Service providers should be skilled and gender-sensitive, undergo ongoing training, conduct their work according to clear guidelines, protocols, and ethics codes, and, where possible, provide female staff members. Each SP should maintain the confidentiality and privacy of the victims they engage with and cooperate and coordinate with all other relevant services. It should monitor and evaluate service provision, seeking the participation of service users. The expertise of specialised NGOs should be recognised (Bradley et al., 2020).

The main findings of the IMPRODOVA analyses reveal that international standards are relatively well implemented in all the partner countries (Bradley et al., 2020; Herbinger et al., 2020). Based on the analysis, we can conclude that police have powers to enter private property and arrest and remove a perpetrator. Protection or restraining orders are available for police to tackle all forms of domestic violence. Police agencies coordinate with, and refer to, specialist support services for domestic violence victims well and that all police organisations have protocols on information sharing on DV cases with other agencies. The IMPRODOVA partners also found that some areas require special attention in the future since gaps between the international standards and the actual practice were discovered. These issues are:

a. police personnel should be trained comprehensively on aspects of domestic violence;

b. victims should be seen as soon as possible by a specially trained officer;

c. there should be at least one specialised officer per police unit, for domestic violence and for sexual violence;

d. police should proceed to risk assessment procedures supported by the timely gathering of intelligence - this intelligence should be gathered from multiple sources and seek the victim's perspective on potential threat; and 
e. police should develop and implement strategies to eliminate or reduce victims' risks.

In addition to these standards, IMPRODOVA researchers also reported deficiencies in standards related to effectively dealing with domestic violence cases: police record systems should enable identification of cases of domestic violence and permit monitoring of all measures taken, repeat victimisation, and case outcomes and police should ensure that encounters between police personnel and victims are nonjudgmental, empathetic, and supportive, and proceed in a manner that considers and prevents secondary victimisation (Bradley et al., 2020).

Comparing the case studies in the eight partner countries yields many lessons, although one sticks out: frontline responders who are specialists of domestic violence serve victims' needs better than frontline responders who are generalists. Specialists are police officers (or social workers, or medical professionals) whose job definition consists mainly of handling domestic violence cases. The generalists are police officers (or social workers, or medical professionals) who indifferently handle all cases in their work routine. The key variable, therefore, is whether victims make themselves known to specialists or generalists. Summarising the main findings, generalists will typically be less knowledgeable about domestic violence, less inclined to take non-physical violence seriously, more inclined to rely on personal discretion, and less likely to make informed and helpful referrals.

Conversely, specialists will be better trained, knowledgeable about the different types of violence, abuse and control dynamics, and the risks they entail. They are more likely to follow protocols and procedures designed to safeguard victims' interests, and they are more likely to be part of a network of professionals from other sectors who seem more likely to help the victim in their multifaceted needs. In some countries, such as Hungary, Slovenia, or Portugal, virtually all police officers on the frontline response to domestic violence are generalists. In other countries, such as Scotland and Finland, most frontline responses are made by specialists. In France, Germany, and Austria, it varies according to locations, with some places served with specialised units and others with only generalists. Beyond necessary discussions on territorial equality, the pattern that the IMPRODOVA team has identified about specialists and generalists proves true both in cross-country comparison and within- 
country differentiation. In all countries, the basic steps of a domestic violence case are the same (Bradley et al., 2020).

The gap analysis of DV data provisions revealed that data provisions for IMPRODOVA partner countries do not enable a direct or easy comparison of the results of national victimisation surveys, nor do they support a sophisticated secondary analysis including such comparisons (Fagerlund \& Houtsonen, 2019, 2021). The data provisions are heterogeneous in their sampling and data collection methodology, representability, definitions of DV, the inclusion of questions about reporting to police and other authorities, the consequences (seriousness) of violence, and their relation to national legislation. The Istanbul Convention requires that data collection and research be briefly presented in the convention, but based on the gap analysis of data sources, we conclude that, unfortunately, nationally representative data, gathered at regular intervals and including all forms of violence covered by the convention, are not available. According to IMPRODOVA analysis (Fagerlund \& Houtsonen, 2019, 2021), the police data sources seem promising and systematic in the broad picture of data provision. Police data appear to be systematically available, at least in a form that allows statistical reporting and secondary analysis. Legal differences in criminal codes may be taken into account in a way that may enable comparative analyses with limitations based on crime statistics. However, these data sources in themselves are not without problems. In addition to differences in legislation affecting practical police work, the police forces are organised differently in different countries. Most country reports also included assessments of considerable deficiency concerning the quality of police data. The data may be more illustrative about police actions, such as reporting and the use of data systems, than the actual phenomenon of domestic violence itself. From other data concerning high-impact domestic violence (HIDV), homicide data seem most promising. It is somewhat standardised compared to other data and is available generally from all IMPRODOVA partner countries. However, analysis of DV-related homicide specifically may include similar issues found in other crime data, and this should be examined more thoroughly in future IMPRODOVA research publications focusing on secondary analysis. Homicide data could also provide information usable in constructing a risk assessment tool. 
Analysing data harmonisation and consolidation, we found that domestic violence data is gathered across various registers and contexts. In looking across these sources, far from being simple, domestic violence data are marked by its variable categories, definitions, and measures, the fluidity of such features to their temporal and spatial contexts, and in some cases, the ambiguity of data categorisations and the meaning. This proves true in the internal efforts of IMPRODOVA partners to compile a comprehensive, comparative picture of country data, and it is also apparent in varying categories and definitions specified in European data requirements outlined in the Istanbul Convention, EIGE administrative data recommendations (2019), and surveys such as FRA (2014). In addition, current debates related to survey data further underscore the contested nature of data measurements and definitions. The resulting question might well be: to what extent can data be meaningfully harmonised, consolidated and compared? As a result of the analyses, the following recommendations for improving data practices were provided (Burman, Brooks-Hay, \& Bradley, 2020, pp. 20-23):

1. Efforts to harmonise data should be underpinned by a clear understanding of the aims, meaning and feasibility of 'data harmonisation' and 'consolidation' concerning different data sources.

Key to this understanding is clarity about the purpose of data harmonisation and how data will be gathered and used. Data harmonisation may occur within countries (across agencies such as police, prosecutors, health, and housing) or across countries for (a) comparability or (b) conceptual alignment (based on research evidence and knowledge about domestic violence and forming the basis of minimum standards/indicators). Surveys are best placed to elicit insights directly from victims and facilitate comparability across countries, while administrative data gathering benefits from conceptual alignment across agencies and countries on key indicators such as age, sex, and the relationship between victim and perpetrator. It should be noted that a harmonised EU definition of domestic violence is likely to be reduced to high impact domestic violence (HIDV), which privileges physical violence. This could effectively obscure all other forms of domestic violence and, in turn, have adverse implications for national interventions.

2. Measuring the extent of domestic violence reported to the police in terms of the numbers of victims, perpetrators, and offences, as recommended by EIGE (2019), should be a minimum standard for police data gathering. These data 
work to raise awareness of the scale of the problem, monitor change over time, and inform the allocation of adequate resources to tackle the problem. As it currently stands, police data on the number of offences are more readily available than the number of victims and perpetrators.

3. Data should be recorded on police action taken in response to acts (incidents) reported as domestic violence, including those incidents not later recorded as criminal offences. This measure provides essential information about incidents coming to the attention of the police and how the police respond to incidents reported to them.

4. Data on types of abuse (e.g. physical, sexual, psychological, and economic) should be priority categories for survey data collection. The collation of this data within surveys should be prioritised and recognised as complementary to administrative data due to the limitations of administrative data in relation to these variables. Indicators relating to types of abuse (and their seriousness) are populated using crime codes as a proxy, yet there are notable limitations of this approach since some types of abuse (e.g. economic and psychological) and are not well recognised or defined in criminal codes.

5. As identified by the Istanbul Convention, recording the sex of the victim and perpetrator and assessing the relationship between them should be a minimum standard for police and survey data gathering. In addition to collecting data on sex, recording the gender identity of victims and perpetrators would be a further step towards inclusivity. These data are crucial to understanding the gendered dynamics of domestic violence and, in particular, intimate partner violence. Data should be able to be disaggregated in order to be of optimum use for FLRs.

6. Where domestic violence data are gathered on violence/abuse perpetrated in a range of family relationships or a domestic unit (as per the definition of domestic violence adopted by the Istanbul Convention), there should be a clear delineation of these relationship categories, and this must include categories for violence/abuse perpetrated by intimate partners and/or ex-partners. Family and other close relationships form a context of violence in which power relations and other factors relevant to the dynamics of violence contribute to the eminently damaging nature thereof in these relationships while simultaneously making it particularly difficult for FLRs to identify cases and intervene. This can happen, e.g., in the case of parental violence against their children, violence perpetrated by adult children against their elderly parents, or violence perpetrated by affinal kin. However, violence perpetrated by partners or ex- 
partners has a distinctive dynamic and should be clearly delineated in gathering and reporting data.

7. Data should be gathered regarding repeat offences and victimisation, and the impact of domestic violence and abuse on victims is a minimum standard for survey data gathering. This data is central to understanding the gendered, ongoing, and coercive nature of domestic violence. These dimensions are important to operational police responses though they are difficult to record consistently within police administrative data, hence the importance of capturing this information directly from victims within surveys.

8. Consideration should be given to how cases reported to the police can be tracked through the criminal justice system (e.g., using unique identifiers for individual cases). The capacity to track cases throughout the criminal justice system will provide the basis for an in-depth understanding of individual cases as they progress through the system. While this recommendation extends beyond police data gathering, this process begins with the police. With victim privacy and data sharing concerns in mind, the use of a unique identifier should be strictly in relation to case tracking, and it should not be shared with agencies outside of the criminal justice system (e.g. health and housing). Unique identifiers pose a threat to privacy and the rights of the accused, and so, while they have undoubted advantages, any implementation needs to consider data infringement risks very carefully.

9. NGOs, social work services, and medical services are important sources of data and can provide information about the incidence and impact of domestic violence across different populations. Consideration should be given to using the definition of domestic violence adopted by the Istanbul Convention in data recording and the utilisation of de-identified and aggregated health or social service data to respond to domestic violence at both individual and community levels. Domestic violence victims' health and social care needs can inform measures that can improve a victim's quality of life and prevent future abuse; however, there are significant issues of confidentiality that must be respected in relation to health and social care data.

10. The needs and demands placed upon FLRs should be a key consideration for development. Adequate support, resources, and GDPR knowledge should be provided for FLRs as they progress their casework and data-recording responsibilities. To minimise the data-gathering burden placed upon FLRs such 
as the police, it should be recognised that surveys are best placed to elicit data from victims on issues such as impact, nature and extent of the abuse.

11. The unidirectional flow of data from FLRs to data gathering systems should be addressed by ensuring that FLRs are data recipients rather than providers. 'Closing the loop' for FLRs will allow FLRs to locate and understand their actions in relation to managing and mitigating domestic violence.

12. Administrative and survey analyses should be made available to the public (and FLRs) and should be made accessible to them. National (anonymised) domestic violence data should be publicly available without request. Accessibility should also be considered in relation to the format and presentation of statistical information.

13. Raw data should be made available for further analyses. Making (anonymised) raw data available to relevant agencies and researchers facilitate analytical insight beyond the headline analyses published as standard and enhances the utility of the data gathered.

14. The EU and the Member States should promote and fund surveys that can be repeated every few years to measure developments over time. This recommendation concurs with the FRA (2014) recommendation on this issue, and its adoption would signify a concerted effort to uncover information on the extent and nature of domestic violence.

15. Alternative methods of gathering and utilising data about the "bigger picture" of domestic violence should be considered, in addition to the use of administrative and conventional survey data. (Burman, Brooks-Hay, \& Bradley, 2020)

Part of the IMPRODOVA project included the development of a risk assessment tool - Domestic Violence Risk Assessment Integration Module - RAIMO, which is described in detail in the chapter by Marianne Mela and Jarmo Houtsonen in this book. Concerning risk assessment, problematic aspects emerged in all sectors (Hera \& Szegö, 2020). Many countries highlighted the rigidity of existing formal risk assessment tools. Some countries have adopted Multi-Agency Risk Assessment Conferences (MARAC). A wide range of statutory and non-statutory agencies participate and share information in these conferences to develop safety plans for high-risk victims of domestic violence. In addition to using MARACs, Scotland has implemented Multi-Agency Tasking and Coordination groups (MATACs) to target and identify repeat offenders of domestic abuse. The MARAC project in Austria was 
negatively evaluated by the participating organisations, as the cooperation between FLRs was ineffective in the context of these conferences. This can, among other variables, be traced back to the strength of data protection regulations, which make it challenging to exchange sensitive information among different FLRs. In this regard, Scotland can be mentioned as an outstanding example for including specialist domestic abuse courts as additional key actors in domestic violence cases. The Scottish courts are unique in their emphasis on the significance of multi-agency cooperation between the police, prosecution, and specialist domestic abuse service providers and reflect the policy aim of improving the coordination of information across criminal justice agencies (Hera \& Szegő, 2020). The IMPRODOVA researchers also reported that some professionals do not condone the use of checklists since, in their experience, such tools do not reflect the particulars of domestic violence incidents. Those tools are seen as too rigid and not sensitive enough to fit individual cases, resulting in false assessment and the negligence of risk situations that do not "fit into the boxes". Thereby, many professionals across the countries argued that formalised tools have to be accompanied by comprehensive and regular professional training and personal expertise.

As a favourable objective, which might result in more dynamic and comprehensive risk assessment processes (Delpeuch \& Bonnet, 2020; Machado et al., 2021; Vogt, 2020; also cf. the chapter by Thierry Delpeuch and François Bonnet in this book), multidisciplinary cooperation across the sectors in risk assessment and case documentation was mentioned by many countries in all sectors. Unified risk assessment and case documentation protocols are the preconditions of such an endeavour. Cross-referenced analysis of the 18 case studies shows that the consolidation of a partnership against domestic violence depends on many factors that have nothing to do with the partnership organisation's design and management. By consolidation, IMPRODOVA researchers mean the institutionalisation and systematic use of working procedures by which partnership bodies and partnership relays contribute and act together in an integrated manner to provide efficient partnership services. These factors include:

a. The existence of a legal framework or public policy that encourages or even enforces partner organisations to engage in the partnership and consider it a priority. These incentives can be negative (regulatory obligation, hierarchical 
order, etc.) or positive (granting of subsidies, allocating additional resources, etc.).

b. Increased social, political, and media pressure to strengthen the efforts against DV. These pressures are often linked to public opinion cases, advocacy, or the adoption of international standards.

c. Strong involvement of institutional entrepreneurs and change agents in the design and promotion of the partnership mechanism and their ability to build alliances with influential partner organisations' members (Vogt, 2020).

d. Securing political support, especially from local authorities.

e. Reference to models applied elsewhere - within the national territory or abroad - that are already acknowledged as "good practices". Such recognition is rarely linked to the availability of rigorous evaluations of "good practices" effectiveness. It most often results from the notoriety of the institutions that have pioneered the practice or are working to disseminate it.

If we want to achieve optimised domestic violence prevention and response, we found that the most effective cooperation of first-line responders comes from a common understanding of the problem. For this reason, we developed a training platform on domestic violence (https://training.improdova.eu/en/) and supported it by analysing the possibilities of using the digital communication platform for interagency collaboration to manage domestic abuse (Pfleiderer \& Juszczyk, 2021). In addition to the domestic-violence risk-assessment integration module (RAIMO), the training platform is probably one of the more relevant and applicable results of the IMPRODOVA project, as it includes all first responders in training, whom we found to have a significant impact on the final success of responding to domestic violence. The importance of training is thoroughly presented by Bettina Pfleiderer and Paulina Juszczyk in this book.

\section{Conclusion}

During the course of the IMPRODOVA project, we presented and published findings, along with providing recommendations addressing multiple audiences and stakeholders. Through years of research, we believe that we have added our pebble to the mosaic of improved and embedded collaborative working between police, other frontline and first-responder agencies, and pertinent stakeholders. As already mentioned, one of the key results of our work is optimised domestic violence 
prevention and response through innovative, gender-sensitive training and education, challenging the traditional masculine-oriented cultures and attitudes within the police. What we find particularly important is that the training platform will be useful in the future, that it is freely accessible, and that it creates the conditions for good cooperation between first responders to domestic violence. We are confident that development, validation, and embedding of common riskassessment practices, combined with increased understanding and awareness, cultural and attitudinal shifts, and openness to collaborative working, will lead to increased victim protection, occupational safety, more efficient use of resources, better cooperation between agencies, and an improved working climate for first responders. So, in the longer term, the improvements put in place by IMPRODOVA will likely raise awareness of the problematic nature of domestic violence among broader groups of citizens and contribute to improving gender equity.

\section{References}

Bradley, L.; Brooks-Hayes, O.; Burman, M.; Bonnet, F.; Cuillerdier, F. Delpeuch, T.; Felgueiras, S.; Giljohann, S.; Hera, G.; Herbinger, P; Houtsonen, J.; Jaffré, J.M.; Jereb, K.; Kersten, J. Leonhardmair, N.; Limonier, C.; Lobnikar, B:, Machado, P.; Mela, M:, Morgado, S.; Neunkirchner, M.; Nipuli, S. October, M.; Pais, L.; Pfleiderer, B.; Richter, L.; Slak, B.; Szegő, D. Vassileva, M. (2020). Country Reports and Cross-National Comparison on the Implementation of International Norms and National Best Practices of Frontline Responders. IMPRODOVA Consortium - Deutsche Hochschule der Polizei.

https://www.improdova.eu/pdf/IMPRODOVA_D2.2_Norms_and_Best_Practices_of_Fro ntline_Responders.pdf?m=1585673378\&

Burman, M., Brooks-Hay, O. \& Bradley, L. (2020). Recommendations for data harmonisation and consolidation. IMPRODOVA Consortium, Deutsche Hochschule der Polizei. https://www.improdova.eu/pdf/Improdova_D3.2_Recommendations_Data_Harmonisatio n_Consolidation.pdf?m $=1591377139 \&$

Delpeuch T. \& Bonnet F. (2020). Identifying Gaps and Bridges of Intra- and Inter-Agency Cooperation. IMPRODOVA Consortium, Deutsche Hochschule der Polizei. https://www.improdova.eu/pdf/IMPRODOVA_D2.4_Gaps_and_Bridges_of_Intra_and_Interagency_Cooperation.pdf?m $=1585673383 \&$

Fagerlund, M. \& Houtsonen, J. (2019). Map of Available Data on Domestic Violence. IMPRODOVA Consortium - Deutsche Hochschule der Polizei. https://www.improdova.eu/pdf/Map-ofAvailable-Data-on-Domestic-Violence.pdf?m $=1555573584 \&$

Fagerlund, M., \& Houtsonen, J. (2021). Status Quo of National Data Sources Concerning Domestic Violence Across Eight European Countries. European Law Enforcement Research Bulletin, 21, 101 - 120. https://bulletin.cepol.europa.eu/index.php/bulletin/article/view/419

Hera, G. \& Szegő, D. (2020). Country Reports and Cross-National Comparison on the Risk Assessment Tools and Case Documentation used by Frontline Responders. IMPRODOVA Consortium, Deutsche Hochschule der Polizei.

https://www.improdova.eu/pdf/IMPRODOVA_D2.3_Risk_Assessment_Tools_and_Case _Documentation_of_Frontline_Responders.pdf?m $=1585673380 \&$ 
Herbinger, P. L., Neunkirchner, M., \& Leonhardmair, N. (2020). European legislation to fight domestic violence. European Law Enforcement Research Bulletin, 20, 141154. http://bulletin.cepol.europa.eu/index.php/bulletin/article/view/415/339

Houtsonen, J. (2020). Policing Domestic Violence: Strategy, Competence, Training. European Law Enforcement Research Bulletin, 19, 135-155.

https://bulletin.cepol.europa.eu/index.php/bulletin/article/view/417/318

Machado, P., Pais, L., Morgado, S., \& Felgueiras, S. (2021). An Inter-Organisational Response to Domestic Violence. European Law Enforcement Research Bulletin, 21, 121-139. https://bulletin.cepol.europa.eu/index.php/bulletin/article/view/418

Pfleiderer, B., \& Juszczyk, P. (2021). European Online Training Platform on Domestic Violence Improving Frontline Responses to Domestic Violence and Sexual Assault; Pp 16-23. In: Megh, M. (2021). PET Prevention, Examination and Treatment of Domestic Violence and Sexual Assault Cases. 1st edition 2021. CBS Publishers \& Distributors.

Vogt, C. (2020). Interagency Cooperation. European Law Enforcement Research Bulletin, 19, 153-163. http://bulletin.cepol.europa.eu/index.php/bulletin/article/view/412/323 


\section{ABOUT THE AUTHORS}


4 ist

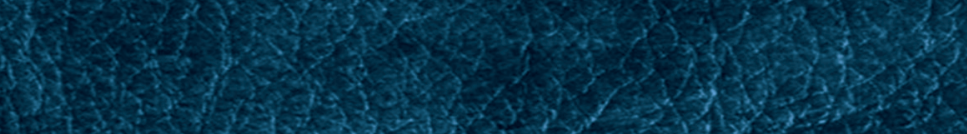

3.1.2.

(1)

W.7.

$$
\text { (1) }
$$

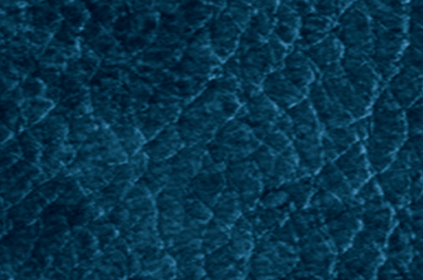

aris

$\cos 2$

1. 3 ?

13:

28.

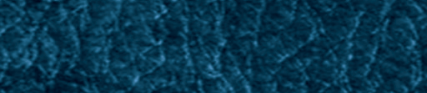

(1)

1)

3

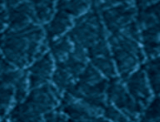

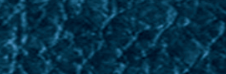

to

(⿻)

xtrat

3.

(1) 


\section{AUSTRIA}

Paul Herbinger, MA (Sociology - Friedrich Schiller University,Jena), is a researcher at the Vienna Centre for Societal Security. His work in socio-legal studies and criminology includes research on policing the pandemic, European projects on multiagency interventions into cases of high-risk domestic violence, as well as national projects on forensic cryptocurrency investigations.

E-mail:paul.herbinger@vicesse.eu

Norbert Leonhardmair, BA is a researcher and project manager at the Vienna Centre for Societal Security. His research on policing and internal security include national and European projects on countering extremism, mental health, community policing, and forensic practices. Currently, he is working on domestic violence and human trafficking. He has consulted for data analysis for the Ministry of Justice, City of Vienna and GIZ projects.

E-mail:norbert.leonhardmain@vicesse.eu

Marion Neunkirchner, BA (Social Work - University of applied sciences in Vienna), MA (Sociology - University of Vienna) is a social Worker in court prison and a researcher at the Vienna Centre for Societal Security (VICESSE). Her work in sociology of law and criminology includes research on domestic violence, criminal law, child protection and offender work practice.

E-mail:marion.neunkirchner@vicesse.eu

\section{FINLAND}

Jarmo Houtsonen, $\mathrm{PhD}$ (Sociology), is a Senior Researcher at the Police University College, Finland. His current research interests cover community policing, surveillance of online communication and the policing of domestic violence. Mr. Houtsonen has been involved in several national and international research and innovation projects funded by the European Commission, NordForsk and the Academy of Finland.

E-mail: jarmo.houtsonen@polamk.fi 
Marianne Mela, M. Soc. Sc. (Political Science), is a researcher at the Police University College of Finland and a $\mathrm{PhD}$ student at the University of Helsinki. Having served as a police officer for 15 years, she has gained a profound insight into the everyday work of Finnish police. Ms Mela has been involved in national and international research and innovation projects funded by European Commission. Her research interests focus on domestic violence, risk assessment and training. E-mail: marianne.mela@poliisi.fi

Suvi Nipuli, Master of Social Science (Sociology), is a Development Manager at the Finnish Institute for Health and Welfare (THL) in Finland. She is responsible for developing shelter services for victims of domestic violence in Finland. Ms Nipuli has been involved in several national development projects responding to Violence against Women.

E-mail: suvi.nipuli@thl.fi

Martta October, Master of Laws, is a Development Manager at the National Institute for Health and Welfare Finland. She has taken part in drafting several national anti-violence policies and is responsible for developing the services responding to Violence against Women and Domestic Violence in Finland. Ms October has been involved in several national and international research and development projects funded by the European Commission, Council of Baltic States and the Nordic Council of Ministers.

E-mail: martta.october@thl.fi

\section{FRANCE}

Francois Bonnet, PhD, Senior research fellow, CNRS - UMR Pacte (University of Grenoble Alpes),

E-mail: francois.bonnet@umrpacte.fr

Thierry Delpeuch, PhD, Researh fellow, CNRS - UMR Pacte (University of Grenoble Alpes),

E-mail: thierry.delpeuch@umrpacte.fr 
Marion Tillous,Associate Professor, Université Paris 8 Vincennes Saint-Denis UMR LEGS / UMR PACTE (délégation CNRS),

E-mail: marion.tillous@univ-paris8.fr

Margarita Vassileva, PhD, Research Engineer, PACTE, CNRS, University Grenoble-Alpes

\section{GERMANY}

Stefanie Giljohann, Research Assistant, Polizei Berlin,

E-Mail: gil@zedat.fu-berlin.de

Paulina Juszczyk, M.A., Research Assistant in the research group Cognition \& Gender, Medical Faculty, Westfalian Wilhelm-University of Muenster, Germany. Research assistant and social pedagogue Paulina Juszczyk has been working in the field of domestic and sexual violence since completing her master studies. Her educational background has given her a broad base from which to develop the IMPRODOVA training platform. She works in the research group Cognition \& Gender at the Medical Faculty of the University of Muenster, Germany.

E-mail: paulina.juszczyk@wwu.de

Prof. em. Dr. Joachim Kersten, Guest Professor, Kriminologie und Interdisziplinäre Kriminalprävention, Deutsche Hochschule der Polizei. Prof. Joachim Kersten has studied science, history, and political science at the Free University Berlin and McMaster University in Hamilton, Ontario, from where he holds a master's degree in social science. His doctorate is from the University of Tübingen and a post-doctoral degree from the University of Konstanz. He has published books and journal articles on juvenile prison, youth violence, gendered violence, and police accountability/police and minorities. Joachim Kersten is a Senior Research Professor at the German Police University. He is the coordinator of H2020 IMPRODOVA Improving Frontline Responses to High Impact Domestic Violence. E-mail: joachim.kersten@t-online.de 
Prof. Dr. Dr. Bettina Pfleiderer, PhD. MD., Head research group Cognition \& Gender and clinic for Radiology, Medical faculty, Westfalian Wilhelm-University Muenster, Germany. She is a physician and human rights activist and works in the field of gendered domestic and sexual violence since many years. She had been president of the Medical Women's International association (2016-2019) and is giving talks on domestic violence all over the world as one of the leading medical experts globally. She and her research team developed the IMPRODOVA training platform and piloted a course for medical students based on the materials of this platform. She works as associate professor at the Medical Faculty of the University of Muenster, Germany.

E-mail: pfleide@wwu.de

Lisa Sondern, M.Sc. Psych., Research Assistant in the research group Cognition \& Gender, Medical Faculty, Westfalian Wilhelm-University Muenster, Germany. Psychologist Lisa Sondern is part of the research team led by Prof. Pfleiderer at the medical faculty in Muenster. Together with other German partners, she was responsible for the data acquisition and analysis in the various work packages for Germany and the creation of the training platform and the teaching materials. Her experience and knowledge as a psychotherapist and the associated work with perpetrators and victims of domestic violence found its way into the project.

E-Mail: Lisa.Sondern@wwu.de

Dr. Catharina Vogt, Dipl.-Psych., Senior Researcher, Kriminologie und Interdisziplinäre Kriminalprävention, Deutsche Hochschule der Polizei. Dr Catharina Vogt is a post-doctoral researcher at the German Police University (DHPol) steering the EU-funded project IMPRODOVA. She pursued her $\mathrm{PhD}$ at the University of Hamburg in cooperation with Kühne Logistics University and as a visiting scholar at the Otago Business School. In her research, Dr Vogt focuses on the issue of interpersonal cooperation. Among others, she explores the effects of respectful leadership, ways of conflict resolution in policing and customer interactions. During her career, Dr Vogt has worked in several project management roles and as a business consultant. Today, she is an external member of the thinktank RespectResearchGroup, which she headed for four years.

E-mail: c.vogt@respectresearchgroup.org 


\section{HUNGARY}

Dr. Gábor Héra, Foresee Research Group, Hungary, E-mail: gabor.hera@foresee.hu

Dr. Dóra Szegő, Foresee Research Group, Hungary, E-mail: szegodori@gmail.com

\section{PORTUGAL}

Sérgio Felgueiras, PhD, Assistant professor and researcher at ICPOL - Research Centre of the Higher Institute of Police Sciences and Internal Security, Lisbon, Portugal.

E-mail: srfelgueiras@psp.pt

Paulo Machado, PhD, Assistant professor and researcher at ICPOL - Research Centre of the Higher Institute of Police Sciences and Internal Security, Lisbon, Portugal.

E-mail: pfsmachado@psp.pt

Lúcia G. Pais, PhD, Assistant professor and researcher at ICPOL - Research Centre of the Higher Institute of Police Sciences and Internal Security, Lisbon, Portugal.

E-mail: lmpais@psp.pt

Carina Quaresma, PhD, a researcher at ICPOL - Research Centre of the Higher Institute of Police Sciences and Internal Security, Lisbon, Portugal. E-mail: carina.quaresma@gmail.com 


\section{SCOTLAND (UK)}

Oona Brooks-Hay, $\mathrm{PhD}$, Reader in Criminology, Scottish Centre for Crime and Justice Research, University of Glasgow. Dr Brooks-Hay's main research interests include victim-survivor experiences of rape and domestic abuse, criminal justice responses to sexual and domestic offences, and the meaning of 'justice'. Her research in these areas has been funded by the EU, the Scottish Government, the Chief Scientists Office, Police Scotland, Rape Crisis Scotland and the Scottish Institute for Policing Research. She is the founder of the University of Glasgow GBV Research Forum, a member of Member of the European Society for Criminology Gender, Crime and Justice Group.

E-mail: Oona.Brooks@glasgow.ac.uk

Michele Burman, BA(Hons); MSc; PhD. FRSE. FAcSS. Professor of Criminology, Scottish Centre for Crime and Justice Research, University of Glasgow. She has extensive experience of teaching and researching the criminal justice response to gender-based violence, spanning over 30 years. She has been the Co-Convenor of the European Society of Criminology Working Group on Gender, Crime and Justice since 2010. From 2015 to 2020, Professor Burman was Co-Editor-in-Chief of the international journal Criminology and Criminal Justice. She was made a Commander of the British Empire (CBE) in 2019 for Services to Criminology.

E-mail: michele.burman@glasgow.ac.uk

Ruth Friskney, PhD, Research Associate, Scottish Centre for Crime and Justice Research, University of Glasgow. Dr Friskney's research centres on the relationships between institutions and individuals, with a particular focus on the experiences of children affected by domestic abuse.

E-mail: Ruth.Friskney@glasgow.ac.uk 


\section{SLOVENIA}

Karmen Jereb, $\mathrm{PhD}$, is a researcher at the Faculty of Criminal Justice and Security, University of Maribor, Slovenia. Her research focuses mainly on the psychology of deception and its detection and interview and interrogation techniques. In 2017, she received a Fulbright grant and spent a year in the United States. She completed her postgraduate training at the Department of Homeland Security, Federal Law Enforcement Training Centers, where she conducted empirical research on investigative interviewing.

E-mail: carmen.jereb@gmail.com

Aleksander Koporec Oberčkal, $\mathrm{PhD}$, is Senior Police Inspector in Research and Social Skills Centre in Slovenian Police, where he leads a Police Research Task Force and Research Team. His research interests include contemporary trends in the field of policing with an emphasis on police scientific research, psychological aspects of police work, organizational culture, organizational climate and public opinions.

E-mail: aleksander.koporec.oberckal@policija.si

Branko Lobnikar, former police officer and police supervisor, obtained $\mathrm{PhD}$ in human resource management. He is a Full Professor of Security Studies at the Faculty of Criminal Justice and Security, University of Maribor. He has (co)authored several papers on human resource management and human resource development, organizational behaviour, policing, police integrity and deviance at the workplace. He was a Slovenian national coordinator of an H2020 project - IMPRODOVA Improving Frontline Responses to High Impact Domestic Violence.

E-mail: branko.lobnikar@um.si

Kaja Prislan, $\mathrm{PhD}$, is an Assistant Professor at the Faculty of Criminal Justice and Security, University of Maribor, where she is a member of the Chair of Policing and Security Studies. Her research interests include security risk management and contemporary trends in the field of policing and the provision of safety and security, with an emphasis on the use and role of modern technologies in the security context. E-mail: kaja.prislan@um.si 
Boštjan Slak, PhD, Assistant Professor of Security Studies and Research Fellow at the Faculty of Criminal Justice and Security, University of Maribor, Slovenia. E-mail: bostjan.slak@um.si 


\title{
IMPROVING FRONTLINE
}

\section{RESPONSES TO DOMESTIC}

\section{VIOLENCE IN EUROPE}

\author{
Branko LOBNIKAR, ${ }^{1}$ CATHARINA VOGT ${ }^{2} \&$ \\ JOACHIM KERSTEN ${ }^{2}$ (EDS.) \\ ${ }^{1}$ University of Maribor, Faculty of Criminal Justice and Security, Ljubljana, Slovenia. \\ E-mail: branko.lobnikar@um.si \\ ${ }^{2}$ German Police University, Criminology and Interdisciplinary Crime Prevention, \\ Münster, Germany. \\ E-mail: c.vogt@respectresearchgroup.org; joachim.kersten@t-online.de
}

Abstract The monograph on improving the response of first responders to domestic violence in Europe aims to identify gaps in the cooperation of first-line responders and deliver recommendations, toolkits and collaborative training for European police organizations and medical and social work professionals. The goal is to improve integrate institutional response to domestic violence. Shared training and adequate risk assessment tools will create a positive feedback loop, increasing reporting rates of domestic violence to police, the medical profession, and community and social work practitioners.

Keywords: domestic violence, first responders, risk assessments, police, social work, health, cooperation, training, Europe 


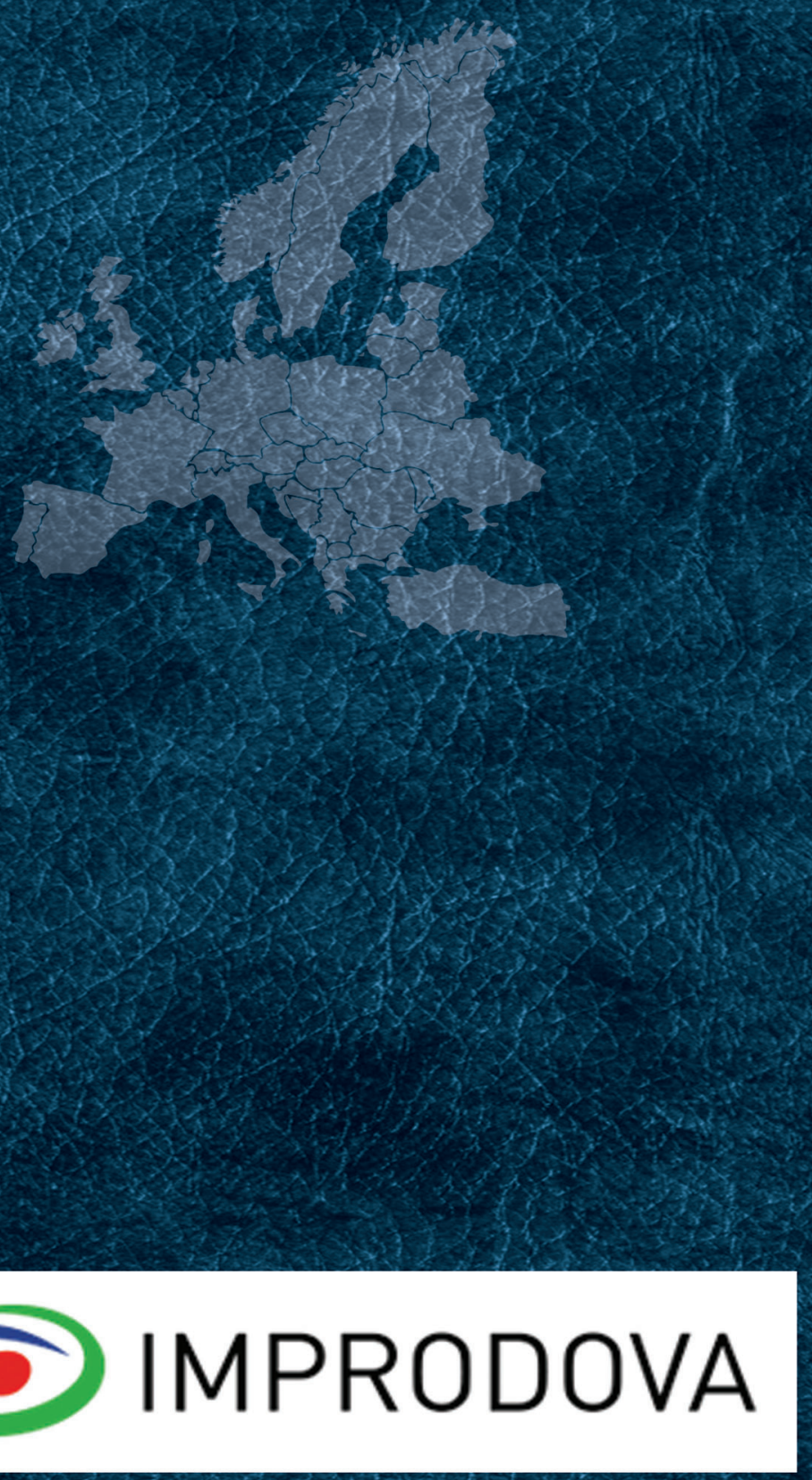

